VAGNER LUIZ GAVA

PROCESSO PARA ESPECIFICAÇÃO DE REQUISITOS DE SOFTWARE COM FOCO DE APLICAÇÃO EM TRABALHO COOPERATIVO

SÃO PAULO 
VAGNER LUIZ GAVA

\section{PROCESSO PARA ESPECIFICAÇÃO DE REQUISITOS DE SOFTWARE COM FOCO DE APLICAÇÃO EM TRABALHO COOPERATIVO}

Tese apresentada à Escola

Politécnica da Universidade de São

Paulo para obtenção do título de

Doutor em Engenharia

SÃO PAULO 
VAGNER LUIZ GAVA

\section{PROCESSO PARA ESPECIFICAÇÃO DE REQUISITOS DE SOFTWARE COM FOCO DE APLICAÇÃO EM TRABALHO COOPERATIVO}

Tese apresentada à Escola

Politécnica da Universidade de São

Paulo para obtenção do título de

Doutor em Engenharia

Área de Concentração:

Engenharia de Produção

Orientador: Prof. Livre-Docente

Mauro de Mesquita Spinola

SÃO PAULO 
Este exemplar foi revisado e alterado em relação à versão original, sob responsabilidade única do autor e com a anuência de seu orientador.

São Paulo, 14 de dezembro de 2009.

Assinatura do autor

Assinatura do orientador

FICHA CATALOGRÁFICA

Gava, Vagner Luiz

Processo para especificação de requisitos de software com foco de aplicação em trabalho cooperativo / V.L. Gava. -- ed.rev. -- São Paulo, 2009.

$288 \mathrm{p}$.

Tese (Doutorado) - Escola Politécnica da Universidade de São Paulo. Departamento de Engenharia de Produção.

1. Engenharia de requisitos 2. Ergonomia no trabalho 3. Cooperação I. Universidade de São Paulo. Escola Politécnica. Departamento de Engenharia de Produção II. t. 


\section{DEDICATÓRIA}

Dedico este trabalho a meus pais a minha esposa e, em especial, a meus filhos.

Espero que um dia o esforço pela elaboração desta pesquisa possa servir-lhes de inspiração nos caminhos que decidirem trilhar. 


\section{AGRADECIMENTOS}

Ao Prof. Dr. Mauro de Mesquita Spinola, por todo o apoio, incentivo, aprendizado e orientação no desenvolvimento desta pesquisa e dos artigos publicados.

À Dra. Leda Leal Ferreira, pelos ensinamentos sobre Análise Coletiva do Trabalho em todas as oportunidades que me recebeu na FUNDACENTRO.

À Dra. Uiara Montedo, por suas valiosas contribuições durante a qualificação.

Aos Professores Doutores Marcelo Pessôa e Fernando Laurindo pelo apoio e incentivo.

Ao pessoal do Grupo GTI e Elabsoft, pela solidariedade e aprendizado adquiridos, em especial, Rodrigo pela parceria em nossas pesquisas e Ivelise e Lidia, pela atenção e suporte dispensados.

Ao IPT, por proporcionar a oportunidade única de realizar este estudo. Agradeço, em particular, ao Dr. Walter Furlan pelo apoio neste último ano.

A todos aqueles que, de forma direta ou indireta, contribuíram para a consecução deste objetivo, meus sinceros agradecimentos. 
"Nenhum homem é uma ilha; qualquer homem é uma parte do todo. A morte de qualquer homem me diminui, porque faço parte da humanidade; assim, nunca procures saber por quem dobram os sinos: eles dobram por ti." John Donne (1572-1631) 


\section{RESUMO}

O trabalho dos usuários em sistemas de informação é uma atividade social que envolve grupos de pessoas que cooperam entre si para desempenhar as mais variadas funções. A natureza da cooperação, por si só é complexa e depende dos indivíduos envolvidos, do ambiente físico e da organização onde o trabalho se desenvolve. Os aspectos ligados ao trabalho cooperativo dos usuários não são considerados no enfoque tradicional da engenharia de software, uma vez que o usuário é visto de modo independente do meio ou grupo em que está inserido, com o modelo individual generalizado para o estudo do comportamento coletivo envolvendo todos os usuários. O objetivo deste trabalho é propor um processo de requisitos de software para tratar as questões envolvendo o trabalho cooperativo em sistemas de informação que apresentem coordenação distribuída nas ações dos usuários e a comunicação entre eles ocorre, preponderantemente, de modo indireto por meio dos dados inseridos no uso do software. Para tanto, a pesquisa faz uso de conceitos da ergonomia, da cognição e da engenharia de software. Utiliza-se a pesquisa-ação como metodologia de pesquisa em três ciclos, aplicada durante o desenvolvimento de um sistema de workflow corporativo em uma empresa de pesquisa tecnológica. No primeiro ciclo, o processo trata da definição dos requisitos do domínio do problema e das contribuições individuais dos usuários. No segundo ciclo, as contribuições do grupo (suas ações e interrelações) são consideradas com as contribuições individuais pela simulação da solução proposta. No terceiro ciclo, o processo trata do refinamento dos requisitos do trabalho cooperativo, com o software em uso real no ambiente de trabalho. Os resultados obtidos no final do ciclo 2 e início do ciclo 3 durante a aplicação do processo em campo, mostraram a necessidade de melhoria do processo. Esta evolução é necessária, visto que a inclusão do sistema informatizado altera o ambiente de trabalho dos usuários, passando da interação face a face para a interação mediada pelo software. Os resultados obtidos evidenciaram que o maior grau de consciência dos usuários sobre como os inter-relacionamentos de suas atividades são realizados contribuem para um decréscimo em seus erros individuais, diminuindo o retrabalho de recodificação do software e acima de tudo o uso inadequado do sistema, evitando a propagação das consequências desses erros nos resultados finais do trabalho em grupo.

Palavras-chave: Análise Coletiva do Trabalho. Requisitos de Software. Modelos mentais. Trabalho cooperativo apoiado por computador. Mente coletiva 


\begin{abstract}
Users' work in information systems is a social activity that involves people groups cooperating to perform many different functions. The nature of cooperation itself is complex and depends on the people involved, on the workplace environment and on the organization in which the work develops. Aspects related to the users' cooperative work are not considered in the traditional approach of software engineering, since the user is viewed independently of his/her workplace environment or group, with the individual model generalized to the study of collective behavior of all users. This work proposes a process for software requirements to address issues involving cooperative work in information systems that provide distributed coordination in the users' actions and the communication among them occurs indirectly through the data entered while using the software. To achieve this goal, this research uses ergonomics, cognition and software engineering concepts. Research-action is used as a research methodology applied in three cycles during the development of a corporate workflow system in a technological research company. In the first cycle, the proposed process exposes the definition of the problem domain requirements and the users' individual contributions. In the second cycle, the contributions of the group (their actions and inter-relationships) are considered together with the individual contributions through the simulation of the proposed solution. In the third cycle, the process deals with the refinement of the cooperative work requirements with the software in actual use in the workplace. The results at the end of cycle 2 and the beginning of cycle 3 during the process application in the field show the need for process improvement. This is necessary because the inclusion of a computer system changes the users' workplace, from the face to face interaction to the interaction mediated by the software. The results show that the highest degree of users' awareness as the interrelationship of their activities are carried out contributes to a decrease in their individual errors, reducing software recoding rework and above all the inappropriate use of the system, avoiding the spread of the consequences of these errors in the final results of the group work.
\end{abstract}

Keywords: Collective analysis at work. Software requirements. Mental models. Computer supported cooperative work. Collective mind 


\section{LISTA DE ILUSTRAÇÕES}

Figura I.1 - Representação gráfica da pesquisa proposta.................................28

Figura I.2 - Contextualização da pesquisa .......................................................33

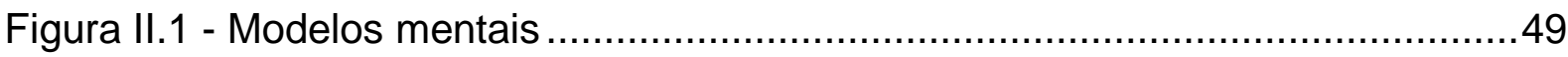

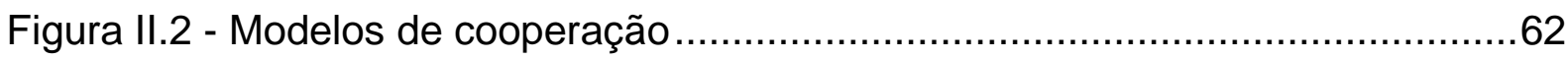

Figura II.3 - Diagrama dos 3Cs e awareness ................................................. 64

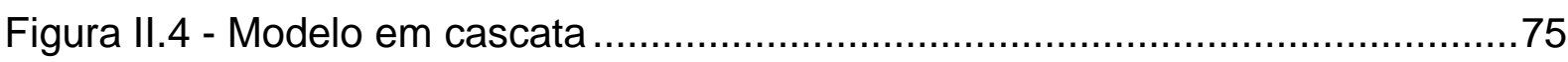

Figura II.5 - Modelo Espiral de processo de software ..........................................78

Figura II.6 - Desenvolvimento baseado em componentes ................................81

Figura II.7 - Entradas e saídas do processo de Engenharia de Requisitos ..............87

Figura II.8 - Subprocessos do processo de Engenharia de Requisitos ....................88

Figura II.9 - Notação do diagrama de fluxo de dados (DFD) ..............................94

Figura II.10 - Modelo de entidade e relacionamento (MER) ..................................95

Figura II.11 - Caso de uso .................................................................. 100

Figura III.1 - Ciclos da Pesquisa-ação......................................................115

Figura III.2 - Iteração dos ciclos da Pesquisa-ação ..........................................120

Figura III.3 - Espiral dos ciclos da Pesquisa-ação .........................................122

Figura IV.1 - Macroprocesso para a identificação das características do trabalho cooperativo Fonte: elaborado pelo autor ....................................130

Figura IV.2 - Modelo da teoria proposta ..................................................... 131

Figura IV.3 - Processo para análise de viabilidade e aplicabilidade .......................132

Figura IV.4 - Processo para identificação das características individuais do trabalho cooperativo

Figura IV.5 - Processo para simulação e identificação das características cooperativas do trabalho.

Figura IV.6 - Modelo para aplicação das sessões de ACT. 143

Figura IV.7 - Relação entre fases do processo e interfaces gráficas das sessões de ACT 
Figura IV.8 - Processo para o refinamento da identificação das características do trabalho cooperativo

Figura IV.9 - Modelo para a aplicação das sessões de ACT. 150

Figura IV.10 - Passos da Pesquisa-ação e correspondentes atividades para os processos de identificação e refinamento das características cooperativas do trabalho.

Figura V.1 - Fluxograma inicial e respectivas fases: processo não informatizado 167

Figura V.2 - Diagrama de contexto inicial do ciclo 1 170

Figura V.3 - Constituição do pedido 172

Figura V.4 - Análise crítica do contrato 172

Figura V.5 - Habilitação do pedido 172

Figura V.6 - Realização do trabalho 172

Figura V.7 - Encerramento do processo 173

Figura V.8 - Diagrama de contexto final do ciclo 1 do software de atendimento laboratorial 174

Figura V.9 - Fluxograma final do ciclo 1 174

Figura V.10 - Solicitação do pedido. 175

Figura V.11 - Orçamentação 176

Figura V.12 - Registro de material. 176

Figura V.13 - Realização do trabalho 177

Figura V.14 - Entrega

Figura VI.1 - Passos da Pesquisa-ação e correspondentes atividades

Figura VI.2 - Dinâmica das iterações do ciclo 2 189

Figura VI.3 - Orçamentação (reprodução do ciclo 1). 191

Figura VI.4 - Fase de orçamentação: interface em DHTML 192

Figura VI.5 - Diagrama simplificado de navegação da fase de orçamentação: Inserir serviço do laboratório 193

Figura VI.6 - Reprodução do fluxograma final do ciclo 1 194

Figura VI.7 - Orçamentação multilaboratorial 196

Figura VI.8 - Dados utilizados do sistema Custos e Preços 196 
Figura VI.9 - Diagrama simplificado de navegação da fase de orçamentação: inserir orçamento gerado por outro laboratório

Figura VI.10 - Fluxograma do processo após a iteração 1 198

Figura VI.11 - Fluxograma do processo discutido na iteração 2 (segunda sessão) 199

Figura VI.12 - Diagrama de contexto, considerando a interface com o sistema de numeração do documento técnico 200

Figura VI.13 - Fluxograma final do processo, considerando o detalhamento desta sessão 201

Figura VI.14 - Registro de material e distribuição de OS .204

Figura VI.15 - Inspeção e execução da OS. 205

Figura VI.16 - Composição do documento técnico 206

Figura VI.17 - Coordenação individual e página principal do software 208

Figura VI.18 - Coordenação individual e página principal do software. 209

Figura VI.19 - Coordenação com as atividades do grupo 209

Figura VI.20 - Balanço das atividades do grupo de trabalho 211

Figura VII.1 - Diagrama dos 3Cs e awareness adaptado ao ciclo 3 225

Figura VII.2 - Coordenação individual e página principal do software - reprodução

Figura VII.3 - Coordenação com as atividades do grupo - reprodução .227

Figura VII.4 - Passos da Pesquisa-ação e correspondentes atividades (ciclo 3) ....228

Figura VII.5 - Dinâmica das iterações do ciclo 3 229

Figura VII.6 - Página principal e opções 239

Figura VII.7 - Troca de cliente/Alteração cadastral 240

Figura VII.8 - Alteração cadastral 241

Figura VII.9 - Inspeção e execução da OS (serviços associados ao material da fase)

Figura VII.10 - Inspeção e execução da OS (serviços associados aos demais materiais) 243

Figura VII.11 - Visão geral 244

Figura VII.12 - Histórico de follow-up .245 
Figura VII.13 - Página principal: acesso transversal 246

Figura VII.14 - Acesso transversal: pendências ……........................................247

Figura VII.15 - Acesso transversal: escolha da fase ........................................247

Figura VII.16 - Composição do documento técnico visualizado por meio do artefato Acesso transversal .248

Figura VII.17 - Histórico de andamento do pedido .249

Figura VIII.1 - Variação da intensidade dos tipos de requisitos nos ciclos da PA ...262

Figura VIII.2 - Variação esperada da intensidade dos tipos de requisitos nos ciclos da PA, após a aplicação das mudanças sugeridas .263 


\section{LISTA DE TABELAS}

Tabela VII.1 - Avaliação qualitativa do trabalho cooperativo da sessão 1 ...............250

Tabela VII.2 - Avaliação qualitativa do trabalho cooperativo da sessão $2 . . . . . . . . . . . .253$

Tabela VII.3 - Avaliação qualitativa do trabalho cooperativo das sessões 1 e 2 ....257 


\section{LISTA DE QUADROS}

Quadro I.1 - Quadro geral da pesquisa .32

Quadro II.1 - Elementos de awareness para sistemas assíncronos e desacoplados

Quadro II.2 - Papéis no processo de Engenharia de Requisitos .89

Quadro III.1 - Principais métodos de pesquisa em Engenharia de Produção 111

Quadro III.2 - Síntese dos passos e ações utilizadas 116

Quadro III.3 - Delineamento da pesquisa. 121

Quadro IV.1 - Análise de viabilidade: questões a serem consideradas. 133

Quadro IV.2 - Identificação das características iniciais: questões a serem consideradas

Quadro IV.3 - Simulação do protótipo em papel: questões a serem consideradas.139

Quadro IV.4 - Avaliação sobre o término da prototipação em papel: questões a serem consideradas

Quadro IV.5 - Avaliação sobre término da prototipação não funcional: questões a serem consideradas

Quadro IV.6 - Elementos de awareness (reprodução do Quadro II.1) 152

Quadro IV.7 - Avaliação qualitativa sobre a intensidade da mente coletiva nas sessões de ACT

Quadro IV.8 - Quadro metodológico 157

Quadro V.1 - Análise da viabilidade: respostas..... 164

Quadro V.2 - Situações de referência e ações futuras prováveis 170

Quadro V.3 - Identificação das características iniciais: respostas 171

Quadro V.4 - Simulação do protótipo em papel: respostas 178

Quadro V.5 - Avaliação sobre término da prototipação em papel: respostas. 183

Quadro VII.1 - Resumo das entrevistas realizadas no passo de análise e planejamento 1 
Quadro VII.2 - Elementos de awareness para sistemas assíncronos e desacoplados .236

Quadro VII.3 - Artefatos desenvolvidos como resultados obtidos das entrevistas da

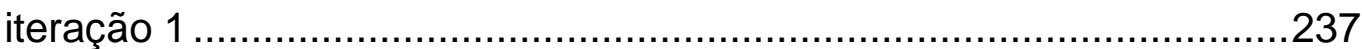

Quadro VII.4 - Avaliação qualitativa do trabalho cooperativo nas sessões de ACT .239

Quadro VII.5 - Artefatos emergentes da sessão 2, elementos de awareness e ações 


\section{LISTA DE ABREVIATURAS E SIGLAS}

ACT Análise Coletiva do Trabalho

CASE $\quad$ Computer Aided Software Engineering

CMM Capability Maturity Model

CSCW Computer Supported Cooperative Work

DFD Diagrama de Fluxo de Dados

DHTML Dynamic Hyper Text Markup Language

DotNet Framework de ferramentas de desenvolvimento da Microsoft

ED Engenharia de Domínio

ELABSOFT Laboratório de Desenvolvimento de Projetos e Processos de Software do Departamento de Engenharia de Produção

ENEGEP Encontro Nacional da Engenharia de Produção

EP Engenharia de Produção

EPN Engenharia de Processos de Negócios

ER Engenharia de Requisitos

ERP Enterprise Resource Planning

ES Engenharia de Software

$\mathrm{IDEF}_{0} \quad$ Integration Definition Language

JAD Joint Application Development

ISO International Organization for Standardization

MANWAPP Manutenção de serviços via aplicações WEB

MER Modelo de Entidade e Relacionamentos

MSF Microsoft Solution Framework

PA Pesquisa-Ação

PesqTec Empresa pública de desenvolvimento de pesquisa tecnológica

RUP Rational Unified Process

Sistema Sistema informatizado 
$\mathrm{TI}$

TIC

TQM

UML

WWW
Tecnologia da Informação

Tecnologia da Informação e Comunicação

Total Quality Management

Unified Modeling Language

World Wide Web 


\section{SUMÁRIO}

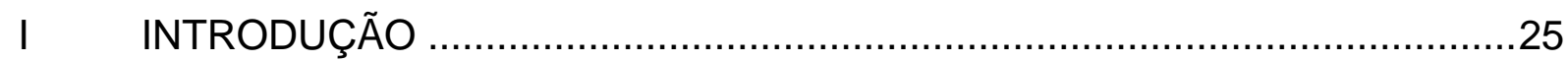

I.1 APRESENTAÇÃO E CONTEXTUALIZAÇÃO DO PROBLEMA ..................25

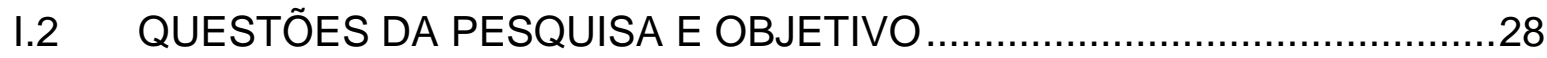

I.3 NECESSIDADES EMPÍRICAS PARA A CONDUÇÃO DA PESQUISA .......30

I.4 O ASPECTO METODOLÓGICO DA PESQUISA …..................................32

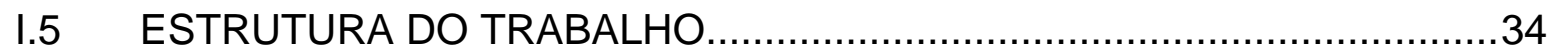

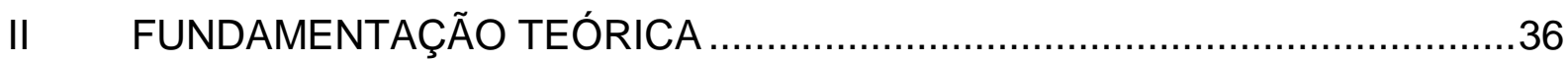

II.1 A DIMENSÃO COLETIVA DO TRABALHO E O TRABALHO

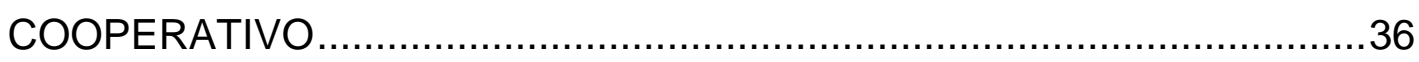

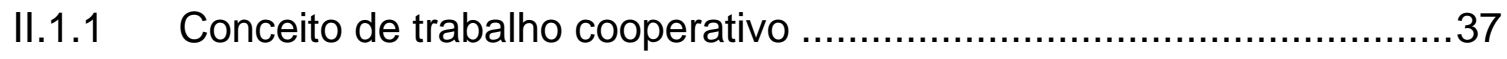

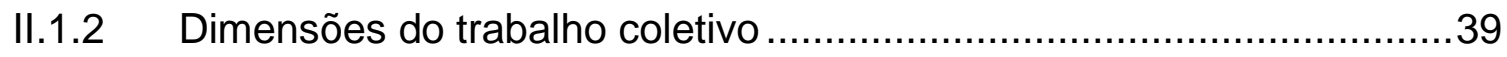

II.1.3 Considerações sobre a dimensão coletiva do trabalho..........................41

II.2 ANÁLISE COLETIVA DO TRABALHO.....................................................

II.2.1 Introdução/conceituação ............................................................ 42

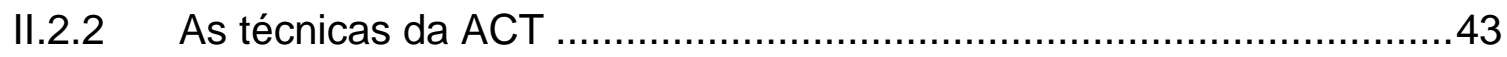

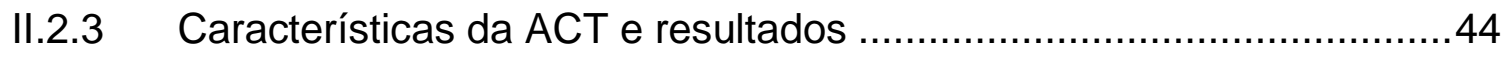

II.2.4 Considerações sobre a aplicação do método da Análise Coletiva do

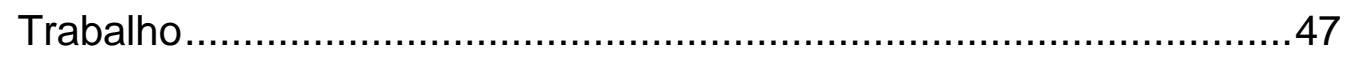

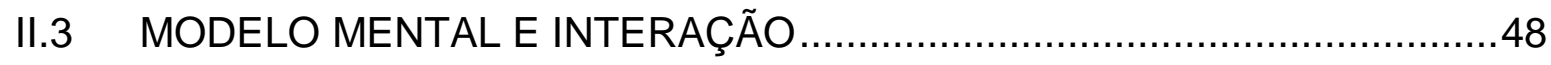

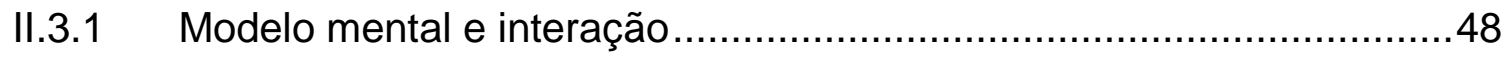

II.3.2 A ergonomia das interfaces ......................................................

II.3.3 Considerações sobre modelo mental e interação e ergonomia das interfaces ........................................................................... 52

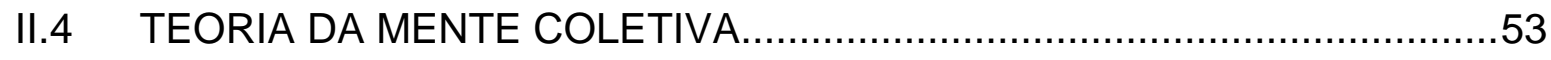

II.4.1 Ações ligadas à teoria da mente coletiva em desenvolvimento dos sistemas informatizados 
II.4.2 Processos sociais no desenvolvimento da mente coletiva ..................58

II.4.3 Considerações sobre a teoria da mente coletiva .................................60

II.5 CSCW, GROUPWARE, MODELO 3C E AWARENESS ..........................61

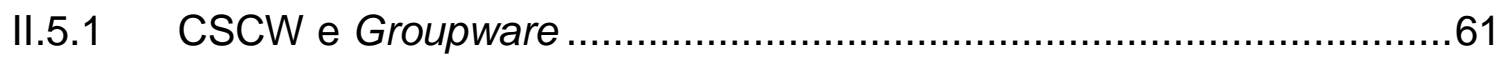

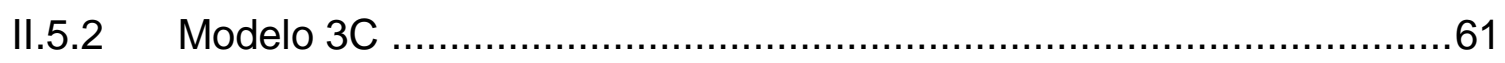

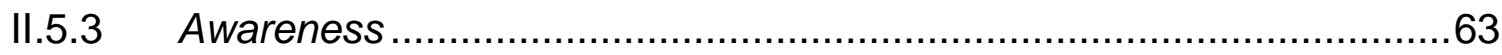

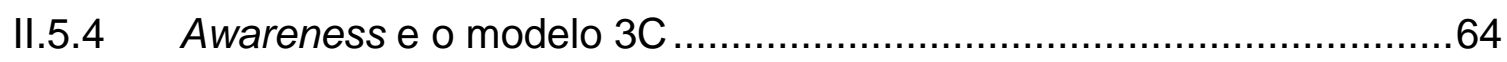

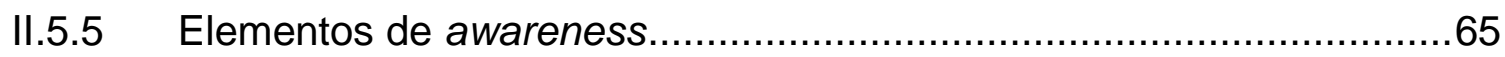

II.5.6 Considerações sobre awareness...................................................73

II.6 MODELOS E PROCESSOS DE SOFTWARE ......................................74

II.6.1 Conceitos e definições ............................................................. 74

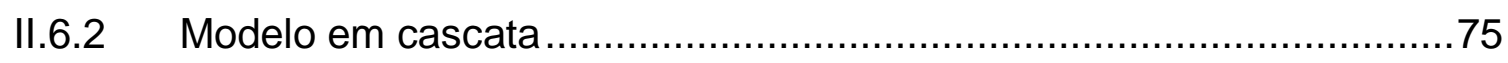

II.6.3 Modelo de desenvolvimento iterativo evolucionário ...............................77

II.6.4 Modelo de transformação formal ................................................... 80

II.6.5 Modelo de desenvolvimento baseado em componentes .....................80

II.6.6 Processo de desenvolvimento de software .......................................

II.6.7 Considerações sobre modelos e processos de software ......................83

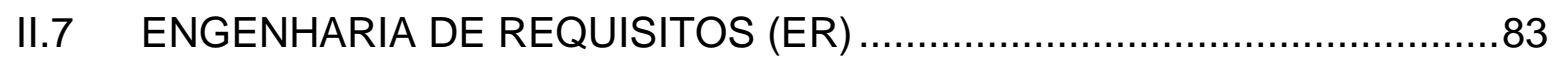

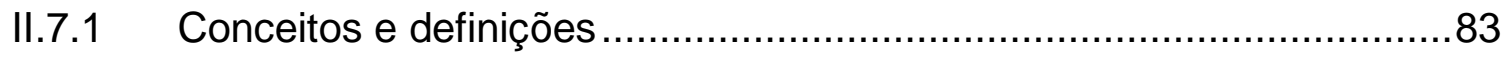

II.7.2 Elementos da Engenharia de Requisitos ......................................... 84

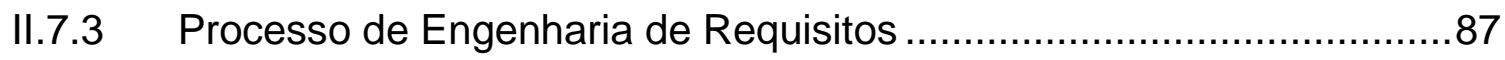

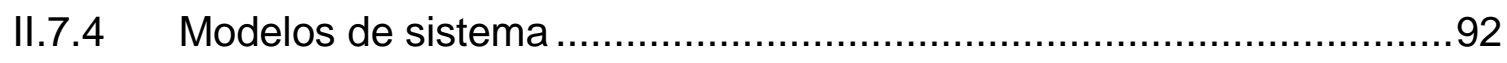

II.7.5 Considerações sobre Engenharia de Requisitos ...............................98

II.8 TÉCNICAS UTILIZADAS NA DESCOBERTA DE REQUISITOS................99

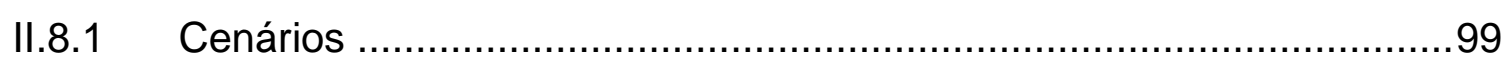

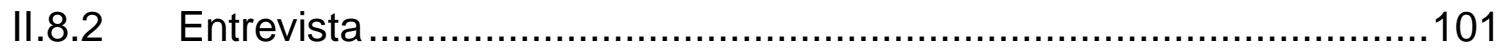

II.8.3 Storyboarding/Técnicas de Prototipação ........................................101

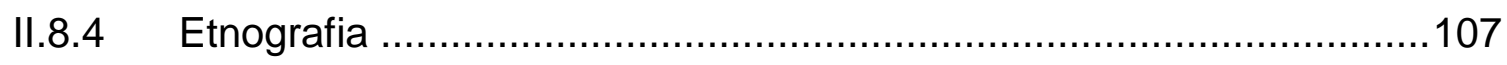

II.8.5 Considerações sobre técnicas utilizadas na descoberta de requisitos 
III METODOLOGIA DE PESQUISA

III.1 INTRODUÇÃO ........................................................................110

III.2 ESTRATÉGIA METODOLÓGICA: PESQUISA-AÇÃO.............................111

III.2.1 Conceituação geral da pesquisa-ação ...........................................111

III.2.2 Ciclos da pesquisa-ação ..........................................................114

III.3 CARACTERIZAÇÃO DA CONDUÇÃO DA PESQUISA-AÇÃO.................116

III.4 DELINEAMENTO DO PROJETO DE PESQUISA .................................119

III.4.1 Revisão bibliográfica metodológica e aplicada ................................123

III.4.2 Contexto e propósitos ..........................................................123

III.4.3 Condução do primeiro ciclo da pesquisa-ação: processo para especificação de requisitos de software com foco na identificação das características individuais do trabalho cooperativo e das características de domínio 124

III.4.4 Condução do segundo ciclo da pesquisa-ação: processo para especificação de requisitos de software com foco na identificação e simulação das características cooperativas do trabalho 125

III.4.5 Condução do terceiro ciclo da pesquisa-ação: Processo para especificação de requisitos de software com foco no refinamento das características do trabalho cooperativo (em uso real); 125

III.4.6 Elaboração da tese com os resultados da pesquisa .........................126

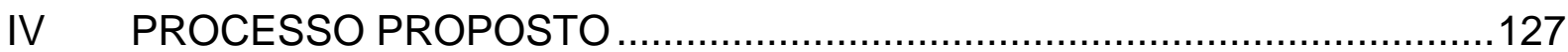

IV.1 CONTEXTO

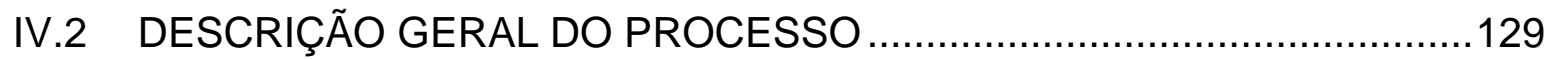

IV.3 ANÁLISE DE VIABILIDADE E DA APLICALIBIDADE DO PROCESSO ...131

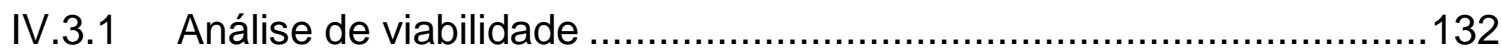

IV.3.2 Verificação da aplicabilidade do processo ao sistema candidato ......133

IV.4 PROCESSO PARA ESPECIFICAÇÃO DE REQUISITOS DE SOFTWARE COM FOCO NA IDENTIFICAÇÃO DAS CARACTERÍSTICAS INDIVIDUAIS DO TRABALHO COOPERATIVO E DAS CARACTERÍSTICAS DE DOMÍNIO 
IV.4.1 Implementação/revisão do protótipo em papel ...............................135

IV.4.2 Simulação do protótipo em papel...................................................138

IV.4.3 Análise dos dados- avaliação sobre o término da prototipação em papel.

IV.5 PROCESSO PARA ESPECIFICAÇÃO DE REQUISITOS DE SOFTWARE COM FOCO NA IDENTIFICAÇÃO E SIMULAÇÃO DAS

CARACTERÍSTICAS COOPERATIVAS DO TRABALHO

IV.5.1 Implementação/revisão protótipo não funcional................................144

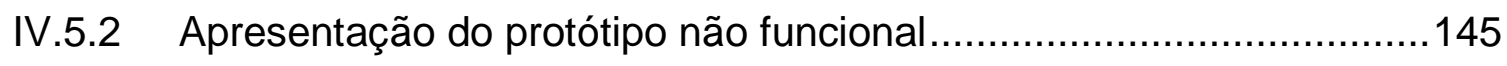

IV.5.3 Análise dos dados - avaliação sobre o término da prototipação não funcional

IV.6 PROCESSO PARA ESPECIFICAÇÃO DE REQUISITOS DE SOFTWARE COM FOCO NO REFINAMENTO DAS CARACTERÍSTICAS DO TRABALHO COOPERATIVO...........................................................149

IV.6.1 Implementação em cascata ....................................................150

IV.6.2 Apresentação do protótipo evolucionário (funcional) ….....................152

IV.6.3 Análise dos dados - avaliação do término do protótipo evolutivo ......155

IV.7 PLANEJAMENTO DE EXECUÇÃO DO PROCESSO PROPOSTO EM FUNÇÃO DOS CICLOS DA PESQUISA-AÇÃO 156

V FASE PRELIMINAR E CICLO 1 DA PESQUISA-AÇÃO: PROCESSO PARA ESPECIFICAÇÃO DE REQUISITOS DE SOFTWARE COM FOCO NA IDENTIFICAÇÃO DAS CARACTERÍSTICAS INDIVIDUAIS DO TRABALHO COOPERATIVO E DAS CARACTERÍSTICAS DE DOMÍNIO .....................160

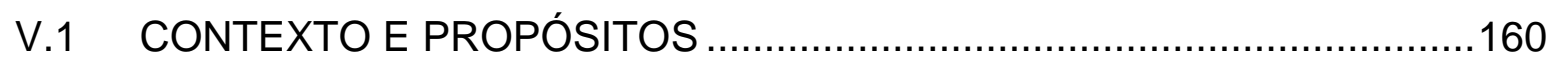

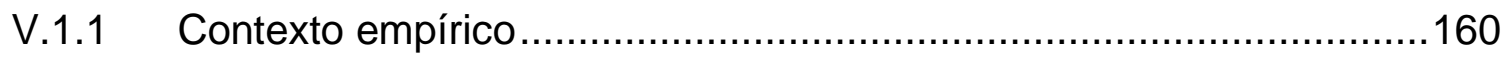

V.1.2 Contexto conceitual: análise de viabilidade ....................................162

V.1.3 Contexto conceitual: verificação da aplicabilidade do processo ao sistema candidato 164

V.2 CICLO 1: PROCESSO PARA ESPECIFICAÇÃO DE REQUISITOS DE SOFTWARE COM FOCO NA IDENTIFICAÇÃO DAS CARACTERÍSTICAS INDIVIDUAIS DO TRABALHO COOPERATIVO 


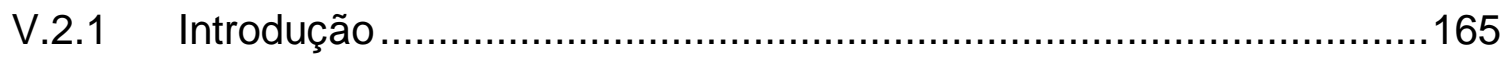

V.2.2 Implementação .....................................................................166

V.2.3 Levantamento e discussão dos dados .............................................178

V.2.4 Análise e planejamento do ciclo 1 ...............................................182

V.2.5 Conclusões do ciclo 1 (passo de monitoramento da PA)...................184

VI CICLO 2 DA PESQUISA-AÇÃO: PROCESSO PARA ESPECIFICAÇÃO DE REQUISITOS DE SOFTWARE COM FOCO NA IDENTIFICAÇÃO E SIMULAÇÃO DAS CARACTERÍSTICAS DO TRABALHO COOPERATIVO 185

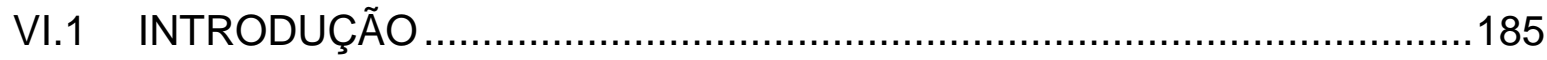

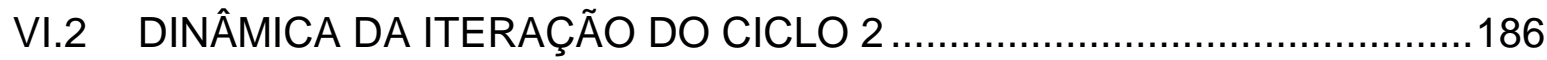

VI.2.1 Dados do grupo e do ambiente das sessões ...................................186

VI.2.2 Dinâmica geral das iterações.........................................................187

VI.3 RESULTADOS (DETALHAMENTO DAS ITERAÇÕES) ..........................190

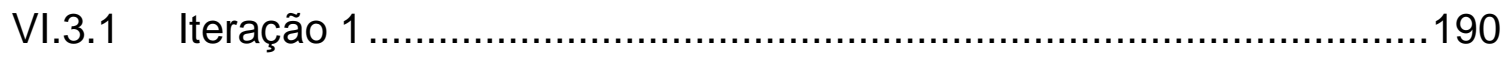

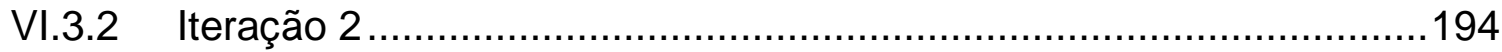

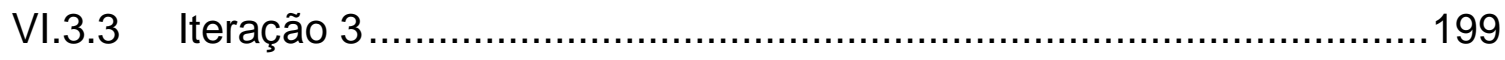

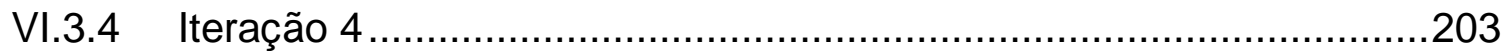

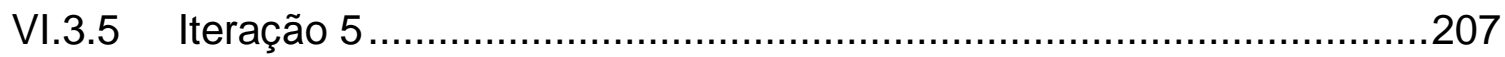

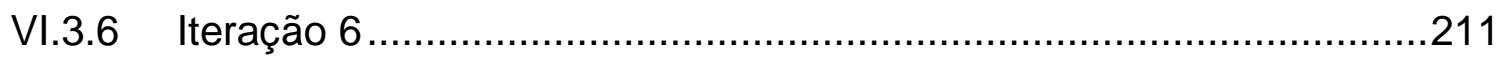

VI.4 CONCLUSÕES DO CICLO 2 (PASSO DE MONITORAMENTO DA PA) .219

VII CICLO 3 DA PESQUISA-AÇÃO: PROCESSO PARA ESPECIFICAÇÃO DE REQUISITOS DE SOFTWARE COM FOCO NO REFINAMENTO DAS CARACTERÍSTICAS DO TRABALHO COOPERATIVO (EM USO REAL) ..222

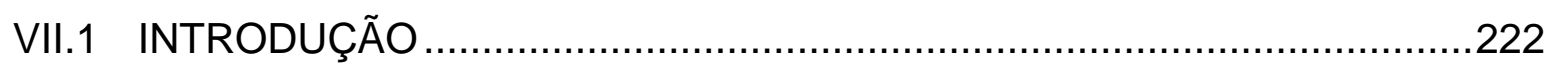

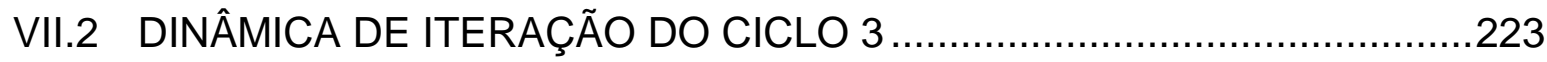

VII.2.1 Dados do grupo e do ambiente das sessões ..................................223

VII.2.2 Modelo 3C e awareness para o ciclo 3 ……................................225

VII.2.3 Características gerais do sistema informatizado desta PA ...............227

VII.2.4 Dinâmica geral das iterações .......................................................228 
VII.3 RESULTADOS (DETALHAMENTO DAS ITERAÇÕES) ….....................230

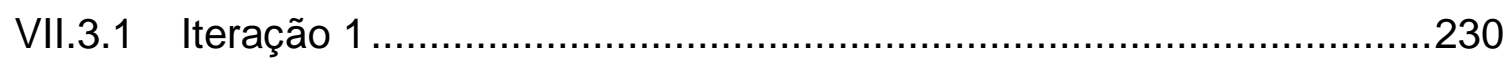

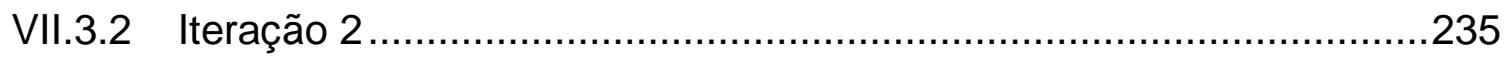

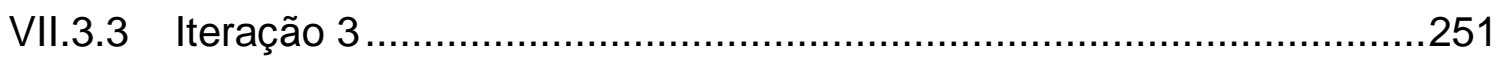

VII.4 CONCLUSÕES DO CICLO 3 (PASSO DE MONITORAMENTO DA PA) .254

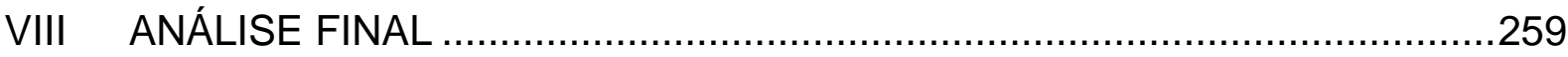

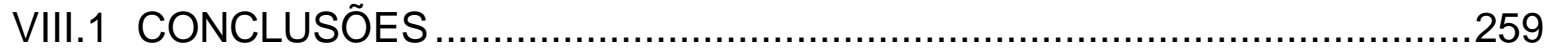

VIII.2 PROPOSTA DE ALTERAÇÃO DO PROCESSO …................................262

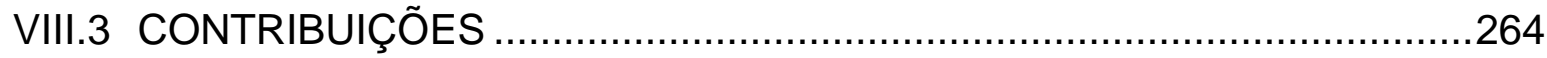

VIII.4 PROPOSTAS PARA FUTUROS TRABALHOS …................................265

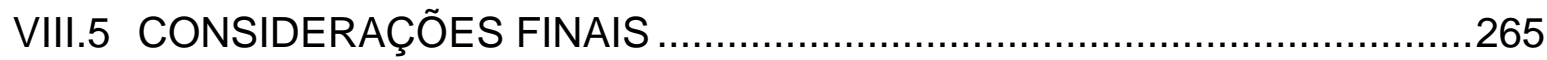

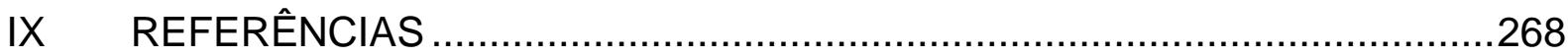

APÊNDICE A: PROCESSOS, MODELAGEM E WORKFLOW ..........................278

APÊNDICE B: ERGONOMIA DAS INTERFACES (USABILIDADE) ....................285 


\section{INTRODUÇÃO}

Este capítulo descreve qual é o problema estudado pela pesquisa e seu respectivo enquadramento dentro das áreas da ciência. As principais questões, os objetivos e os motivos que levaram à realização deste trabalho são apresentados.

A metodologia da pesquisa-ação é aplicada em um projeto de workflow corporativo de uma empresa de pesquisa tecnológica brasileira.

\section{I.1 APRESENTAÇÃO E CONTEXTUALIZAÇÃO DO PROBLEMA}

O avanço tecnológico é conseqüência das demandas sociais e dos setores produtivos. Os problemas e desafios do mundo moderno apresentam dimensões e complexidade tais que suas soluções envolvem cada vez mais o trabalho em equipe, em razão do aumento da concorrência, da rápida evolução da demanda, da presente inovação dos produtos e da transformação das tecnologias.

Deste modo, as empresas abdicam dos modelos clássicos de organização, considerados mais eficazes em contextos mais estáveis e de produção de massa, passando para um modelo focado no contexto da cooperação, cujas decisões relativas à concepção, fabricação e comercialização devem ser tomadas (SALERNO, 1999). Assim, aposta-se no trabalho cooperativo como meio de transformação conjunta dos indivíduos, das coletividades e das organizações, tendo como objetivo o incremento da eficácia organizacional (TAVARES, 2002).

A definição de cooperação utilizada neste trabalho é dada por Dejours (2005, p. 93):

Cooperação é uma conduta coordenada, definida como a ação de participar de uma obra comum. A cooperação supõe um lugar onde, ao mesmo tempo, convergem as contribuições singulares e cristalizam-se as relações de dependência entre os sujeitos.

A dimensão coletiva do trabalho é colocada no centro da mudança pelo discurso e prática empresarial, com a mudança de organização do trabalho, de procedimentos de fabricação, de práticas profissionais e, também, das mudanças nas competências dos trabalhadores. 
Hoje, embora a maioria das metodologias utilizadas em desenvolvimento de software preveja a participação e o envolvimento dos usuários em várias fases de seu processo de desenvolvimento, a questão do trabalho cooperativo necessário para executar as atividades que serão informatizadas, não é considerada de modo explícito desde o início de seu projeto.

Uma das explicações para esta situação é que na abordagem tradicional de desenvolvimento de software (para sistemas de computadores tradicionais ou sistemas comerciais, fortemente orientados a dados), a hipótese mais frequentemente utilizada é a de que os modelos são centrados em um único usuário (tido como padrão e independente do meio ou grupo no qual está inserido), sendo generalizados para o estudo do comportamento cooperativo, envolvendo todos os usuários.

Nesta pesquisa, serão utilizados dois conceitos recorrentes cujas definições logo no início deste trabalho são necessárias: sistema de informação (SI) e sistemas informatizados (software).

O sistema de informação corresponde a um sistema informatizado ou manual que abrange pessoas, máquinas e/ou métodos organizados para coletar, processar, guardar, transmitir e disseminar dados que representam informação para o usuário. Já o sistema informatizado ou software, corresponde à parte do sistema de informação que será automatizada por meio da Tecnologia de Informação - TI (neste trabalho, o termo sistema é equivalente a sistema informatizado).

Sommerville (2007) cita a importância de utilização de métodos alternativos na fase de descoberta dos requisitos de um sistema informatizado quando se trata particularmente das seguintes situações:

- Os requisitos de software são derivados do modo como as pessoas trabalham (trabalho real) mais do que aquilo que a definição dos processos recomenda para o trabalho (trabalho prescrito);

- Os requisitos de software são derivados da cooperação e percepção das atividades de outras pessoas (grifo do autor).

Para estes casos em questão, o autor recomenda o uso de técnicas de etnografia (definida pelo autor como uma técnica observacional que pode ser utilizada para se entender os requisitos sociais e organizacionais, na qual o analista se integra e 
interage no ambiente onde o sistema informatizado será utilizado), com a aplicação de técnicas de cenários (definidos como exemplos relacionados ao mundo real de como os usuários podem interagir com o sistema de informação).

Pressman (2005) cita que, na fase de descoberta de requisitos (elicitação), é importante o uso de reuniões colaborativas para definição dos requisitos, nas quais a meta é identificar o problema, propor diferentes abordagens e definir um conjunto de requisitos consensuais. $O$ autor não define mecanismos para estabelecer como 0 trabalho cooperativo deverá ser mapeado para o sistema informatizado que dará suporte ao SI.

Por sua própria natureza, o trabalho cooperativo depende da vontade das pessoas trabalharem em conjunto, não pode ser prescrito (DANIELLOU e SIX, 2003), e a introdução de sistemas informatizados transforma por completo o ambiente e a atividade. Neste caso, o trabalho com o novo sistema será diferente do atual e mesmo que se faça uma análise acurada do trabalho existente, não há garantias de que seja possível imaginar de modo completo sua utilização futura.

Para que seja possível tratar o paradoxo da concepção (DANIELLOU, 2007) - na construção de um sistema informatizado que irá substituir parte de um SI, é preciso dispor desse sistema antecipado e para concebê-lo adequadamente é necessário conhecer em primeiro lugar a atividade futura - deverá ser estabelecido um processo que trata esta questão, levando em conta sobretudo o fato de que as pessoas trabalham em conjunto para atender a uma série de objetivos estabelecidos e que os usuários têm inerentemente dificuldades para discutir como efetivamente esta cooperação ocorre (SOMMERVILLE, 2007).

Esta pesquisa enquadra-se dentro dos campos de Engenharia de Software (subárea da Engenharia de Requisitos) e da ciência denominada trabalho cooperativo apoiado por computador (Computer Supported Cooperative Work - CSCW). O CSCW é um campo interdisciplinar, no qual os pesquisadores de várias áreas (cientistas sociais, psicólogos, cientistas cognitivos, ergonomistas e profissionais de interação humanocomputador) contribuem com diferentes perspectivas e metodologias para aquisição de conhecimento do trabalho em grupo e para sugestões de como o trabalho em grupo pode ser suportado por meio do uso das tecnologias de redes de 
computadores e respectivo hardware (denominado de groupware) $(\mathrm{KOCH} e$ GROSS, 2006; GROSS; TRAUNMULLER, 1996).

A Figura I.1 mostra a contextualização desta pesquisa, em que pode ser visto que este trabalho dá apoio à Engenharia de Requisitos de Software (ER) por meio de um processo para a especificação de requisitos de software, focando, pelo uso de conhecimentos de outras áreas da ciência, o componente do trabalho cooperativo do Sistema de Informação (domínio do problema) que está sendo informatizado.

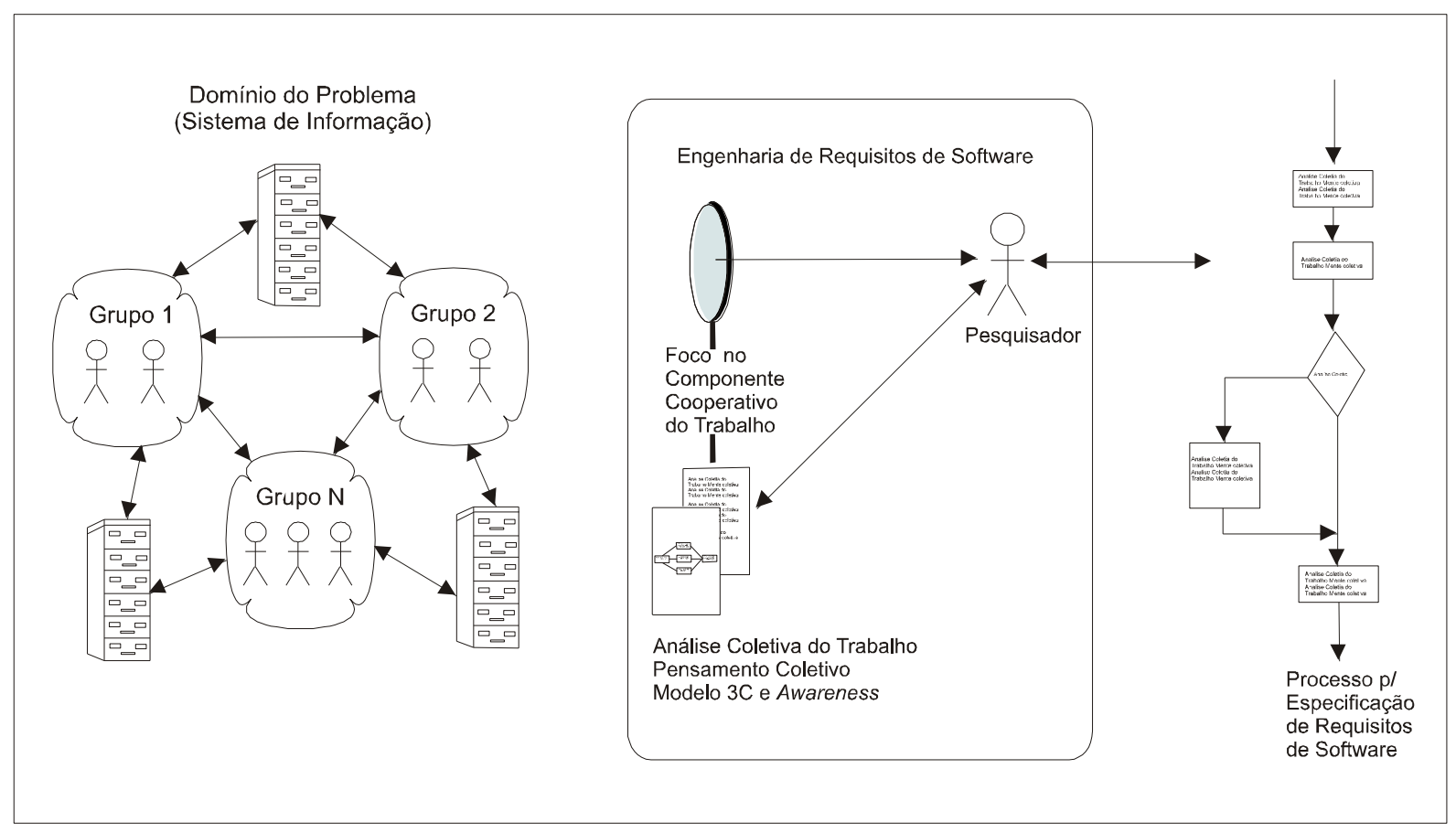

Figura I.1 - Representação gráfica da pesquisa proposta

Fonte: elaborado pelo autor

\section{I.2 QUESTÕES DA PESQUISA E OBJETIVO}

Considerando a busca por meios que conduzam à(s) resposta(s) ao problema apresentado, do foco principal da pesquisa e após a realização da pesquisa bibliográfica, este trabalho procura responder à seguinte questão principal:

- Como considerar na especificação de requisitos de software a dimensão cooperativa do trabalho em sistemas de informação?

Com a derivação das seguintes questões:

- Como, pelas contribuições (individuais) dos stakeholders, estabelecer os principais artefatos necessários para a simulação do trabalho cooperativo por 
meio do software que será implementado? (No caso de sistemas informatizados, stakeholders são todos os envolvidos no processo de especificação e uso, por exemplo, clientes, colaboradores, investidores, fornecedores, comunidade, etc. Artefatos são definidos em engenharia de software como subprodutos de uma ou mais atividades dentro do contexto do desenvolvimento de um software);

- Quais são os instrumentos a serem elaborados para captar os requisitos de software da dimensão cooperativa do trabalho de um SI durante a simulação do sistema informatizado que lhe dará suporte?

- Como estes instrumentos podem ser concatenados para captar os requisitos de software do trabalho cooperativo durante a simulação do sistema informatizado?

- A solução proposta pode ser aplicada para refinar os requisitos de software do trabalho cooperativo durante o uso (em situação de trabalho) do sistema informatizado?

- Quais são os instrumentos a serem elaborados para refinar os requisitos de software da dimensão cooperativa do trabalho de um SI durante o uso do sistema informatizado que Ihe dará suporte?

- Como estes instrumentos podem ser concatenados para refinar os requisitos de software do trabalho cooperativo durante o uso do sistema informatizado?

- Como avaliar a evolução da identificação dos requisitos de software do trabalho cooperativo obtidos durante o uso do sistema informatizado pela aplicação da solução proposta?

Em função do problema e das questões apresentadas, esta pesquisa tem como objetivo principal:

- Contribuir para o mapeamento das características do trabalho cooperativo de um ambiente de produção em uma especificação de software por meio de um processo para levantamento de requisitos.

E como objetivos específicos: 
- Com base na literatura, estudar e propor conceitos, técnicas e métodos que devem ser aplicados à Engenharia de Requisitos, levando em conta o trabalho cooperativo em sistemas de informação;

- Planejar, estruturar e executar uma pesquisa-ação voltada para desenvolver, aplicar, avaliar e aperfeiçoar o processo proposto.

Assim, este trabalho pretende oferecer uma contribuição de cunho empírico, associada a uma contribuição teórica no sentido de um refinamento e/ou extensão da teoria (I.4).

\section{I.3 NECESSIDADES EMPÍRICAS PARA A CONDUÇÃO DA PESQUISA}

A motivação inicial da pesquisa sobre o tema surgiu em 2004, com a participação do autor no projeto Manwapp, do ElabSoft - Laboratório de Desenvolvimento de Projetos e Processos de Software do Departamento de Engenharia de Produção da Escola Politécnica da Universidade de São Paulo, constituído por um grupo de especialistas em Tecnologia da Informação (TI).

Para Trindade (2006), o objetivo principal do ElabSoft constitui-se em levantar, discutir, experimentar e gerir conhecimentos direta e indiretamente ligados à aplicabilidade da Engenharia de Software, visando potencializar a produtividade no desenvolvimento de software por meio de processos otimizados, tanto de manufatura como de organização e gerenciamento da produção.

O projeto Manwapp teve o objetivo de gerenciar serviços de campo (serviços terceirizados) ligados às áreas de telecomunicações e energia elétrica, entre outras. Este gerenciamento se deu pelo acompanhamento da solicitação de chamadas (serviços) até o seu término, envolvendo a área administrativa do cliente, infraestrutura, logística e manutenção e o prestador de serviços.

Este projeto usava a plataforma Internet como meio de integração e acesso dos usuários ao sistema, sendo apoiado também por tecnologias wireless. O Manwapp foi desenvolvido, com a colaboração dos participantes do grupo, baseado na utilização de técnicas de orientação a objetos e ferramentas CASE (Computer Aided Software Engineering) apoiadas na UML (Unified Modeling Language), tanto no projeto (design), como na programação do sistema, no modelo de arquitetura de três 
camadas: apresentação, negócios e persistência, na tecnologia DotNet e processo RUP (Rational Unified Process), além de um conjunto de técnicas e ferramentas de implementação.

A partir de uma pesquisa realizada durante o desenvolvimento deste projeto, o autor iniciou o estudo do presente trabalho que originou uma publicação no ENEGEP de 2004 - Proposta de processo de especificação de software a partir de técnicas baseadas em suas funcionalidades sob a óptica de seus usuários finais - que fazia uso combinado de técnicas de prototipação orientada por casos de uso e JAD e da lista de eventos, utilizados desde a fase de elicitação de requisitos e reaproveitados durante todo o ciclo de vida do processo de desenvolvimento de software (GAVA et al., 2004).

O autor participou também de outros projetos para levantamento de requisitos na empresa onde atua, percebendo a falta de um tratamento formal do trabalho cooperativo em software que não é tratado como groupware (ou seja, sistemas informatizados comerciais) e as implicações práticas de se considerar implicitamente estas características, como por exemplo, de um maior retrabalho na fase de codificação do produto, pois é nesta fase que este tipo de software acaba considerando implicitamente as características do trabalho cooperativo.

A oportunidade para aplicar os conceitos desta pesquisa surgiu em uma empresa pública de desenvolvimento de pesquisa tecnológica, que será denominada neste trabalho como PesqTec. O projeto em foco corresponde a um workflow e tem como objetivo seguir as várias etapas de um processo de atendimento de solicitações de serviços, desde a abertura de um pedido, passando por todas as fases de execução até sua finalização, de modo a envolver o trabalho cooperativo dos participantes do laboratório (técnicos, supervisores e secretárias).

Neste projeto, o autor como funcionário regular da PesqTec, atuou em equipes multidisciplinares, com competências de analista de processos, analista de sistemas e, sobretudo, pesquisador. Desta forma, aconteceu a continuidade empírica do estudo, caracterizando a metodologia de pesquisa como pesquisa-ação e consolidando-se o objetivo principal do presente trabalho. 


\section{I.4 O ASPECTO METODOLÓGICO DA PESQUISA}

Marconi e Lakatos (2000) sintetizam os passos necessários que devem estar presentes nas investigações científicas:

- Descobrimento do problema, que corresponde à identificação da lacuna de conhecimento ou da oportunidade de melhoria de forma clara e precisa;

- Procura de conhecimentos ou instrumentos importantes, no sentido de buscar mais informação ou identificar respostas e meios para solucionar o problema;

- Investigação de como o problema está sendo tratado ou solucionado por outras pessoas;

- Esboço de solução para o problema, de forma plausível e viável;

- Implementação, teste e conclusões sobre a solução proposta.

Nesta pesquisa, será utilizada a metodologia de pesquisa-ação descrita em Coughlan e Coghlan (2002) e Thiollent (2004) aplicada em um projeto de workflow corporativo em uma grande empresa de pesquisa tecnológica no Brasil, mostrando como considerar as questões cooperativas do trabalho em um projeto de desenvolvimento de software e os resultados obtidos.

Nos dados do Quadro I.1 abaixo podem ser vistos os detalhes com relação à aplicação da pesquisa e na Figura I.2 a contextualização de sua condução.

\section{Quadro l.1 - Quadro geral da pesquisa}

\begin{tabular}{|l|l|}
\hline Componente & Pesquisa-ação \\
\hline Unidade(s) de & Identificação: \\
intervenção & Empresa de economia mista de pesquisas tecnológicas de grande \\
& porte, que atua no setor público, com cerca de 1.600 pessoas na força \\
de trabalho, denominada neste trabalho como PesqTec. & Características gerais: \\
& Ambiente multifuncional, multidisciplinar, multiplataforma, diversidade \\
de clientes, produtos e serviços oferecidos, diversidade de infra- & estrutura de hardware e software. \\
& Unidades de Intervenção: \\
& - Unidade de Intervenção do ciclo1: \\
& Grupo de analistas de negócio \\
& - Unidade de Intervenção do ciclo 2: \\
& Representantes dos laboratórios e analistas de negócio \\
& - Unidade de Intervenção do ciclo 3: \\
& Trabalhadores de dois laboratórios com características diferentes \\
\hline
\end{tabular}




\begin{tabular}{|l|l|}
\hline Componente & Pesquisa-ação \\
\hline Envolvidos na pesquisa & $\begin{array}{l}\text { Pesquisadores, diretores, gerentes, analistas de negócio, } \\
\text { representantes dos laboratórios (administrativos e técnicos) e usuários }\end{array}$ \\
\hline $\begin{array}{l}\text { Interessados nos } \\
\text { resultados }\end{array}$ & $\begin{array}{l}\text { Organizações produtoras de software e fábricas de software, por meio } \\
\text { da alta direção, dos empresários, diretores, gerentes, analistas, } \\
\text { desenvolvedores, técnicos e especialistas; } \\
\text { Pesquisadores das áreas de melhoria de processos de } \\
\text { desenvolvimento de software } \\
\text { Pesquisadores da área de CSCW }\end{array}$ \\
\hline
\end{tabular}

Fonte: elaborado pelo autor

CONTEXTO: Sistemas de informação comerciais e sua automação através de softwares envolvendo múltiplos usuários trabalhando de forma cooperativa.

Questão principal:

Como considerar na especificação de requisitos de softwares comerciais a dimensão cooperativa do trabalho em sistemas de informação?

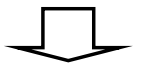

Premissa:

A definição da dimensão cooperativa do trabalho em softwares exige conhecimentos de outras áreas, além da informática.

Proposição:

Definir um processo de requisitos de software orientado ao trabalho cooperativo de um Sl.

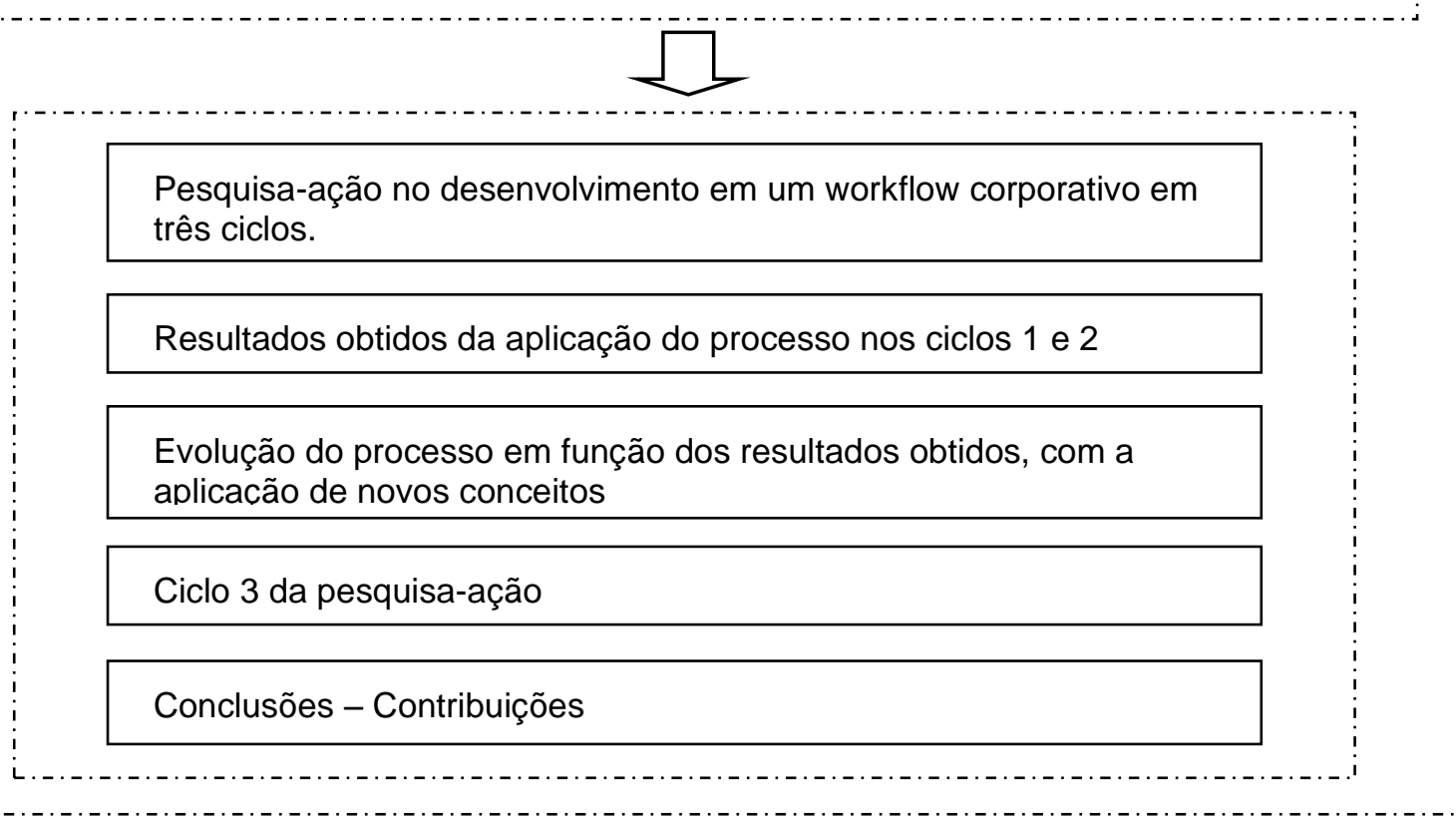

Figura I.2 - Contextualização da pesquisa

Fonte: elaborado pelo autor 
Esta pesquisa pretende oferecer uma contribuição de cunho empírico, no sentido de definir e estabelecer um processo para a especificação de requisitos de software orientado ao trabalho cooperativo. O objetivo para o meio acadêmico é contribuir como referência para estudos relacionados ao uso de técnicas de outras áreas do conhecimento aplicadas em engenharia de software para auxiliar no levantamento de requisitos (de software) referentes ao trabalho cooperativo.

O método é o instrumento do pesquisador. Se ele escolher um instrumento que não se adapte ao seu objeto, não conseguirá fazer um bom trabalho. É apenas quando objeto e instrumento se ajustam que o resultado aparece. $E$ aí fica difícil saber o que foi objeto ou instrumento. Surge apenas um novo produto (FERREIRA, 1999, p. 98).

\section{I.5 ESTRUTURA DO TRABALHO}

Esta pesquisa está organizada em oito capítulos, resumidos a seguir:

O Capítulo I apresenta a proposta do trabalho, o contexto do problema, a motivação do estudo, os objetivos a serem alcançados e sua estrutura da pesquisa.

O Capítulo II trata da fundamentação teórica por meio de assuntos envolvidos no processo proposto: a dimensão coletiva do trabalho e o trabalho cooperativo, análise coletiva do trabalho, modelo mental e interação e ergonomia das interfaces, teoria da mente coletiva, o modelo $3 \mathrm{C}$ da cooperação em sistemas CSCW (Computer Supported Cooperative Work), awareness em trabalho cooperativo apoiado por computador, modelos e processo de software, Engenharia de Requisitos e técnicas utilizadas no descobrimento de requisitos.

O Capítulo III apresenta a metodologia de pesquisa, a estrutura e a lógica do processo de pesquisa, focando o método de pesquisa-ação.

O Capítulo IV apresenta o macroprocesso proposto dividido em três processos componentes: para obtenção das características individuais do trabalho cooperativo (protótipo inicial do sistema), para a simulação das características do trabalho cooperativo (protótipo não funcional) e para o refinamento destas características (protótipo funcional). 
O Capítulo $V$ trata da Fase Preliminar da pesquisa referente à caracterização da empresa estudada e o ciclo 1 da pesquisa-ação, com foco no trabalho individual dos usuários por meio da prototipação em papel.

O Capítulo VI descreve o ciclo 2 da pesquisa-ação considerando, além dos aspectos do trabalho individual, as características do trabalho cooperativo mais ligadas ao ambiente de trabalho dos usuários (suas ações e inter-relações) .

O Capítulo VII descreve o ciclo 3 da pesquisa-ação, que, além de considerar os aspectos dos dois ciclos anteriores, considera também o aspecto de como a inclusão do sistema informatizado altera o ambiente de trabalho dos usuários, passando da iteração face a face para a iteração mediada pelo software que o substitui (awareness).

O Capítulo VIII faz a análise final, conclusões do trabalho, contribuições relevantes e sugestões para trabalhos futuros.

No final, as referências bibliográficas que nortearam o estudo e os anexos necessários para complementar a fundamentação teórica são apresentados. 


\section{FUNDAMENTAÇÃO TEÓRICA}

A fundamentação teórica foi efetuada ao longo do período de duração da pesquisaação. O estudo serviu como embasamento para a construção dos modelos e do processo que, por sua vez, serviram como guia para o monitoramento e condução da pesquisa-ação, assim como ao entendimento do complexo contexto do ambiente pesquisado, culminando na associação do estudo empírico com o teórico.

O estudo de um processo para especificação de requisitos de software orientado ao trabalho cooperativo em sistemas de informação exige olhar este sistema por meio de uma estratégia de análise multidisciplinar (ergonomia, sociologia e engenharia de software) que, ao ser abordado, leva à descoberta gradual dos elementos do processo, auxiliando a compreensão de como a dimensão coletiva do trabalho deve ser considerada em seu desenvolvimento.

Nesta seção são definidos os principais aspectos teóricos do processo proposto, focando-se o trabalho cooperativo por meio de duas abordagens, primeiramente considerando-se as interações face a face entre usuários (pela conceituação de trabalho coletivo, Análise Coletiva do Trabalho e da teoria da mente coletiva) e depois estas interações são consideradas por intermédio do software produzido (modelo $3 \mathrm{C}$ de cooperação e awareness em trabalho cooperativo apoiado por computador).

Para finalizar, o próximo passo é a consideração dos conceitos ligados ao modelo mental, interação e interfaces que servem como suporte para a aplicação dos conceitos acima descritos pela Engenharia de Software (modelos de processo de software, Engenharia de Requisitos (ER) e técnicas utilizadas na ER).

\section{II.1 A DIMENSÃo COLETIVA DO TRABALHO E O TRABALHO COOPERATIVO}

A valorização crescente do trabalho em grupo, conforme observado no item I.1 dá margem para a consequente valorização de sua análise. Esta tendência mostra a necessidade das empresas procurarem outros modelos de organização além dos modelos tradicionais (taylorismo/fordismo), considerados eficazes em ambientes 
mais estáveis e de produção em massa, e as decisões relativas à concepção, fabricação e comercialização passam a ser concebidas em um contexto de cooperação (SALERNO, 1999).

Neste item, exploram-se com mais profundidade os conceitos envolvidos com o trabalho coletivo/cooperativo, assim como as dimensões que o mesmo pode assumir.

\section{II.1.1 Conceito de trabalho cooperativo}

Em geral, os modelos clássicos utilizados em análises do trabalho não abordam aspectos da dimensão coletiva do trabalho, em relação à interdependência existente entre tarefas e/ou atividades de vários operadores ou quanto à importância das relações sociais em uma equipe de trabalho (BARTHE, 2003).

A tarefa é a prescrição do que deve ser feito por um operador, sendo definida pela organização com base em um objetivo (o estado final desejado) e pelas condições para sua realização (os procedimentos, os constrangimentos de tempo, os meios à disposição e pelas características do ambiente físico, etc.). A atividade é o que é feito, a estratégia de adaptação que o sujeito mobiliza para efetuar a tarefa, sendo que o operador fixa para si um objetivo, a partir do objetivo da tarefa, para finalizar a atividade (FALZON, 2007).

Uma vez que a dimensão coletiva do trabalho torna a situação mais flexível, cada vez mais complicada e menos determinista (para um dado observador) das interrelações (interações, retroações, interferências, etc.), a complexidade sistêmica aumenta, manifestando-se no fato que o todo possui qualidades e propriedades que não se encontram no plano das partes consideradas isoladamente e, também, pelo fato de que as partes possuem qualidades e propriedades que desaparecem sob 0 aspecto das coações organizacionais do SI (MORIN, 2002).

Uma nova ordem de complexidade aparece quando a existência e a manutenção de sua diversidade são inseparáveis das inter-relações com o ambiente, inter-relações (e que são ao mesmo tempo autônomas e dependentes) com as quais o SI tira do exterior matéria-energia e em um grau de complexidade superior: informação (MORIN, 2002). 
Para De Terssac e Maggi (2004), o trabalho é cada vez menos considerado como uma realidade já constituída, diante da qual o indivíduo deve se submeter. $\mathrm{O}$ trabalho torna-se uma ação coletiva por meio da qual os indivíduos vão cooperar para obter certo resultado, dentro de condições dadas. Esta ação se desenrola tendo alguns constrangimentos, em razão do contexto estruturado pelos dispositivos, regras e normas que irão definir o espaço de ação e que poderão ser ou não questionados pelos indivíduos.

A ergonomia passou a pesquisar e empregar noções ligadas ao trabalho coletivo, como: cooperação, colaboração, coordenação e outras, fundamentais para essa forma de trabalho. É possível encontrar na literatura diferentes definições e abordagens para estas noções e, desta forma, considerou-se importante apresentar algumas definições utilizadas nesta pesquisa.

Conforme citado no item I.1, a definição de cooperação utilizada neste trabalho é dada por Dejours (2005, p. 93):

Cooperação é uma conduta coordenada, definida como a ação de participar de uma obra comum. A cooperação supõe um lugar onde, ao mesmo tempo, convergem as contribuições singulares e cristalizam-se as relações de dependência entre os sujeitos.

O autor salienta que a cooperação remete ao coletivo de trabalho e é uma conduta coordenada que possibilita desempenhos superiores e suplementares em relação aos desempenhos individuais.

A cooperação não idealiza o operador humano, pois faz a integração das diferenças entre as pessoas, articulando os talentos específicos de cada trabalhador e compensando as possíveis falhas singulares. Segundo o autor, a qualidade do trabalho, a confiabilidade e a segurança estão diretamente ligadas à qualidade da cooperação, podendo compensar as falhas da organização do trabalho prescrito e as restrições dos desempenhos humanos.

O termo cooperação, quando se trata da questão do trabalho, pode ser definido de uma forma mais ampla no sentido que duas ou mais pessoas cooperam quando se empenham em uma tarefa conjunta em direção a um determinado objetivo. Para que este objetivo seja alcançado, são necessárias ações de ambos (cada um dos parceiros executa as ações), de modo que cooperar é operar em comum, buscando 
o ajuste por meio de novas operações de correspondência, reciprocidade ou complementaridade (PIAGET, 1996).

Segundo Tavares (2002), a cooperação exige que os participantes estejam de acordo com respeito a um conjunto de regras que deve ser observado no decorrer da atividade. Acordo e regras não precisam ser o resultado de uma comunicação formal nem mesmo de intenção explícita. Podem se desenvolver no decorrer da própria interação, por tradição, por experiência anterior com sucesso, tentativa e erro ou processos evolutivos relacionais. A cooperação exige, portanto, que os agentes:

- Identifiquem um objetivo comum;

- Estejam engajados em ações para realizar esse objetivo comum;

- Sejam aptos para reconhecer que os outros agentes estão engajados no mesmo objetivo;

- Enfim, que sejam aptos para evitar os conflitos ou para resolvê-los.

O indivíduo integrado a um SI no qual a distribuição de competências, de tarefas, de papéis, necessita de processos integrantes (coordenação, comunicação, organização/cooperação). A dualidade entre o todo e as partes, entre unificação e distribuição, entre homogeneidade e heterogeneidade raramente é levada em conta nos métodos de análise e concepção de sistemas informatizados (ERCEAU et al, 1994). Esta questão será mais bem detalhada no item II.5, onde os processos integrantes serão associados ao trabalho cooperativo de um grupo, focado por meio de um software que o implementa.

\section{II.1.2 Dimensões do trabalho coletivo}

Para Guérin et al. (2001), existe uma série de termos utilizados para descrever as dimensões do trabalho coletivo:

- Coordenação: neste caso pressupõe que os operadores devem levar em conta mutuamente o ordenamento de suas ações e respectivas decisões, tendo ou não objetivos imediatos diferentes;

- Coação: corresponde a um caso de coordenação no qual os operadores realizam ações paralelas, e que em dado momento devem convergir; 
- Cooperação: realização conjunta de uma mesma tarefa, em um mesmo objeto de trabalho, em uma relação de dependência mútua. Nesta situação, as diferentes pessoas envolvidas na ação obtêm informação sobre o andamento da ação das outras, de maneira a poder ajustar a maneira como trabalham em tempo real;

- Colaboração: é o caso dos trabalhadores que, normalmente, não trabalham no mesmo objeto, mas compartilham suas competências para lidar com uma situação particular, ou mesmo famílias de situações.

A coordenação aparece ainda como um fato característico das formas organizacionais e constitui uma condição para a cooperação, em que a cooperação aparece como um processo que vai além da coordenação, englobando-a. Outro elemento chave para a compreensão da cooperação corresponde à noção de objetivo, em que um grupo corresponde a uma reunião de agentes que compartilham um mesmo objetivo (TAVARES, 2002).

Ainda segundo Guérin et al. (2001), é necessário que cada um dos participantes do grupo tenha uma representação suficiente do trabalho que os outros efetuam, sendo que duas condições são importantes:

- Conhecer a organização geral do seu trabalho e de seus colegas, considerando suas diversas fases, assim como suas limitações;

- Ter informações que possibilitem avaliar em um determinado momento como o desdobramento de suas ações afetam os demais.

Outro aspecto inerente à atividade coletiva diz respeito à comunicação entre os elementos do grupo, em que cada um dos participantes está comprometido com uma ação, interpretando as informações que lhe chegam baseadas em sua focalização naquele momento, tendo como apoio o conhecimento das ações dos demais participantes do grupo. Considera-se que ocorre comunicação sempre que há transmissão de informação entre uma pessoa e outra.

A comunicação pode ser explícita (palavras trocadas entre os elementos do grupo, gestos, etc.) ou implícitas (por uma atividade especificamente realizada, ou por meio de um som produzido por um determinado elemento do grupo, etc.). 
A ergonomia direcionou suas análises e não considera somente a ação individual e a relação "tarefa-atividade" de um só operador, mas a ação coletiva e as relações entre tarefas, atividades e diversos operadores (MAGGI, 2005).

Assim, a efetiva organização do trabalho, além de exigir a coordenação de experiências singulares e, sobretudo de cooperação, implica a vontade das pessoas trabalhar em conjunto, de modo que a mesma não pode ser prescrita, exigindo uma relação de confiança das pessoas na construção de normas e regras que determinem a forma de executar o trabalho (DANIELLOU; SIX, 2003).

\section{II.1.3 Considerações sobre a dimensão coletiva do trabalho}

Esta seção mostra a importância de se considerar o trabalho coletivo e, mais particularmente, o trabalho cooperativo, tanto nos sistemas de informação como nos softwares desenvolvidos para dar suporte a este ambiente. São descritos os conceitos a respeito da dimensão coletiva do trabalho e a contextualização do trabalho cooperativo.

Os conceitos aqui descritos sobre cooperação serão utilizados ao longo da pesquisa, sendo refinados e adaptados na medida que métodos e técnicas relativas ao trabalho cooperativo e ao levantamento dos requisitos de software neste ambiente forem introduzidos durante seu andamento.

\section{II.2 ANÁLISE COLETIVA DO TRABALHO}

Nesta seção, foca-se o método da Análise Coletiva do Trabalho, no qual os trabalhadores, em grupo, explicam às pessoas externas as relações de trabalho de suas próprias atividades.

Suas principais características são apresentadas, assim como as técnicas utilizadas em sua construção. 


\section{II.2.1 Introdução/conceituação}

A Análise Coletiva do Trabalho (ACT) é um método de análise na qual trabalhadores (usuários, no caso da informática), em grupo, descrevem sua própria atividade em situação de trabalho para outros trabalhadores e a pessoas externas a relação de trabalho (stakeholders, também, no caso da informática). É a fala dos trabalhadores e a escuta dos pesquisadores que se encontram no centro do processo.

Mas existem etapas preliminares para a aplicação do método. Primeiro, é necessária uma demanda, um problema concreto a ser enfrentado; nesta ocasião, é feita uma análise das possibilidades de atendê-la ou não por meio da ACT. A demanda representa, assim, um compromisso na obtenção de resultados por parte dos trabalhadores (FERREIRA, 1993).

A ACT apoia-se nas seguintes premissas:

- Trabalha-se com grupos de indivíduos e não com indivíduos isolados. No decorrer do processo, os trabalhadores vão tomando consciência das ações, de toda perícia necessária para realizar o trabalho e de toda dificuldade. Esta consciência adquire maior valor ainda, porque os outros colegas vão se identificando com quem está falando e manifestando esta identificação, ou então, discordando, descobrindo-se, desse modo, os pontos comuns, não permitindo também que se derive para problemas de ordem pessoal e individual;

- O objetivo dos trabalhadores é explicar aos pesquisadores o que fazem no trabalho. A pergunta condutora é: "o que você faz" é uma questão positiva (ao contrário das questões sobre doenças, que estão na maioria das abordagens em Medicina e Psicologia do Trabalho, que são negativas) e está sempre sendo reapresentada pelos pesquisadores. Todos os participantes podem fazer perguntas e ajudar a respondê-las: o que você precisa para fazer esta peça? Quem é que Ihe passa o trabalho? O que acontece quando você erra? Como se faz determinada operação? Como reage seu colega de trabalho em tal situação? etc.;

- Há, pelo menos, dois pesquisadores conduzindo a reunião. Durante todo o decorrer da reunião, os pesquisadores estão sendo testados para verificar se 
merecem a confiança dos trabalhadores, quer em termos de compreensão do que está sendo dito (os trabalhadores têm o cuidado de converter seus termos operacionais para uma linguagem compreensível pelos pesquisadores), quer pelo respeito de que não se pode ou não se quer dizer claramente. É fundamental que o resultado da análise, em forma de relatório, antes de ser divulgado, seja avalizado pelos participantes;

- Todos os participantes são voluntários e conhecem a atividade que está sendo analisada;

- As reuniões são feitas fora do local de trabalho;

- O anonimato dos trabalhadores deve ser assegurado.

Este método diferencia-se do Grupo Focal que, de acordo com Morgan (1997), é uma técnica de pesquisa que coleta dados por meio das interações grupais ao se discutir um tópico especial sugerido pelo pesquisador, possuindo um caráter mais exploratório e menos diretivo que a ACT, cujo fio condutor é a atividade dos trabalhadores descrita pelos próprios trabalhadores.

\section{II.2.2 As técnicas da ACT}

Conforme cita Ferreira (1993), as técnicas podem variar bastante, podendo haver uma ou várias reuniões sucessivas, com duração de 90 minutos cada, que pode ser gravada (desde que em comum acordo).

A estas reuniões, existem etapas preliminares. Assim, é preciso haver uma solicitação externa, um problema a ser resolvido ou esclarecido, uma análise da solicitação. Neste ponto, será possível avaliar se esta demanda pode ser atendida com a ACT e também se esclarecerá como funciona o processo de reuniões.

Outro aspecto para a aplicação da ACT é que todos os participantes sejam voluntários, dando-Ihes garantias de anonimato. Estas podem ajudar a criar um clima de confiança que é necessário ao andamento correto do processo.

Uma regra fundamental é que todos participantes entendam a atividade que está sendo analisada. Os participantes podem fazer perguntas e ajudar a respondê-las. $O$ 
diálogo que se estabelece, permite que a atividade vá sendo descrita, explicada e interpretada.

Para determinados grupos, após uma apresentação geral e breve de cada um, escolhe-se um pessoa que irá explicar mais detalhadamente a atividade. Em outros, cada trabalhador poderá falar mais detalhadamente. Dois pontos importantes são reforçados:

- Deve ser dada uma explicação inicial sobre o objetivo do trabalho, por parte dos pesquisadores. Novos assuntos poderão ser desenvolvidos com o grupo, mas devem ser motivo de novas negociações;

- Os pesquisadores devem entender detalhes sobre a atividade e procurar fazê-los de várias formas, mesmo que demorem bastante tempo. Não se pode fingir que entendeu. Deve-se entender mesmo. Uma boa técnica corresponde a se descrever a atividade cronologicamente.

O trabalho termina com um relatório escrito pelos pesquisadores que deve, antes de sua divulgação, ser apresentado ao conhecimento dos participantes, para que possa detectar erros de interpretação e precisem pontos que não ficaram esclarecidos durante as reuniões.

\section{II.2.3 Características da ACT e resultados}

Para a proposta de trabalho em questão, alguns resultados e características gerais sobre ACT devem ser destacados:

- Inverte-se o processo de saber. São os trabalhadores que sabem, os pesquisadores não sabem. Todos têm algo próprio e único para contar: sua atividade real. Segundo a autora, esta inversão valoriza o trabalhador e cria um clima altamente positivo;

- Para se explicar o que se faz, deve-se antes refletir sobre o que se faz, o que não é um processo usual, fazendo com que se torne explícito e consciente tudo o que se fazia de modo automático: "Para o sujeito falante, exprimir é tomar consciência: não exprime somente para os outros, exprime para que ele próprio saiba o que visa". Normalmente, não se pensa na atividade que se 
faz, mas em seus resultados, é a atividade em si que é importante e é ela quem precisa ser explicada;

- O processo facilita descobrir os pontos comuns na atividade dos trabalhadores;

- Permite analisar o trabalho sob diversas situações: o do conteúdo do trabalho, das exigências da produção, das relações com os colegas e chefias, do ambiente de trabalho, etc.;

- A ACT cria condições para reproduzir, fora do local de trabalho, uma espécie de réplica condensada do que acontece dentro do local de trabalho;

- O sujeito e a atividade estão absolutamente entrelaçados, e é como se o pensamento sobre a atividade não se distinguisse do pensamento do próprio sujeito. A ACT transforma a atividade em um tema de reflexão e cria condições para que se pense sobre ela, como se fosse um objeto externo.

- O resultado da ACT não possui só objetividade, mas também subjetividade (os trabalhadores valoram o que descrevem: o que é bom, ruim, do que gostam, ou então, o que é perigoso);

- O material resultante da ACT pode ser utilizado de diversas formas por várias áreas de especialização.

Assim, de acordo com o exposto, tem-se uma ideia clara dos aspectos invisíveis, ou subjacentes a uma atividade, como a atividade cognitiva. Aparecem explicados em detalhes, quais tipos de cálculos são necessários realizar, o que é preciso saber de cor, o que fica guardado na memória, que tipo de raciocínio é feito quando ocorre um incidente, que tipo de indicadores são utilizados para avaliar a qualidade de um produto, o estado de funcionamento de um equipamento, etc.

É comum os trabalhadores surpreenderem-se com o que fazem, como se o processo os levasse a refletir sobre algo que até então permanecesse inconsciente, pois acontece um processo em que uma percepção intuitiva vai se transformando em uma percepção mais reflexiva (FERREIRA, 1998).

Este método usa a memória do trabalhador. Embora fale de sua atividade no presente, como se a estivesse realizando enquanto a descreve, pode referir-se a vários acontecimentos do passado e compor uma história que dê sentido à sua 
atividade. Em geral, fala-se das diferenças de uma atividade e como ela acontece, por exemplo, quando todos estão presentes ou quando uma colega falta, em período de pico ou baixa produção, quando se é novato ou experiente. Obtém-se uma explicação do desenvolvimento temporal de determinada atividade, conhecendo-se um pouco de sua história.

Ocorre, também, uma condensação de informações, em que em poucas horas consegue-se uma quantidade de informações dificilmente obtida por outros métodos. A autora compara a um filme já editado, em que só as cenas mais significativas aparecem. Em algumas situações, a informação está condensada: um processo que na vida real dura anos, é descrito em uma frase curta. Outras vezes, um gesto de trabalho que dura apenas alguns segundos, pode demorar vários minutos para ser explicado, ocorrendo uma espécie de dilatação do tempo.

Com este método, trabalha-se com grupos e não individualmente, e esta característica implica de várias maneiras sobre seus resultados. O coletivo funciona como um elemento que introduz uma nova dimensão à compreensão das vivências de cada um. Em primeiro lugar, encorajando os trabalhadores a expressar-se. Como eles são sempre maioria com relação aos pesquisadores, o fato diminui o problema inicial da situação proposta, na qual é o saber dos trabalhadores que predomina sobre os pesquisadores.

Outra característica é que a presença de várias pessoas falando de seu trabalho facilita a comparação, e fica mais claro o que é comum na atividade de cada um e o que é diferente. Consequentemente, os aspectos coletivos do trabalho são mais bem abordados. Para explicar o que cada um faz, em geral, é necessário explicar o que os outros fazem antes ou depois dele no processo produtivo, acima, ao lado ou abaixo na escala hierárquica. Em geral, a fala dos trabalhadores é marcada entre o "nós" e "eles", no qual "nós" são todos os que têm a mesma atividade. "Eles" são os outros, aqueles que controlam o trabalho, os que não conhecem aquele trabalho.

Como resultado, as informações obtidas na ACT permitem dois tipos de abordagens: primeiramente, uma caracterização geral da atividade de trabalho, na qual os principais pontos se destacam e, em um segundo momento, na caracterização bem pormenorizada de determinados aspectos da atividade que normalmente passam despercebidas por observadores externos, como por exemplo, a perícia necessária 
para se realizar uma determinada operação, os macetes empregados, etc. (FERREIRA, 1999).

\section{II.2.4 Considerações sobre a aplicação do método da Análise Coletiva do Trabalho}

O método da Análise Coletiva do Trabalho tem como vantagem permitir explorar a dinâmica que está subentendida nos vínculos de cooperação entre os sujeitos, visto que os trabalhadores (usuários, no caso de informática) descrevem sua própria atividade em situação de trabalho para outros trabalhadores e para pessoas externas à relação de trabalho (stakeholders, também, no caso de informática).

Em função das características listadas no item II.2.3, este método é aplicado tanto no ciclo 2 como no ciclo 3 da pesquisa-ação proposta, visando, inicialmente, a simular o comportamento do futuro software no ambiente em que o mesmo será inserido e, posteriormente, com uma versão deste software em uso, refinar suas características e seu uso (os detalhes de como a ACT será aplicada nos ciclos 2 e 3 serão apresentados ao longo desta pesquisa).

É importante ressaltar que embora originalmente o método da Análise Coletiva do Trabalho tenha sido aplicado em reuniões fora do ambiente de trabalho, com todos os participantes voluntários e com seu anonimato mantido, no contexto sob estudo, estes cuidados metodológicos também foram observados, com as reuniões realizadas em um ambiente fora do local de trabalho, mas dentro da empresa, assim como o anonimato relativo a certas colocações dos usuários nas reuniões de ACT também foram observados, quando se fez necessário.

Por último, a questão do termo "demanda" utilizada inicialmente no método de ACT, que representa uma solicitação externa (sendo na maioria das vezes oriunda dos sindicatos dos trabalhadores ou dos próprios trabalhadores). Nesta pesquisa, foi realizada por uma solicitação da alta direção da empresa PesqTec, correspondendo, portanto, a uma demanda gerencial (ver item V.1.1).

Ao longo da aplicação das várias sessões de ACT nos ciclos da pesquisa-ação, esta demanda é subdividida em um conjunto de regras de negócio que são abordadas 
com o grupo nas respectivas reuniões de ACT, sendo as mesmas previamente acordadas com os participantes da reunião (ver itens VI.2 e VII.2).

\section{II.3 MODELO MENTAL E INTERAÇÃO}

$\mathrm{Na}$ interação com o mundo, as pessoas formam modelos de si e dos objetos que interagem. Estes modelos são utilizados como suporte para a interação com o sistema informatizado, tanto para aprendizado de seu uso como projeto, assim como elementos de representação comum, constituindo-se em importante ferramenta dentro do processo proposto.

\section{II.3.1 Modelo mental e interação}

As pessoas formam modelos mentais internos de si mesmas, dos objetos e daspessoas com as quais interagem. Estes modelos fornecem meios para a compreensão das interações, sendo afetados fortemente, tanto pela natureza das interações como pelas experiências e conhecimentos anteriores. A despeito de não serem completos e precisos, são modelos úteis para orientar grande parte do comportamento humano (NORMAN, 1986).

Assim, o conceito de modelo mental é utilizado para definir uma representação mental de um sistema físico ou software, com um conjunto de associações que conectam estímulos aos resultados. É uma estrutura elaborada e rica que reflete o entendimento do projetista/usuário sobre as funções e comportamento do sistema, permitindo decidir por antecipação as ações que devem ser executadas, sendo úteis para o aprendizado, solução de problemas e para racionalizações sobre o comportamento do sistema (CARROL; OLSON ,1988).

Segundo Norman (2002), para o projeto de um sistema deve-se, primeiro, fazer com que este siga uma conceituação consistente e coerente - o modelo de projeto - e depois prover meios de modo que o usuário desenvolva um modelo mental deste sistema - o modelo mental do usuário - consistente com o modelo de projeto.

A proposta de Norman (1986) e Norman (2002) prevê três modelos mentais: de projeto, do usuário e imagem do sistema (Figura II.1): 
- De projeto (ou conceitual): é a conceituação que o projetista tem em mente e é criado baseado nos requisitos dos usuários, suas capacidades, conhecimentos e experiências, sendo útil para projetar o sistema e ensinar a usá-lo. Esta conceituação deve considerar também a experiência dos usuários, suas experiências e as facilidades e limitações de seus mecanismos de processamento de informações (por exemplo, limites de memória de curta duração);

- Do usuário: são modelos que as pessoas têm de si próprias, dos outros, do ambiente e das coisas com as quais interagem, sendo definido como 0 resultado das ações dos usuários, baseadas em sua experiência e decorrentes de outras ações em outros sistemas e tarefas. É o modelo que o usuário interioriza para explicar a operação do sistema e é formado sobretudo por meio da interpretação que é feita das ações percebidas da parte visível do dispositivo ou do software;

- O físico ou imagem do sistema é a estrutura concreta que foi construída (inclusive a documentação, instruções, rótulos, etc.) e que nem sempre guarda relação com o modelo mental, sendo de importância crítica, pois o projetista deve assegurar que tudo pertinente ao produto seja consistente com a operação do modelo de projeto apropriado.

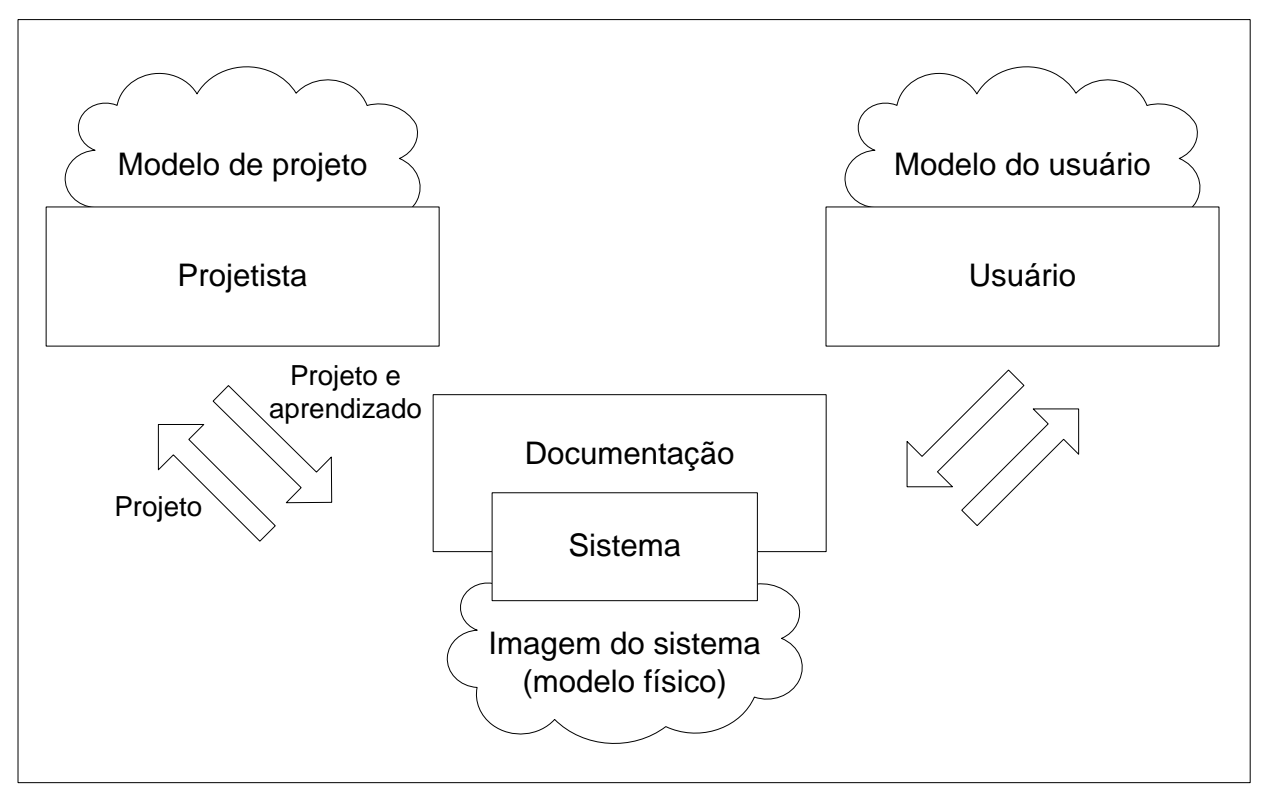

Figura II.1 - Modelos mentais

Fonte: adaptado de Norman (1986); Carrol e Olson (1988) 
Deste modo, o modelo conceitual é um meio para criar o mental e deve permitir ao usuário interpretar o que está acontecendo por meio da interface e documentação do sistema.

De acordo com Norman (1986), a maior facilidade da aprendizagem e da utilização dependem de um correto mapeamento entre o modelo mental e o conceitual. $O$ modelo mental não se forma com base no modelo do projeto, e o mesmo resulta do modo como o usuário interpreta a imagem de sistema.

Assim, a tarefa do projetista é construir uma imagem adequada do sistema, compreendendo que todos os elementos com que o usuário interage ajudam a formar esta imagem, como por exemplo: botões físicos, teclados, monitores de vídeo, documentação (manuais de instrução, helps, etc.), mensagens de erro, entrada e saída de dados, facilidades de ajuda e os elementos da interface homemmáquina.

Com base nestes conceitos, Carrol e Olson (1988) sugerem três abordagens de projeto:

- Modelo conceitual preconcebido. É a determinação do modelo conceitual aos usuários pelos projetistas de modo a se iniciar o projeto com um modelo preconcebido inicial e por meio de prototipação interativa buscar o modelo do usuário, dentro de um nível adequado de usabilidade;

- Comunicação de um modelo ao usuário. Corresponde à criação de cenários baseados nas principais tarefas dos usuários, de modo que, passo a passo, 0 retorno do usuário sirva como elemento para refinar o projeto e construir outras interações. A dificuldade reside em não interromper o fluxo do aprendizado e preservar o que já foi aprendido pelo usuário;

- Foco na tarefa. O conhecimento deve ser representado formal e posteriormente estudado, de modo a se transformar esta descrição na interface. Esta abordagem não é suficiente para descrever a interface (imagem do sistema), pois uma mesma descrição de comando pode ter representações visuais diferentes.

Com relação ao aprendizado, o emprego de modelos conceituais durante o treinamento oferece resultados melhores do que se fossem utilizadas apenas instruções sobre procedimentos. Estes autores afirmam que aparentemente 0 
modelo organiza o conhecimento para evitar confusão e facilitar o entendimento do sistema, e diversos estudos mostram que é mais fácil incorporar do que induzir um modelo.

$\mathrm{Na}$ aplicação do conceito de modelo mental a um grupo de usuários, uma das principais metas corresponde em obter os objetivos que são comuns, conforme discutido em II.1.2.

Dentro do contexto de uma dinâmica coletiva que exige ações de cooperação, o grau e a natureza da interação de um agente e seus engajamentos dependem necessariamente de seus objetivos individuais, de suas interações, de suas crenças e dos modelos que têm de si mesmo, dos outros e de seu ambiente (ERCEAU et al., 1994).

Para estes autores, o comportamento de um grupo não é a soma dos comportamentos individuais dos agentes do grupo, e a obtenção de um estado mental coletivo se dá por meio de um engajamento partilhado entre os agentes, de modo que grupo possa agir como um agente único, descrito por um conjunto de crenças, objetivos e intenções.

Wittorski (1997), também, cita a importância de se criar as imagens operativas comuns (definidas como a representação mental que uma pessoa tem de sua tarefa), códigos e linguagens comuns em sistema de trabalho cooperativo.

\section{II.3.2 A ergonomia das interfaces}

Conforme visto no item II.3.1, a imagem mental do usuário é montada pela imagem do sistema, e o principal elemento desta imagem corresponde à interface com o usuário. É por meio da interface que a usabilidade é percebida pelo usuário, que a satisfação subjetiva será alcançada. Para os usuários, a interface, praticamente, constitui o sistema.

A interface é o resultado da interação homem-computador e é constituída de dois elementos (HIX e HARTSON, 1993):

- O desenvolvimento da interação. Neste momento, é desenvolvida a comunicação com o usuário em termos das ações do operador e do funcionamento da interface, considerando-se os princípios da ergonomia, 
orientações, limitações cognitivas dos usuários, projeto gráfico, estilos de interação e especificações de usabilidade. O objetivo é assegurar usabilidade, funcionalidade, desempenho e satisfação do usuário;

- O desenvolvimento do software que provê esta interação. Neste momento, será implementada a interação por meio de algoritmos, linguagens de programação, estruturas de dados, e outras técnicas da tecnologia da informação. É importante ressaltar que a maior parte dos esforços de programação está no desenvolvimento desta interação, na qual este número pode chegar até a 80\% desse esforço (SILVA, 1997);

No desenvolvimento da componente interação da interface, pode-se utilizar uma série de estilos, sendo definidos como uma coleção de objetos e técnicas que estão disponíveis aos projetistas da interface para o desenvolvimento da interação, incluindo, a aparência e o comportamento dos objetos da interação, vistos pelo usuário.

Scapin (1986) descreveu um conjunto de critérios para analisar/projetar a relação homem-sistema, consistentes com os estilos de interação (ver Apêndice B). Este modelo pode ser considerado como um guia aos projetistas para orientar a construção de formas mais naturais e intuitivas de interação homem-computador, por meio da melhor adequação às necessidades dos usuários, melhorias da eficácia de utilização e do aprendizado.

\section{II.3.3 Considerações sobre modelo mental e interação e ergonomia das interfaces}

Esta seção mostra que o modelo mental do usuário forma-se com base na imagem do sistema, de modo que, para se desenvolver um software que atenda às necessidades dos usuários, os projetistas devem construir uma imagem adequada do sistema para o usuário, baseado no modo como os projetistas entendem o sistema (modelo de projeto).

Nesta pesquisa, para se construir um software mais próximo possível do modelo mental do usuário foi utilizado o conceito de prototipação evolutiva (ver itens II.6.3 e II.8.3), no qual é desenvolvido um modelo inicial do sistema e por meio da 
prototipação busca-se o modelo mental do usuário. Neste caso, ao contrário da aplicação de prototipação em desenvolvimento de software tradicional, o desenvolvimento do protótipo, seja não funcional ou funcional (item II.8.3), é realizado durante a aplicação das sessões de ACT, para focar, tanto os requisitos individuais como os requisitos do trabalho cooperativo (representação, item II.4.1).

$\mathrm{Na}$ medida que as sessões de ACT vão evoluindo, o modelo mental também evolui por meio da evolução da imagem do sistema, cujos conceitos da ergonomia das interfaces e usabilidade são aplicados.

No ciclo 1, a imagem do sistema foi simulada pela prototipação em papel, cujas ações e respostas com os usuários (interações) eram apresentadas por meio de uma primeira aproximação das interfaces desenhadas em folhas de papel.

No ciclo 2, a imagem do sistema (implementação física do software) foi realizada (ver itens III.4.4 e IV.4.1), de modo a simular as respostas às ações (cliques em botões, escolha de opções, etc.) dos usuários por intermédio de interfaces gráficas pré-programadas, isto é, sem o código (software) que implementa a interação, considerando, tanto os requisitos individuais como parte dos requisitos do trabalho cooperativo.

Finalmente, no ciclo 3, utilizando como base os resultados das interações do ciclo 2, a imagem do sistema (software) é implementada totalmente, com as respostas dinâmicas às solicitações dos usuários via interface gráfica (neste caso, ocorre uma transação, isto é, a troca de dados dinâmica com o banco de dados do software), considerando, também, os requisitos associados à contextualização das atividades individuais pela compreensão das atividades realizadas por outras pessoas.

\section{II.4 TEORIA DA MENTE COLETIVA}

A teoria proposta por Weick e Roberts (1993) ajuda o entendimento de como tratar sistemas de informação que não estão sob um centro de organização simples, ou seja, sem uma distinção clara entre comunicação e coordenação (ver modelo $3 \mathrm{C}$ item II.5.2) mas sim distribuídos no padrão de comportamento (ações) dos usuários (coordenação horizontal) (CROWSTON; KAMMERER,1998). 
A principal proposta desta teoria corresponde ao fato que o desempenho global do grupo é facilitado quando os indivíduos desenvolvem uma compreensão compartilhada das atividades do grupo e de si mesmos.

A teoria da mente coletiva é descrita como disposição para ouvir e cooperar na medida que são estas ações que constroem o inter-relacionamento do grupo. Se cada membro de um grupo tem o desejo e meios para agir de modo a promover os objetivos e necessidades do grupo conscientemente, então, o grupo exibe um comportamento que pode ser descrito como coletivamente inteligente, mesmo sendo os indivíduos de fato inteligentes, não o grupo.

Várias ações individuais e processos sociais de base são os pontos mais importantes desta teoria para a construção e manutenção desta disposição consciente e das capacidades que serão discutidas nos próximos itens.

\section{II.4.1 Ações ligadas à teoria da mente coletiva em desenvolvimento dos sistemas informatizados}

Existe um grupo de ações que só é possível, quando cada participante tem uma representação que inclui as ações dos outros e suas relações. As respectivas ações convergem de modo relevante, dando suporte e suplementando umas às outras, somente quando a situação conjunta é representada em cada um e quando as representações são estruturalmente similares. Só quando estas condições ocorrem, os indivíduos podem subordinar a si mesmos as necessidades da ação conjunta. Estas representações e ações reforçam a existência do grupo.

Segundo Weick e Roberts (1993), existem três ações individuais que representam as atividades do grupo, nas quais os atores em um sistema constroem suas ações contribuindo para os resultados do grupo (contribuição), compreendendo que o sistema consiste em ações conectadas por eles mesmos e por outros, de modo que um indivíduo construa modelos internos do grupo (representação) e do interrelacionamento de suas ações com o sistema, colocando os objetivos do grupo acima de seus objetivos pessoais (subordinação).

Quando estas condições ocorrem, há um sistema social de forma definida que comporta as ações dos indivíduos. Tal sistema não reside nos indivíduos tomados 
em separado, a despeito do fato de que cada indivíduo contribua para o mesmo nem resida fora deles. Ele está presente nas inter-relações entre as atividades dos indivíduos e focando no modo como este inter-relacionamento é feito, revela o processo mental coletivo que difere em graus de desenvolvimento.

Estas ações ocorrem em qualquer grupo. A questão para a teoria da mente coletiva é quão conscientemente estas ações são realizadas: cuidadosa, crítica, consistente, decidida, atenta e deliberadamente, de modo alerta, com consciência e persistência? Quanto mais extensas forem, o grupo mostrará maior capacidade para exprimir a mente coletiva.

Uma maneira de se avaliar o desenvolvimento da mente coletiva corresponde ao uso de uma tabela na qual as linhas são as pessoas, e as colunas são ou as ações de contribuição, representação e subordinação, ou seus componentes de comportamento (por exemplo: convergindo com, ajudando ou suplementando). Inicialmente, as entradas das células podem ser simples (sim ou não). Sim, significa que a pessoa executa a ação de modo consciente; não, que a ação é feita de modo menos consciente. Quanto mais sim na tabela mais a mente coletiva será desenvolvida.

A despeito de serem conceituadas separadamente, estas três ações se sobrepõem e reforçam umas as outras em algum grau. É difícil imaginar contribuições conscientes (heedful), vindas de indivíduos motivados e talentosos com uma fraca representação da estrutura e necessidades do grupo. De modo similar, um indivíduo não pode construir uma representação do grupo sem as contribuições dos demais, nem pode se subordinar de modo conscientemente (heedfully), sem uma representação precisa dos objetivos do grupo.

Um aumento na capacidade de inter-relacionamento consciente pode prevenir ou corrigir falhas de compreensão em, pelo menos, três modos:

- Alongamentos de períodos de tempo podem ser conectados, na medida que mais conhecimento é trazido por meio do passado e elaborado dentro de novas contribuições e representações que remetem a um futuro mais distante; 
- A compreensão pode ser melhorada se mais atividades forem conectadas, tais como quando as inter-relações alternam estágios mais adiantados e atrasados da sequência de tarefas;

- A compreensão pode ser aumentada se mais níveis de experiência forem conectados, como o caso dos usuários iniciantes que se inter-relacionam com os mais velhos.

Quanto mais consciente for este processo espalhado por um número maior de atividades e conexões, ocorrerão menos erros. Abaixo estão descritas com mais detalhes as três ações ligadas à mente coletiva:

\section{Contribuição}

Corresponde à parcela de contribuição individual para o trabalho em grupo. Os indivíduos contribuem quando executam uma tarefa, como por exemplo: entrada de algum tipo de dado no sistema (desde dados alfanuméricos até o acionamento de eventos), emissão de relatórios ou participar de um processo social que constrói a mente coletiva (item II.4.2).

Estas contribuições podem ser feitas de modo mais ou menos consciente, isto é, de modo a se aproximar das perspectivas do grupo conscientemente, tomando-se decisões de modo inteligente, coordenando suas contribuições com os demais elementos do grupo e assim por diante.

É importante que os elementos do grupo trabalhem para desenvolver uma compreensão recíproca de quem está fazendo o que e como as contribuições se encaixam juntas, assim como deve haver uma ênfase organizacional no compartilhamento da informação entre os membros da equipe e por intermédio da organização por meio de pequenos e grandes encontros.

Os membros do grupo devem com frequência reservar tempo com as outras partes interessadas para explicar o que fazem e como fazem. Esta atividade libera os indivíduos para mais eficientemente direcionar seus esforços em seu trabalho conjunto. 


\section{Representação}

Representação é o conjunto de contribuições do grupo para o sistema que é percebida em vários graus por indivíduo. Na medida que os indivíduos fazem e dizem coisas (exercem suas atividades), estas ações são interpretadas e sintetizadas pelos demais que usam estas informações para construírem seus próprios modelos internos do grupo (modelo mental do grupo).

Por meio deste modelo, é possível que cada elemento do grupo entenda como se encaixa no mesmo, como os demais irão proceder e como suas próprias ações deverão afetar os demais. Este modelo incorpora as ideias de cada elemento do grupo a respeito de suas metas e como podem ser acompanhadas.

O ponto importante é que os indivíduos precisam desenvolver modelos sobre o que os demais fazem e uma compreensão compartilhada do problema nos quais estão trabalhando.

Por exemplo, é importante determinar quais são as atividades de cada indivíduo do grupo e como executá-las, quem são os responsáveis pelas demais atividades (dos demais processos), como as mesmas se sobrepõem, quem pode ser afetado por erros em suas respectivas atividades, se há sobreposição de trabalho não intencional, visão geral do processo, etc.

\section{Subordinação}

Subordinação envolve a confiança que um elemento do grupo possui sobre o sistema. A subordinação individual ocorre quando se confia nos demais elementos do grupo para suprir as informações necessárias ao andamento de seu trabalho, quando há obediência aos superiores e quando as decisões são tomadas baseadas nos interesses do sistema, acima das necessidades individuais.

A representação que os indivíduos têm do sistema ao qual se subordinam pode ser mais ou menos precisa e os indivíduos podem ou não escolher seus próprios interesses sobre os do sistema. Para que a questão de subordinação seja estabelecida, é preciso que o modelo coletivo do processo esteja formado de modo que fique clara a posição do indivíduo dentro do mesmo e como sua contribuição individual repercute no resultado final do trabalho. 
Caso contrário, a despeito dos indivíduos realizarem seus serviços da melhor forma que acreditam contribuir, o fato de não conhecerem os objetivos gerais pode implicar um resultado final não esperado.

\section{II.4.2 Processos sociais no desenvolvimento da mente coletiva}

Para Weick e Roberts (1993) processo social significa um conjunto de interações que estão ocorrendo no sistema de atividade social dos quais os participantes continuamente extraem um senso de mudança de suas próprias inter-relações e as recolocam em ação no sistema. O processo de interação que está em progresso no sistema é recapitulado nas vidas individuais e continua a despeito da substituição de um ou mais indivíduos.

Uma vez que a teoria da mente coletiva está baseada no inter-relacionamento das atividades sociais e é dependente do maior ou menor grau de consciência de como estes inter-relacionamentos são feitos, os processos sociais tornam-se importantes para a teoria.

A relação entre indivíduo e grupo é somente parte-todo e depende da recapitulação da estrutura do todo na parte. As capacidades do sistema que são relevantes para o funcionamento do todo, são construídas nas partes. Em cada uma destas reconstruções, os processos sociais são os recursos dos quais o pensamento individual, o "eu" e a ação são modelados.

Os padrões de inter-relacionamento dos processos sociais podem ser internalizados e recapitulados pelos indivíduos com maior ou menor intensidade, conforme estes se movem para dentro ou fora do sistema. Se o relacionamento consciente for considerado e preservado, haverá uma boa chance de que os novos usuários aprenderão este estilo de trabalho, incorporarão para si as definições do que representam no sistema e reafirmarão e talvez aumentem este estilo de agir.

Assim, os autores citados sugerem três tipos de processos sociais para servirem de base para a construção da mente coletiva: socialização, conversação e recapitulação: 


\section{Socialização}

A teoria da mente coletiva sugere ser importante prestar atenção ao processo de socialização dos novos membros. Pessoas unindo-se a um grupo sentem a necessidade de saber como se encaixam no processo em execução (isto é, sua contribuição e subordinação), precisam ser encorajadas e educadas para interagir entre si para desenvolver um forte senso sobre como podem fazer seu trabalho no ambiente (representação). Quanto mais rico for o ambiente social mais rico poderá ser esta compreensão.

A socialização de novos participantes é, especialmente importante, pois no ato de explanar a situação aos demais, os usuários mais experientes têm oportunidade para refletir criticamente sobre a situação e mudá-la, de modo efetivo socializando a si próprios neste processo.

Embora o processo de socialização pareça natural, é comum os indivíduos dentro de uma empresa descobrirem por si mesmos o que devem fazer, mais do que serem treinados ou socializados, ou então, indivíduos que se movem em distintos grupos na mesma função, perceberem uma nova visão do processo e de suas responsabilidades dentro de cada um deles.

A socialização pode ser melhorada por meio de arranjos organizacionais, tais como tutores ou mentores, por exemplo, pelo uso de empregados específicos para o programa de cooperadores, de modo que os novos empregados já cheguem conhecendo a organização.

\section{Conversação}

Weick e Roberts (1993) acentuam a importância da conversação. É difícil obter a mente coletiva se as pessoas não conversarem entre si de algum modo. Encontros, eventos sociais, conversas de corredor e por meios eletrônicos ou conferências são todos meios nos quais os membros do grupo podem entrar em contato com o que os demais estão fazendo ou pensando.

A conversação pode ser melhorada por meio de encontros periódicos do grupo. 


\section{Recapitulação}

Os autores citados também reforçam a importância da recapitulação para manter a mente coletiva forte e viável, eventos importantes devem ser revisados (recontados) e reanalizados e divididos com os novos usuários. A história que define o que são e como são feitas as atividades em uma organização, deve ser continuamente reforçada, reinterpretada e atualizada.

Dos três processos, este é o mais difícil de detectar. A recapitulação pode ser promovida pelo encorajamento de sessões de detalhamento onde os indivíduos recontam suas perspectivas dos recentes eventos. Estas sessões mostram-se de valor como meio de socializar novos membros do grupo, mesmo que diretamente não eduquem os ouvintes em como se comportar.

\section{II.4.3 Considerações sobre a teoria da mente coletiva}

A teoria da mente coletiva mostra como característica fundamental que os indivíduos precisam desenvolver modelos sobre o que os demais fazem e uma compreensão compartilhada do problema nos quais estão trabalhando. O fato é importante, pois, a mente coletiva está localizada no processo de inter-relacionamento das ações individuais.

Para Weick e Roberts (1993), existem três ações individuais que representam as atividades do grupo: contribuição, representação e subordinação e três tipos de processos sociais para servirem de base para a construção da mente coletiva: socialização, conversação e recapitulação.

Para esta pesquisa, estes conceitos são importantes, pois são aplicados aos tipos de sistemas informatizados estudados: sistemas que não estão sob um centro de organização simples, ou seja, sem uma distinção clara entre comunicação e coordenação mas sim distribuídos no padrão de comportamento dos usuários.

A teoria da mente coletiva é aplicada nos segundo e terceiro ciclos da pesquisaação para orientar a aplicação da ACT, assim como este conceito é utilizado para avaliar a evolução das sessões de ACT no terceiro ciclo da PA.

A aplicação dos conceitos de modelo mental, utilizando como âncora o protótipo do software em desenvolvimento em sessões de ACT, tem como objetivo principal 
desenvolver modelos mentais sobre o que os usuários fazem e uma compreensão compartilhada do problema nos quais estão trabalhando.

\section{II.5 CSCW, GROUPWARE, MODELO 3C E AWARENESS}

Neste trabalho, os conceitos de CSCW, groupware, modelo $3 \mathrm{C}$ e awareness são utilizados sobretudo para mostrar como as interações face a face de um ambiente de trabalho cooperativo são especificadas de modo a serem mediadas por de uma solução informatizada que automatiza esse ambiente.

\section{II.5.1 CSCW e Groupware}

CSCW (Computer Supported Cooperative Work) é a área de estudo que investiga como as pessoas trabalham em conjunto, empregando a tecnologia de computadores. Tipicamente, as aplicações CSCW incluem correio eletrônico, videoconferência, sistemas de chat, interações entre múltiplos indivíduos, aplicações compartilhadas de tempo real, sistemas de notificação e o suporte à awareness (item II.5.3).

Groupware é uma tecnologia de apoio à interação entre participantes de um grupo de trabalho e normalmente considerada como sinônimo de CSCW. Esta tecnologia tem sido bastante difundida para modelar sistemas distribuídos, empregando mídias digitais e redes de computadores (ASSIS, 2000).

\section{II.5.2 Modelo 3C}

O modelo 3C de cooperação usado nesta pesquisa é derivado do artigo de Ellis et al. (1991) e apoia-se na concepção de que para cooperar os membros de um grupo (C) comunicam-se, (C) coordenam-se e (C) colaboram (3Cs), conforme pode ser visto na Figura II.2, onde observa-se a ocorrência de um ciclo, indicando que as pessoas devem se comunicar para coordenar seu esforços de trabalho e colaborar em torno de um objetivo. 
Para cooperação, há a necessidade de comunicação, seja ela direta ou por meio de informações obtidas dentro do ambiente onde 0 trabalho ocorre. Em cada relacionamento, há o estímulo fornecido pelas informações de awareness (item II.5.4) que possibilitam a ocorrência do entendimento compartilhado em torno de um objeto de colaboração. $O$ objeto de colaboração constitui-se das metas e objetivos estabelecidos para conclusão de uma tarefa ou de todo o trabalho (ASSIS, 2000).

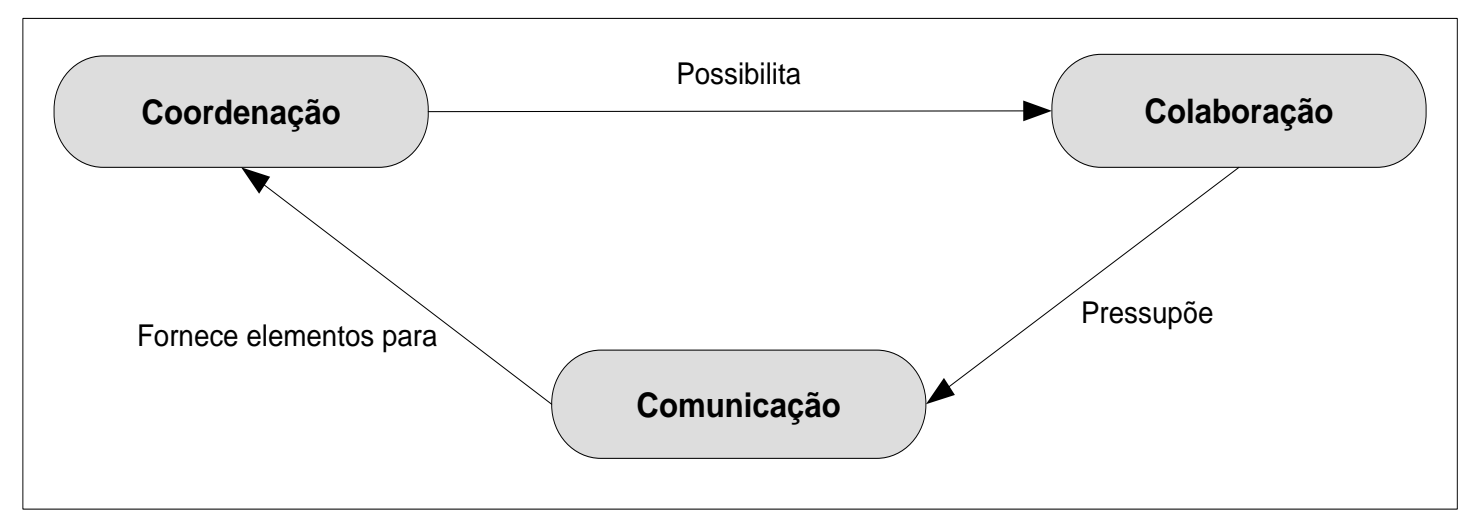

Figura II.2 - Modelos de cooperação

Fonte: Ellis et al. (1991) e Fuks et al. (2007)

Apesar da separação destas atividades para fins de análise, a comunicação, a coordenação e a colaboração não são realizadas de maneira estanque e isolada: são feitas continuamente e iterativamente durante o trabalho em grupo (FUKS et al., 2005). As tarefas originam-se dos compromissos negociados durante a comunicação, são gerenciadas pela coordenação e realizadas durante a colaboração.

A cooperação é a operação conjunta dos membros do grupo em um espaço compartilhado, que executa as tarefas ao gerar e manipular objetos de colaboração na realização das tarefas. Ao colaborar, é preciso renegociar e tomar decisões sobre situações inesperadas, o que requer novas rodadas de comunicação e coordenação. Antes de efetivamente executar uma tarefa, por exemplo, o grupo organiza-se e articula-se. Nesta atividade, também há necessidades específicas de cooperação que são distintas daquelas que ocorrem durante a execução da tarefa. Os indivíduos que planejam, podem não ser os mesmos que executam, como normalmente ocorre na linha de montagem, cujas atividades são planejadas e, posteriormente, cada indivíduo realiza sua tarefa sem interagir diretamente com os demais. 
Na cooperação, o plano é renegociado de modo dinâmico, não sendo possível separar plenamente a coordenação da colaboração. Enquanto os indivíduos cooperam, eles aprendem e refinam os processos de trabalho, renegociando os planos iniciais e intercalando ação e negociação (GEROSA, 2006).

\section{II.5.3 Awareness}

Neste trabalho de pesquisa, awareness é definido como a consciência sobre a contextualização das atividades individuais por meio da compreensão das atividades realizadas por outras pessoas (mesmo quando não estão se comunicando diretamente) referindo-se a ter conhecimento das atividades do grupo, saber o que aconteceu, o que está acontecendo e/ou o que poderá vir a acontecer, além do próprio conhecimento do que são este trabalho e o grupo. Resumindo: awareness significa uma compreensão do estado total do sistema, incluindo atividades passadas, situação atual e opções futuras (BRINCK; McDANIEL, 1997; PINHEIRO et al., 2001).

Esta "consciência" (awareness) é essencial para a coordenação com outros indivíduos em tarefas cooperativas em que nem sempre ocorre comunicação direta, podendo se referir inclusive a formas indiretas de comunicação, como por exemplo, fazer deduções ou suposições sobre o que outra pessoa está argumentando com base nas informações que estão sendo transmitidas ou nos gestos que estão sendo realizados no espaço que compartilham.

Neste trabalho, a palavra awareness não será traduzida, uma vez que o termo comumente utilizado em Engenharia de Groupware: "percepção" possui significados diferentes dentro de outras áreas abordadas nesta pesquisa.

A situação mostra-se complicada nos sistemas informatizados distribuídos (utilizados por vários usuários em ambientes distintos), nos quais os recursos para esse tipo de informações são pobres se comparados aos recursos do cenário face a face, cujos mecanismos de interação são diferentes dos usuais. Como consequência, o trabalho em conjunto por intermédio de um software, que se baseia em tecnologia digital e distribuída, aparentemente, pode parecer ineficiente e desgastante em comparação 
com o trabalho face a face. Ter este tipo de consciência é um fator importante no fluxo e na naturalidade da cooperação (ASSIS, 2000).

\section{II.5.4 Awareness e o modelo 3C}

Para possibilitar a coordenação e a cooperação como um todo, são necessárias informações sobre o que está acontecendo e sobre o que as outras pessoas estão fazendo. Por meio destas informações, os participantes podem construir um entendimento compartilhado em torno dos objetos de cooperação e dos objetivos das tarefas ou de todo o trabalho (DOURISH; BELLOTI, 1992).

Ao ter consciência das atividades dos companheiros e dos impactos que ocorrem no conhecimento gerado pela cooperação, as pessoas terão informações que auxiliarão na sincronização do trabalho, coordenando-se em torno de seus contextos individuais (FUKS, ASSIS, 2001).

Uma das possíveis representações (instâncias) de como se coloca o conceito de awareness em relação aos mecanismos de comunicação, coordenação e cooperação pode ser vista na Figura II.3, na qual se nota que o ponto inicial que alimenta esse diagrama é o objetivo do grupo, isto é, a realização do trabalho de forma cooperativa (FUKS et al., 2007).

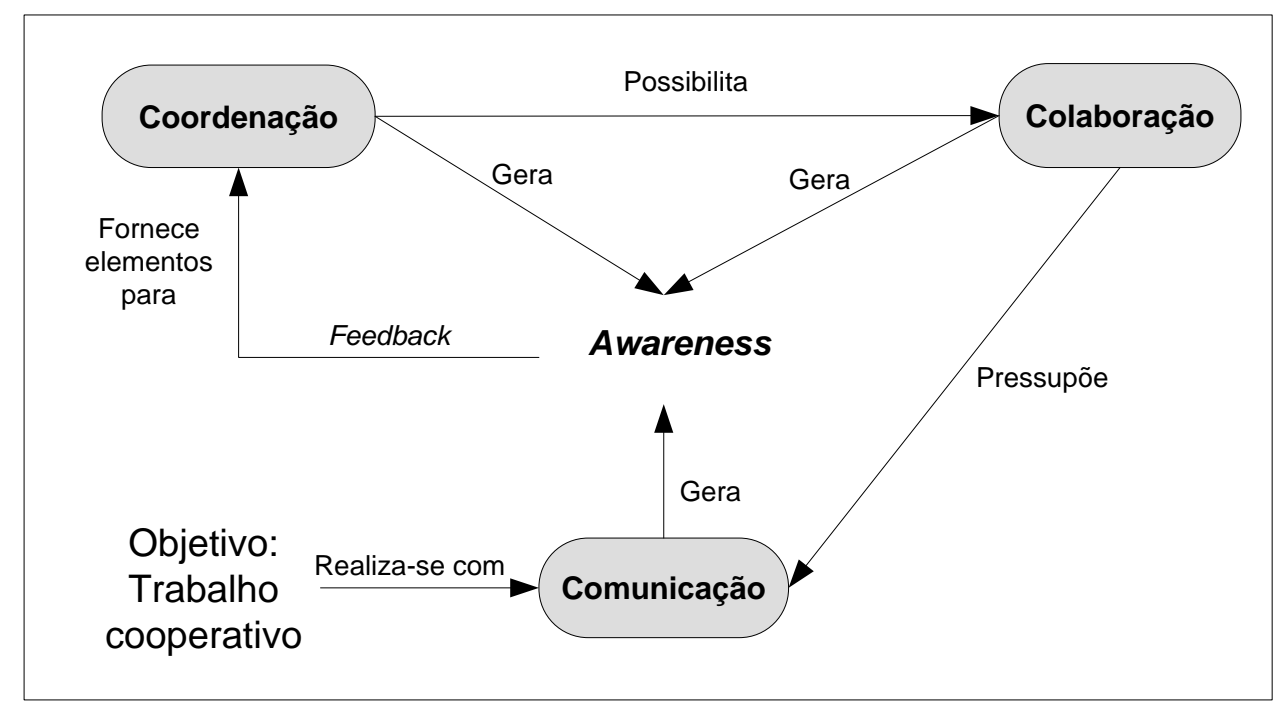

Figura II.3 - Diagrama dos 3Cs e awareness

Fonte: Assis (2000) 
Ao se observar a figura acima, percebe-se que ela apresenta diversos estímulos de entrada e um estímulo de saída. Isso significa que vários eventos dos participantes de um grupo sejam voluntários ou não, devem ter um elemento de awareness que gere feedback (retorno) para a coordenação dos membros do grupo de trabalho. Deste modo, pode-se definir a figura como um diagrama de coordenação, em que cada mecanismo gera novos elementos que devem se tornar perceptíveis para aumentar o entendimento compartilhado do grupo, facilitando a cooperação.

No exemplo da Figura II.3, pode ser ressaltado que a geração de informações destinadas à coordenação e colaboração não deve ser obrigatória, visto que o feedback pode não ser desejado em todos os momentos do trabalho. Já o evento de comunicação irá proporcionar sempre algum grau de awareness, visto que o fluxo de realização do trabalho poderia ser interrompido e estagnar, sem a transmissão da informação (ASSIS, 2000).

\section{II.5.5 Elementos de awareness}

Os sistemas informatizados que são desenvolvidos para ambientes cooperativos devem prover elementos de awareness que disponibilizem de maneira adequada, tanto as informações necessárias à cooperação como ao trabalho individual.

Ao conhecer o funcionamento dos mecanismos de comunicação, coordenação e colaboração, sobretudo como eles devem ser usados para manter diferentes elementos de awareness, podem ser criadas técnicas e ferramentas que forneçam aos usuários as informações apropriadas a respeito das metas, tarefas e dos outros integrantes do ambiente.

Guiados pela consciência sobre o que outras pessoas estão fazendo e o conhecimento do que está acontecendo à sua volta, os indivíduos criam um entendimento compartilhado e coordenam-se de forma que seus esforços individuais agreguem valor ao trabalho do grupo. Ao se projetar um sistema informatizado com estas características, deve-se levar em conta estes elementos, quais informações serão necessárias, como gerá-las, reuni-las e distribuí-las (GEROSA et al., 2003).

As informações de awareness devem ser projetadas para se complementarem e auxiliarem o trabalho individual no contexto da cooperação. Alguns exemplos são: o 
objetivo comum, o papel de cada um dentro do contexto, o que fazer, como proceder, qual o impacto das ações, até onde atuar, quem está por perto, o que o companheiro pode fazer, o que as outras pessoas estão fazendo, a localização, a origem, a importância, as relações e a autoria dos objetos de cooperação (GEROSA et al., 2003).

Para dar suporte às informações sobre awareness, algumas considerações precisam ser consideradas: qual informação fornecer, como provê-la e como dar aos indivíduos o controle da informação (se pode ser visualizada, alterada, etc.). Há diversos tipos de elementos de awareness, classificados por finalidade, tempo, escopo, abstração, agregação, perspectiva, forma de fornecimento, personalização, entre outros (BRINCK; McDANIEL, 1997).

Estes elementos visam a responder basicamente às questões "o que, quando, onde, como e quem", cada uma identificando aspectos importantes para o fornecimento de awareness dentro de ferramentas de groupware síncronas e assíncronas.

Em ambientes síncronos, os membros do grupo estão trabalhando simultaneamente (a interação síncrona descreve a situação em que mais de um usuário está acessando concorrentemente a dados compartilhados), como em videoconferências. Já em um ambiente assíncrono, pode haver um intervalo de tempo entre a atuação de um usuário e sua percepção por seus colegas, ou seja, os usuários não precisam estar trabalhando simultaneamente para que o objetivo seja atingido.

Com isso, sistemas de groupware síncronos e assíncronos diferem quanto às suas necessidades por awareness, já que usuários obrigatoriamente trabalhando ao mesmo tempo terão necessidades de awareness diferentes daqueles que não precisam trabalhar simultaneamente. Dessa forma, torna-se importante, ao analisar cada uma das cinco questões mencionadas acima, observar de qual ambiente se trata (PINHEIRO et al., 2001).

\section{O que}

Refere-se a quais informações devem ser fornecidas aos usuários, estando intimamente ligadas a dois aspectos principais: as atividades e os papéis. As atividades são a base do trabalho cooperativo, uma vez que o objetivo a ser alcançado geralmente é dividido em atividades menores (ver Apêndice A), 
distribuídas entre os membros do grupo. O conhecimento da distribuição das atividades é importante para 0 andamento do trabalho, tanto síncrono como assíncrono, pois representa saber as atividades dos colegas de trabalho.

Em um sistema assíncrono, é mais interessante ter uma visão ampla das atividades, já que não há garantia sobre o momento em que uma tarefa será realizada.

Os papéis também são elementos importantes em um ambiente cooperativo, pois representam a noção de hierarquia dentro do grupo, indicando as responsabilidades e possibilidades dos membros sobre o trabalho.

Deste modo, os papéis desempenhados fornecem uma boa indicação sobre o tipo de informação de awareness necessária a seu desempenho. Por exemplo, as informações que são precisas para um participante, diferem das necessárias a um coordenador. A coordenação é fundamental em atividades cooperativas, e o fornecimento de awareness específico para a coordenação é importante, tanto em sistemas síncronos como assíncronos (PINHEIRO et al., 2001).

\section{Quando}

Quando ocorrem os eventos geradores das informações de awareness e quando se dá a apresentação destas informações. As informações de awareness são geradas por eventos que ocorrem durante o trabalho do grupo e em função de seu momento de ocorrência serão mais ou menos úteis à tomada de consciência pelo indivíduo e pelo grupo.

Pode-se dividir a ocorrência dos eventos em quatro momentos:

- Passado: o passado inclui eventos que já ocorreram há algum tempo e cujos resultados podem não ser mais válidos;

- Passado contínuo: para eventos que começaram no passado, mas que continuam válidos até agora, representando aqueles que, apesar de terem se iniciado no passado, continuam valendo até o presente;

- Presente: para eventos que estão ocorrendo neste momento;

- Futura: representa as opções do grupo, os eventos que ainda poderão ocorrer, mas que precisam se tornar disponíveis ao usuário. Por exemplo, o caso de um alarme que avise quanto à aproximação dos prazos para as 
atividades, cuja chegada do prazo limite (evento gerador) só ocorrerá no futuro, mas o alarme, que fornece a informação de awareness desse evento, ocorre antes.

Em ambientes assíncronos, como há um possível espaço de tempo entre a atuação dos colegas, é vital manter o contexto sobre o que foi feito (eventos no passado) e do que ainda está sendo feito (passado contínuo), para que os participantes possam encaixar suas próprias atividades nas do grupo. A percepção de eventos futuros representa uma opção interessante para manter os membros atentos aos possíveis rumos do trabalho.

A persistência da informação (tempo de utilidade da informação) é determinada pelo interesse nos eventos ocorridos em um ou outro momento. Até quando as informações de awareness são úteis para o trabalho do grupo? Serão estas informações persistentes?

Em sistemas assíncronos, como o interesse maior reside na percepção de eventos no passado ou no passado contínuo, as informações continuam úteis ao grupo, mesmo após o momento de sua ocorrência havendo a necessidade de uma alta persistência.

É importante determinar um limite para este armazenamento, em que estas informações perdem sua utilidade. Eventos em um passado contínuo só são úteis ao grupo na medida que forem verdadeiros, podendo ser descartados, assim que deixarem de ser.

Por outro lado, os eventos no passado são úteis mesmo quando não forem mais verdadeiros e devem ser mantidos, exigindo a definição de um critério de caducidade que inutiliza estas informações. Este critério pode ser um tempo de vida fixo, o fornecimento das informações para um ou mais membros, ou mesmo combinações de eventos.

Outra característica importante refere-se ao momento da apresentação das informações de awareness. Em sistemas assíncronos, há um intervalo de tempo entre os eventos geradores e os demais membros para que possam percebê-los, de modo que a informação é apresentada normalmente em um momento posterior à ocorrência dos eventos. Neste caso, é adequado permitir ao próprio usuário decidir o momento de receber tais informações (PINHEIRO et al., 2001). 


\section{Onde}

A atividade em grupo implica o trabalho sobre um conjunto de objetos dispostos dentro de um espaço de trabalho (workspace), compartilhado entre os membros. A consciência do que está ocorrendo neste espaço compartilhado, é chamada de workspace awareness, que é o conhecimento do que está acontecendo no workspace compartilhado no momento atual, sendo um elemento natural dentro de ambientes físicos de trabalho.

Em ambientes assíncronos, não há como garantir a presença dos colegas no workspace em um intervalo de tempo, de modo que o foco de awareness localiza-se nos objetos compartilhados por estes colegas, pois a comunicação entre os membros ocorre por meio destes objetos, de sua manipulação e de seu histórico, que mostram o que houve e está acontecendo dentro do trabalho em grupo, criando, assim, o contexto para as atividades de cada membro. Em ambientes assíncronos, o artefato compartilhado é essencialmente o único espaço compartilhado disponível aos participantes, constituindo-se em peça-chave na cooperação assíncrona.

Independe do sistema ser síncrono ou assíncrono, é de inteira responsabilidade do projetista desenvolver um ambiente capaz de dar suporte adequado, seja a workspace awareness, seja a objetos compartilhados. Deste modo, é necessário apresentar uma metáfora adequada ao tipo de informação desejada. Assim, são usadas, tanto as metáforas de escritório como as de sistema, e as metáforas de escritório são ideais para sistemas síncronos e representam elementos do ambiente de trabalho real, presentes no dia a dia dos participantes, como salas e mesas, diminuindo a possibilidade de má interpretação.

As metáforas de sistema relacionam o groupware com versões monousuárias do sistema, estas metáforas afetam o modo como as informações são capturadas pelos participantes, havendo necessidade de enriquecê-las adequadamente com as informações de awareness, de modo a permitir aos participantes uma consciência mais clara das atividades do grupo, enfatizando os aspectos de cooperação e fornecendo aos usuários a sensação de estarem realmente trabalhando em grupo (ver itens VIII.2 e VIII.5) (PINHEIRO et al., 2001). 


\section{Como}

É a interface do sistema, indicando como as informações são apresentadas aos usuários. A interface com o usuário é a responsável pelo fornecimento das informações de awareness. Para evitar a sobrecarga dos membros e permitir uma rápida assimilação, estas informações devem ser apresentadas de forma resumida. Os usuários não podem se sentir sobrecarregados nem tê-las omitidas.

Assim, para fazer o projeto de uma interface balanceada, deve-se trabalhar com elementos de interface adequados, podendo ser ícones ou cores associados a informações específicas, como papéis e participantes, gráficos representativos do progresso do trabalho, ou ainda, uma combinação de elementos como estes. Devese buscar que estes elementos apresentem as informações de percepção de forma resumida, sem sobrecarga nem perda de conteúdo significativo.

Para tanto, estes elementos deverão fazer uma filtragem ou um agrupamento das informações, mostrando apenas aquilo que for mais útil e interessante a cada participante. Estes processos de filtragem e agrupamento podem utilizar vários critérios, desde o papel até preferências pessoais de cada membro.

Uma possibilidade em ambientes assíncronos é a utilização de interfaces desacopladas, isto é, que não sejam acopladas às interfaces dos demais colegas, permitindo a cada membro adaptar a interface às suas necessidades individuais, sem que os demais sejam notificados disto, mas não impedindo a interface de incluir elementos de awareness.

Assim, o projetista de um groupware deve decidir entre beneficiar atividades individuais ou priorizar a percepção das atividades coletivas. Em sistemas síncronos, o trabalho é feito pelo grupo simultaneamente, fazendo com que uma percepção uniforme do workspace e dos objetos seja mais importante do que a flexibilidade para o usuário isolado, sendo importante ter a oportunidade de ver onde seu colega está trabalhando agora e o que está fazendo em detalhes.

Em ambientes assíncronos, não é necessário utilizar interfaces conectadas umas às outras, que foquem as ações dos colegas presentes, pois não há garantias de que eles estarão trabalhando ao mesmo tempo. Uma possibilidade é unir interfaces com a ideia de múltiplas visões, fornecendo aos participantes a oportunidade de escolher 
entre uma visão mais adequada à sua atividade individual e outra que favoreça sua colaboração (PINHEIRO et al., 2001).

\section{Quem}

O conhecimento sobre quem está trabalhando e atento no momento é importante para o andamento das atividades no grupo, pois age como facilitador da cooperação, à medida que estimula a interação e a comunicação informal entre os membros.

A noção de presença dos outros participantes é fundamental em ambientes síncronos, visto que é inviável realizar uma tarefa simultaneamente com um grupo de pessoas sem saber quem são estas pessoas. Nestes ambientes, os participantes obrigatoriamente precisam estar conscientes da presença dos demais para que 0 trabalho prossiga e obtenha resultados satisfatórios.

Tanto em ambientes síncronos como assíncronos fornecer informações sobre os colegas é importante para o fortalecimento da noção de grupo. O conhecimento cria um senso maior de comunidade, na medida que os membros vão conhecendo melhor seus colegas e o uso de mecanismos de comunicação reforça a coesão entre esses membros.

A noção da presença envolve também saber se alguém está ou não atento ao sistema, pois, estando os membros geograficamente distantes, a mera presença não garante que o colega esteja realmente atento. De posse desse conhecimento, é possível a um membro conversar, trocar ideias, pedir auxílio ou mesmo resolver possíveis conflitos por meio de ferramentas de comunicação, permitindo tornar as relações entre os participantes mais pessoais e interativas e menos formais.

Já em ambientes assíncronos, destaca-se o uso de ferramentas assíncronas, como email, quadro de avisos e notas que garantem aos membros a oportunidade de manter uma comunicação informal com seus colegas (PINHEIRO et al., 2001). 


\section{Quadro de elementos de awareness para sistemas assíncronos}

Em todo ambiente, devem ser feitas estas perguntas, para identificar quais elementos os usuários deveriam conhecer para ter consciência da situação e proporcionar o entendimento.

Os dados do Quadro II.1 mostram os elementos caracterizados por seu significado. Com esses dados, projetistas podem analisar, por exemplo, como as situações face a face seriam traduzidas para um ambiente groupware. Isto não significa que o projetista deva dar suporte a todos estes elementos igualmente na interface (ASSIS, 2000).

Quadro II.1 - Elementos de awareness para sistemas assíncronos e desacoplados

\begin{tabular}{|c|c|c|}
\hline Categoria & Elemento & Significado \\
\hline \multirow[t]{7}{*}{ O quê } & Atividades: & $\begin{array}{l}\text { Visão ampla das tarefas individuais e do grupo e de sua } \\
\text { produção: }\end{array}$ \\
\hline & \multirow{4}{*}{$\begin{array}{c}\text { Ações } \\
\text { Artefatos } \\
\text { Produção } \\
\text { Histórico de } \\
\text { ações }\end{array}$} & O que fazer e o que os outros estão fazendo \\
\hline & & Em quais objetos estão trabalhando no momento \\
\hline & & Quais são os resultados preliminares do trabalho \\
\hline & & O que um indivíduo esteve realizando \\
\hline & \multirow{2}{*}{$\begin{array}{l}\text { Papéis: } \\
\text { Alcance }\end{array}$} & Diferenciação das informações em função do papel \\
\hline & & Até onde podem ou devem \\
\hline \multirow[t]{5}{*}{ Quando } & $\begin{array}{c}\text { Eventos } \\
\text { passados, } \\
\text { passado } \\
\text { continuo e } \\
\text { presentes: }\end{array}$ & $\begin{array}{l}\text { Contexto sobre o que foi feito (eventos no passado) e do que } \\
\text { ainda está sendo feito (passado contínuo), }\end{array}$ \\
\hline & $\begin{array}{l}\text { Histórico de } \\
\text { eventos }\end{array}$ & Quando um evento aconteceu \\
\hline & Eventos futuros & $\begin{array}{l}\text { Representam uma opção interessante para manter os } \\
\text { membros atentos aos possíveis rumos do trabalho. }\end{array}$ \\
\hline & Persistência & $\begin{array}{l}\text { Alta: Definição de um critério de caducidade, que inutiliza } \\
\text { estas informações. }\end{array}$ \\
\hline & $\begin{array}{l}\text { Apresentação } \\
\text { das informações } \\
\text { de awareness }\end{array}$ & Posterior (a critério do usuário) \\
\hline \multirow[t]{4}{*}{ Onde } & $\begin{array}{c}\text { Espaço } \\
\text { compartilhado }\end{array}$ & $\begin{array}{l}\text { Objetos compartilhados pelo grupo. Através de sua } \\
\text { manipulação mostra o que houve e está acontecendo dentro } \\
\text { do trabalho em grupo. }\end{array}$ \\
\hline & $\begin{array}{l}\text { Histórico de } \\
\text { artefatos }\end{array}$ & Como um determinado artefato chegou àquele estado \\
\hline & $\begin{array}{l}\text { Histórico de } \\
\text { localização }\end{array}$ & Onde um indivíduo esteve \\
\hline & $\begin{array}{l}\text { Metáforas de } \\
\text { sistema }\end{array}$ & $\begin{array}{l}\text { Relacionam o groupware com versões monousuárias do } \\
\text { sistema, havendo a necessidade de enriquecê-la }\end{array}$ \\
\hline
\end{tabular}




\begin{tabular}{|c|c|l|}
\hline Categoria & Elemento & \multicolumn{1}{c|}{ Significado } \\
\hline Como & Interface & $\begin{array}{l}\text { adequadamente com as informações de awareness. } \\
\text { incluir elementos para awareness }\end{array}$ \\
\hline & $\begin{array}{c}\text { Balanceamento } \\
\text { de interface }\end{array}$ & $\begin{array}{l}\text { Filtragem ou um agrupamento das informações, mostrando } \\
\text { apenas aquilo que for mais útil }\end{array}$ \\
\hline Quem & Autoria & Quem realizou um determinado evento \\
\hline & $\begin{array}{c}\text { Histórico de } \\
\text { presença }\end{array}$ & Quem esteve em um local do ambiente e quando \\
\hline & $\begin{array}{c}\text { Ferramentas de } \\
\text { comunicação }\end{array}$ & $\begin{array}{l}\text { Essencialmente ferramentas assíncronas (email, quadro de } \\
\text { avisos e notas, etc.) }\end{array}$ \\
\hline
\end{tabular}

Fonte: adaptado de ASSIS (2000) e Pinheiro et al., 2001

\section{II.5.6 Considerações sobre awareness}

Esta seção traz conceitos da Engenharia de Groupware utilizados em projetos de software, voltados ao trabalho cooperativo em ambientes virtuais por meio do conceito de awareness, apresentando diretrizes de como as situações face a face de um sistema de informação podem ser traduzidas para um software utilizado por vários usuários em ambientes distintos onde os recursos para esse tipo de informações são pobres, se comparados aos recursos do cenário face a face, e os mecanismos de interação são diferentes dos usuais.

Com relação à pesquisa proposta, os aspectos abordados nesta seção são utilizados em parte dos ciclo 2 e ciclo 3 da pesquisa-ação, uma vez que os métodos e técnicas empregados durante os ciclos 1 e 2 da PA baseiam-se sobretudo em interações face a face.

No ciclo 2, os requisitos mais transacionais do trabalho cooperativo são focados por meio do uso do modelo $3 \mathrm{C}$. No ciclo 3 , são focados os elementos de awareness que, com o modelo $3 \mathrm{C}$, permitem aos usuários construir um entendimento compartilhado em torno dos objetos de cooperação e dos objetivos das tarefas, de modo que possuam percepção das atividades dos companheiros e dos impactos que ocorrem no conhecimento gerado pela cooperação. Os usuários terão informações que auxiliarão na sincronização do trabalho, coordenando-se em torno de seus contextos individuais. 


\section{II.6 MODELOS E PROCESSOS DE SOFTWARE}

Esta seção descreve os principais modelos utilizados em engenharia de software, passando do modelo cascata, até o modelo iterativo e evolucionário. Em seguida, são descritos os principais componentes do processo de desenvolvimento de software.

Estes conceitos são empregados para possibilitar o entendimento de como sua composição adapta-se ao processo proposto nesta pesquisa.

\section{II.6.1 Conceitos e definições}

Um processo de software é um conjunto organizado de atividades e resultados associados que transformam entradas em saídas e geram um produto de software (ver Apêndice A). O processo é o fundamento da Engenharia de Software (disciplina da engenharia relativa a todos os aspectos da produção de software, desde os estágios iniciais de especificação do sistema até sua manutenção), possibilitando o desenvolvimento racional do software pela efetiva utilização da tecnologia de engenharia em todos os aspectos de sua produção.

Um processo de desenvolvimento de software constitui, também, a base para 0 controle gerencial de projetos de software e estabelece o contexto para aplicação de métodos na produção de artefatos (modelos, documentos, dados, relatórios, formulários, etc.) (KOTONYA; SOMMERVILLE, 1998; PRESSMAN, 2005).

Um modelo de processo de software ("paradigmas de processo" ou "ciclo de vida") é uma descrição simplificada de um processo de software, uma abstração útil para explicar as diferentes abordagens de desenvolvimento. Corresponde, enfim, à estrutura do processo, sem entrar em pormenores sobre o mesmo, podendo ser estendido e adaptado para se criar processos de engenharia de software mais específicos (SOMMERVILLE, 2007).

Nos próximos itens, serão descritos os principais modelos do processo de software: modelo em cascata, desenvolvimento evolucionário, transformação formal e baseado em componentes, assim como um detalhamento dos processos de software. 


\section{II.6.2 Modelo em cascata}

O modelo em cascata, proposto por Royce (1987), também denominado "modelo sequencial linear", "abordagem top-down" ou "ciclo de vida clássico", é um dos primeiros e mais importantes modelos, tornando-se uma espécie de gabarito para muitos dos modelos modernos e ainda continua sendo amplamente usado (PRESSMAN, 2005; SOMMERVILLE, 2007).

Este modelo foi proposto como contraposição à abordagem composta apenas de análise e codificação (Figura II.4.a), que só se aplica, quando o esforço do desenvolvimento é pequeno, e o produto final é operado por quem o construiu, no qual apenas estes dois passos fracassam na produção de sistemas mais complexos, sendo, então, necessárias outras etapas complementares (Figura II.4.b) (ROYCE, 1987).

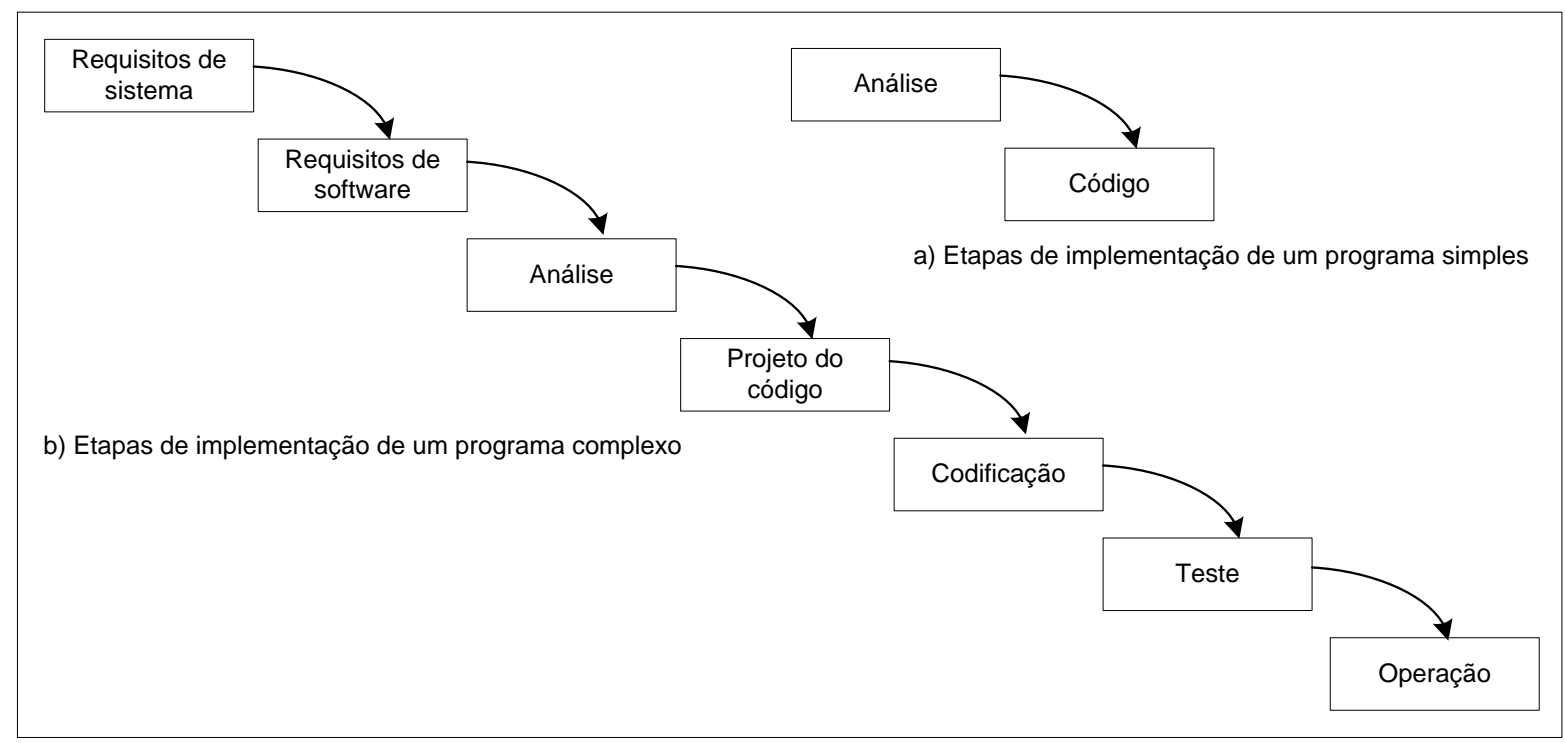

Figura II.4 - Modelo em cascata

Fonte: Royce (1987)

Seguindo um ciclo convencional de engenharia, sistemático e controlado, o modelo estabelece as seguintes etapas para o desenvolvimento de software:

- Requisitos: funcionalidades, restrições e objetivos são estabelecidos com o cliente e os usuários do sistema informatizado;

- Análise: os requisitos definidos na etapa anterior são detalhados em termos de funcionalidade, comportamento, desempenho e interface com usuário para servir como especificação do software a ser construído; 
- Projeto: a arquitetura geral do sistema informatizado é estabelecida, sendo descritas as abstrações fundamentais e as relações entre elas;

- Codificação: o projeto é traduzido para uma linguagem de programação;

- Teste: são realizados os testes para descobrir erros e verificar se os requisitos foram atendidos;

- Operação e Manutenção: o sistema informatizado é entregue para ao cliente, sendo instalado e colocado em operação. A manutenção envolve corrigir erros não descobertos em estágios anteriores ou modificar o sistema à medida que o cliente requisita novas funcionalidades ou melhoria de desempenho.

O princípio do modelo em cascata é que as diferentes etapas seguem uma sequencia: a saída de uma etapa 'flui' para a etapa seguinte, o desenvolvimento só prossegue quando uma etapa for concluída. $\mathrm{O}$ modelo original prevê ciclos de realimentação, mas as iterações são estabelecidas apenas indiretamente, e a maioria das organizações trata 0 modelo como se fosse estritamente linear (SOMMERVILLE, 2007).

Dentre as principais críticas ao modelo em cascata, Hanna (1995) destaca que é difícil estabelecer adequadamente todos os requisitos logo no começo do projeto e uma versão executável só fica disponível no término do projeto, assim um erro grosseiro pode ser desastroso se for detectado apenas quando o sistema estiver em execução, uma vez que projetos reais raramente se orientam pelo fluxo sequencial estabelecido.

Esta abordagem, possivelmente, foi emprestada das indústrias de fabricação de linha de montagem, cujo ciclo de vida em cascata é útil, por exemplo, para montar automóveis em uma linha de montagem, mas, só depois que o protótipo do automóvel foi completamente corrigido (YOURDON, 1992).

O modelo em cascata é adequado aos projetos de software em que os requisitos são bem conhecidos e definidos desde o início, e o processo de produção do sistema pode ser sequencialmente estabelecido. 


\section{II.6.3 Modelo de desenvolvimento iterativo evolucionário}

Nesta abordagem, um sistema é desenvolvido por meio de sucessivas versões. Gera-se rapidamente um executável com base nas especificações iniciais. Em seguida, deve-se refiná-lo, apoiando-se nos retornos obtidos (feedback) do cliente visando a produzir um sistema que satisfaça suas necessidades. O sistema é, então, entregue ou, como alternativa, reimplementado, usando uma abordagem mais estruturada para produzir um sistema mais robusto com maior capacidade de manutenção.

Há duas principais estratégias de desenvolvimento evolucionário:

- Protótipos descartáveis. O objetivo de se construir protótipos descartáveis é definir os requisitos que estejam mal compreendidos, objetivando desenvolver uma boa especificação. Neste caso, a prototipação concentra-se em torno da definição de requisitos que estão mal definidos;

- Desenvolvimento exploratório (modelo evolucionário). O desenvolvimento inicia-se com as partes do sistema que são bem definidas, evoluindo com o acréscimo de novas características, à medida que são requisitadas pelo cliente.

Seguindo o modelo evolucionário, tornou-se conhecido 0 modelo de desenvolvimento em espiral (Figura II.5) proposto por Boehm (1988). Em vez de uma sequência linear de atividades, este processo é representado como uma espiral, em que cada volta representa uma fase do processo: a volta mais interna relaciona-se à viabilidade do sistema; a volta seguinte, à definição dos requisitos; a próxima volta, ao projeto; e, assim, por diante.

Cada volta da espiral, por sua vez, é dividida em quatro setores:

- Definição de objetivos: são definidos os objetivos de cada etapa do projeto, sendo preparado um plano de gerenciamento, incluindo os riscos e alternativas;

- Avaliação e redução de riscos: para cada risco identificado, é realizada uma análise com tomada de providências para diminuir o risco. Por exemplo, se há risco dos requisitos serem inadequados, poderá ser desenvolvido um protótipo; 
- Desenvolvimento e validação: escolhe-se um modelo para o desenvolvimento do sistema. Por exemplo, se os riscos na interface do usuário são predominantes, um modelo apropriado de desenvolvimento poderá ser um protótipo evolutivo;

- Planejamento: o projeto é revisto para decidir se deve ser continuado. Se a decisão for continuar, então, será planejada a próxima fase do projeto, dando início a uma nova volta na espiral.

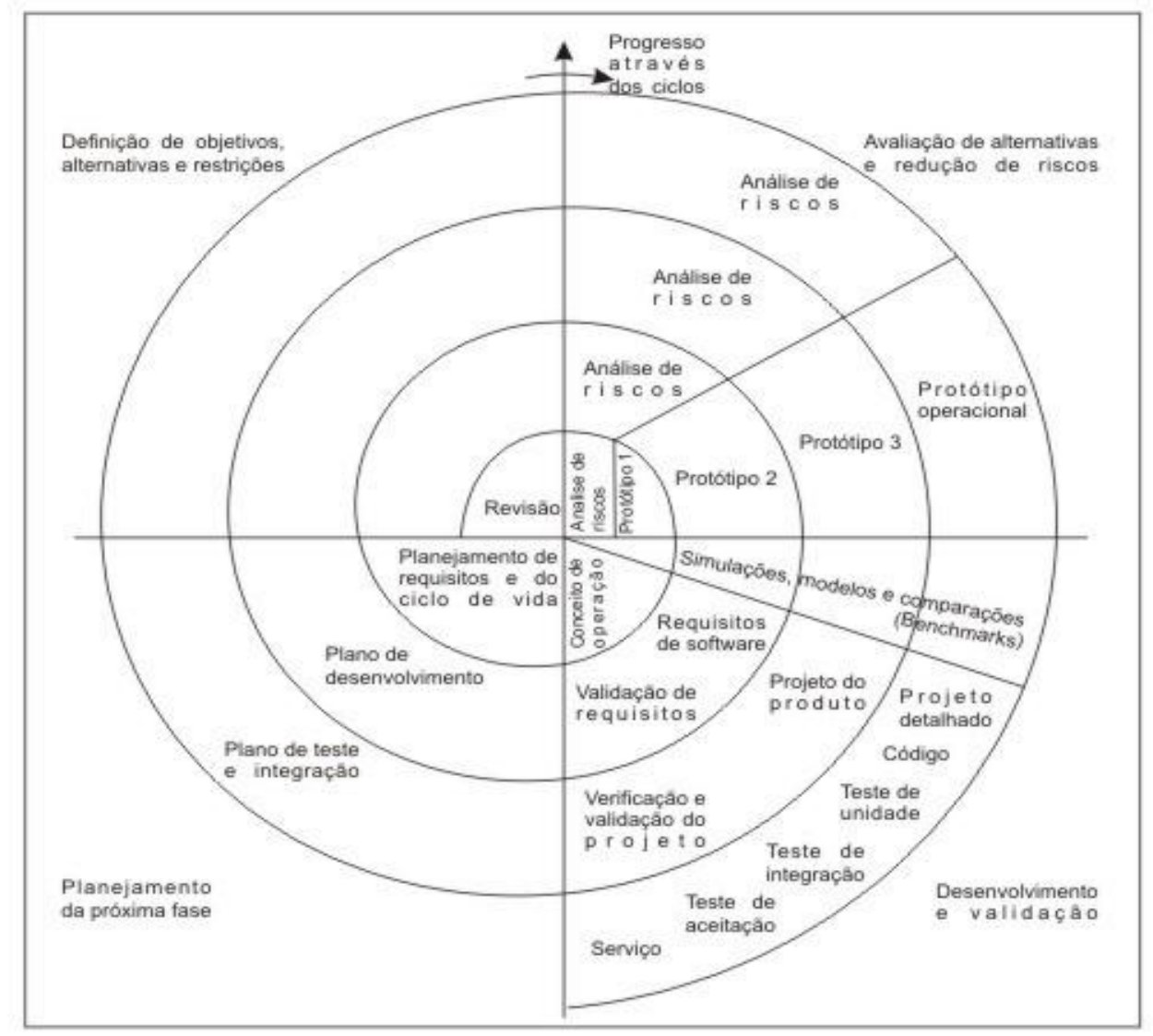

Figura II.5 - Modelo Espiral de processo de software Fonte: baseado em Boehm (1988)

A contribuição do modelo em espiral é a explícita gerência de projeto, considerandose os riscos (SOMMERVILLE, 2007). Não há fases fixas, e este modelo faz uso de outros, por exemplo, a prototipação pode ser usada para resolver dúvidas relativas aos requisitos, e esta fase pode ser seguida por um desenvolvimento convencional em cascata.

$\mathrm{Na}$ abordagem incremental (desenvolvimento exploratório), sugerida inicialmente por Mills et al. (1980), os clientes identificam algumas funções e as ordenam-nas pela 
relevância, em seguida, são definidas uma série de entregas, fornecendo um subconjunto das funcionalidades do sistema na ordem estabelecida de prioridade. $O$ objetivo é adiar algumas decisões sobre o detalhamento de requisitos até que clientes e usuários tenham alguma experiência com o sistema. Esta abordagem encontra-se recentemente em evidência com a programação extrema (BECK, 2004). Em comparação com o desenvolvimento em cascata, 0 desenvolvimento evolucionário incremental tem a vantagem de desenvolver a especificação gradativamente, conforme os usuários compreendam melhor o sistema, evitando assim que erros grosseiros sejam identificados somente no final do processo. Contudo, a partir da perspectiva da engenharia e do gerenciamento, são identificados os seguintes problemas:

- Os sistemas são frequentemente mal estruturados: a mudança constante tende a corromper a estrutura do software, tornando-se cada vez mais difícil e oneroso realizar modificações;

- O processo não é visível: os sistemas são desenvolvidos rapidamente, não sendo produzidos documentos que reflitam cada versão, dificultando a medição do progresso do desenvolvimento e, consequentemente, dificultando a gerência do projeto.

Segundo Sommerville (2007), para pequenos e médios sistemas, a solução incremental é a melhor escolha. Já para sistemas complexos, grandes, de longa duração e/ou desenvolvidos por equipes diferentes, a melhor solução contempla o uso de prototipação (descartável ou não) para a definição dos requisitos que estejam mal compreendidos, com uma implementação por meio de um modelo melhor estruturado (modelo em cascata).

Neste trabalho, o termo prototipação incremental ou evolucionária é usado e, conforme Sommerville (2007), pode ser empregado como sinônimo de desenvolvimento incremental, no qual o protótipo não é descartado, mas evolui para atingir os requisitos dos stakehoders. 


\section{II.6.4 Modelo de transformação formal}

Nesta abordagem, o sistema é especificado por meio de uma rigorosa notação matemática. Em seguida, são aplicados métodos formais para transformar a especificação em um programa. Ambiguidades e inconsistências são descobertas e corrigidas, não por meio de revisões comuns, mas pela aplicação da análise matemática. Estas transformações preservam a correção, garantindo que o programa produzido esteja livre de erros.

Esta abordagem é adequada ao desenvolvimento de sistemas que tenham rigorosas exigências de segurança e confiabilidade, como os sistemas de aeronaves e dispositivos médicos. Contudo, fora dos domínios especializados, os processos com base em transformação formal não são amplamente usados porque (SOMMERVILLE, 2007; PRESSMAN, 2005):

- Requerem perícia especializada, com poucos desenvolvedores de software com treinamento necessário para aplicar métodos formais;

- O desenvolvimento dos modelos formais é atualmente lento e dispendioso;

- Em relação a outras abordagens, não oferecem vantagens significativas de custo ou qualidade para a maioria dos sistemas;

- São difíceis usar os modelos, como um mecanismo de comunicação com clientes, geralmente despreparados tecnicamente.

\section{II.6.5 Modelo de desenvolvimento baseado em componentes}

O desenvolvimento baseado em componentes é uma estratégia recente e vem se tornando cada vez mais usada (SOMMERVILLE, 2007).

A técnica supõe que partes do sistema já existem, e o desenvolvimento concentrase na integração destas partes. O foco é no reuso de componentes (desenvolvimento com reuso), mas, eventualmente desenvolvendo novos componentes (desenvolvimento para reuso). A Figura II.6 apresenta uma descrição simplificada das atividades realizadas no desenvolvimento, baseado em componentes. 


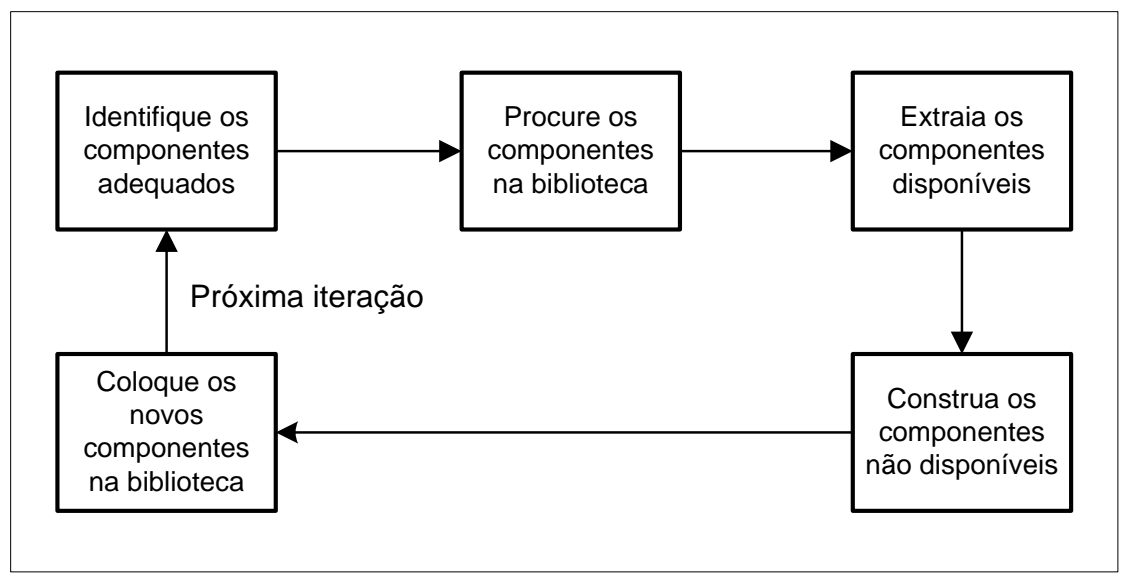

Figura II.6 - Desenvolvimento baseado em componentes

Fonte: baseado em Pressman (2005)

Seguindo esta abordagem, tornaram-se conhecidos processos como UML Components (CHEESMAN e DANIELS, 2001) e Rational Unified Process (KRUCHTEN; KROLL, 2003).

\section{II.6.6 Processo de desenvolvimento de software}

A despeito da existência de vários tipos de processos de software, algumas atividades são comuns a todos:

- Especificação: nesta atividade, devem ser definidas as funcionalidades do software, bem como as restrições em sua operação;

- Projeto e implementação: correspondem à produção do software para atender à especificação;

- Validação: garante que o mesmo executa as funcionalidades definidas pelos usuários;

- Evolução: o software deve evoluir para atender às necessidades em contínua mudança dos usuários.

Os processos de desenvolvimento do software evoluem para explorar as capacidades das pessoas na organização e as características específicas dos sistemas que serão desenvolvidos, de modo que, por exemplo, para sistemas críticos é necessário um processo muito bem estruturado e, para sistemas de negócio, cujas mudanças dos requisitos podem variar mais rapidamente, processos mais ágeis e flexíveis são mais efetivos (PRESSMAN, 2005; SOMMERVILLE, 2007). 
Um ambiente de desenvolvimento de software inicia-se com uma sólida definição do processo que inclui atividades, usualmente, denominadas como fases, tarefas ou passos, e o que será produzido em cada uma dessas atividades. O processo especifica a ordenação das atividades que podem ser sequenciais, concorrentes ou paralelas, e todas reunidas definem a base da execução do desenvolvimento (PAULK et al. ,1994).

Expandindo as atividades acima descritas, Pfleeger e Atlee (2006) apresentam os processos do desenvolvimento de software de maior interesse:

- Requisitos: descrição das necessidades do usuário, transformação em especificações funcionais e não funcionais e determinação dos vários componentes do software a serem desenvolvidos: escopo, entidades envolvidas, funcionalidades, padrões de usabilidade e regras de aceitação;

- Projeto: estruturação da forma com a qual o software estará resolvendo cada uma das especificações formuladas, contemplando o código computacional, o tratamento de dados e a interface homem-máquina;

- Codificação: transformação das especificações em linguagem computacional, criando os artefatos especificados no projeto;

- Testes: eliminação dos erros e falhas encontrados no código e no conjunto do software no qual cada artefato estará presente. Os testes envolvem as atividades de validação (presença de todos os requisitos) e verificação (funcionamento correto de cada componente);

- Integração: adequação de todos os novos artefatos no conjunto do software, garantindo o perfeito funcionamento. Assim como a integração do teste envolve a validação e a verificação de todos os requisitos;

- Instalação: disponibilização do software no ambiente produtivo com o usuário;

- Aceitação: manifestação do grau de satisfação do cliente com o software;

- Manutenção: correção dos erros surgidos após a entrega ao usuário. 


\section{II.6.7 Considerações sobre modelos e processos de software}

O desenvolvimento dos sistemas informatizados abordados nesta pesquisa requer competências e procedimentos específicos, tais como: conhecimento sobre cooperação, métodos de análise do trabalho coletivo, técnicas de Engenharia de Requisitos, realização de pesquisa-ação e avaliação diferenciada da interface com usuário (que não é mais entre usuário e sistema mas sim entre usuário e grupo).

$\mathrm{Na}$ literatura específica desta área, não é proposto um modelo diferente dos já conhecidos mas sim são elaboradas especificações de processos conhecidos para incorporar as práticas específicas para o desenvolvimento dos tipos de sistemas informatizados.

Não há um processo que possa ser considerado ideal e nem se pode demonstrar que um processo é sempre melhor que outro (PRESSMAN, 2005; SOMMERVILLE, 2007). Cada processo incorpora "boas práticas" que o fazem adequado para determinados tipos de projetos. Nesta pesquisa, o processo proposto aborda a atividade de análise de requisitos e mostra-se adequado especificamente para o desenvolvimento evolucionário de sistemas, cuja coordenação é distribuída pelas ações dos usuários.

\section{II.7 ENGENHARIA DE REQUISITOS (ER)}

Nesta etapa da fundamentação, são abordados os principais conceitos tratados pela Engenharia de Requisitos, o detalhamento do processo de especificação de requisitos de software, do macroprocesso de desenvolvimento de software e os modelos de sistema informatizados utilizados para documentar e analisar os requisitos de sistema, constituindo-se em uma importante ponte de ligação entre a análise de requisitos e o projeto do software.

\section{II.7.1 Conceitos e definições}

A Engenharia de Requisitos (ER) é uma subárea da Engenharia de Software, estuda o processo de definição dos requisitos que o software deverá atender. 
Requisitos, para Sommerville et al. (1998), são descrições de como o software deve comportar-se, informações do domínio da aplicação, restrições sobre operação de software ou especificações de propriedade ou atributo de um software. Os requisitos são definidos durante os estágios iniciais do desenvolvimento do software, como uma especificação do que poderá ser implementado. Os requisitos contêm invariavelmente uma mistura de informação do problema, declarações de comportamento e propriedades do software, condições do projeto e restrições de construção.

O processo de Engenharia de Requisitos, conforme Kotonya e Sommerville (1998), é um conjunto estruturado de atividades para conhecer requisitos, validar e mantêlos em um documento de requisitos. Estas atividades incluem elicitação, análise, negociação e validação de requisitos. Uma descrição completa inclui quais atividades são destacadas e a estruturação ou escalonamento destas atividades, quem é o responsável, as entradas e/ou saídas para/de e as ferramentas usadas para suportar ER.

Esta sessão aborda os conceitos tradicionais da ER. A sessão II.5 traz a abordagem do trabalho cooperativo em um sistema informatizado por meio dos conceitos do modelo 3C (FUKS et al., 2007), awareness (ASSIS, 2000) e groupware.

\section{II.7.2 Elementos da Engenharia de Requisitos}

Além dos requisitos em si, abaixo estão descritos os principais elementos encontrados na Engenharia de Requisitos.

\section{Ambiente ou Domínio da Aplicação}

O ambiente ou domínio da aplicação é onde ocorrem os fenômenos que caracterizam os problemas referentes aos requisitos particulares do cliente (JACKSON, 1995).

É o primeiro elemento a ser conhecido e representado na análise de requisitos, observando o contexto nos quais os fenômenos estão presentes e interagem. 


\section{Problema}

No contexto de elicitação de requisitos, o problema é a razão principal para o entendimento, especialização e domínio do conhecimento. Identificar o que é o problema, qual sua definição, quem o tem e qual é sua essência (sob o ponto de quem o tem) caracteriza a complexidade do processo.

Segundo Jackson (1995), é necessário distinguir claramente um processo de definição do problema (conhecimento dos requisitos) de um processo de solução do problema (aplicação de ferramentas de software como solução). Já que a fonte dos problemas é intrínseca no comportamento das pessoas, é importante identificar qual o desejo de ter resolvido o problema e se existe realmente o desejo de uma solução.

\section{Stakeholders}

Stakeholders compreendem o conjunto de pessoas ou objetos que, direta ou indiretamente, são afetados pela solução do software a ser construído (RYAN, 1998), e para quem o resultado do processo de desenvolvimento de software constitui interesse.

\section{Requisitos}

- Funcionais: devem descrever o que o sistema deve fazer, como deve reagir a determinadas entradas e como deve se comportar em determinadas situações; portanto, referem-se às condições e exigências de transformação de entradas em saídas;

- Não funcionais: são restrições dos serviços ou funções oferecidas pelo sistema. Incluem restrições de tempo, restrições no processo e padrões (SOUZA; CASTRO, 2004). Geralmente, são aplicados ao sistema como um todo e podem ser classificados em: requisitos de processos, de produtos e externos. Referem-se às especificações técnicas de padrões e métodos do processo produtivo, da qualidade do produto e características desejáveis e das políticas aplicáveis ao processo e ao produto gerado. Segundo Leite (2002), os requisitos não funcionais podem ser expressos de duas maneiras: independentes ou associados a um requisito não funcional; 
- Requisitos de domínio: estes requisitos são oriundos do domínio da aplicação e refletem as características e restrições deste domínio, podem ser funcionais ou não funcionais. Usualmente, incluem terminologia especializada do domínio da aplicação ou referência aos conceitos desse domínio. Estes tipos de requisitos são importantes, pois refletem os fundamentos do domínio da aplicação, de modo que pode ser impossível desenvolver o sistema de informação, se os mesmos não forem satisfeitos;

- Requisitos de usuários: devem descrever os requisitos funcionais e não funcionais, de modo que sejam compreensíveis pelos usuários sem conhecimento técnico detalhado. Devem apenas especificar o comportamento externo do sistema, evitando o máximo possível detalhes técnicos sobre os mesmos, focando nas facilidades-chave que serão fornecidas;

- Requisitos de sistema: é uma versão ampliada dos requisitos dos usuários que são usados pelos desenvolvedores do sistema, como ponto de partida para o projeto do sistema. Estes requisitos adicionam detalhes para explicar como os requisitos de usuários podem ser atendidos pelo sistema e devem se concentrar no comportamento externo do sistema e suas restrições, sem se preocupar no modo como o sistema será implementado ou projetado.

\section{Especificação de interfaces}

Quase todo tipo de sistema informatizado deve operar com outros existentes que já tenham sido implementados e instalados no ambiente. Caso estes sistemas devam trabalhar em conjunto, as interfaces do sistema informatizado existente devem ser especificadas, desde o início do processo de definição de requisitos.

$\mathrm{Na}$ Figura II.7 abaixo, estes elementos podem ser vistos, considerando o processo de engenharia de requisitos como um todo. 


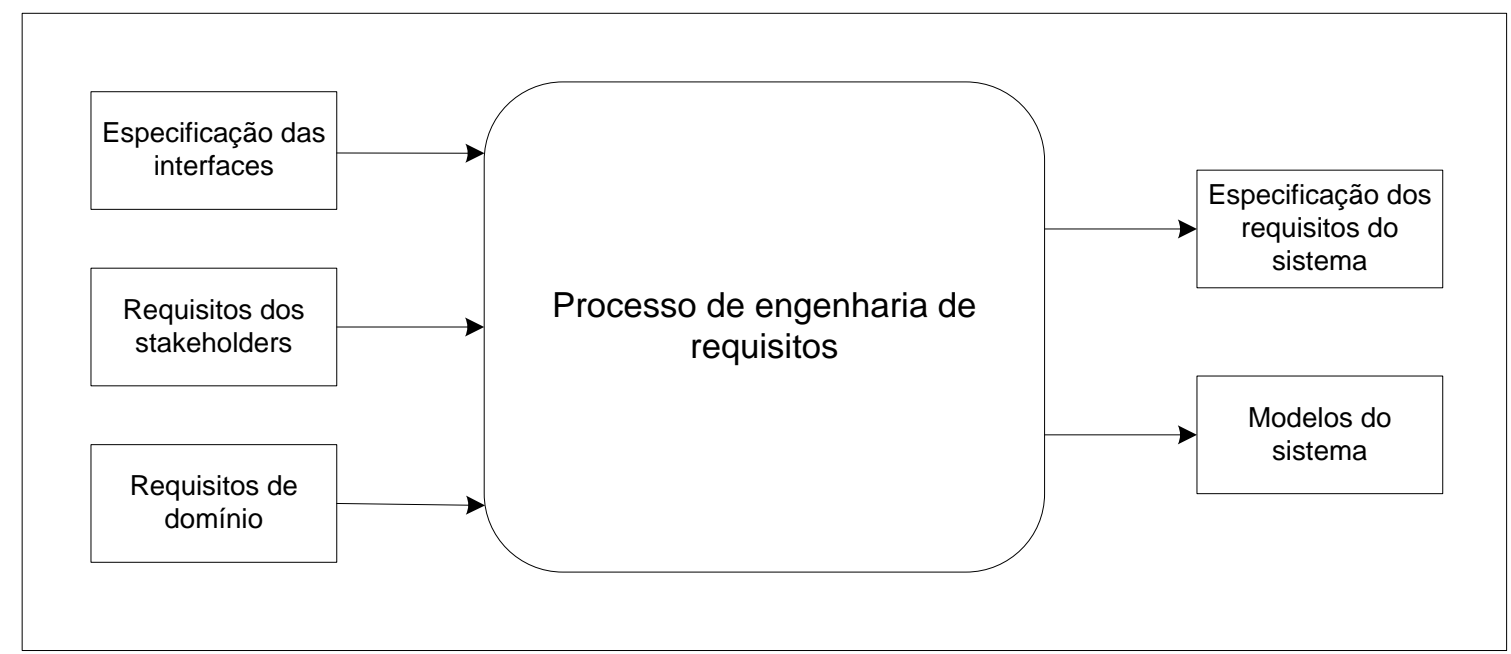

Figura II.7 - Entradas e saídas do processo de Engenharia de Requisitos Fonte: baseado em Kotonya e Sommerville (1998)

\section{Modelos do sistema}

Um conjunto de modelos, tais como fluxo de dados, modelo de objetos, modelo do processo, modelo de dados, etc. que descrevem o sistema a partir de diferentes pontos de vista (item II.7.4).

\section{II.7.3 Processo de Engenharia de Requisitos}

A Figura II.8 abaixo destaca os quatro subprocessos da Engenharia de Requisitos. O estudo de viabilidade verifica se o sistema a ser desenvolvido é útil ao negócio. As fases de elicitação e análise tratam da descoberta dos requisitos, a especificação converte estes requisitos em alguma forma padrão e a fase de validação verifica se os requisitos realmente definem o sistema que os stakeholders esperam (SOMMERVILLE, 2007). 


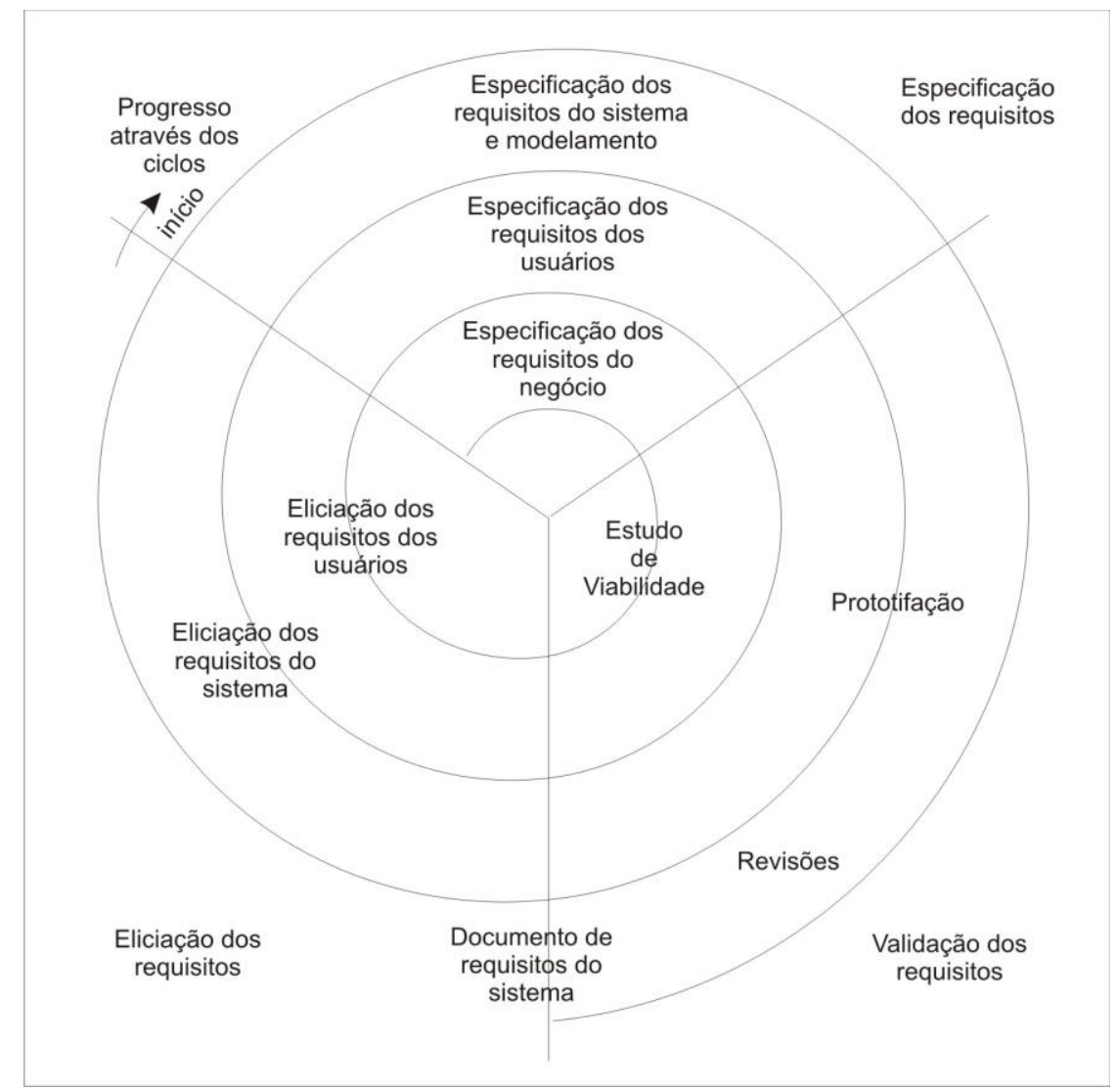

Figura II.8 - Subprocessos do processo de Engenharia de Requisitos Fonte: baseado em Kotonya e Sommerville (1998); Sommerville (2007)

\section{Estudo de viabilidade}

A entrada do estudo de viabilidade corresponde a um conjunto preliminar de requisitos do negócio e corresponde a uma descrição resumida do sistema e de que modo este deverá dar apoio aos processos de negócio. O resultado do estudo de viabilidade pode ser um relatório que recomende se vale a pena seguir o processo de levantamento de requisitos.

Neste estudo, várias fontes devem ser consultadas, tais como gerentes de departamentos onde o sistema será utilizado, engenheiros de software com familiaridade no sistema proposto, especialistas em tecnologia e usuários finais desse sistema. Dependo do resultado deste estudo, poderão ser propostas mudanças em seu escopo, orçamento e cronograma do sistema, além de requisitos complementares ao mesmo. 


\section{Elicitação e análise de requisitos}

Essencialmente, o subprocesso de elicitação de requisitos é relacionado com a descoberta dos requisitos do sistema e compreensão das necessidades dos usuários. Assim, analistas e engenheiros de software trabalham com clientes e usuários finais no domínio da aplicação para descobrir o problema a ser resolvido, os serviços do sistema, o desempenho necessário, restrições de hardware e outras informações. Nos dados do Quadro II.2, Kotonya e Sommerville (1998) apresentam os papéis essenciais para a execução da atividade de elicitação de requisitos.

Quadro II.2 - Papéis no processo de Engenharia de Requisitos

\begin{tabular}{|l|l|}
\hline \multicolumn{1}{|c|}{ Papel } & \multicolumn{1}{c|}{ Descrição } \\
\hline Especialista do domínio & $\begin{array}{l}\text { Responsável por prover informações sobre o } \\
\text { domínio de aplicação e do problema específico a } \\
\text { ser resolvido naquele domínio }\end{array}$ \\
\hline Usuário final & Responsável pelo uso do sistema após a entrega \\
\hline Engenheiro de Requisitos & $\begin{array}{l}\text { Responsável por identificar e especificar os } \\
\text { requisitos do sistema }\end{array}$ \\
\hline Engenheiro de Software & $\begin{array}{l}\text { Responsável por desenvolver o protótipo do } \\
\text { sistema }\end{array}$ \\
\hline Gerente de Projeto & Responsável pelo planejamento do projeto \\
\hline
\end{tabular}

Fonte: Kotonya e Sommerville (1998)

Observa-se que nenhuma definição fornece a real dimensão da dificuldade na condução da atividade. Tal dificuldade surge da natureza menos técnica e mais social da atividade de ER, como destacam Goguen e Linde (1993).

A forte influência das questões sociais acaba por introduzir problemas nos requisitos levantados, e estes problemas precisam ser identificados para que possam ser tratados. Entre os problemas comuns enfrentados na atividade de elicitação, Kotonya e Sommerville (1998) citam:

- A forma dispersa como são encontrados os requisitos (em livros, manuais, conhecimento de pessoas específicas, etc.);

- A terminologia específica do domínio da aplicação que precisa ser compreendida para garantir o entendimento do problema no contexto do domínio da aplicação;

- A tarefa de auxiliar no levantamento de requisitos é, via de regra, secundária no contexto de trabalho dos stakeholders, constituindo uma barreira à 
execução do trabalho de requisitos, culminando com o não envolvimento dos stakeholders no processo de requisitos;

- Questões organizacionais e fatores políticos que exercem grande influência sobre os requisitos, este fatores nem sempre são identificados pelos usuários finais e podem passar despercebidos pelo engenheiro de requisitos.

Além destes problemas, a possibilidade de automação altera a perspectiva dos stakeholders sobre o próprio trabalho, fazendo com que não tenham uma correta percepção sobre os requisitos do sistema (KRUCHTEN, 2003).

Segundo Sommerville (2007), a fase de elicitação de requisitos é apresentada em quatro atividades:

- Descoberta dos requisitos: corresponde ao processo de reunir informações sobre o sistema proposto e o $\mathrm{SI}$ existente, extraindo os requisitos dos usuários e do sistema destas informações. As fontes de informação utilizadas na descoberta de requisitos incluem documentação, stakeholders do sistema e especificações de sistemas similares. Várias técnicas são usadas para a descoberta destes requisitos que são discutidas no item II.8. Somando-se aos stakeholders de sistema, devem ser empregados os requisitos oriundos do domínio da aplicação e de outros sistemas que interagem com o sistema que está sendo especificado. Estas fontes de requisitos (stakeholders, domínio e sistema) podem todas ser representadas por pontos de vista de sistema, pois cada ponto de vista representa um subconjunto dos requisitos do sistema (NUSEIBEH et al., 2003; SABETZADEH et al., 2010);

- Classificação e organização dos requisitos: esta atividade trabalha com requisitos vindos de diferentes stakeholders distribuídos em coleções desestruturadas, grupos relacionados e sobreposição entre requisitos, organizando-os em famílias coerentes. A maneira mais comum de agrupar os requisitos é pela utilização dos modelos da arquitetura do sistema para identificar subsistemas e requisitos associados a cada subsistema;

- Negociação e priorização dos requisitos: quando múltiplos tipos de stakeholders estão envolvidos, inevitavelmente, haverá conflito nos requisitos. Esta atividade relaciona-se com a priorização dos requisitos, encontrando e resolvendo conflitos por meio da negociação. 
- Documentação de requisitos: nesta atividade, os requisitos que foram descobertos são documentados de modo que poderão ser empregados na ajuda de novas descobertas de requisitos.

\section{Especificação de requisitos}

A especificação de requisitos ou documento de requisitos tem por finalidade formalizar os requisitos que serão utilizados como referência para as outras fases do ciclo de vida do software.

O documento de requisitos é o meio empregado para descrever as restrições quanto às características do produto e quanto ao processo de desenvolvimento, a interface com outras aplicações, a informação a respeito do domínio da aplicação e informações de suporte ao conhecimento do problema, tais como: modelos, termos especializados do negócio, recuperação e gerenciamento de informações em mudança.

A informação que deve ser incluída na especificação, depende do tipo de software que está sendo desenvolvido e da abordagem de desenvolvimento utilizada. Se uma abordagem evolucionária é adotada para o desenvolvimento do software, a especificação de requisitos pode deixar fora muitos detalhes sobre os mesmos. $O$ objetivo será definir os requisitos do usuário e os requisitos não funcionais de alto nível. Neste caso, os programadores e projetistas devem usar seu julgamento para decidir como alcançar requisitos do sistema (SOMMERVILLE , 2007).

\section{Validação}

Após a documentação dos requisitos ter sido produzida, inicia-se o processo de validação, buscando verificar se os requisitos estão certos, ou seja, descritos de forma apropriada, procurando eliminar os problemas dos requisitos incompletos, ambiguidade, inconsistência, facilidade de verificação por meio de testes e verificação de validade entre requisitos. A validação dos requisitos sobrepõe-se à descoberta e análise, na medida que a mesma também se refere à busca de problemas nos requisitos.

Uma das técnicas mais importantes utilizadas na validação corresponde à revisão dos requisitos, no qual são analisados sistematicamente por um grupo de revisores. 
$\mathrm{Na}$ revisão, o grupo de desenvolvimento do sistema caminha com o cliente do sistema por meio dos requisitos, explicando as implicações de cada um deles. Os revisores devem verificar cada requisito com respeito à sua consistência, assim como observar se os requisitos estão completos (KOTONYA; SOMMERVILLE, 1998).

\section{Gerenciamento}

Embora não seja uma, permeia todas as fases da Engenharia de Requisitos, sendo responsável por controlar a evolução dos requisitos de um sistema, seja pela constatação de novas necessidades, seja pela comprovação das deficiências nos requisitos registrados até o momento.

Sempre que os requisitos alocados forem alterados, os planos de software, os artefatos e as atividades afetadas devem sofrer ajustes para continuarem consistentes. Um aspecto importante é que os requisitos sejam dinâmicos e estejam em uso durante todo o ciclo de vida, sendo a base para a modelagem do sistema.

Congelar os requisitos, após a etapa de validação, é inviável, já que os negócios não são estáveis. Como eles se adaptam às mudanças, os sistemas também devem se adaptar. A capacidade de adaptação do processo do desenvolvimento é hoje um diferencial estratégico entre as empresas de software. Esta capacidade de adaptação é mérito em grande parte do processo do gerenciamento de requisitos.

\section{II.7.4 Modelos de sistema}

Os requisitos de usuário devem ser escritos na forma de texto em razão da necessidade de serem entendidos por pessoas que não sejam especialistas técnicas. Entretanto, requisitos de sistema devem ser descritos de um modo mais técnico. Uma técnica utilizada corresponde na documentação da especificação do sistema, como um conjunto de modelos.

Estes são mais representações gráficas baseadas em conceitos computacionais, tais como objetos e funções, descrevendo o processo de negócio, o problema a ser resolvido e o sistema que será desenvolvido, do que conceitos do domínio da aplicação. 
Assim, o processo de formulação, estruturação e modelagem dos requisitos pode ser guiado pelos modelos do sistema que são uma abordagem sistematizada para documentar e analisar os requisitos de sistema, sendo um importante elo de ligação entre a análise de requisitos e o projeto do software (SOMMERVILLE, 2007).

O aspecto mais importante de um modelo de sistema é o de não considerar detalhes da solução, já que corresponde a uma abstração de parte SI em estudo, simplificando e colocando em evidência seus aspectos mais importantes.

Tipos diferentes de modelos são caracterizados por distintos tipos de abstração, sendo importante ressaltar que não existe um único modelo ideal. Por exemplo, um modelo de fluxo de dados concentra-se no fluxo dos dados e em suas transformações funcionais, deixando de lado os detalhes de suas estruturas. Já o modelo de entidade e relacionamento de dados documenta as estruturas dos dados em detrimento das funcionalidades (KOTONYA e SOMMERVILLE, 1998).

Nos próximos itens, serão descritos os principais modelos de sistema e respectivas abstrações.

\section{Modelo de fluxo de dados}

Modelo de fluxo de dados corresponde a um modo intuitivo para mostrar como os dados fluem por meio de uma sequência dos passos de processamento (funções ou transformações) e fornecem uma abstração orientada para funções, cujos dados são transformados em cada uma dessas sequências, antes de se mover para o próximo estágio. Este modelo utiliza o diagrama de fluxo de dados (DFD) para representar graficamente as entidades externas, processos, fluxo de dados e depósito de dados e foi proposto originalmente por Demarco (1989).

Assim, o DFD é composto por dados que se movem, sendo representado por setas nomeadas pelos dados, pela transformação de dados em outros dados, mostrados nos círculos (o nome deste círculo corresponde a uma função/transformação), fontes e destinos de dados, representados por retângulos (designados de terminadores) e do depósito de dados, mostrado como linhas paralelas (Figura II.9).

As funções representadas pelos círculos são a base para a decomposição funcional posterior, de modo que este tipo de modelo é apresentado de um modo hierárquico, cujo primeiro modelo (também chamado de diagrama de contexto) representa 0 
sistema como um todo e os próximos DFDs refinem o diagrama de contexto, fornecendo mais detalhes em cada nível do diagrama subsequente.

O diagrama de contexto ajuda na visão do sistema como uma caixa preta onde é feita uma análise do tipo de dados que entram no sistema e suas respectivas fontes, assim como dos dados que saem do sistema e seus destinos, permitindo definir as fronteiras do sistema, de modo a facilitar que clientes e desenvolvedores possam entrar em acordo com o escopo do sistema a ser desenvolvido (PRESSMAN, 2005).

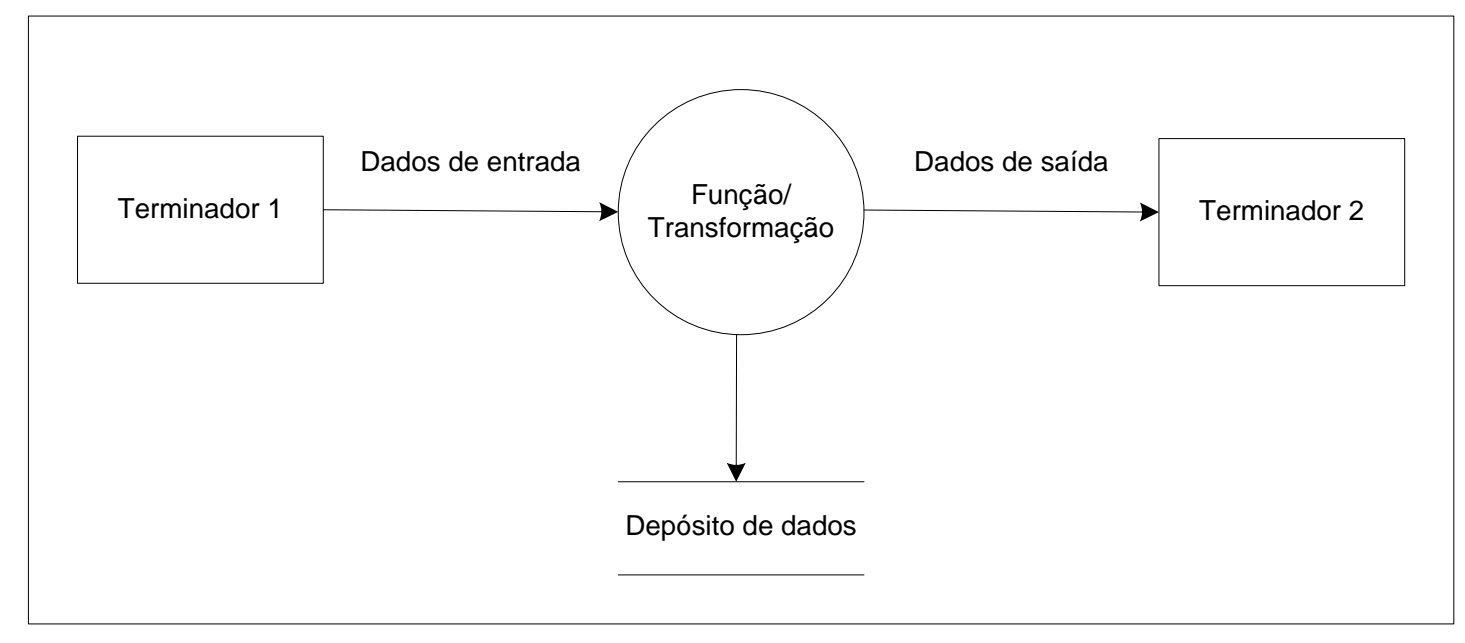

Figura II.9 - Notação do diagrama de fluxo de dados (DFD)

Fonte: baseado em Pressman (2005)

\section{Modelo de dados semântico}

Este modelo descreve em alto nível de abstração como os dados se relacionam em um sistema; é importante, pois permite evidenciar as estruturas dos dados, suas propriedades e seus relacionamentos, independente do processamento que ocorrerá, permitindo responder questões como: quais são os dados necessários para o negócio? Como estes dados relacionam-se com os demais? Estes dados pertencem a quem? Quem está autorizado a ter acesso aos mesmos?

Para viabilizar um modelo que permitisse fornecer informações a respeito da semântica dos dados, Chen (1990) propôs o modelo de entidade e relacionamentos (MER), que identifica as entidades em um banco de dados, seus atributos e a relação explícita entre eles.

Assim como outros modelos, o MER é descrito por meio de uma notação gráfica para facilitar o entendimento (Figura II.10) e possui os seguintes elementos: 
- Entidade: representa uma coleção ou um conjunto de objetos (coisas) do mundo real, cujos objetos individuais possuem as seguintes propriedades: só podem ser identificados de uma única forma, exercem um papel no sistema em construção e podem ser descritos por um ou mais elementos dos dados (atributos);

- Relacionamento e cardinalidade: são as associações entre as entidades dos dados, representam uma ligação entre objetos do domínio; e seu relacionamento representa um conjunto de conexões entre os objetos, de modo que cada conexão represente uma associação entre zero ou mais ocorrências de um objeto e zero ou mais ocorrências do outro objeto (cardinalidade);

- Entidade de relacionamento: corresponde a uma representação de um relacionamento sobre a qual é importante manter informações na forma de uma entidade.

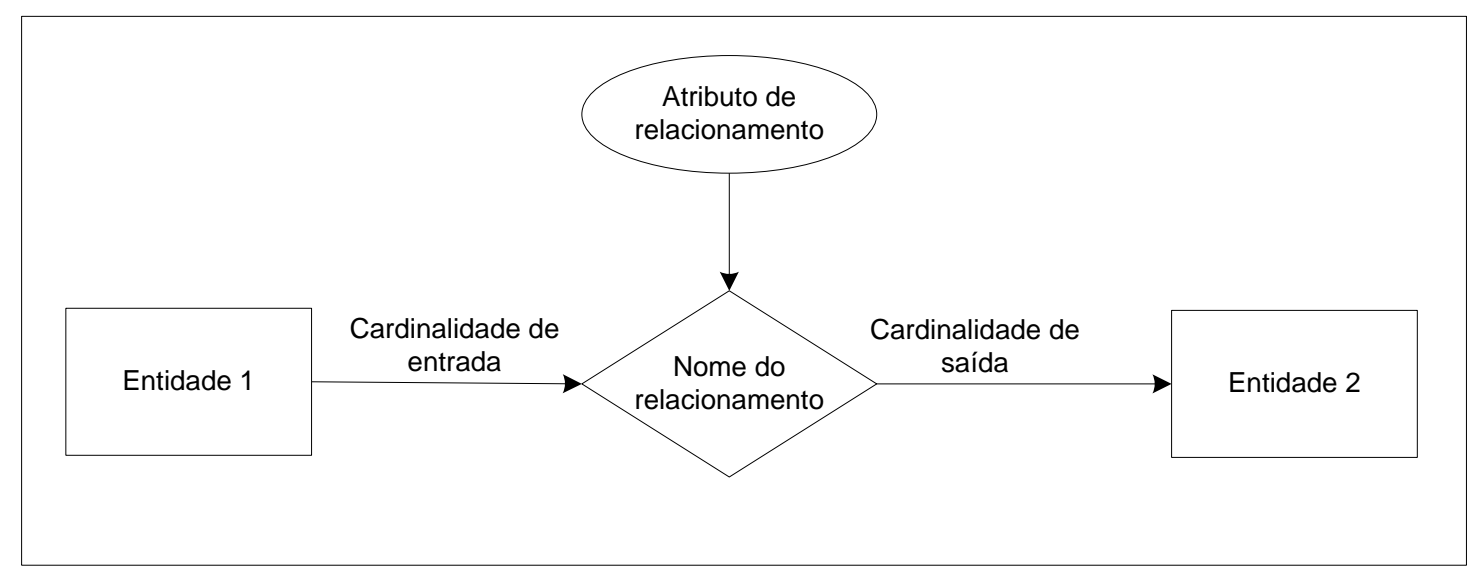

Figura II.10 - Modelo de entidade e relacionamento (MER)

Fonte: baseado em Chen (1990)

\section{Modelo de Objetos}

O modelo orientado a objetos combina o uso dos dois modelos anteriores, sendo mais próximo do modelo de dados semântico, tendo como diferença fundamental o conceito de encapsulamento dos dados.

No centro deste modelo, estão as classes de objetos que representam uma abstração a respeito de um conjunto de objetos que identifique atributos e serviços (operações) em comum. Cada objeto (ou instância) desta classe possui os atributos 
e serviços desta classe e os modelos são desenvolvidos, utilizando como centro da análise os objetos da classe e seus relacionamentos.

Neste tipo de análise, os objetos do mundo real devem ser representados por meio de classes de objetos, criando-se diferentes tipos de classes e de como se relacionam entre si, como os objetos são agregados para formar outras classes e como os objetos relacionam-se entre si.

Vários métodos de análise orientada a objetos foram propostos, sendo os principais: projeto e modelagem orientado a objetos (RUMBAUGH et al., 1991), engenharia de software orientada a objetos (JACOBSON et al., 1992) e análise orientada a objetos (BOOCH, 1994). Uma vez que estes métodos possuíam muitas similaridades, estes três autores decidiram integrar suas propostas para produzir um método unificado denominado UML (Unified Modeling Language) (UML, 2008).

Para certas classes de problemas, o modelo de objetos é um modo natural de refletir as entidades do mundo real que são manipuladas pelo sistema. Esta questão, particularmente, é verdadeira quando o sistema processa informações a respeito das entidades tangíveis, tais como carros, aviões ou livros, que têm atributos claramente identificáveis (por exemplo, sistema em tempo real). Em sistemas que possuem entidades mais abstratas, tais como os comerciais, é mais difícil modelar suas classes de objetos, não possuindo necessariamente uma interface simples com atributos e operações independentes.

Embora este tipo de modelo facilite a transição entre a análise de requisitos e a programação, os usuários com frequência consideram o modo pouco natural e mostram dificuldade para entendê-lo, preferindo adotar o modelo mais funcional de processamento de dados.

\section{Modelo de transição de estados}

Este modelo descreve como um sistema responde a eventos internos ou externos, foi proposto inicialmente por Ward e Mellor (1985). O modelo de transição de estados mostra os estados e os eventos que causam mudanças de um estado para outro, enfatizando o comportamento tempo-dependente do sistema. 
O tipo de modelo não se preocupa com o fluxo de dados dentro do sistema, sendo útil para representação de sistemas em tempo real, uma vez que, em geral, são guiados pelos estímulos do ambiente do sistema.

Assim, o modelo de transição de estados pressupõe que o sistema seja um dos possíveis estados assumidos pelo mesmo, sendo seu maior problema que o número de possíveis estados aumenta rapidamente com a complexidade do sistema.

\section{Modelo de contexto, processo e de fluxo de trabalho (workflow)}

Logo nos estágios iniciais da descoberta de requisitos (elicitação), deve-se decidir onde estão as fronteiras do sistema: deste modo, limitando os custos do sistema e o tempo necessário para análise. Uma vez definida as interfaces do sistema deve-se conhecer o contexto e as dependências dos sistemas e seu ambiente. Para tanto, o diagrama de contexto discutido no modelo de fluxo de dados pode ser utilizado.

Assim, após definir o contexto, o modelo deverá ser complementado com o modelo de processo, que mostra as principais atividades envolvidas na execução do fluxo de trabalho. Modelar o processo consiste, basicamente, na representação gráfica de um modelo das relações existentes entre: tarefas, pessoas, informações e objetos envolvidos, com o objetivo de explicitar a realidade estabelecida no ambiente estudado (ver Apêndice A; DAVENPORT, 1993).

Com o processo modelado e o sistema possuindo um número diferente de grupos de usuários, cada um com diversas atribuições, fazendo uso das distintas interfaces do usuário, muitas vezes, é necessário ir além da análise dos processos, aplicando uma análise de fluxo de trabalho (workflow). Esta técnica permite a compreensão de como o processo de trabalho é completado, quando diferentes pessoas (e regras) estão envolvidas.

$\mathrm{Na}$ medida que o fluxo de trabalho é analisado, deve ser definida passo a passo uma hierarquia de subatividades para cada atividade do fluxo principal, acompanhada das respectivas interfaces do usuário (PRESSMAN, 2005). 


\section{II.7.5 Considerações sobre Engenharia de Requisitos}

Esta seção expõe características gerais sobre a Engenharia de Requisitos, contextualizando-a dentro da Engenharia de Software, mostrando seus principais conceitos e definições, seus principais elementos, o processo para obtenção de requisitos de software e os principais modelos empregados para documentar a especificação do sistema.

Mostra, também, que as dificuldades surgem sobretudo da natureza menos técnica e mais social da atividade de ER, com poucos esforços de aprofundar os conhecimentos desenvolvidos na área das ciências sociais (GOGUEN e LINDE, 1993), de modo que a forte influência das questões sociais acaba por introduzir problemas nos requisitos levantados.

Outro aspecto importante a ser destacado é a possibilidade de automação, segundo Kruchten (2003), que altera a perspectiva dos stakeholders sobre o próprio trabalho, fazendo com que não tenham um correto entendimento sobre os requisitos do sistema: deste modo, introduzindo o paradoxo apontado nos itens I.1 e II.8.3.

Nesta pesquisa, os modelos de contexto, de processo e de fluxo de trabalho (workflow) foram usados para documentar o sistema, descrevendo o processo de negócio, o problema a ser resolvido e o sistema que será desenvolvido. Este modelo de sistema foi escolhido, pois define em um único modelo as interfaces do sistema, seu contexto e as dependências dos sistemas e seu ambiente.

Outra razão para a escolha deste modelo foi o fato de que seus componentes foram utilizados como elementos de representação comum nas sessões de ACT realizadas nos ciclos 2 e 3 .

O processo de negócio (ver Apêndice A) foi modelado por intermédio de um fluxograma e apresentado nas sessões aos usuários, com uma hierarquia de subatividades para cada atividade do fluxo principal, acompanhada das respectivas interfaces de usuário, uma vez que diferentes pessoas, papéis e regras estavam envolvidos, sendo paulatinamente complementado na medida que as sessões ocorriam (sobretudo nos ciclos 2 e 3 da pesquisa-ação). 


\section{II.8 TÉCNICAS UTILIZADAS NA DESCOBERTA DE REQUISITOS}

O objetivo desta seção é apresentar algumas das principais técnicas de descoberta de requisitos para a contextualização do processo proposto nesta pesquisa. Assim, nos próximos itens serão focadas as técnicas de cenários, entrevistas, storyboard/prototipação e etnografia.

\section{II.8.1 Cenários}

Em geral, os usuários preferem utilizar exemplos da vida real a descrições abstratas, sendo mais fácil compreender e criticar um cenário que mostra como interagir com o software do sistema. Os cenários são descrições de exemplos de sessões de interação com o sistema e são referentes a um determinado tipo de interação entre o usuário final e o sistema. Os usuários explicam o que estão fazendo, e as informações que necessitam do sistema para executar a tarefa descrita no cenário.

Os cenários podem ser descritos como histórias que explicam, como o sistema é utilizado, sendo úteis, inicialmente, para agregar detalhes em uma descrição resumida de requisitos. Uma vez possuindo uma ideia básica de como o sistema deve atender aos requisitos, desenvolvem-se os cenários em torno desta solução.

O cenário inicia-se com um resumo de interação e durante o processo de descoberta de requisitos (elicitação) novos detalhes são adicionados ao mesmo, visando a criação de uma descrição completa da interação. Os cenários podem ser escritos de diferentes maneiras, mas devem incluir, pelo menos, as seguintes informações:

- Uma descrição do que os usuários esperam quando o cenário se inicia;

- Uma descrição do fluxo normal de eventos no cenário;

- Uma descrição do que pode sair errado e como tratar este erro;

- Informações de outras atividades que podem estar acontecendo ao mesmo tempo;

- Uma descrição do estado do sistema, antes de iniciar o cenário e após seu término. 
Uma das técnicas mais conhecidas que utiliza cenários, é o casos de uso (PRESSMAN, 2005).

\section{Casos de uso (use cases)}

Casos de uso é uma técnica baseada em cenários para obtenção de requisitos e que se tornou uma característica fundamental da notação em UML, para descrever modelos de sistemas orientados a objetos (KRUCHTEN, 2003).

Para criar um caso de uso, o analista deve primeiro identificar os diferentes tipos de pessoas (ou dispositivos) envolvidos no sistema ou produto. Na verdade, esses atores, representam papéis que as pessoas (ou dispositivos) desempenham quando o sistema opera.

Em essência, um caso de uso conta uma história sobre como um usuário final (representando um dos diversos papéis) interage com o sistema sob um conjunto específico de circunstâncias. Esta história pode ser um texto narrativo, um resumo de tarefas ou interações, uma descrição baseada em um modelo ou uma representação gráfica. Independente da forma, um caso de uso retrata um sistema sob a ótica do usuário.

A Figura II.11 abaixo representa um caso de uso, em que cada ator é representado por uma figura de traços e cada classe de interação é definida por um nome na elipse. Um conjunto de casos de uso representa todas as possíveis interações que podem ser representadas nos requisitos de sistema.

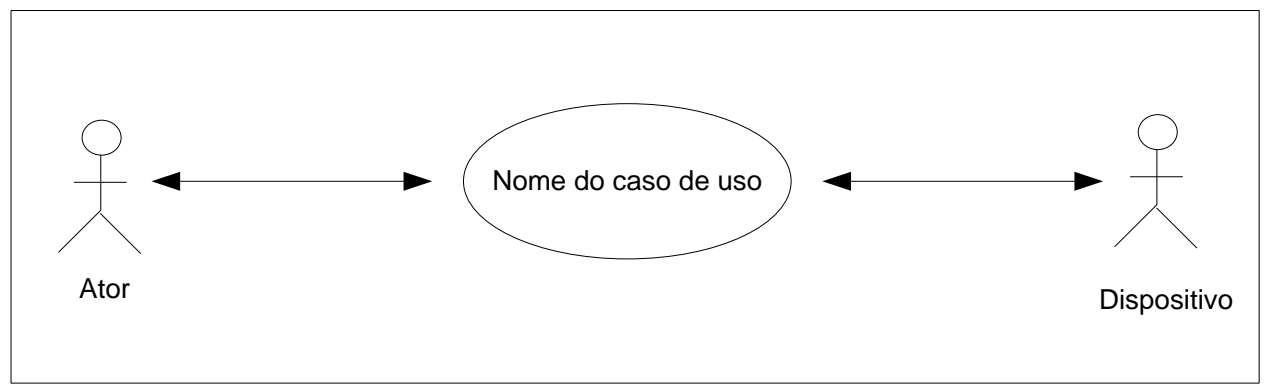

Figura II.11 - Caso de uso

Fonte: baseado em Leffingwell (2003)

A técnica de cenário e de casos de uso são efetivos para a elicitação de requisitos sob o ponto de vista da interação, em que cada tipo de interação pode ser representada como um caso de uso. Entretanto, em função do foco recair sobre a 
interação, esta técnica não é efetiva na descoberta de requisitos não funcionais e de negócio do domínio da aplicação.

\section{II.8.2 Entrevista}

Entrevistas formais ou informais fazem parte da maioria dos processos de engenharia de requisitos, em que são formuladas perguntas aos stakeholders sobre o sistema que utilizam e o futuro sistema que será desenvolvido. Os requisitos são derivados das respostas a estas questões. Há basicamente, segundo Kotonya e Sommerville (1998), dois tipos de entrevista:

- Entrevistas fechadas, nas quais os stakeholders respondem a um conjunto pré-definido de perguntas;

- Entrevistas abertas, em que não há agenda predefinida e discute-se, de modo aberto, o que os stakeholders esperam do sistema.

Em geral, só a entrevista aberta não funciona adequadamente como técnica de requisitos, uma vez que a maioria das entrevistas necessita de algumas questões para iniciar e mantê-la centrada no sistema a ser desenvolvido.

De modo geral, um bom entrevistador deve possuir duas características:

- Mente aberta para evitar ideias preconcebidas a respeito dos requisitos e estar disposto a ouvir os stakeholders;

- Dar ao entrevistado um ponto de partida para a entrevista, como por exemplo, uma pergunta, uma proposta de requisito, um sistema existente ou uma sugestão para um trabalho em conjunto em um protótipo. Em geral, os entrevistados expressam-se melhor a respeito de um contexto definido do que tema mais gerais.

\section{II.8.3 Storyboarding/Técnicas de Prototipação}

\section{Storyboarding}

Storyboarding, basicamente, corresponde a qualquer técnica que expressa o comportamento do sistema, projeto ou intenção de implementação pela perspectiva 
do usuário. No início, foi usada no cinema e cartoons e representa um esboço das personagens e da história.

Esta técnica permite acelerar de muitas maneiras o desenvolvimento conceitual de um sistema. Storyboards podem ser empregadas para compreender a visualização dos dados e usabilidade, para definir e ajudar a compreender as regras de negócio que serão implementadas, na definição de algoritmos, na demonstração de relatórios e outros tipos de saídas para uma revisão antecipada dos sistemas. Deste modo, esta técnica pode ser usada para virtualmente qualquer tipo de aplicação, na qual a participação dos stakeholders seja um fator-chave.

Segundo Leffingwell e Widrig (2003), storyboards podem ser categorizadas em três tipos:

- Passivo: são constituídos de quadros, fotos, esboços, etc. Neste caso são apresentadas ao usuário as regras do sistema em sua sequência, com uma explanação do tipo "Quando você faz isto, acontece isto";

- Ativo: corresponde a uma sequência de figuras que mostram uma descrição automatizada do modo como o sistema se comporta em um uso típico ou em um cenário operacional, por exemplo, em uma apresentação automática de slides;

- Interativo: permite ao usuário interagir com o sistema de um modo mais realístico, exigindo sua participação. Pode ser uma simulação dos possíveis cenários (protótipo não funcional), ou mesmo um protótipo funcional simplificado do sistema.

\section{Prototipação}

No desenvolvimento de software, um protótipo corresponde a uma versão do sistema que está disponível logo nas primeiras fases de um processo de desenvolvimento. A prototipação funcional, de acordo com Boar (1984), implementa parte dos requisitos do sistema por meio da construção de um protótipo que executa o comportamento real deste sistema (com a implementação de algoritmos e banco de dados), podendo, inclusive, valer-se de ferramentas, especialmente, construídas para a confecção desse tipo de protótipo (a prototipação funcional é utilizada no ciclo 3 desta pesquisa). 
Posteriormente, este protótipo é descartado, passando-se para o efetivo desenvolvimento do sistema pela sequência tradicional (análise, projeto, implementação e testes), de posse de um conjunto de requisitos bem refinados.

Conforme apresentado no item II.6.3, neste trabalho é empregado o termo de prototipação incremental ou evolucionária, como sinônimo do desenvolvimento incremental (o protótipo não é descartado, mas evolui para atingir os requisitos dos stakehoders).

Já a prototipação não funcional (usada no ciclo 2 desta pesquisa) obtém o comportamento dos stakeholders e do sistema por de interações e iterações com estes, por meio de um conjunto de interfaces gráficas simulando o comportamento real do sistema (sem a implementação de algoritmos e banco de dados).

Uma técnica de prototipação não funcional de fácil implementação e baixo custo é a prototipação em papel (RETTIG, 1994). A técnica (é utilizada no ciclo1 desta pesquisa) permite que os usuários executem atividades realísticas pela interação com uma versão em papel da interface do software que é manipulada por uma pessoa que faz o papel de um computador e que não explica como a interface deve funcionar, simulando as respostas do sistema.

Assim, é escolhido um usuário representativo do perfil ou do grupo de trabalho do processo de negócio que será estudado. São definidas as atividades típicas que representam o que os usuários devem realizar e construídas as versões da interface (esboços manuais ou impressões de telas), não sendo necessário desenvolver uma versão funcional destas interfaces.

Após a criação do protótipo em papel, são realizados os testes. O usuário é colocado para fazer as interações com o protótipo em papel, com um membro da equipe de desenvolvedores atuando como computador. Por meio da figura de um facilitador, o usuário é instruído a respeito das atividades a executar e suas reações e comentários são anotados por uma ou mais pessoas da equipe de software.

Deste modo, é possível descobrir rapidamente quais partes da interface (e do processo de negócio) funcionam bem ou não, podendo ser facilmente alteradas para corrigir as deficiências apontadas pelos usuários (SNYDER, 2003). 
O uso de storyboards interativos que, na realidade, são protótipos do sistema (funcionais ou não) permite uma série de vantagens (BOAR, 1984; LEFFINGWELL, 2003):

- Redução da distância entre os participantes do projeto: a comunicação é um problema fundamental no desenvolvimento. Mesmo quando uma pessoa sabe o que quer, sempre ocorrem mudanças quando estas necessidades transformam-se em requisitos;

- Aumento da participação e interesse dos atores: sistemas complexos que envolvem várias áreas de uma empresa requerem um compromisso, concordância e consenso entre vários atores para poderem operar corretamente;

- Sistemas por meio de exemplos: com o passar do tempo, pelo uso contínuo desta técnica, será produzido uma série de protótipos que poderão ser utilizados para demonstrar diferentes soluções aos usuários, permitindo estimular ideias, identificar estilos, mostrar o que é possível e permitir a explicação de suas necessidades em termos de modificações nos protótipos existentes;

- Permite medidas do tamanho das funcionalidades pela análise de pontos de função: a partir da identificação das funções do tipo dado e das funções do tipo transação e um esboço do modelo de dados do sistema é possível o cálculo dos pontos de função, desde o início do sistema e seu refinamento durante os diversos ciclos de desenvolvimento (GAVA, 2004);

- É um veículo para a validação de requisitos;

- Permite desde cedo o teste das interfaces.

Em termos de interface do usuário, segundo Pressman (2005), a prototipação é o único modo prático de se validar o que foi projetado.

Em um estudo de 39 projetos que utilizaram prototipação, Gorden e Bieman (1995) citam os seguintes benefícios:

- Redução no esforço de desenvolvimento;

- Um melhor atendimento das expectativas dos usuários;

- Melhora na qualidade do projeto; 
- Melhora na usabilidade dos sistemas;

- Melhora na facilidade de manutenção.

O uso de um protótipo aumenta o custo de um projeto em seus estágios iniciais de desenvolvimento, mas o custo final do projeto pode não ser alterado, uma vez que, com os requisitos melhores esclarecidos, os stakeholders demandam menos modificações no sistema.

\section{A ergonomia e a concepção informática na simulação e prototipação de sistemas}

Conforme refere Daniellou (2007), o paradoxo concepção (ver item I.1), quando se olha a atividade futura, é tratado na ergonomia de concepção como um meio de se prever o espaço das formas possíveis desta atividade (margens de manobra), avaliando em que medida as escolhas de concepção permitirão a implementação dos modos operatórios compatíveis com os critérios escolhidos (saúde, eficácia produtiva, desenvolvimento pessoal, trabalho coletivo, etc.)

Para agregar uma reflexão sobre a atividade futura é preciso preparar as condições de sua simulação, de modo que mesmo que não se possa observar a atividade futura, devem ser procuradas as situações existentes (situações de referência) cuja análise permitirá esclarecer os objetivos e condições da futura atividade (DANIELLOU, 2007).

No caso de uma modernização, a análise das situações de referência pode ser as encontradas no começo do projeto, tendo como objetivo na concepção de programas de computador iterativos conhecer os objetivos do trabalho, os procedimentos e identificar as informações e dados tratados pelos usuários, permitindo, também, identificar sua linguagem e sua terminologia. De acordo com Bastien e Scapin (2007), não se trata de compreender o trabalho para reproduzi-lo, de modo idêntico, mas transformá-lo, informatizando-o, de forma a otimizá-lo, tornando-o menos custoso ao usuário.

Após a avaliação das principais situações de referência, parte-se para determinar quais as fontes de variabilidade observadas nestas situações são capazes de aparecer no futuro sistema, cuja formalização da análise passa por uma lista de situações de ações características futuras prováveis (DANIELLOU, 2007). 
Cada situação de ação característica escolhida poderá ser definida pelas atividade a cumprir, pelos critérios de produção (qualidade, prazo, etc.), pelas categorias profissionais envolvidas e pelos fatores capazes de influenciar o estado interno das pessoas (por exemplo: trabalho noturno, exposição às intempéries, etc.).

Para o autor citado, o uso das ações características prováveis no futuro sistema é uma ferramenta essencial em ergonomia de concepção, na medida que permite estabelecer uma ponte entre as atividades analisadas e a abordagem da atividade futura (DANIELLOU, 2007).

Em especial, na concepção informática, as ferramentas de prototipagem permitem visualizar a aparência e o funcionamento de sistemas a um baixo custo, em ciclos de iteração rápida ao longo do processo, com a participação dos usuários antes das etapas finais de concepção. Estes protótipos sucessivos do software oferecem uma representação concreta para se comunicar com os usuários e os projetistas, constituindo, também, um guia para a especificação de sucessivas versões (BURKHARDT; SPERANDIO, 2007).

As soluções de concepção podem assumir diversas formas, iniciando em protótipo em papel, passando por etapas intermediárias como protótipos estáticos ou dinâmicos até o produto final.

Para esta implementação, uma série de condições devem ser estabelecidas (DANIELLOU, 2007):

- Condições de aceitabilidade social;

- Escolha adequada dos participantes da simulação;

- No uso de suportes materiais como protótipo, é importante a participação dos projetistas para comentar as informações que nela figuram;

- Desenvolver roteiros a partir das situações de ação características prováveis previamente levantadas.

De acordo com Bastien e Scapin (2007), a concepção em geral ocorre em três etapas. Inicialmente, é elaborado o modelo conceitual do programa, tratando-se de um modelo de alto nível do sistema, envolvendo basicamente as funcionalidades e a arquitetura de diálogo, podendo tomar a forma de um croqui, ilustrando as principais funcionalidades do sistema. 
Na segunda etapa, o modelo conceitual é detalhado e validado junto ao usuário, tratando-se de protótipos detalhados, em que são realizadas as caixas de diálogos, seus encadeamentos e a organização dos menus.

$\mathrm{Na}$ terceira etapa, o sistema será desenvolvido em detalhes, com base nos desenvolvimentos anteriores, cujas interfaces com o usuário poderão seguir guias estilísticos.

A avaliação das soluções propostas irá requerer a participação dos usuários (assim como nas etapas anteriores), em que um ou mais usuários participam da execução das atividades representativas, podendo ser uma exploração livre das interfaces, por meio das ações características.

Assim, as interfaces podem ser avaliadas em sistemas completamente desenvolvidos ou nas etapas anteriores, para avaliar as escolhas de concepção junto aos usuários.

Finalmente, a avaliação deverá continuar em campo, pois podem ocorrer dificuldades em condições de uso que não poderiam ter sido recriadas nos testes realizados na fase de concepção (BASTIEN; SCAPIN, 2007).

\section{II.8.4 Etnografia}

Etnografia é uma técnica de observação que pode ser utilizada para compreender requisitos sociais e organizacionais. Um analista fica imerso no ambiente de trabalho no qual o sistema será utilizado, observando o trabalho do dia a dia e tomando nota das atividades nas quais os usuários estão envolvidos.

O valor desta técnica corresponde em ajudar os analistas a descobrir requisitos implícitos que refletem o processo real de trabalho, uma vez que os indivíduos do grupo desenvolvem melhorias em seu modo normal de trabalho, utilizando ferramentas e documentos de um modo intuitivo, muitas vezes, sem perceber como estão procedendo para tal.

Quando as atividades tornam-se rotineiras, as pessoas envolvidas com esse trabalho podem passar a não ter consciência de suas atividades, torna-se muito difícil para elas articular o modo como o trabalho é executado. 
Esta técnica é, particularmente, importante em duas situações (VILLER e SOMMERVILLE, 2000; MARTIN e SOMMERVILLE, 2004):

- Requisitos que são derivados do modo como os usuários realmente trabalham (atividades) do que o trabalho prescrito;

- Requisitos que são derivados da cooperação e consciência das atividades de outros usuários (awareness).

Os autores citados acima sugerem também que esta técnica pode ser analisada a partir de três pontos de vista:

- Ajuste do local de trabalho: descreve o contexto e a localização física dos objetos de trabalho e como os usuários utilizam-nos para executar suas atividades;

- Perspectivas sociais e organizacionais: mostram a experiência do dia a dia do trabalho sob o ponto de vista de diferentes usuários (como o trabalho é realizado, como são tratadas as exceções, etc.). Cada usuário vê o trabalho sob diferentes perspectivas, e este ponto de vista procura organizar e integrar todos estas perspectivas;

- Perspectiva do fluxo de trabalho: apresenta o trabalho com base em uma série de atividades, com as informações fluindo de uma atividade para outra.

A etnografia pode ser combinada com a prototipação, de modo que, pelas suas características, menos ciclos de prototipação serão necessários.

Apesar de revelar detalhes críticos do processo que, normalmente, são perdidos pelas outras técnicas de descoberta de requisitos, pelo fato de se basear na visão dos usuários finais, não é apropriada para a descoberta de requisitos de domínio, não permitindo identificar facilmente novas características que devem ser inseridas no sistema.

Pela sua própria natureza de aplicação, esta técnica apresenta um tempo longo para obtenção de resultados, assim como alto custo.

Do mesmo modo que as demais técnicas descritas, etnografia deve ser complementada com outras técnicas visando a obter os requisitos do sistema como um todo. 


\section{II.8.5 Considerações sobre técnicas utilizadas na descoberta de requisitos}

Conforme descrito no capítulo IV, a parte prática deste trabalho é baseada em três ciclos de uma pesquisa-ação, de modo que em cada um destes ciclos são utilizadas algumas das técnicas descritas nesta seção.

No primeiro ciclo, são empregadas as técnicas de entrevista, cenário e de prototipação em papel.

No segundo, é utilizada a técnica de prototipação não funcional descrita no item II.8.3, obtendo-se o comportamento dos stakeholders e do sistema pelas interações e iterações com estes, por meio do modelo de contexto, de processo e de fluxo de trabalho, simulando o comportamento real do sistema (sem a implementação de algoritmos e banco de dados), tendo como base o fluxograma do processo em sessões de ACT (item IV.5).

No terceiro ciclo, é empregada a técnica de prototipação funcional evolutiva, em que, uma vez implementada a primeira versão do software após o término do ciclo 2, o mesmo é colocado em uso no ambiente real e, posteriormente, são realizadas novas sessões de ACT para refinar esta versão funcional, conforme descrito com mais detalhes no item IV.6. 


\section{METODOLOGIA DE PESQUISA}

Este capítulo apresenta, fundamenta e detalha a metodologia de pesquisa utilizada, baseada na adoção do método de pesquisa-ação. Mostra, também, o delineamento do projeto de pesquisa, considerando as decisões estratégicas tomadas para seu desenvolvimento, de modo a atender às questões endereçadas em I.2.

\section{III.1 INTRODUÇÃO}

O papel da metodologia consiste em avaliar as condições de uso das técnicas e métodos utilizados na pesquisa, orientando o investigador na estrutura de sua pesquisa (Com que raciocínio trabalhar? Qual o papel das proposições? Como chegar a uma certeza maior na elaboração dos resultados e interpretações?) (THIOLLENT, 2004).

Conforme citam Nakano e Fleury (1996), as abordagens de pesquisa orientadas para a Engenharia de Produção são de cunho quantitativo quando se referem a temas técnicos das engenharias ou, de cunho qualitativo, quando o tema está associado às ciências sociais.

Segundo Bryman (1989), a pesquisa qualitativa está na ênfase dada ao objeto em estudo, seja indivíduo, organização ou processo, sendo voltada mais à compreensão dos fatos e a pesquisa quantitativa é impulsionada por um conjunto de questões previamente definidas (extraídas da teoria e literatura), sendo mais voltada à mensuração do fenômeno.

Nakano e Fleury (1996) realizaram um estudo a respeito dos principais métodos de pesquisa aplicados à Engenharia de Produção, mostrando que apesar da aparente simplicidade da classificação, nem sempre parece possível uma distinção tão clara. $\mathrm{Na}$ prática da pesquisa, encontram-se diversas situações em que há superposição de conceitos. Os principais métodos de pesquisa na Engenharia de Produção são caracterizados nos dados do Quadro III.1, e os três métodos mais comuns de pesquisa qualitativa são: o estudo de caso, a pesquisa-ação, e a pesquisa participante. 
Quadro III.1 - Principais métodos de pesquisa em Engenharia de Produção

\begin{tabular}{|l|l|l|l|}
\hline $\begin{array}{l}\text { Métodos de } \\
\text { pesquisa }\end{array}$ & \multicolumn{1}{|c|}{ Descrição } & $\begin{array}{c}\text { Abordagem } \\
\text { principal }\end{array}$ & Instrumentos \\
\hline $\begin{array}{l}\text { Estudo de } \\
\text { caso }\end{array}$ & $\begin{array}{l}\text { Documenta e analisa a atividades de uma } \\
\text { organização ou de um pequeno grupo dentro } \\
\text { dela. A unidade de análise é a organização } \\
\text { como um todo ou um departamento ou área. }\end{array}$ & Qualitativa & $\begin{array}{l}\text { Entrevistas e } \\
\text { outras fontes }\end{array}$ \\
\hline Survey & $\begin{array}{l}\text { Coleta de dados por entrevista ou questionário. } \\
\text { A análise dos dados exige tratamento } \\
\text { estatístico. }\end{array}$ & Quantitativa & Questionários \\
\hline Experimental & $\begin{array}{l}\text { Teste das hipóteses de um experimento } \\
\text { Controlado. }\end{array}$ & Quantitativa & Experimentos \\
\hline $\begin{array}{l}\text { Pesquisa } \\
\text { participante }\end{array}$ & $\begin{array}{l}\text { Baseada em metodologia de observação } \\
\text { participante. }\end{array}$ & Qualitativa & $\begin{array}{l}\text { Observação } \\
\text { direta }\end{array}$ \\
\hline Pesquisa-ação & $\begin{array}{l}\text { É realizada juntamente com uma ação ou } \\
\text { resolução de um problema, onde os } \\
\text { pesquisadores desempenham um papel ativo } \\
\text { nessa resolução. }\end{array}$ & Qualitativa & $\begin{array}{l}\text { Observação e } \\
\text { participação } \\
\text { direta }\end{array}$ \\
\hline
\end{tabular}

Fonte: Nakano e Flaury (1996)

\section{III.2 ESTRATÉGIA METODOLÓGICA: PESQUISA-AÇÃO}

\section{III.2.1 Conceituação geral da pesquisa-ação}

Para Yin (2003), um projeto de pesquisa é a sequência lógica que conecta os dados empíricos às questões de pesquisa iniciais do estudo e, em última análise, suas conclusões. $\mathrm{O}$ autor relaciona cinco componentes do projeto de pesquisa:

- A questão do estudo, ou seja, o núcleo da pesquisa. Envolve as perguntas que deverão ser respondidas depois de concluído o trabalho, em que surgirão as conclusões sobre a análise realizada;

- As proposições, que representam afirmações teóricas criadas inicialmente no trabalho de pesquisa, a fim de agir como um guia na análise do que está sendo estudado;

- As unidades de análise devem guardar direta correlação com as perguntas básicas da pesquisa, já que são elas que indicam o objetivo do trabalho;

- A lógica que une os dados às proposições. $O$ autor sugere a estruturação dos dados em um padrão de adequação que facilite a análise pontual e contribua com a visão global do fenômeno; 
- Os critérios para se interpretar as descobertas. Segundo o autor não há maneira adequada para o estabelecimento dos critérios para a interpretação das descobertas, pois envolve a subjetividade para a análise de cada caso.

Thiollent (2004) refere que a pesquisa participante e a pesquisa-ação são muito semelhantes. Toda pesquisa-ação é do tipo participativo, em que a participação das pessoas implicadas nos problemas investigados é absolutamente necessária. A principal diferença entre ambas reside no fato de que a pesquisa participativa não inclui necessariamente uma ação planejada.

Segundo o autor, pesquisa-ação corresponde a um tipo de pesquisa social com base empírica que é concebida e realizada em estreita associação com uma ação ou com a resolução de um problema coletivo e no qual os pesquisadores estão envolvidos de modo cooperativo ou participativo. Deve seguir, pelo menos, quatro grandes fases:

- A fase exploratória: onde o pesquisador ou os pesquisadores investigam a situação atual, detectam os principais problemas, atores e possíveis ações de melhoria;

- A fase de pesquisa aprofundada: na qual a situação é investigada com mais detalhes por meio dos instrumentos de coleta de dados e de referências documentais e experiências similares;

- A fase de ação: apresenta os resultados das pesquisas, define os objetivos alcançáveis e implementa as ações e/ou plano de ações apropriados;

- A fase de avaliação: tem por objetivo observar, redirecionar o que realmente acontece e resgatar o conhecimento produzido no decorrer do processo.

Esta divisão tem um propósito didático para facilitar a compreensão das principais atividades envolvidas neste tipo de pesquisa. Na prática, as fases alternam-se e, muitas vezes, são concorrentes e recorrentes, sobretudo as três últimas.

A caracterização da pesquisa-ação é complementada pelo mesmo autor, quando afirma que esta envolve:

- Ampla e explícita interação entre pesquisadores e pessoas implicadas na situação investigada; 
- Ordenação de prioridade dos problemas a serem pesquisados e das soluções a serem encaminhadas sob forma de ação concreta;

- A resolução ou, pelo menos, esclarecimento dos problemas da situação observada;

- Um acoplamento das decisões, das ações e de toda a atividade intencional dos atores da situação;

- Aumento do conhecimento dos pesquisadores e dos níveis de consciência das pessoas e grupos envolvidos.

Gummesson (2000) e Coughlan e Coghlan (2002) expandem este conceito agregando uma série de características que serão relacionadas com a presente pesquisa em III.3:

- O pesquisador executa uma ação (não é mero observador);

- A pesquisa-ação envolve dois objetivos: solucionar um problema e contribuir para a ciência, nos quais além do lado empírico, nunca deixa de colocar as questões relativas aos quadros de referência teórica, sem os quais a pesquisa empírica não faria sentido;

- A pesquisa-ação é interativa. Há uma ampla e explícita interação entre pesquisador e pessoas implicadas na situação investigada;

- Desta interação, resulta a ordem da prioridade dos problemas a serem pesquisados e das soluções a serem encaminhadas sob forma de ação concreta;

- A pesquisa-ação objetiva desenvolver um entendimento completo do problema. O pesquisador deve alternar entre o perfil formal técnico e o perfil informal, focado nas relações interpessoais;

- O planejamento de uma pesquisa-ação é muito flexível, sendo diferente de outros tipos de pesquisa, pois não é composto de uma série de fases rigidamente ordenadas e limitadas aos aspectos acadêmicos e burocráticos da maioria das pesquisas convencionais. Na pesquisa-ação, o planejamento das ações é realizado pelos atores sociais, podendo ser o pesquisador um animador ou um participante ativo; 
- É fundamentalmente relacionada à mudança, aplicável na compreensão, planejamento e implementação de mudanças em empresas de negócios e outras organizações;

- A pesquisa-ação pode incluir todos os tipos de coleta de dados (técnicas quantitativas e qualitativas);

- Requer um pré-entendimento do ambiente organizacional, das condições da estrutura e dinâmica das operações, das condições de negócio, dos processos produtivos, do ambiente de trabalho, entre outros;

- Deve ser conduzida em tempo real, embora em pesquisa-ação retrospectiva também seja aceitável. Deve ser um estudo de caso "ao vivo" escrito, conforme se desenrola;

- Seu paradigma exige critérios de qualidade específicos. Pesquisa-ação não deve ser avaliada pelos critérios positivistas (como no caso de simulações matemáticas, pesquisas experimentais, surveys, etc.);

- Exige uma compreensão dos princípios éticos da organização pesquisada. O pesquisador deve compreender e respeitar valores e normas da organização envolvida na pesquisa.

Estas características devem ser consideradas desde o momento da concepção da pesquisa, de modo que a pesquisa-ação compreenda três fases principais: uma preliminar, um ciclo de condução e uma metafase (COUGHLAN; COGHLAN, 2002).

\section{III.2.2 Ciclos da pesquisa-ação}

Como pode ser visto na Figura III.1, o ciclo de condução da pesquisa compreende a seis passos principais, e a metafase está presente em cada um destes seis passos. Durante a apresentação dos resultados, cada um dos passos será contextualizado dentro das respectivas fases.

A primeira fase (fase preliminar) corresponde a um entendimento sobre o contexto no qual a pesquisa será realizada, bem como o propósito da condução do trabalho. Essa fase envolve ainda o estabelecimento das justificativas para a ação requerida, além das justificativas para a pesquisa. 
A segunda fase é composta por seis passos e inicia-se com a coleta de dados (diagnóstico e/ou dados coletados quando a pesquisa encontra-se em regime), feedback dos dados (para os envolvidos com a pesquisa), análise desses dados (com os envolvidos na pesquisa), planejamento da ação (definição da intervenção a ser feita), implementação da ação (colocar em prática o que foi planejado) e avaliação (verificar se os resultados da implementação surtiram ou não os efeitos desejados), retornando para uma nova coleta de dados (se necessário), encerrando o ciclo (primeira iteração).

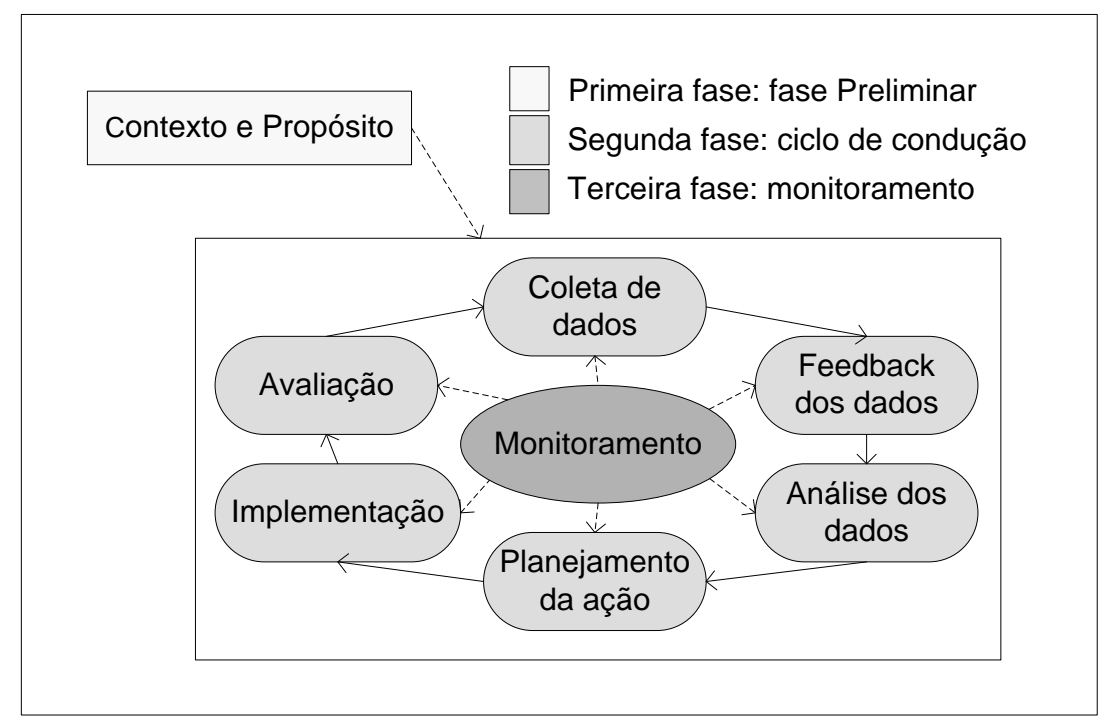

Figura III.1 - Ciclos da Pesquisa-ação

Fonte: baseado em Coughlan e Coghlan (2002)

O dados do Quadro III.2 mostram os principais meios utilizados para a execução de cada um destes ciclos, assim como uma breve descrição dos mesmos.

Os ciclos são constantes e sequenciais, sendo contínuos pelo período em que forem necessários, com a possibilidade da existência de um ciclo mais abrangente (para a pesquisa como um todo) e ciclos menores para as partes específicas do trabalho.

A terceira fase (monitoramento) compreende uma verificação de cada um dos seis passos anteriores, de modo a verificar qual é o aprendizado gerado na condução da pesquisa-ação, sendo seu monitoramento executado de diferentes modos, à medida que a pesquisa avança por meio dos passos da segunda fase.

Assim, do lado organizacional, pode ocorrer a criação de um grupo diretivo durante a execução da pesquisa-ação, com maior interesse em seus resultados práticos. 
Quadro III.2 - Síntese dos passos e ações utilizadas

\begin{tabular}{|c|c|c|}
\hline Passo & Descrição & Meios \\
\hline Coleta de dados & $\begin{array}{l}\text { Dados são gerados por meio do } \\
\text { envolvimento com o processo } \\
\text { organizacional }\end{array}$ & $\begin{array}{l}\text { Dados qualitativos: observação } \\
\text { direta, discussões, entrevistas } \\
\text { Dados quantitativos: relatórios, } \\
\text { registros operacionais }\end{array}$ \\
\hline Feedback dos dados & $\begin{array}{l}\text { Os dados são retornados para a } \\
\text { organização visando a disponibilizá-los } \\
\text { para análise }\end{array}$ & $\begin{array}{l}\text { Relatórios elaborados pelo } \\
\text { pesquisador, reuniões de } \\
\text { feedback }\end{array}$ \\
\hline Análise dos dados & $\begin{array}{l}\text { Análise conjunta realizada pelo } \\
\text { pesquisador e membros envolvidos } \\
\text { (por exemplo, membros dos times de } \\
\text { trabalho) }\end{array}$ & $\begin{array}{l}\text { Ferramentas e critérios de } \\
\text { análise que necessitam estar } \\
\text { relacionados aos propósitos da } \\
\text { pesquisa e da intervenção }\end{array}$ \\
\hline $\begin{array}{l}\text { Planejamento da } \\
\text { ação }\end{array}$ & $\begin{array}{l}\text { Atividade conjunta que estabelece o } \\
\text { que vai ser feito e com que prazo }\end{array}$ & $\begin{array}{l}\text { Responder questões do tipo: o } \\
\text { que necessita ser alterado e em } \\
\text { que parte da organização? } \\
\text { Qual o apoio necessário? } \\
\text { Como o comprometimento } \\
\text { pode ser obtido? Como superar } \\
\text { as resistências? }\end{array}$ \\
\hline $\begin{array}{l}\text { Implementação da } \\
\text { ação }\end{array}$ & $\begin{array}{l}\text { A ação estabelecida é então } \\
\text { implementada visando a promover as } \\
\text { mudanças planejadas }\end{array}$ & $\begin{array}{l}\text { Ferramentas estabelecidas } \\
\text { para executar a implantação } \\
\text { em colaboração com os } \\
\text { envolvidos }\end{array}$ \\
\hline Avaliação & $\begin{array}{l}\text { Reflexão dos resultados esperados ou } \\
\text { não decorrentes da implementação da } \\
\text { ação }\end{array}$ & $\begin{array}{l}\text { Revisão do processo visando a } \\
\text { avaliar os resultados, incluindo } \\
\text { melhorias para o ciclo seguinte }\end{array}$ \\
\hline
\end{tabular}

Fonte: Miguel (2005)

Pelo lado do pesquisador, o mesmo deve estar interessado não somente na operação do projeto, mas também no monitoramento do processo de aprendizagem, que levará à contribuição teórica deste tipo de desenvolvimento empírico (COUGHLAN; COGHLAN, 2002; MIGUEL, 2005).

\section{III.3 CARACTERIZAÇÃO DA CONDUÇÃO DA PESQUISA-AÇÃO}

Esta pesquisa pretende oferecer uma contribuição de cunho empírico, associada à contribuição teórica no sentido da geração de conhecimento dentro do domínio do problema estudado.

Para elaborar o plano de pesquisa para este trabalho, primeiramente, foi necessário definir qual método de pesquisa seria aplicado. Para isso, algumas características do contexto da pesquisa foram consideradas, na qual em III.2.1 foram detalhadas as principais características que uma pesquisa-ação deve conter, conforme Coughlan e 
Coghlan (2002) e Gummesson (2000). A seguir, apresenta-se um paralelo entre essas características e a presente pesquisa:

- O pesquisador executa uma ação: pois é o principal responsável pela condução do projeto na empresa, com participação ativa nos processos de condução do mapeamento, definição e estabelecimento do sistema informatizado utilizado nesta pesquisa;

- A pesquisa-ação soluciona um problema e contribui para a ciência: o trabalho envolve a solução de um problema de ordem prática que corresponde ao desenvolvimento de um software para dar suporte ao processo de atendimento dos serviços correntes da empresa PesqTec. Paralelamente, sua contribuição científica está ligada ao processo para especificação dos requisitos de software com foco de aplicação no trabalho cooperativo em sistemas de informação que apresentam coordenação distribuída nas ações dos usuários, e a comunicação entre eles ocorre preponderantemente de modo indireto por meio dos dados inseridos durante o uso do software;

- A pesquisa-ação é interativa e iterativa: a pesquisa desenvolvida é interativa pelo lado dos grupos de trabalho, bem como iterativa pelo lado da evolução do sistema implantado. Pelo lado dos grupos de trabalho, a pesquisa desenvolvida obteve a contribuição e interação dos profissionais das áreas da organização diretamente envolvidas no processo de desenvolvimento e manutenção de sistemas. Assim como de diversos grupos de stakeholders compondo grupos multidisciplinares de trabalho, por meio de ações planejadas. Houve a utilização do saber dos pesquisadores e especialistas e das experiências concretas dos participantes, para solução do problema, assim como para captação dos dados compilados para a pesquisa. Pelo lado da implantação do sistema, o uso da técnica de prototipação em todas suas fases tornou a participação dos todos os envolvidos do sistema também iterativa;

- Tem o objetivo de desenvolver um entendimento completo do problema: Em termos empíricos, este aspecto foi inerente à própria natureza do trabalho, que correspondeu à informatização de um dos principais processos de negócio da empresa (ressalta-se o papel do trabalho cooperativo nesta 
situação), tornando-se necessária a devida compreensão do modo como este processo estava ligado aos demais, pelas suas interfaces, assim como a compreensão de outros processos de negócio da empresa. Proporcionou, também, sob o ponto de vista teórico, um estudo amplo da literatura, que somente foi possível pela condução desta pesquisa-ação. $O$ entendimento completo do problema envolveu a compreensão do contexto no qual a pesquisa foi conduzida e a ligação entre teórico e empírico;

- É fundamentalmente relacionada à mudança: a pesquisa foi motivada diretamente pela necessidade da organização PesqTec automatizar a forma de atendimento aos clientes em serviços correntes da empresa, passando de um atendimento manual e desnormalizado (cada área com seu processo de atendimento), para um único processo da empresa; desta forma, ampliando a preocupação com melhoria de processos e produtos;

- A pesquisa-ação pode incluir todos os tipos de coleta de dados: foram adotadas, tanto técnicas qualitativas como técnicas quantitativas para coleta e análise dos dados. Os métodos de coleta de dados usados foram efetuados por meio de e-mails, investigação de documentos, observações, dados de palestras, questionários, entrevistas e reuniões com analistas, técnicos, especialistas, gerentes pesquisadores, usuários finais, técnicos e chefes de laboratório. Também foram realizadas apresentações internas para os envolvidos diretamente com a pesquisa e às gerências e direção da empresa. Fez-se uso de gravações de áudio das sessões de análise coletiva do trabalho, assim como gravações em vídeo de algumas dessas sessões e de registros escritos do andamento do projeto;

- Requer um pré-entendimento do ambiente organizacional: Durante a fase preliminar para a condução da pesquisa-ação, foram levantados os detalhes do ambiente, nos quais o processo proposto nesta pesquisa seria aplicado, com o delineamento do processo atual de atendimento aos serviços correntes, além de um estudo sob o contexto organizacional da empresa. A experiência do pesquisador em outros projetos equivalentes, também, apresentou-se como um fator diferenciador na condução da pesquisa-ação; 
- Deve ser conduzida em tempo real: a pesquisa-ação deste trabalho iniciou-se em fevereiro de 2006 e seu término em janeiro de 2008, havendo o cuidado de capturar os dados e eventos relevantes para a redação deste trabalho;

- Requer critérios próprios de qualidade para sua avaliação. Foram desenvolvidos critérios específicos para avaliação desta pesquisa (sobretudo no que se refere à medição da intensidade do trabalho cooperativo apresentado pelos usuários com o uso do sistema), embora se tenha consultado a literatura como referência. Utilizou-se de apresentações para a direção geral da empresa, para o departamento da qualidade e demais partes interessadas na avaliação do andamento do trabalho, além de apresentações no meio acadêmico de três artigos nacionais: Gava et al. (2004), Gava et al. (2007) e Gonçalves et al. (2005) e dois internacionais: Gava et al. (2008) e Gonçalves et al. (2008).

- Exige uma compreensão dos princípios éticos da organização pesquisada. O pesquisador, na posição de colaborador da empresa PesqTec, teve e tem a preocupação e obrigação de respeitar as exigências de ética e confidencialidade da instituição e dos participantes das sessões de ACT no que concerne aos resultados desta pesquisa.

Assim, pelo que foi exposto neste item, conclui-se que as características desejáveis para a condução da pesquisa-ação foram estabelecidas nesta pesquisa.

\section{III.4 DELINEAMENTO DO PROJETO DE PESQUISA}

Visando a atender às questões e objetivos colocados em I.2, esta pesquisa utiliza o método de pesquisa-ação (ver item III.2.2) por meio dos ciclos de condução (Figura III.2) e do processo proposto (ver capítulo IV), com o seguinte planejamento:

1. Revisão bibliográfica metodológica e aplicada (referente aos conceitos de trabalho cooperativo, Engenharia de Requisitos e temas relacionados);

2. Contexto e propósitos: elaboração do contexto específico da PA; 
3. Condução do primeiro ciclo da pesquisa-ação: processo para especificação de requisitos de software com foco na identificação das características individuais do trabalho cooperativo e das características de domínio;

4. Condução do segundo ciclo da pesquisa-ação: processo para especificação de requisitos de software com foco na identificação e simulação das características cooperativas do trabalho;

5. Condução do terceiro ciclo da pesquisa-ação: processo para especificação de requisitos de software com foco no refinamento das características do trabalho cooperativo (em uso real);

6. Elaboração da tese com os resultados da pesquisa.

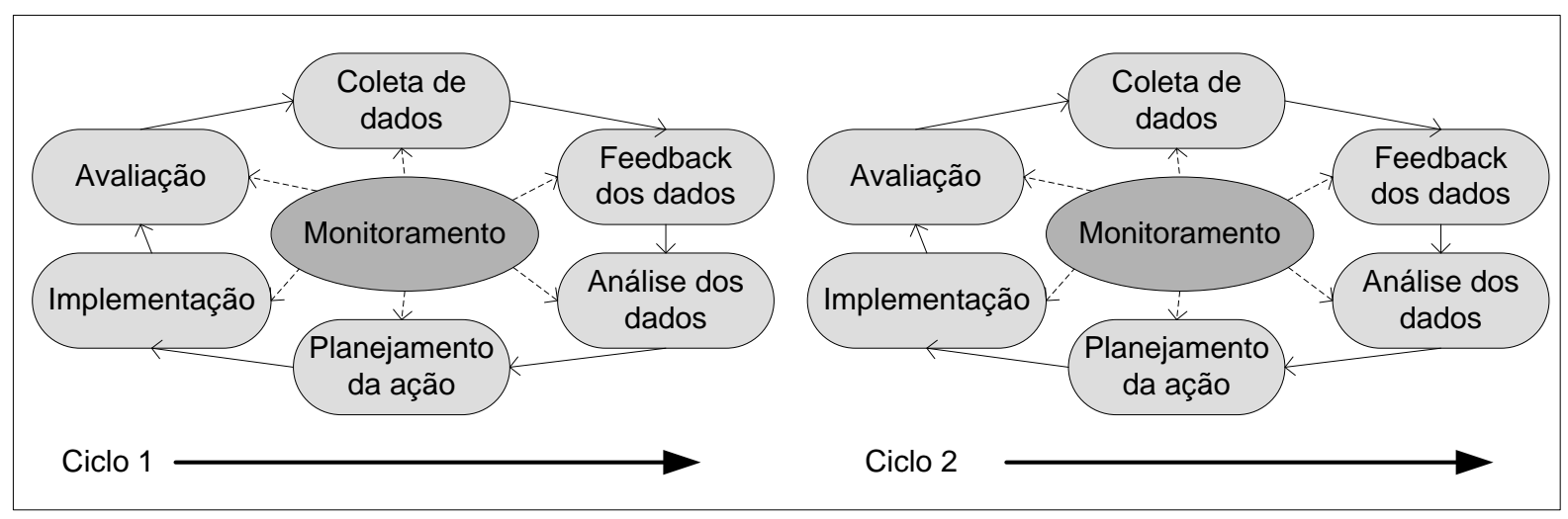

Figura III.2 - Iteração dos ciclos da Pesquisa-ação

Thiollent (2004) destaca que é importante já no início da pesquisa (fase exploratória), identificar os principais atores envolvidos na pesquisa. Para este projeto, os atores são:

- Autor: responsável pelo levantamento de requisitos e implementação do software responsável pela informatização do sistema de informação, alvo desta pesquisa;

- Analistas de negócio: técnicos das áreas usuárias do futuro software com profundo conhecimento das regras de negócio a serem informatizadas e envolvidos na contextualização do projeto dentro da estratégia da organização e na apresentação dos principais direcionadores do trabalho em um nível macro durante o desenvolvimento do primeiro ciclo de condução (ver item V.2) ; 
- Diretoria executiva: patrocinadora do projeto, auxiliando com os custos, apoio gerencial e oferecendo seu conhecimento e experiência sobre o assunto e cultura da corporação (ver item V.1);

- Equipe de supervisores de laboratório: responsáveis por apresentar detalhes operacionais do SI e da futura solução informatizada, durante o desenvolvimento do segundo ciclo de condução (ver capítulo VI);

- Usuários dos laboratórios: responsáveis por apresentar detalhes operacionais da solução informatizada em condições reais (supervisores dos laboratórios, técnicos, secretárias e gerentes de centro de custo), durante o desenvolvimento do terceiro ciclo de condução (ver capítulo VII);

- Usuários gerenciais: responsáveis por apresentar detalhes gerenciais do sistema (responsáveis pela área de qualidade, assessores da diretoria executiva, etc.) durante o desenvolvimento do segundo ciclo de condução (ver capítulo VI).

No dados do Quadro III.3 abaixo encontra-se o delineamento geral da pesquisa.

\section{Quadro III.3 - Delineamento da pesquisa}

\begin{tabular}{|c|c|}
\hline Aspecto analisado & Conceitos e práticas / categorização \\
\hline Abordagem metodológica & Pesquisa-ação em três ciclos (planejado) \\
\hline Propósitos & $\begin{array}{l}\text { Definição de um processo para obtenção dos requisitos de software } \\
\text { orientado ao trabalho cooperativo em SI com coordenação distribuída }\end{array}$ \\
\hline Objeto de análise & Empresa nacional de tecnologia \\
\hline Unidade de análise & $\begin{array}{l}\text { Processo de atendimento de serviços correntes - enfoque no trabalho } \\
\text { cooperativo }\end{array}$ \\
\hline $\begin{array}{l}\text { Referencial teórico para o } \\
\text { processo de identificação } \\
\text { das características } \\
\text { individuais do trabalho } \\
\text { cooperativo }\end{array}$ & $\begin{array}{l}\text { Técnicas de entrevista, prototipação em papel, técnicas da Engenharia } \\
\text { de Requisitos. }\end{array}$ \\
\hline $\begin{array}{l}\text { Referencial teórico sobre a } \\
\text { simulação e identificação } \\
\text { das características } \\
\text { cooperativas do trabalho }\end{array}$ & $\begin{array}{l}\text { Técnicas de entrevista, técnicas da Engenharia de Requisitos, análise } \\
\text { coletiva do trabalho }\end{array}$ \\
\hline $\begin{array}{l}\text { Referencial teórico sobre o } \\
\text { refinamento da } \\
\text { identificação das } \\
\text { características do trabalho } \\
\text { cooperativo }\end{array}$ & $\begin{array}{l}\text { Técnicas de entrevista, técnicas de usabilidade, análise coletiva do } \\
\text { trabalho, teoria da mente coletiva e awareness. }\end{array}$ \\
\hline Tipologia dos dados & Basicamente qualitativos \\
\hline Coleta dos dados & $\begin{array}{l}\text { Investigação documental, e-mails, observações, dados de palestras, } \\
\text { questionários, entrevistas e reuniões com analistas, técnicos, } \\
\text { especialistas, gerentes pesquisadores, usuários finais, técnicos e } \\
\text { chefes de laboratório e anotações em caderno de pesquisa e } \\
\text { gravações de áudio. }\end{array}$ \\
\hline
\end{tabular}




\begin{tabular}{|l|l|}
\hline \multicolumn{1}{|c|}{ Aspecto analisado } & \multicolumn{1}{c|}{ Conceitos e práticas / categorização } \\
\hline Análise dos dados & $\begin{array}{l}\text { Interpretação de dados qualitativos, critérios próprios para avaliação } \\
\text { de dados de questionários (definido na parte prática - terceiro ciclo) e } \\
\text { critérios para avaliação das sessões de ACT em função do ciclo da } \\
\text { pesquisa-ação. }\end{array}$ \\
\hline $\begin{array}{l}\text { Qualidade e validade da } \\
\text { pesquisa }\end{array}$ & $\begin{array}{l}\text { Apresentações internas aos grupos de interessados ( stakeholders), } \\
\text { externas (públicas) em seminários e congressos e diferenciação entre } \\
\text { a pesquisa-ação e um projeto de consultoria }\end{array}$ \\
\hline
\end{tabular}

\section{Fonte: elaborado pelo autor}

Em termos do planejamento para a condução da pesquisa em campo, os ciclos descritos por Coughlan e Coghlan (2002) serão implementados como uma adaptação do modelo espiral (Figura III.3).

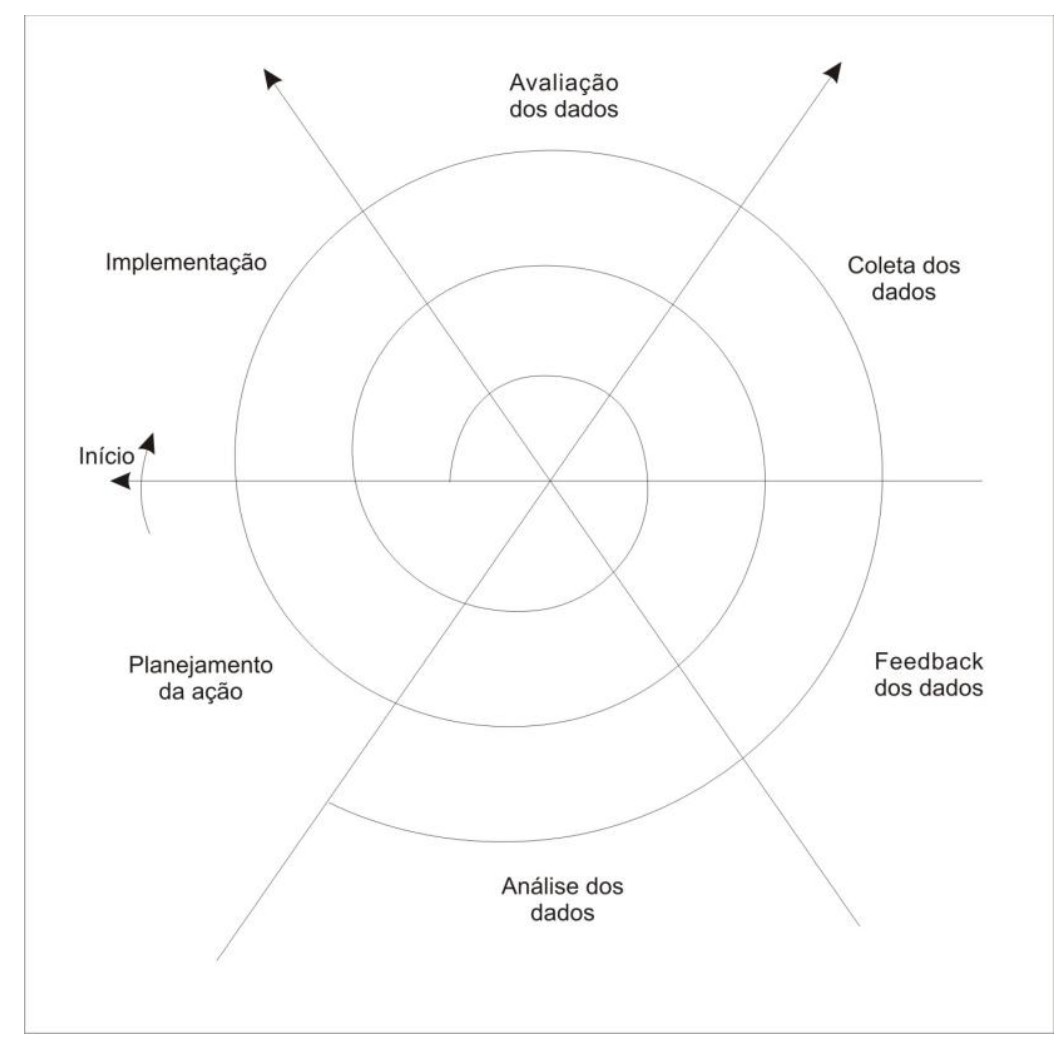

Figura III.3 - Espiral dos ciclos da Pesquisa-ação

Fonte: elaborado pelo autor

O detalhamento dos ciclos da PA em função do processo proposto está mais bem explorado no item IV.7, Quadro IV.8 (quadro metodológico).

Apresentadas as fases, os atores e o enquadramento do ciclo padrão da PA com a realidade que será executada em campo, é possível detalhar melhor cada etapa do plano: 


\section{III.4.1 Revisão bibliográfica metodológica e aplicada}

Levantamento e revisão de livros, artigos e demais documentos sobre metodologias de pesquisa, aspectos do trabalho coletivo, em particular, o trabalho cooperativo, engenharia de software dentro da subárea denominada Engenharia de Requisitos e a relação entre as características do trabalho cooperativo de sistemas de informação e sua informatização por meio de softwares transacionais pelo uso dos conceitos de análise coletiva do trabalho, da teoria da mente coletiva, modelos $3 \mathrm{Cs}$ e percepção.

\section{III.4.2 Contexto e propósitos}

Visando a um melhor entendimento do contexto empresarial no qual está inserida a pesquisa-ação aplicada neste trabalho, é feita uma breve descrição da empresa e do sistema de informação tratado na pesquisa-ação. Posteriormente, no desenvolvimento efetivo do trabalho que se dá com a parte da pesquisa de campo, as informações deste item são mais bem detalhadas no capítulo V.1.1 deste trabalho.

A empresa onde é aplicada a teoria desenvolvida nesta pesquisa, corresponde a uma grande empresa nacional que desenvolve tecnologia, possuindo em torno de 1.500 colaboradores.

Vários tipos de atendimento ao público são prestados, desde serviços tecnológicos especializados (sob medida para um dado problema), até serviços correntes (que são considerados rotineiros dentro dos laboratórios).

O atendimento a uma solicitação de serviços correntes pode ser realizado por meio de um único laboratório; neste caso, sendo constituído por um ou mais serviços oferecidos por este laboratório, ou então, por uma solicitação constituída por serviços envolvendo o trabalho cooperativo de múltiplos laboratórios da empresa PesqTec.

O processo de atendimento é realizado de modo independente por cada um destes laboratórios, sem padronização e sem conexão com o software corporativo (ERP) desta empresa. Em muitos deles é feito por meio de arquivos em papel, tornado o processo fragmentado e de difícil controle, implicando uma subutilização dos 
recursos laboratoriais (humanos e materiais), além de tornar as informações ligadas a este processo de difícil recuperação e consequente agregação.

Deste modo, face à realidade apresentada, a diretoria da empresa em questão aprovou o desenvolvimento de um software para dar suporte a este sistema de informação, com o seguinte objetivo: uniformizar os métodos de acompanhamento e gerenciamento dos serviços laboratoriais em toda a empresa, dando homogeneidade e maior eficiência ao desenvolvimento e acompanhamento de serviços técnicos correntes, desde o momento da solicitação de um serviço, até seu faturamento.

III.4.3 Condução do primeiro ciclo da pesquisa-ação: processo para especificação de requisitos de software com foco na identificação das características individuais do trabalho cooperativo e das características de domínio

Neste ciclo é aplicada a primeira parte do macroprocesso proposto que corresponde ao processo para identificação das características individuais do trabalho cooperativo, tendo como principal objetivo a coleta e a definição dos requisitos individuais dos usuários e dos requisitos de domínio para confecção do protótipo descartável (papel) do sistema.

Para este ciclo, procura-se responder à seguinte questão de pesquisa:

- Como, pelas contribuições individuais dos stakeholders, estabelecer os principais artefatos necessários para a simulação do trabalho cooperativo por meio software que será implementado (ciclo 2)?

O planejamento da condução deste ciclo da pesquisa-ação em função do processo proposto é descrito no item IV.4. Sugere-se a leitura do capítulo IV para melhor entendimento deste planejamento. 


\section{III.4.4 Condução do segundo ciclo da pesquisa-ação: processo para especificação de requisitos de software com foco na identificação e simulação das características cooperativas do trabalho}

Neste ciclo, é aplicada a segunda parte do macroprocesso proposto no capítulo IV e correspondente ao processo para a simulação e identificação das características cooperativas do trabalho, tendo como principal propósito a obtenção das características do trabalho cooperativo pela utilização da técnica de Análise Coletiva do Trabalho, modelo mental e interação e modelos e processos de software, ancorados pelos artefatos gerados no primeiro ciclo, obtendo-se, assim, o protótipo não funcional do sistema.

Para este ciclo, procura-se responder às seguintes questões de pesquisa:

- Quais são os instrumentos a serem elaborados para captar os requisitos de software da dimensão cooperativa do trabalho de um SI durante a simulação do sistema informatizado que lhe dará suporte?

- Como estes instrumentos podem ser concatenados para captar os requisitos de software do trabalho cooperativo durante a simulação do sistema informatizado?

- A solução proposta neste ciclo pode ser aplicada para refinar os requisitos de software do trabalho cooperativo durante o uso do sistema informatizado (ciclo 3)?

O planejamento da condução deste ciclo da pesquisa-ação em função do processo proposto é descrito no item IV.5. Sugere-se a leitura do capítulo IV para melhor entendimento deste planejamento.

III.4.5 Condução do terceiro ciclo da pesquisa-ação: Processo para especificação de requisitos de software com foco no refinamento das características do trabalho cooperativo (em uso real);

Neste ciclo, é aplicada a terceira parte do macroprocesso proposto que corresponde ao processo para o refinamento da identificação das características do trabalho cooperativo, cuja implementação real do sistema (protótipo funcional usado em 
campo pelos usuários) é utilizada para ancorar as sessões de Análise Coletiva do Trabalho, orientadas ainda pelos conceitos da teoria da mente coletiva e de awareness para o refinamento da definição das características do trabalho cooperativo.

Para este ciclo, procura-se responder às seguintes questões de pesquisa:

- Quais são os instrumentos a serem elaborados para refinar os requisitos de software da dimensão cooperativa do trabalho de um SI durante o uso do sistema informatizado que lhe dará suporte?

- Como estes instrumentos podem ser concatenados para refinar os requisitos de software do trabalho cooperativo durante o uso do sistema informatizado?

- Como avaliar a evolução da identificação dos requisitos de software do trabalho cooperativo obtidos neste ciclo pela aplicação da solução proposta?

- O processo proposto no ciclo 2 pode ser aplicado para refinar os requisitos do trabalho cooperativo de um SI neste ciclo?

O planejamento da condução deste ciclo da pesquisa-ação em função do processo proposto é descrito no item IV.6. Sugere-se a leitura do capítulo IV para melhor entendimento deste planejamento.

\section{III.4.6 Elaboração da tese com os resultados da pesquisa}

Apesar dos dados e eventos relevantes levantados e experimentados ao longo do projeto serem devidamente documentados, a elaboração da tese, como um documento acadêmico e como um relato do projeto de pesquisa, é feita depois da aplicação em campo do processo proposto pela condução dos ciclos da pesquisaação aqui relatados neste planejamento. 


\section{PROCESSO PROPOSTO}

Neste capítulo, descreve-se como o processo proposto nesta pesquisa foi aplicado. Assim, o processo inicia-se com a identificação dos requisitos de domínio dos stakeholders, das atividades dos usuários, assim como a definição dos principais processos de negócio que serão automatizados.

Estes elementos são fornecidos para os usuários na forma de um conjunto de artefatos para definição da usabilidade; concomitantemente com as funcionalidades do sistema, tanto as referentes ao trabalho individual, como aquelas do trabalho cooperativo por intermédio de um processo de prototipação incremental, passando dos modelos em papel, ao modelo não funcional e, finalmente, à prototipação funcional.

Em todas estas etapas, o enfoque no trabalho cooperativo é dado gradualmente, na medida que estas características forem se aflorando, durante a aplicação do processo proposto.

\section{IV.1 CONTEXTO}

Métodos convencionais da descoberta de requisitos assumem que o usuário saiba exatamente o que deseja do futuro sistema e conheça o sistema, de forma que, uma vez implementado, absorva os impactos sobre a forma de trabalho. Estes métodos concentram-se nas funcionalidades do sistema em razão de considerar o contexto em que operam.

$\mathrm{Na}$ realidade, qualquer sistema que envolve intervenção humana tem características de ser volátil, não previsível e complexo. Impor hierarquia e rigor matemático, para reduzir esta complexidade pode distorcer o entendimento. Os elementos não estruturados do sistema sociotécnico podem ser deixados de lado.

O esforço de representação dos requisitos, também, deve ser orientado no registro de demanda de negócio e na identificação das regras do negócio. (KOTONYA; SOMMERVILLE, 1998).

Pela própria natureza dos requisitos e os relacionamentos entre eles, embora tenham disponíveis as mais variadas técnicas, a geração do documento de 
requisitos poderá conter informações que reflitam conflitos, omissões, inconsistências e desatualização dos mesmos.

Os sistemas informatizados não existem isoladamente, pois são usados no contexto social e organizacional da empresa, e os requisitos do sistema são derivados e sofrem restrições oriundas desse ambiente. A necessidade de atender às carências impostas pelo contexto social e organizacional, frequentemente, é crítica para o sucesso dos sistemas de informação e, muitas vezes, é motivo para que estes sistemas não sejam utilizados após sua implantação.

O problema da elicitação (descoberta dos requisitos do sistema e compreensão das necessidades dos usuários) de requisitos não pode ser resolvido com uma abordagem puramente tecnológica, porque nesta fase o contexto social é mais crucial do que na fase de projeto e codificação. Outro aspecto é que os stakeholders sentem dificuldade de articular detalhes de seu trabalho, em razão da segunda natureza que o mesmo representa. Eles podem compreender seu próprio trabalho, mas podem não compreender bem sua relação com outros trabalhos da organização e, também, com outros participantes de seu grupo de trabalho (SOMMERVILLE, 2007).

A este fato, junta-se também que também na fase de teste/manutenção de sistemas informatizados, aspectos ligados à funcionalidade/usabilidade acabam sendo obtidos por meio de técnicas que envolvem os usuários de modo independente, sem levar em conta suas funções e usos cooperativos.

Assim, de modo a tratar as questões acima descritas, e o paradoxo da concepção descrito nos itens I.1e III.4.1, é necessário estabelecer um processo que trate a questão, levando em conta sobretudo o fato de que as pessoas trabalham cooperativamente para atender a uma série de objetivos.

O processo proposto pode, então, ser aplicado, tanto na concepção de novos sistemas informatizados como na melhoria de sistemas já desenvolvidos. Estas situações serão exploradas nos próximos itens. 


\section{IV.2 DESCRIÇÃO GERAL DO PROCESSO}

No desenvolvimento de software, assim como em outras áreas, existem várias metodologias/tecnologias para se criar um produto.

Neste trabalho de pesquisa, o processo adotado segue o modelo espiral, conforme descrito no item II.6.3, no qual, em vez de uma seqüência linear de atividades, o modelo é representado como uma espiral em que cada volta representa uma fase do processo: a volta mais interna relaciona-se à viabilidade do sistema; a volta seguinte, à definição dos requisitos; a próxima volta, ao projeto e, assim, por diante. Por outro lado, visando a atender aos sistemas complexos, grandes, de longa duração e/ou desenvolvidos por equipes diferentes, adotou-se uma solução mista que contempla o uso da prototipação evolutiva (ver item II.6.3) para definição dos requisitos em sistemas sociotécnicos que estejam mal compreendidos, e do modelo em cascata (item II.6.2) para implementação das alterações no processo de prototipação funcional (item II.8.3).

Na Figura IV.1, o diagrama simplificado do processo proposto nesta pesquisa pode ser visto. A parte em destaque corresponde ao recorte que se pretende dar dentro do processo de desenvolvimento dos sistemas de informação da engenharia de software: a subárea que trata da engenharia de requisitos (item II.7).

Dentro deste recorte, os processos de análise de viabilidade e aplicabilidade são considerados para identificação das características individuais do trabalho cooperativo, para identificação e simulação das características cooperativas do trabalho e, finalmente, para refinamento da identificação das características do trabalho cooperativo (que corresponde na realidade à versão funcional do sistema).

Para identificação das características individuais do trabalho cooperativo (itens II.8.3 e IV.4) primeiro é preciso a análise da viabilidade do projeto, assim como a verificação se o sistema é um bom candidato para a aplicação do processo proposto, ou seja, deve ser feito um recorte para verificar a aplicabilidade do processo (descrita com mais detalhes em IV.3). 


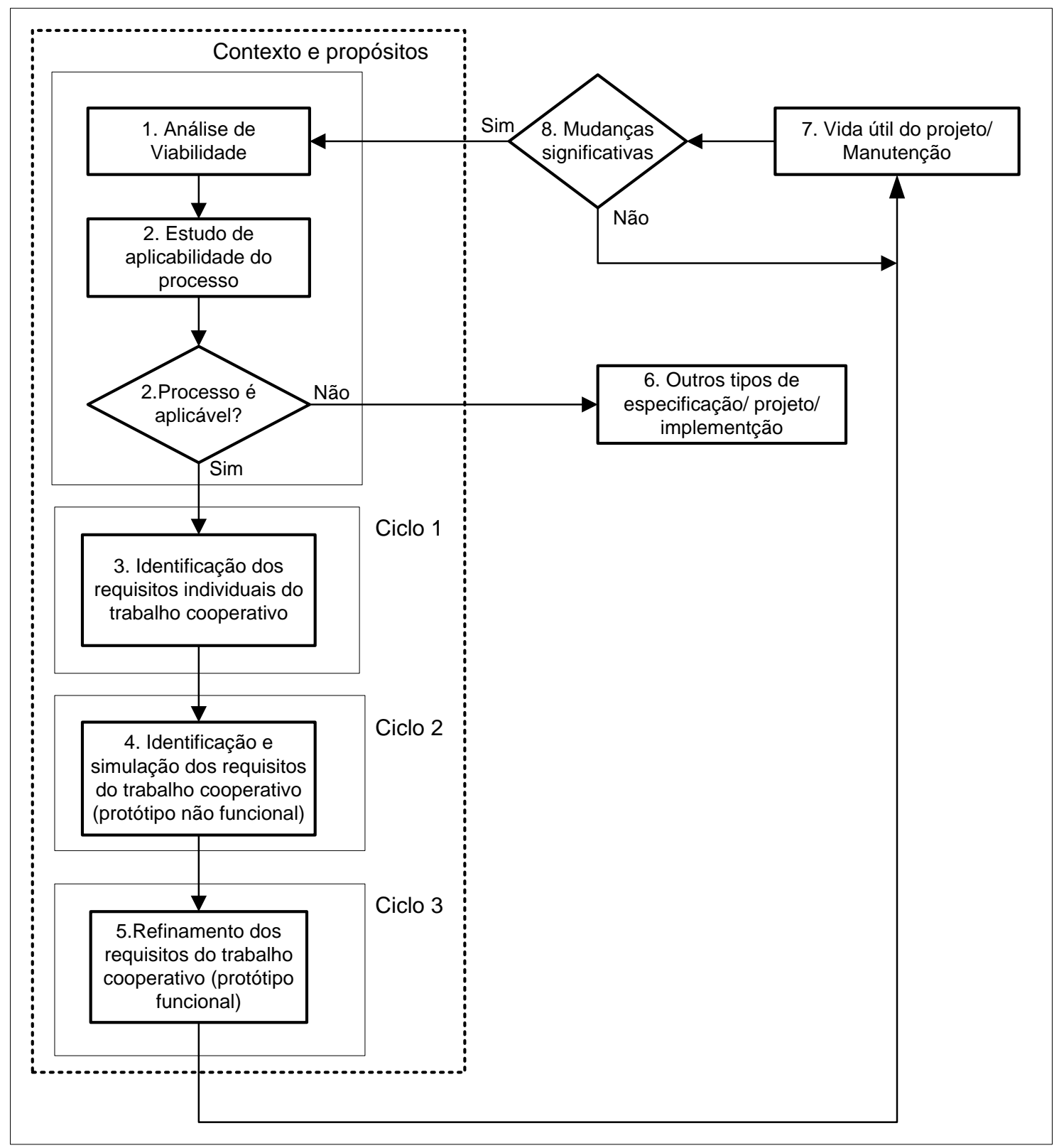

Figura IV.1 - Macroprocesso para a identificação das características do trabalho cooperativo Fonte: elaborado pelo autor

Os artefatos desenvolvidos no processo para identificação das características individuais do trabalho cooperativo (item IV.4) serão o ponto de partida para o estudo das características do trabalho cooperativo em sistemas de informação (item IV.5). Uma vez obtidos os requisitos necessários, parte-se para a implementação do sistema (protótipo funcional), onde, a partir do mesmo serão complementados os requisitos cooperativos do sistema, sobretudo com foco nos conceitos de awareness e mente coletiva (item IV.6). 
Na Figura IV.2, podem ser vistos os aspectos teóricos envolvidos no processo como um todo.

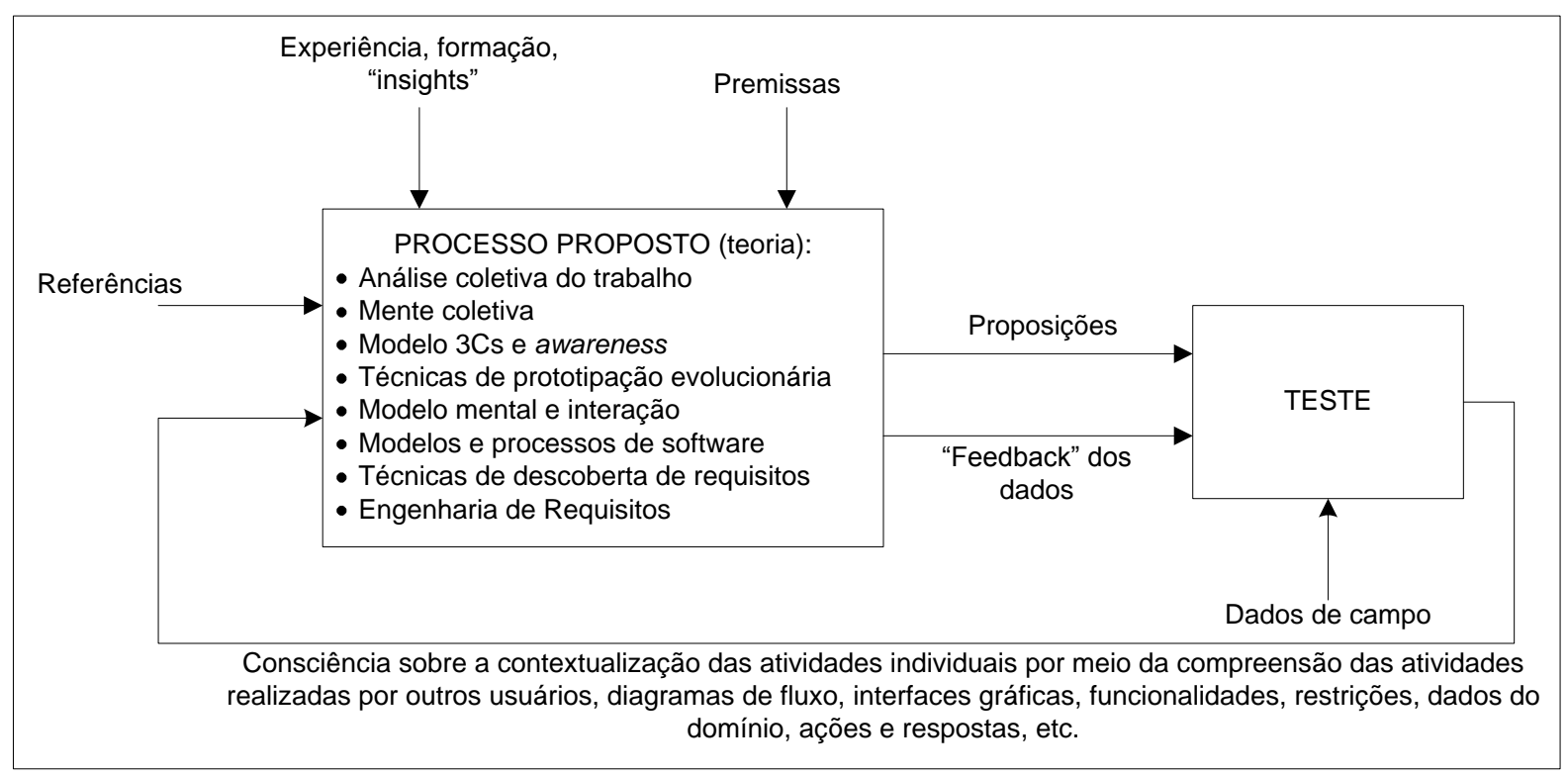

Figura IV.2 - Modelo da teoria proposta

Fonte: elaborado pelo autor

Os próximos itens descrevem o processo proposto neste trabalho, que procura mostrar como os conceitos apresentados no capítulo II podem ser logicamente encadeados para responder à principal questão da pesquisa: como considerar na especificação dos requisitos de software, a dimensão cooperativa do trabalho em sistemas de informação?

\section{IV.3 ANÁLISE DE VIABILIDADE E DA APLICALIBIDADE DO PROCESSO}

Na Figura IV.4 abaixo, o diagrama do processo para identificação das características individuais do trabalho cooperativo pode ser visto. Para cada passo desta figura, será feita uma descrição, um critério de saída e os artefatos produzidos. 


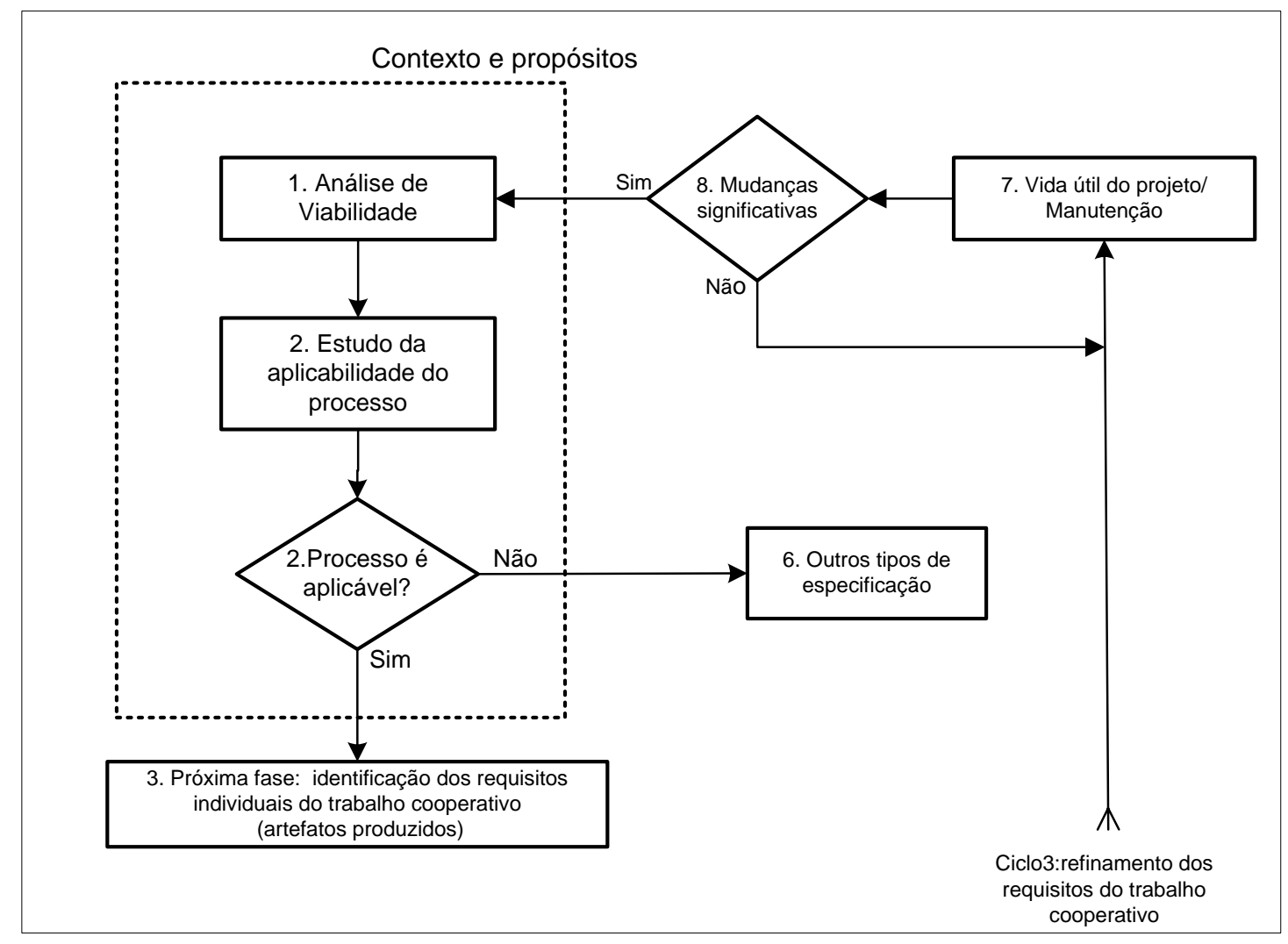

Figura IV.3 - Processo para análise de viabilidade e aplicabilidade Fonte: elaborado pelo autor

\section{IV.3.1 Análise de viabilidade}

Este passo permite verificar se de fato o sistema deve ser desenvolvido. A entrada do processo corresponde a um resumo da descrição do sistema e como este pretende apoiar aos processos de negócio.

Assim, devem ser levantados documentos como: identificação dos problemas operacionais correntes, objetivos do negócio, oportunidades abertas e restrições mais importantes da aplicação, fronteiras deste sistema e pontos de interface com outros sistemas de informação, visão geral das entradas, saídas, metas de custo, benefício e a posição da aplicação dentro do contexto da organização, entre outros.

É importante também avaliar o fluxo do processo a ser informatizado, especificando suas principais fases e interações com os demais sistemas existentes (suas interfaces), buscando sua contextualização frente aos demais fluxos de negócio da empresa. 
Nesta fase do processo, é importante a verificação dos requisitos de domínio, ou seja, os requisitos que vêm do ambiente que suporta a aplicação (seu domínio) refletindo suas características e restrições e não necessidades específicas dos usuários.

Algumas questões são importantes e podem ser resumidas nos dados do Quadro IV.1 abaixo.

Quadro IV.1 - Análise de viabilidade: questões a serem consideradas

O sistema contribui para os objetivos gerais da empresa?

O sistema pode ser desenvolvido com a tecnologia existente, dentro das restrições de custos e prazos?

Este sistema deve ser integrado a outros já existentes?

Como a empresa resolve o problema se este sistema não for implantado?

Quais são os problemas com o processo corrente e como o novo sistema informatizado pode colaborar na solução dos mesmos?

Quais são os ganhos diretos que este sistema pode fornecer para os objetivos de negócio?

As informações deverão ser transferidas de e para outros sistemas da organização?

Este sistema necessita de tecnologia que não foi utilizada previamente na empresa?

Qual será o benefício econômico de uma solução implementada com sucesso?

Quais problemas esta solução resolve?

Qual o ambiente de negócio na qual a solução será utilizada?

Existem características especiais ou restrições que afetam o modo como a novo sistema será proposto?

Fonte: adaptado de Sommerville (2007)

\section{IV.3.2 Verificação da aplicabilidade do processo ao sistema candidato}

O objetivo deste passo é verificar se a teoria proposta pode ser aplicada ao sistema, ou se será necessário outro tipo de processo, para que a definição de requisitos seja desenvolvida.

A prototipação, tal como definida no item II.8.3, pode ser aplicada a um conjunto de sistemas candidatos que devem possuir as seguintes características (BOAR, 1984):

- O sistema não exige grande quantidade de especificação algorítmica. A aplicação deve ser um problema estruturado com uma grande quantidade de elementos de dados e relacionamento entre registros mas, uma pequena quantia de processos algorítmicos;

- Os usuários devem estar dispostos e capazes a participar ativamente, assim como o gerente do projeto; 
- O preparo da equipe envolvida com o uso da metodologia não pode significar risco, assim como a questão da falta espírito da equipe do grupo que estiver participando das sessões;

- O sistema possui muita interação com os usuários por meio de transações com relatórios associados aos bancos de dados, não operando com muito processamento em lote (batch);

- O Sistema de Informação apresenta coordenação distribuída nas ações dos usuários (coordenação horizontal) e a comunicação entre eles ocorre preponderantemente de modo indireto pelos dados inseridos nos objetos de colaboração durante o uso do software. O software que implementa o SI é assíncrono e desacoplado (ver item II.5.5)

A saída para próximo passo ocorre quando a ponderação de todos os fatores é suficiente para decidir se o processo proposto é o mais indicado para o problema em questão.

\section{IV.4 PROCESSO PARA ESPECIFICAÇÃO DE REQUISITOS DE SOFTWARE COM FOCO NA IDENTIFICAÇÃO DAS CARACTERÍSTICAS INDIVIDUAIS DO TRABALHO COOPERATIVO E DAS CARACTERÍSTICAS DE DOMÍNIO}

Na Figura IV.4 abaixo, o diagrama do processo para identificação das características individuais do trabalho cooperativo pode ser visto.

Nesta fase do processo, são coletados vários pontos de vista (tanto dos usuários, como de outros sistemas) sobre o que o sistema deve realizar (requisitos funcionais) e as restrições que the são impostas (requisitos não funcionais) (PRESSMAN, 2005; SOMMERVILLE, KOTONYA, 1998). Diferenças e até inconsistências entre estes pontos de vista ocorrerão nesta fase, quando o sistema é inicialmente especificado e que acabarão sendo incluídas nesta fase do processo. Somente nas fases posteriores será possível a equalização dos vários pontos de vista do sistema. 
Nesta fase do processo, assim como na próxima (simulação e identificação), os documentos dos requisitos apresentados aos usuários deverão ser compreensíveis aos mesmos, sem detalhamento mais técnico e evitando-se jargões.

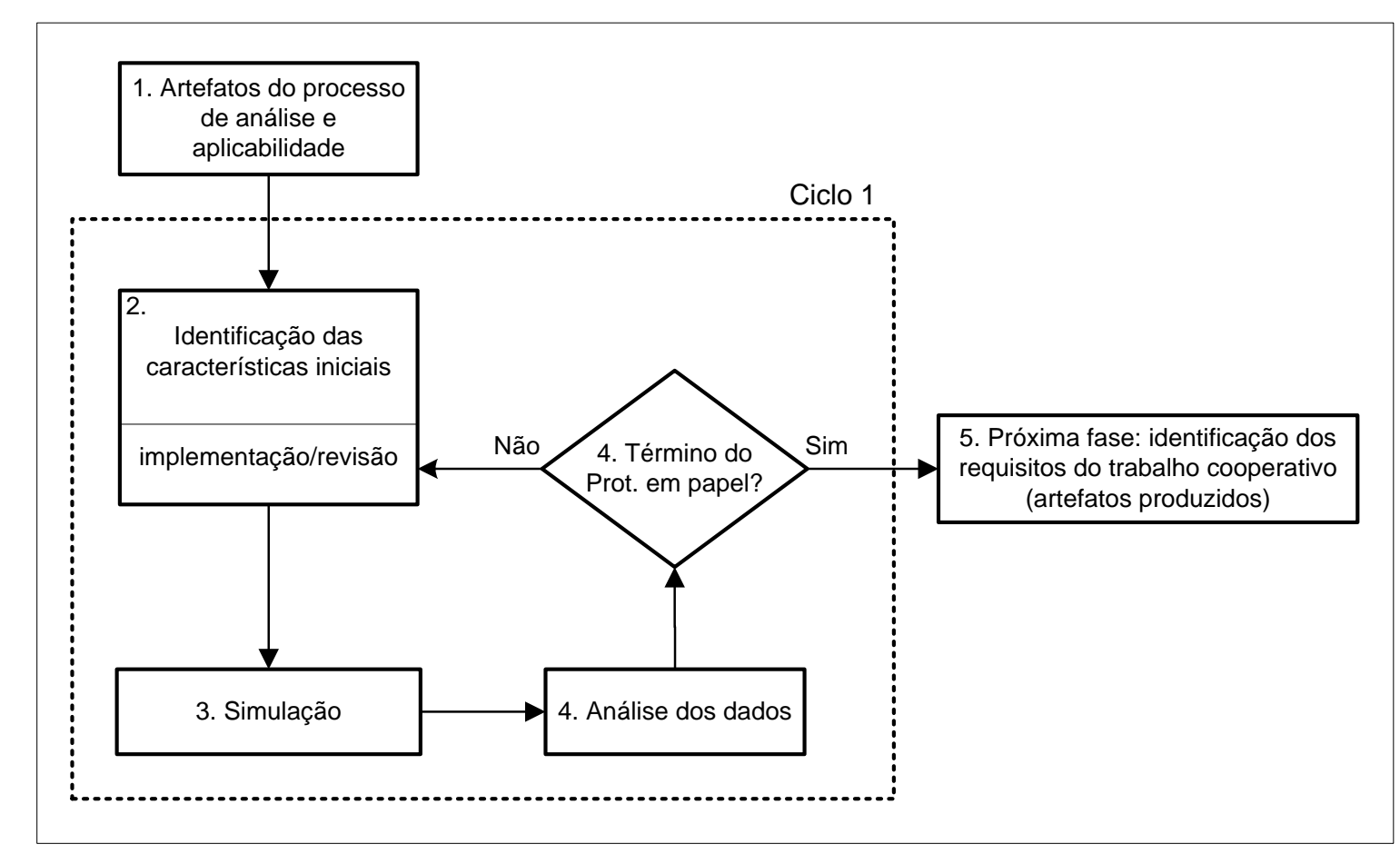

Figura IV.4 - Processo para identificação das características individuais do trabalho cooperativo Fonte: elaborado pelo autor

O processo proposto foca sobretudo os usuários finais do sistema (SOMMERVILLE, 2007), de modo que os requisitos de domínio devem ser agregados à documentação que será apresentada aos usuários na próxima fase.

\section{IV.4.1 Implementação/revisão do protótipo em papel}

Para este processo, a implementação foi dividida em duas partes: a identificação das características iniciais do sistema, que corresponde à situação de análise dos artefatos vindos da fase anterior (análise de viabilidade e aplicabilidade) e posteriores implementações derivadas das iterações do processo (Figura IV.4). 


\section{Identificação das características iniciais do sistema}

Este passo tem como objetivo determinar a essência do sistema, obtendo-se suficientes informações para início da prototipação em papel, e os documentos do passo IV.3.1, também, podem ser utilizados nesta fase.

Assim, as metas, os objetivos, as oportunidades de negócio e os problemas associados a este sistema devem ser buscados, para que, deste modo, seja possível identificar as necessidades básicas que correspondem ao núcleo principal da aplicação.

Tanto nesta fase do processo proposto como na próxima (prototipação não funcional) deve-se procurar, inicialmente, explorar com os stakeholders as características do sistema que não estão claramente definidas.

É importante mapear quais são as principais atividades dentro do processo atual (manual - situações de referência - ver item II.8.3) e como estas atividades serão realizadas pelo novo processo (informatizado - ações características - ver item II.8.3) que substituirá o antigo. Esta atividade deverá ser desenvolvida com os usuários que forem designados para esta fase (conforme item III.4).

Os principais artefatos são o diagrama de contexto e o fluxograma inicial dos processos, com suas principais fases e interfaces gráficas.

Deve-se dar atenção aos fluxogramas dos processos que serão automatizados e servirão como elemento de suporte nas sessões de Análise Coletiva do Trabalho e na prototipação em papel, assim como as interfaces com os sistemas existentes (tanto de estrutura de dados como dos serviços oferecidos por outros sistemas).

Optou-se pelo uso do fluxograma e não do IDEFo (Integrated Definition for Function Modelling), pois segundo Estorilio (2003), esta representação é preferível, pela sua simplicidade e forma de explicitação. Enquanto o IDEFo (ver Apêndice A) apresenta o processo de forma genérica e modelado em diversos cartazes, o fluxograma traz 0 fluxo de trabalho em apenas um modelo, pela interligação das tarefas efetivas.

A definição logo nas primeiras etapas do projeto das interfaces gráficas também é importante, pois as descrições em texto e em forma de diagramas não são suficientes para expressar esses tipos de requisitos. 
Neste processo, assim como próximo, é importante um melhor detalhamento dos requisitos de domínio (performance, acesso, segurança, etc.), conforme discutido nos itens IV.3.1 e II.7.2.

No dados do Quadro IV.2 encontram-se algumas questões que devem ser exploradas nesta fase do processo.

Quadro IV.2 - Identificação das características iniciais: questões a serem consideradas O que precisa ser suportado pelo sistema e o que não deve ser suportado? Quem usará esta aplicação (criar uma lista de "stakeholders")?

O software faz parte integral do trabalho dos usuários, ou será usado somente esporadicamente? Quais as conseqüências se um usuário cometer um erro usando o sistema para a funcionalidade que está sendo discutida?

Existem usuários com pouca familiaridade no uso básico de aplicações informatizadas (inclusive uso em planilhas, navegadores, editores de texto, etc.)?

Os usuários conhecem o processo que estará sendo automatizado?

Qual o perfil por execução das tarefas que os usuários podem ser divididos?

O que pode ser caracterizado como uma saída útil que esta solução pode fornecer?

Fonte: Adaptado de Kotonya e Sommerville (1998)

A saída para o próximo passo ocorre quando os participantes (da área de sistemas) desta fase são capazes de explicar aos demais a documentação do negócio com razoável nível de conhecimento.

\section{Implementação/revisão do protótipo em papel}

A prototipação em papel é um modo barato e rápido de desenvolvimento do protótipo (item II.8.3). Nesta situação, não é preciso desenvolver o software executável e os protótipos não necessitam ser implementados com padrões profissionais gráficos. Um conjunto de interfaces gráficas de usuários é desenhado em função em função do fluxograma inicial de processo, descrevendo como o sistema deve ser usado e quais retornos são importantes aos usuários entrevistados.

O protótipo inicial deve ser detalhado o suficiente para iniciar as sessões de ACT e iteração (próximas fases).

Neste ponto, é mais importante apresentar as funcionalidades levantadas na fase anterior de modo menos sofisticado do que detalhar os storyboards, relatórios e dados (devem ser detalhados ao longo do processo de iteração do protótipo com os usuários). 
A visão do usuário deve ser considerada, levando-se em conta os principais documentos levantados na fase anterior, permitindo que a próxima fase (prototipação não funcional) inicie-se com um conjunto de artefatos de projeto que é uma excelente "ancora" para o processo.

Os principais artefatos de saída são: requisitos funcionais, interfaces gráficas, fluxogramas, modelo preliminar de dados (para fins de projeto) e diagrama de contexto.

Nesta fase, é importante a definição da arquitetura do sistema pelos desenvolvedores, já que a interface e seu modo de interação com o usuário têm dependência com a tecnologia adotada, assim como pelo fato de que para a implementação do protótipo funcional precisa-se de uma visão geral da tecnologia que será adotada.

A saída para o próximo passo ocorre quando os documentos necessários para a próxima fase contemplam as mudanças coletadas na simulação do protótipo em papel.

\section{IV.4.2 Simulação do protótipo em papel}

Para a simulação, é escolhido um usuário representativo do perfil ou do grupo de trabalho do processo de negócio que será estudado. São definidas as tarefas típicas que representam o que os usuários devem realizar e construídas as versões da interface (esboços manuais ou impressões de telas), não sendo necessário desenvolver uma versão funcional destas interfaces.

Após a criação do protótipo em papel, são realizados os testes em que o usuário é colocado para realizar as interações com o protótipo em papel. Um membro da equipe de desenvolvedores atua como computador, apresentando as interfaces (respostas às suas ações no protótipo) que são solicitadas pelo usuário. Pode-se utilizar a figura de um facilitador que instrui o usuário a respeito das tarefas a executar, com suas reações e comentários anotados por uma ou mais pessoas da equipe de software (ouvintes). 
Deste modo, é possível descobrir rapidamente quais partes da interface e do processo de negócio funcionam ou não, podendo ser facilmente alteradas para corrigir as deficiências apontadas pelos usuários (SNYDER, 2003).

Na medida que cada processo do fluxograma é apresentado aos diferentes usuários (individualmente), novas informações são agregadas e novas opções são oferecidas, tanto no que se refere às novas atividades como ao refinamento das que já foram exploradas.

Assim, o método é efetivo para avaliar as reações iniciais relativas ao projeto das interfaces, as informações que os usuários necessitam do sistema e como poderiam normalmente interagir com ele.

O propósito principal desta fase é obter novos e revisados requisitos pelas observações e críticas feitas pelos usuários sobre o protótipo, como por exemplo, o delineamento dos principais fluxos do processo de negócio que será automatizado.

O outro objetivo é definir um conjunto de objetos e suas ações para as principais interfaces de usuários associadas ao processo de negócio e que permitam aos mesmos executar as atividades por eles apresentadas.

Nas iterações iniciais, deve-se concentrar na detecção dos desvios grosseiros dos artefatos construídos na fase anterior (sobretudo nos fluxogramas e storyboards), assim como obter aceitação individual dos participantes sobre o protótipo.

Posteriormente, passa-se para a fase de refinamento, preocupando-se mais com a interface em si e descobrindo-se novas funcionalidades e interações.

Nas entrevistas com os usuários durante a simulação, algumas perguntas devem ser realizadas e que estão resumidas nos dados do Quadro IV.3 abaixo.

Quadro IV.3 - Simulação do protótipo em papel: questões a serem consideradas

\begin{tabular}{|l|}
\hline \multicolumn{1}{|c|}{ Questões básicas sobre a simulação em papel } \\
\hline Qual o trabalho realizado pelos diferentes tipos de usuários e em que circunstâncias? \\
\hline Quais são as atividade e subatividades realizadas enquanto os usuários executam seu trabalho? \\
\hline Qual é a sequência do trabalho realizado (workflow do processo em detalhes)? \\
\hline Dentro dos processos, qual é a hierarquia das atividades? \\
\hline
\end{tabular}

Fonte: Adaptado de Sommerville (2007) e Pressman (2005)

Os principais artefatos de saída são: interfaces gráficas, fluxogramas refinados e modelo de dados preliminar (para o caso de ser necessário o uso de estimativas por 
meio de pontos de função, ou para um planejamento de informações gerenciais) (GAVA et al. , 2004).

\section{IV.4.3 Análise dos dados- avaliação sobre o término da prototipação em papel}

O objetivo deste passo é determinar se a essência da aplicação foi obtida e o ciclo foi concluído.

Esta fase do processo estará terminada quando:

- A interface e demais documentos associados implementam as principais atividades definidas pelos usuários de modo correto;

- Em termos de usabilidade, a interface é fácil de compreender e de "usar";

- A saída para o próximo passo ocorre quando se obtém a aprovação dos usuários entrevistados na simulação;

- Os usuários concordam que o fluxo geral do processo foi mapeado.

O dados do Quadro IV.4 abaixo apresentam questões complementares para avaliação do término da prototipação em papel que devem ser respondidas pelos projetistas do sistema.

Quadro IV.4 - Avaliação sobre o término da prototipação em papel: questões a serem consideradas

\begin{tabular}{|l|}
\hline \multicolumn{1}{|c|}{ Questões básicas sobre avaliação sobre término da prototipação em papel } \\
\hline Cada requisito está consistente com o objetivo global do sistema? \\
\hline $\begin{array}{l}\text { Este requisito é realmente necessário, ou é uma característica adicional que pode não ser essencial } \\
\text { aos objetivos do sistema? }\end{array}$ \\
\hline Cada requisito está bem delimitado e claro? \\
\hline Algum requisito conflita com algum outro? \\
\hline O requisito pode ser testado depois de implementado? \\
\hline $\begin{array}{l}\text { Os artefatos desenvolvidos aqui representam corretamente estes requisitos, com relação ao seu } \\
\text { comportamento, funcionalidade e dados? }\end{array}$
\end{tabular}

Fonte: Adaptado de Sommerville (2007) e Pressman (2005)

Quando a prototipação em papel terminar, o planejamento para a próxima etapa do processo (prototipação não funcional) será feito, com a definição dos temas que serão abordados e quais pessoas convidadas. Cada novo tema que será explorado com os usuários selecionados, será estudado com mais detalhes pelos pesquisadores que realizarão as sessões de ACT. 


\section{IV.5 PROCESSO PARA ESPECIFICAÇÃO DE REQUISITOS DE SOFTWARE COM FOCO NA IDENTIFICAÇÃO E SIMULAÇÃO DAS CARACTERÍSTICAS COOPERATIVAS DO TRABALHO}

O objetivo final desta fase do processo proposto é a obtenção dos requisitos do sistema e dos modelos do sistema (que é o documento que os desenvolvedores de software devem executar), isto é, a versão expandida dos requisitos dos usuários utilizada como ponto de partida para o projeto de sistema que é o documento que os desenvolvedores de software devem executar.

Em sistemas, em que uma solução evolucionária é adotada, este documento pode ser mais simples, com o enfoque na definição dos requisitos do usuário e nos requisitos funcionais de alto nível (SOMMERVILLE, 2007).

Em termos ideais, os requisitos de sistema devem descrever de modo simples o comportamento externo do sistema e suas restrições operacionais, não sendo relacionados com o modo como o sistema deve ser projetado e implementado.

Na prática, esta situação não ocorre, pois em sistemas que utilizam prototipação, pelo menos parte de algumas das características não funcionais do sistema devem ser consideradas, já que parte do mesmo será implementado (prototipação incremental).

Esta etapa do processo proposto começa com os artefatos desenvolvidos durante o processo anterior e serão utilizados como entrada na atividade de implementação/revisão da Figura IV.5 abaixo. Para esta fase do processo, optou-se pela técnica de prototipação não funcional, por atender às seguintes características:

- De acordo com o II.3, o modelo mental do usuário forma-se a partir do modo como o usuário interpreta a imagem do sistema, sendo a interface o elemento mais importante nessa situação;

- De acordo com o II.3, a interface também é o resultado da interação homemcomputador e pode ser separada em dois componentes independentes: um deles o é desenvolvimento da interação e o outro, o software que implementa esta interação (Ciclo 3);

- No desenvolvimento do componente da interação da interface, pode-se utilizar uma série de critérios de usabilidade (ver Apêndice B), como evolução 
da prototipação em papel para o sistema, assim como guia durante todo o processo de aplicação do processo proposto neste trabalho;

- Estes protótipos sucessivos do software oferecem uma representação concreta para se comunicar com os usuários e os projetistas, constituindo também um guia para a especificação de sucessivas versões (BURKHARDT; SPERANDIO, 2007).

Neste processo (item IV.5), o protótipo será constituído, de modo geral, por uma série de artefatos de software, como: fluxograma (ver item IV.4.1), diagrama de contexto (ver item II.7.4), interfaces gráficas representativas do fluxograma (ver item IV.4.1), modelo de dados (para os desenvolvedores - item II.7.4), além da descrição das funções representativas do sistema.

Este modelo deverá ser sucessivamente refinado. Para tanto, serão realizadas sessões de ACT com os usuários, utilizando-se como modelo físico inicial do sistema (ou imagem do sistema - item II.3) os artefatos desenvolvidos na fase anterior e ganhando novos componentes nas interações e iterações nesta etapa do processo proposto (Figura IV.6).

Para Daniellou (2007), uma série de condições deve ser estabelecida para esta simulação:

- Condições de aceitabilidade social;

- Escolha adequada dos participantes da simulação;

- No uso de suportes materiais como protótipo é importante a participação dos projetistas para comentar as informações que nela figuram;

- Desenvolver roteiros com base nas situações de ação características prováveis previamente levantadas.

A seguir, são descritas as fases do processo apresentado na figura abaixo. 


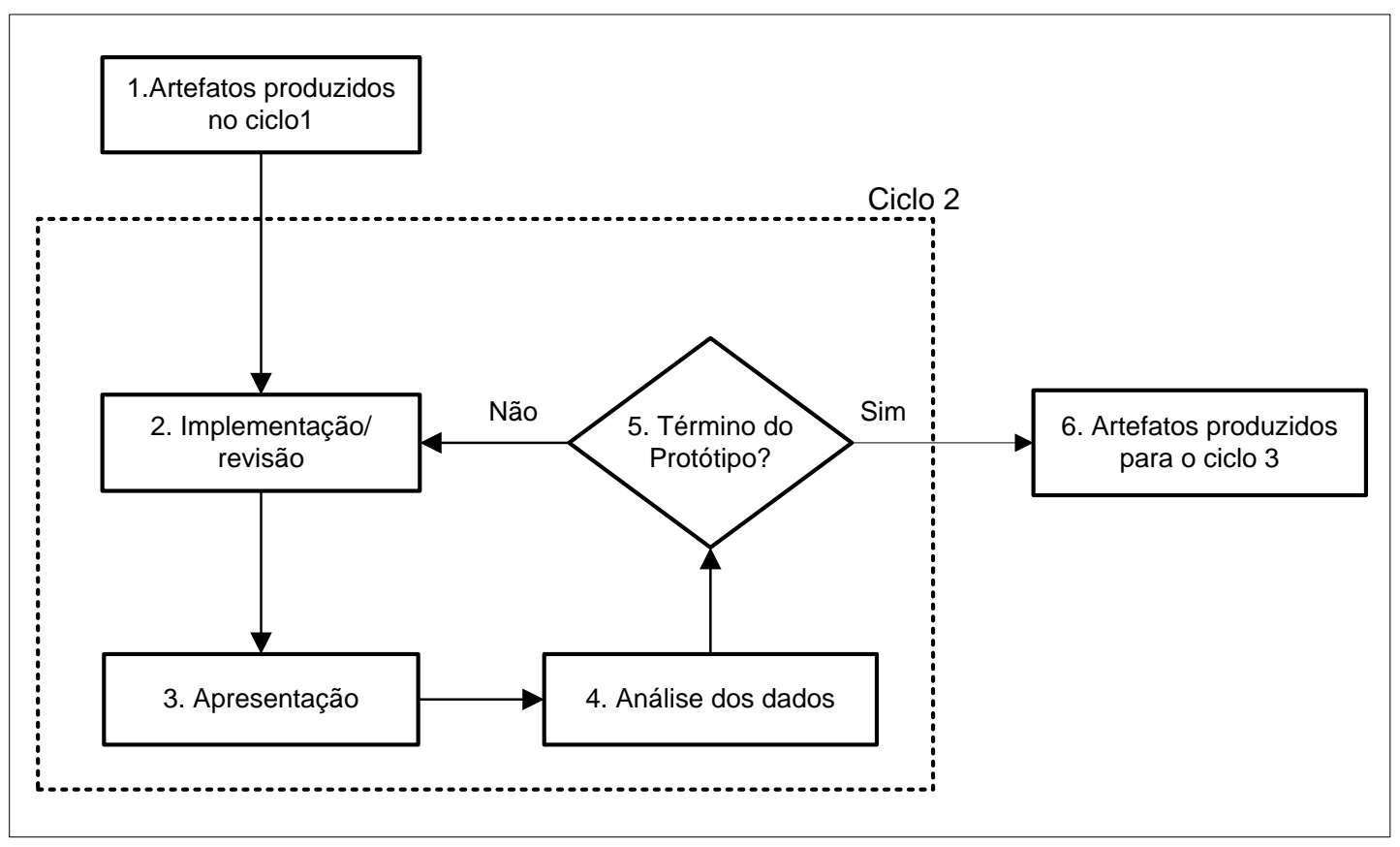

Figura IV.5 - Processo para simulação e identificação das características cooperativas do trabalho

Fonte: elaborado pelo autor

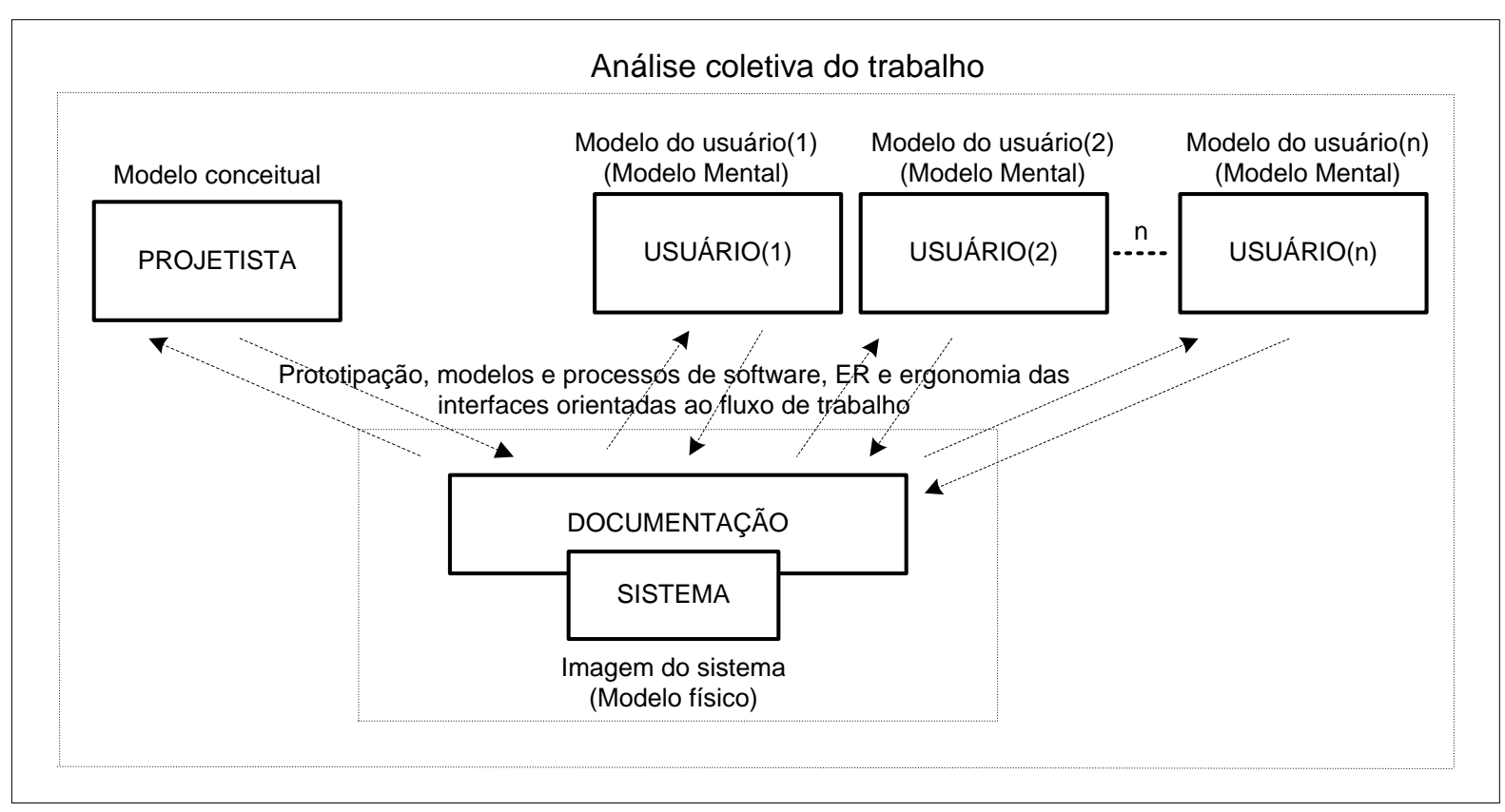

Figura IV.6 - Modelo para aplicação das sessões de ACT

Fonte: adaptado de Norman (1986) e Carrol e Olson (1988) 


\section{IV.5.1 Implementação/revisão protótipo não funcional}

A prototipação não funcional será usada a fim de que seja possível atingir o modelo mental dos usuários, parte-se do modelo inicial desenvolvido no processo anterior e será o modelo de interação inicial do sistema (abordagem do modelo conceitual preconcebido, conforme item II.3.1).

O protótipo inicial deve ser detalhado o suficiente, de modo que sirva para iniciar as sessões de ACT e iteração (iteração no ciclo).

Nesta fase do protótipo, as alterações foram implementadas e propostas pelos usuários na sessão de ACT, assim como as alterações ocorridas na atividade de análise dos dados.

$\mathrm{Na}$ primeira vez que o material para a apresentação for desenvolvido, os artefatos vindos do processo anterior (ver item IV.4) serão convertidos em interfaces já considerando a tecnologia sob qual a interface operará, assim como serão aplicadas sobre as mesmas as regras de ergonomia das interfaces (ver Apêndice B).

Assim como no processo anterior (ver item IV.4.1), como ferramenta gráfica para apresentar o fluxo do processo, foi empregado o fluxograma, por ser de mais fácil compreensão ao usuário (ESTORILIO, 2003).

Deste modo, procurou-se empregar o workflow como ferramenta de suporte para a análise das atividades dos usuários, uma vez que diferentes usuários podem estar envolvidos com diferentes papéis, assim como para mapear a troca das informações entre as diversas fases do processo e entre usuários (PRESSMAN, 2005).

Conforme o autor citado, para cada fase definida no workflow, foi associada uma ou mais interfaces (ver Figura IV.7 e Apêndice A) e para cada uma destas interfaces foi associada a hierarquia das atividades e respectivas interfaces.

Os principais artefatos de saída são: requisitos de sistema, interfaces e funcionalidades associadas, fluxogramas e interfaces associadas, modelo de dados e diagrama de navegação.

Nesta fase, é importante o refinamento da arquitetura do sistema pelos desenvolvedores, pelos mesmos motivos apontados nos itens II.7.4 e IV.4.1. 


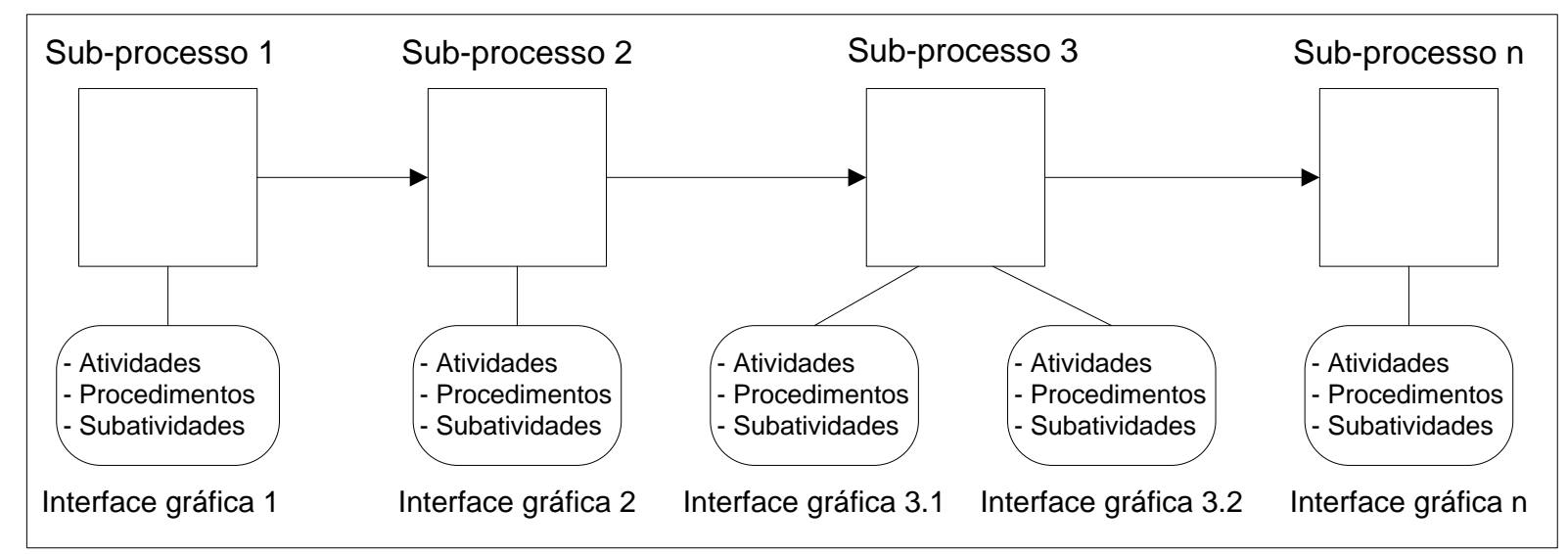

Figura IV.7 - Relação entre fases do processo e interfaces gráficas das sessões de ACT Fonte: elaborado pelo autor

A saída para a próxima fase (item IV.5.2) ocorre quando os documentos necessários contemplam as mudanças coletadas na apresentação (iteração) anterior.

\section{IV.5.2 Apresentação do protótipo não funcional}

O uso dos artefatos (interfaces gráficas, interações, respostas programadas, navegação entre as hierarquias dos formulários definidos pelo fluxograma do workflow) desenvolvidos durante a atividade de implementação/revisão do protótipo não funcional servirão como "guia" para aplicação dos métodos de Análise Coletiva do Trabalho (ACT).

Uma vez que se trata da concepção de um novo sistema, o uso de ACT é necessário na medida que os usuários devem explicar o que fazem e, ao explicar também ocorre reflexão sobre a atividade, fazendo com que se torne explícito e consciente tudo que se fazia de modo automático.

Assim, em linhas gerais, o processo proposto deverá atender aos seguintes aspectos:

- Há, pelo menos dois pesquisadores conduzindo a reunião por meio da pergunta positiva o quê?;

- O objetivo dos usuários é explicar aos pesquisadores o que fazem no trabalho; 
- Deve ser dada uma explicação inicial sobre o objetivo do trabalho, por parte dos pesquisadores. Novos assuntos poderão ser desenvolvidos com o grupo, mas devem ser motivo de novas negociações;

- Verificar na descrição dos usuários o que é comum, e o que é diferente na atividade, procurando avaliar os principais pontos que se destacam e uma caracterização mais detalhada de determinados aspectos da atividade do usuário;

- Procurar entender nas atividades dos usuários as relações com as demais atividades: explicar o que os outros fazem antes ou depois dele no processo produtivo, acima, ao lado ou abaixo na escala hierárquica;

- Os pesquisadores devem entender detalhes sobre a atividade e procurar fazê-la de várias formas, mesmo que demore bastante tempo. Uma boa técnica corresponde a se descrever a atividade cronologicamente.

Além das questões ligadas à análise coletiva do trabalho, as questões do item IV.4.2 (ver Quadro IV.3) podem ser utilizadas, visto que o componente individual do trabalho cooperativo, também, deve evoluir durante a aplicação do processo proposto nesta pesquisa.

Estas perguntas têm o objetivo de mapear as principais atividades no processo atual (não informatizado), ou seja, definir as situações de referência (ver item II.8.3) e avaliar como estas atividades serão realizadas por meio do novo processo, definindo, deste modo, as ações características (ver item II.8.3).

Conforme cada fase do fluxograma é apresentada aos diferentes usuários (coletivamente), novas informações são agregadas e novas opções são oferecidas, tanto no que se refere às novas atividades como ao refinamento das que já foram exploradas.

Assim como no ciclo 1, um dos propósitos desta fase é obter novos e revisados requisitos por meio das observações e críticas feitas pelos usuários sobre 0 protótipo, assim como definir um conjunto de objetos e suas ações aos principais artefatos associadas ao processo de negócio e que permitam aos mesmos executar as atividades por eles apresentadas. 
Um aspecto importante desta técnica reside no fato de que, visto pelo usuário, de fato ocorre uma iteração com o sistema formado pelas interfaces, computador e sistema (conjunto de possíveis respostas predefinidas às solicitações dos usuários). Nesta fase do processo, ocorre também a revisão dos requisitos da fase anterior do protótipo com a fase atual, em que é verificado se o que foi discutido na reunião anterior está implementado no material que está sendo discutido nesta sessão. É importante esta comunicação entre os desenvolvedores e usuários participantes da sessão, para garantir a consistência e garantir, também, que todos os requisitos estejam contemplados nos documentos que serão utilizados para discussão.

A documentação de cada sessão pode ser feita de várias formas, desde anotações específicas até o uso de gravações de áudio e vídeo.

O objetivo é buscar diferenças entre o sistema simulado e o sistema que efetivamente entrará em operação, partindo-se de uma versão inicial.

Nas iterações iniciais, deve-se concentrar na detecção dos desvios dos artefatos construídos na fase anterior (sobretudo nos fluxogramas e storyboards), pelo entendimento de como o trabalho é realizado cooperativamente por meio destes artefatos, procurando-se obter a aceitação coletiva dos participantes sobre os mesmos.

Posteriormente, passa-se à fase de refinamento, preocupando-se mais com a interface em si (usabilidade), descobrindo-se novas funcionalidades e interações entre seus elementos.

\section{IV.5.3 Análise dos dados - avaliação sobre o término da prototipação não funcional}

Deve-se definir como será a sessão de ACT para a apresentação coletiva. Nesta fase, define-se quais temas serão abordados na apresentação e quais pessoas serão convidadas (estas devem conhecer os temas que serão explorados entrevistar individualmente cada participante, buscando entender o que eles fazem, esclarecendo o que é a técnica e o que é esperado de sua participação). Cada tema que será explorado com os usuários selecionados deverá ser estudado com mais detalhes pelos pesquisadores que realizarão as sessões de ACT. 
Deve-se, também, preparar uma agenda para a sessão com os passos que devem ser seguidos no contexto da iteração do processo, mostrando onde o grupo se encontra e para onde está indo e o que deve ser alcançado. Os principais pontos são: introdução, revisão da elaboração dos objetivos gerais, abordagem da sessão, revisão de pendências, revisão geral e avaliação da sessão.

Para a avaliação das atividades dos usuários, podem ser feitas as seguintes perguntas de âmbito geral ligadas ao processo e que estão descritas nos dados do quadro abaixo.

Quadro IV.5 - Avaliação sobre término da prototipação não funcional: questões a serem consideradas

\begin{tabular}{|l|}
\hline \multicolumn{1}{|c|}{ Questões para verificação do término da prototipação não funcional } \\
\hline Cada requisito está consistente com o objetivo global do sistema? \\
\hline $\begin{array}{l}\text { Este requisito é realmente necessário ou é uma característica adicional que pode não ser essencial } \\
\text { aos objetivos do sistema? }\end{array}$ \\
\hline Cada requisito está bem delimitado e claro? \\
\hline Algum requisito conflita com algum outro? \\
\hline $\begin{array}{l}\text { Todos os requisitos estão especificados em seu próprio nível de detalhe, ou seja, existe algum } \\
\text { requisito que está especificado com nível técnico inapropriado para este estágio do processo? }\end{array}$ \\
\hline $\begin{array}{l}\text { Os artefatos desenvolvidos aqui representam corretamente estes requisitos, com relação a seu } \\
\text { comportamento, funcionalidade e dados? }\end{array}$ \\
\hline Cada requisito possui uma fonte (quem o definiu)? \\
\hline Cada requisito é implementável no ambiente técnico que suportará o sistema? \\
\hline $\begin{array}{l}\text { A definição das interfaces ligadas aos processos e as respectivas hierarquias das atividades estão } \\
\text { de acordo com as funções e comportamentos que foram coletados na última apresentação aos } \\
\text { usuários? }\end{array}$ \\
\hline
\end{tabular}

Fonte: Adaptado de Sommerville (2007) e Pressman (2005)

O processo como um todo termina quando a essência da aplicação foi obtida, de modo que sucessivos refinamentos acabem trazendo melhorias marginais ao processo, e as mudanças passem de análise de funcionalidades e interações da interface para o detalhamento dos atributos da interface, sem afetar a usabilidade, sinalizando que o protótipo está maduro. Assim, o processo estará terminado quando:

- A interface e demais documentos associados implementam as principais atividades definidas pelos usuários de modo correto;

- Em termos de usabilidade, a interface é fácil de compreender e usar;

- A saída para o próximo passo ocorre quando se obtém a aprovação dos usuários participantes nas sessões de ACT;

- Os usuários concordam que o fluxo geral do processo foi mapeado. 
Outro aspecto ligado ao término deste processo é o planejamento deve ser realizado para a próxima etapa do processo (prototipação funcional) sobretudo no que se refere ao cronograma de implementação da primeira versão funcional do software.

\section{IV.6 PROCESSO PARA ESPECIFICAÇÃO DE REQUISITOS DE SOFTWARE COM FOCO NO REFINAMENTO DAS CARACTERÍSTICAS DO TRABALHO COOPERATIVO}

As atividades desta última fase do processo equivalem ao caso do processo identificação e simulação, mas agora existe um sistema real que foi desenvolvido utilizando os principais requisitos do processo anterior.

A fase do processo proposto começa com os artefatos desenvolvidos na fase anterior e utilizados como entrada na atividade de implementação da Figura IV.8 abaixo. Com relação à fase anterior, os requisitos definidos nesta fase serão efetivamente implementados e não simulados em ação/resposta pré-programada.

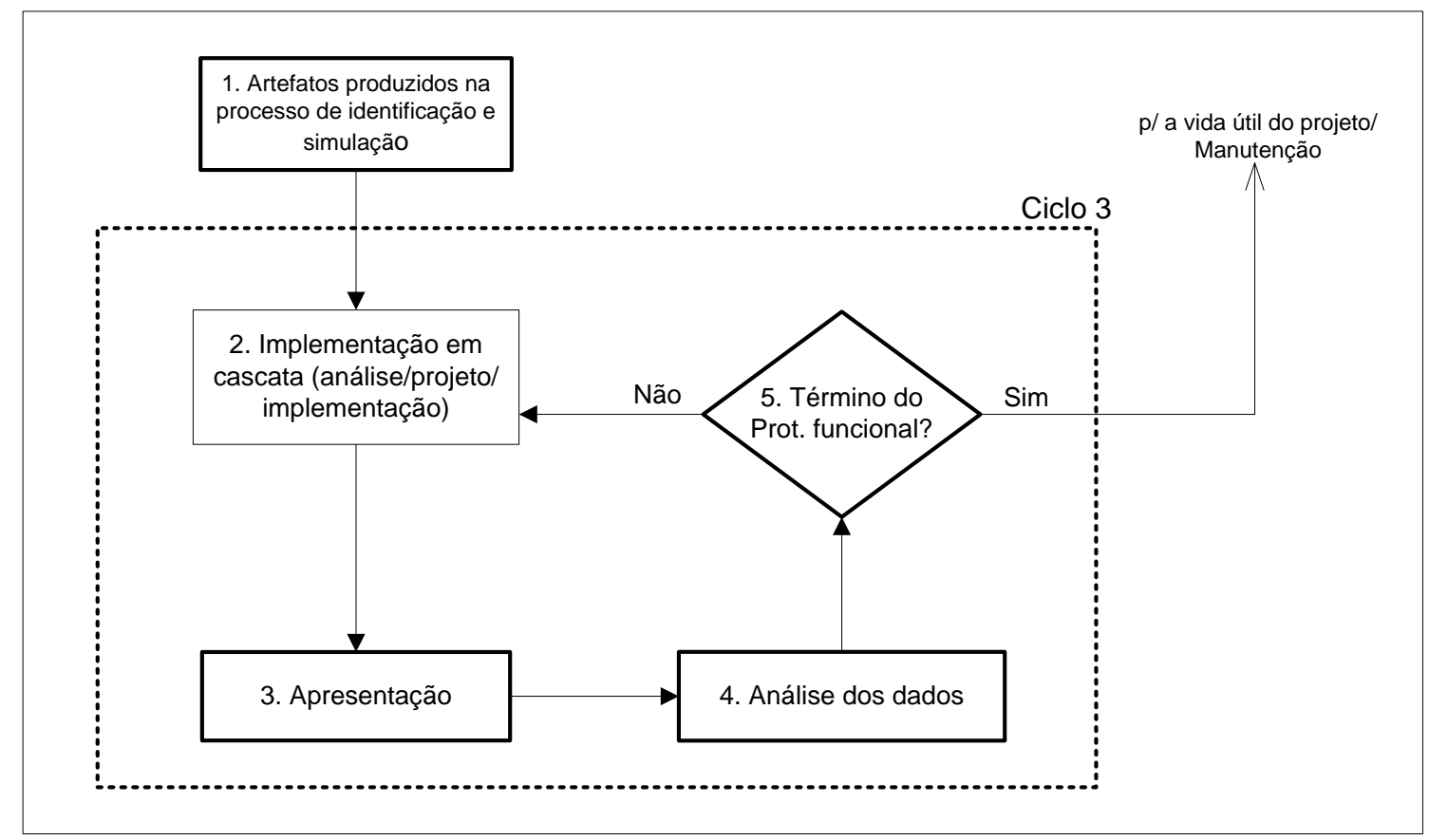

Figura IV.8 - Processo para o refinamento da identificação das características do trabalho cooperativo

Fonte: elaborado pelo autor 
As sessões de ACT que serão realizadas com os usuários seguem as mesmas diretrizes definidas no processo de prototipação não funcional, utilizando-se como modelo físico inicial (ou imagem do sistema, item II.3) o sistema implementado e ganhando novos componentes durante as interações e iterações nesta fase do processo proposto (Figura IV.9). Um aspecto importante que diferencia esta etapa do processo com a anterior é que estas sessões serão orientadas pelos conceitos da teoria da mente coletiva e awareness.

A segunda iteração (apresentação) é outro aspecto diferenciador e deverá ser realizada, após o sistema ter sido suficientemente empregado no ambiente de trabalho dos usuários.

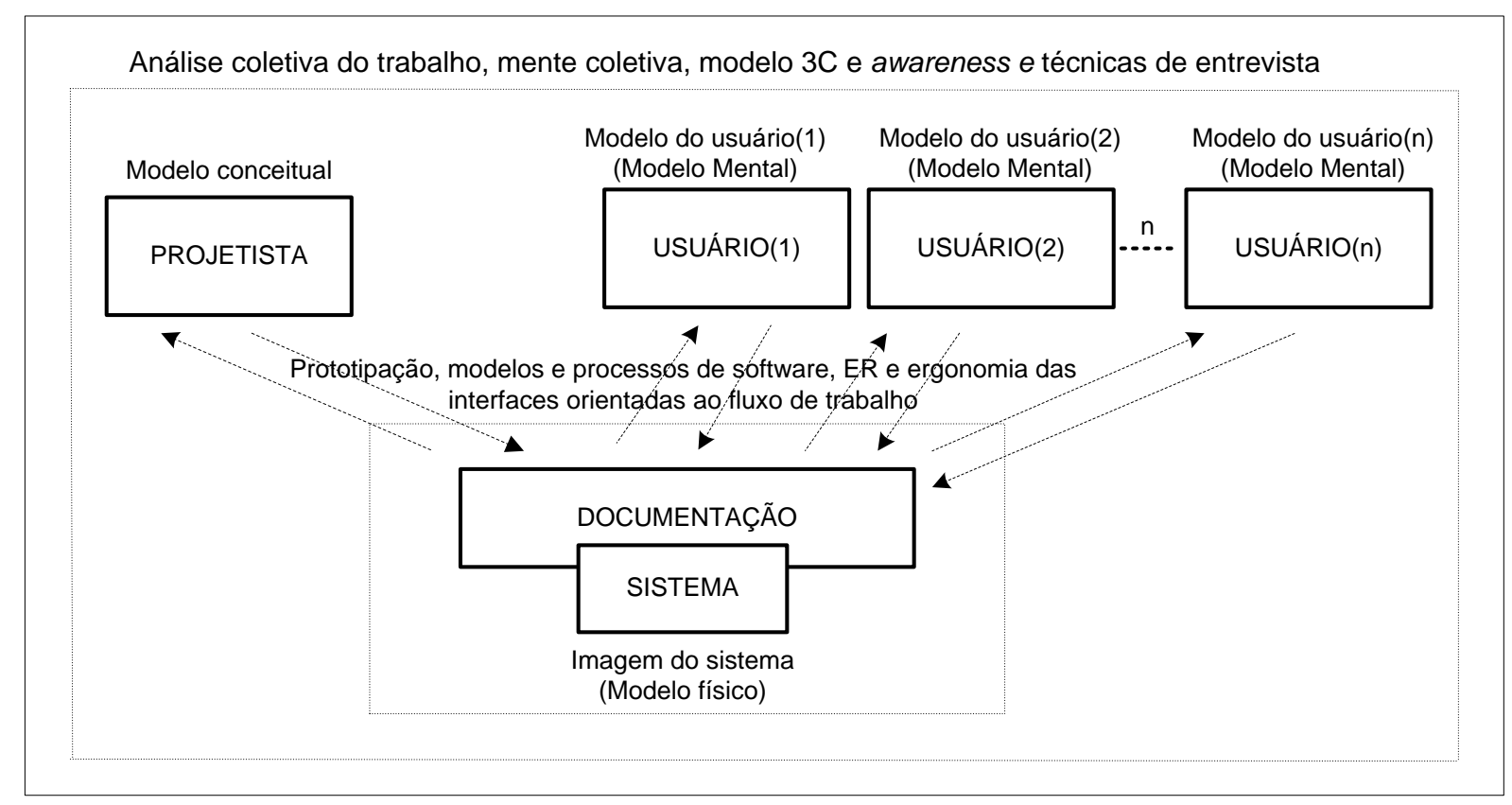

Figura IV.9 - Modelo para a aplicação das sessões de ACT

Fonte: adaptado de Norman (1986); Carrol e Olson (1988)

\section{IV.6.1 Implementação em cascata}

A prototipação evolucionária inicia seu primeiro ciclo nesta atividade, recebendo os artefatos da fase anterior que servirão para o desenvolvimento de uma primeira versão funcional do sistema que será utilizada pelos usuários em seus postos de trabalho. 
Nesta fase, a implementação utiliza o modelo em cascata, cuja saída de uma etapa "flui" para a etapa seguinte, e o desenvolvimento só prossegue quando uma etapa tiver sido concluída. Para assumir esta opção, é preciso que caso ocorra alguma alteração dos requisitos após a fase de apresentação (item IV.6.2) e análise dos dados (item IV.6.3), estes deverão esperar o próximo ciclo para serem implementados, ou seja, haverá um "congelamento" dos requisitos atuais discutidos com os usuários durante a iteração corrente.

Gonçalves et al. (2005) dão mais detalhes sobre a arquitetura utilizada nesta atividade (não faz parte do escopo desta pesquisa).

Assim, uma vez que a arquitetura da aplicação já foi definida na fase anterior (prototipação não funcional), serão implementados todos os formulários DHTML e seus elementos de interação, utilizando os conceitos de ergonomia das interfaces e awareness (a partir da segunda iteração), assim como o sistema gerenciador de banco de dados para implementação das transações, eventos, relatórios e rotinas associadas ao sistema que está sendo desenvolvido.

O desenvolvimento do sistema é orientado ao fluxo do processo, em que, para cada fase definida no workflow foi associada uma ou mais interfaces e para cada uma destas interfaces foi associada a hierarquia de subatividades e respectivas interfaces.

A saída para a próxima fase (item IV.6.2) ocorre quando os documentos necessários contemplam as mudanças coletadas na apresentação relativa ao ciclo de desenvolvimento corrente.

Assim como no processo (ciclo 2) anterior (item IV.5), para que seja possível atingir o modelo mental dos usuários, parte-se do modelo funcional desenvolvido nesta atividade inicial e que será o modelo de interação inicial do sistema.

Os principais artefatos de saída são: requisitos de domínio, fluxogramas e interfaces, assim como funcionalidades associadas, modelo de dados implementado, diagrama de navegação e artefatos associados ao conceito de awareness e mente coletiva.

Nos dados do quadro abaixo são reproduzidos os elementos de awareness (ver item II.5.5) que são utilizados na implementação dos requisitos do trabalho cooperativo levantados neste ciclo. 
Quadro IV.6 - Elementos de awareness (reprodução do Quadro II.1)

\begin{tabular}{|c|c|c|}
\hline Categoria & Elemento & Significado \\
\hline \multirow[t]{7}{*}{ O quê } & \multirow{5}{*}{$\begin{array}{c}\text { Atividades: } \\
\text { Ações } \\
\text { Artefatos } \\
\text { Produção } \\
\text { Histórico de } \\
\text { ações }\end{array}$} & $\begin{array}{l}\text { Visão ampla das tarefas individuais, do grupo e de sua } \\
\text { produção: }\end{array}$ \\
\hline & & O que fazer e o que os outros estão fazendo \\
\hline & & Em quais objetos estão trabalhando no momento \\
\hline & & Quais são os resultados preliminares do trabalho \\
\hline & & O que um indivíduo esteve realizando \\
\hline & \multirow{2}{*}{$\begin{array}{l}\text { Papéis: } \\
\text { Alcance }\end{array}$} & Diferenciação das informações em função do papel \\
\hline & & Até onde podem ou devem \\
\hline \multirow[t]{5}{*}{ Quando } & $\begin{array}{l}\text { Eventos } \\
\text { passados, } \\
\text { passado } \\
\text { continuo e } \\
\text { presentes: }\end{array}$ & $\begin{array}{l}\text { Contexto sobre o que foi feito (eventos no passado) e do que } \\
\text { ainda está sendo feito (passado contínuo), }\end{array}$ \\
\hline & $\begin{array}{l}\text { Histórico de } \\
\text { eventos }\end{array}$ & Quando um evento aconteceu \\
\hline & Eventos futuros & $\begin{array}{l}\text { Representam uma opção interessante para manter os } \\
\text { membros atentos aos possíveis rumos do trabalho. }\end{array}$ \\
\hline & Persistência & $\begin{array}{l}\text { Alta: Definição de um critério de caducidade, que inutiliza } \\
\text { estas informações. }\end{array}$ \\
\hline & $\begin{array}{l}\text { Apresentação } \\
\text { das informações } \\
\text { de awareness }\end{array}$ & Posterior (a critério do usuário) \\
\hline \multirow[t]{4}{*}{ Onde } & $\begin{array}{l}\text { Espaço de } \\
\text { trabalho: }\end{array}$ & $\begin{array}{l}\text { Objetos compartilhados pelo grupo. Por meio de sua } \\
\text { manipulação e de seu histórico que mostram o que houve e } \\
\text { está acontecendo dentro do trabalho em grupo. }\end{array}$ \\
\hline & $\begin{array}{l}\text { Histórico de } \\
\text { artefatos }\end{array}$ & Como um determinado artefato chegou àquele estado \\
\hline & $\begin{array}{l}\text { Histórico de } \\
\text { localização }\end{array}$ & Onde um indivíduo esteve \\
\hline & $\begin{array}{l}\text { Metáforas de } \\
\text { sistema }\end{array}$ & $\begin{array}{l}\text { Relacionam o groupware com versões monousuárias do } \\
\text { sistema, havendo necessidade de enriquecê-la } \\
\text { adequadamente com as informações de awareness. }\end{array}$ \\
\hline \multirow[t]{2}{*}{ Como } & Interface & $\begin{array}{l}\text { Interfaces desacopladas, mas não impedindo a interface de } \\
\text { incluir elementos para awareness }\end{array}$ \\
\hline & $\begin{array}{l}\text { Balanceamento } \\
\text { de interface }\end{array}$ & $\begin{array}{l}\text { Filtragem ou um agrupamento das informações, mostrando } \\
\text { apenas aquilo que for mais útil }\end{array}$ \\
\hline \multirow[t]{2}{*}{ Quem } & Autoria & Quem realizou um determinado evento \\
\hline & $\begin{array}{l}\text { Histórico de } \\
\text { presença }\end{array}$ & Quem esteve em um local do ambiente e quando \\
\hline
\end{tabular}

Fonte: Adaptado de Assis (2000) e PINHEIRO et al. (2001)

\section{IV.6.2 Apresentação do protótipo evolucionário (funcional)}

Assim como no caso de prototipação não funcional, os artefatos desenvolvidos na fase de implementação em cascata (interfaces gráficas, interações, respostas 
programadas, navegação entre as hierarquias dos formulários e o fluxograma do workflow) serão utilizados, como "guia" para aplicação da Análise Coletiva do Trabalho.

Para a realização da primeira sessão de ACT (que ocorrerá no segundo ciclo de iteração), será preciso que os usuários façam uso do sistema em situação real de trabalho, após receberem treinamento adequado na primeira versão funcional do sistema (primeiro ciclo de iteração).

Em linhas gerais, os aspectos abordados nas sessões de ACT, além das que foram citadas no ciclo anterior (item IV.5.2), devem focar o uso real do sistema, observando que alguns destes aspectos devem reforçar as ações (contribuição, representação e subordinação), processos sociais (socialização, conversação e recapitulação) e da consciência sobre a contextualização das atividades individuais por intermédio da compreensão das atividades realizadas por outras pessoas (awareness):

- Inverte-se o processo do saber. São os trabalhadores que sabem, os pesquisadores não sabem. Todos têm um algo próprio e único para contar: sua atividade real (subordinação e contribuição);

- Para se explicar o que se faz, deve-se antes refletir sobre o que se faz, o que não é um processo usual, fazendo com que se torne explícito e consciente tudo o que se fazia de modo automático, visto que a pessoa que se exprime, também toma consciência, não se exprime somente para as demais pessoas, exprime para que ela mesma saiba o que visa. Normalmente, não se pensa na atividade que se faz, mas em seus resultados, é a atividade em si que é importante, e é ela quem precisa ser explicada (subordinação, contribuição e elementos de awareness);

- Verificar na descrição dos trabalhadores o que é comum, e o que é diferente na atividade, procurando avaliar os principais pontos se que destacam e uma caracterização mais detalhada de determinados aspectos da atividade do usuário (representação, contribuição e elementos de awareness);

- Procurar entender nas atividades dos usuários as relações com as demais atividades: explicar o que os outros fazem antes ou depois dele no processo 
produtivo, acima, ao lado ou abaixo na escala hierárquica (representação e elementos de awareness);

- Durante a sessão, verificar a necessidade de introdução de elementos de awareness, conforme os conceitos apresentados no item II.5.5 e do Quadro IV.6, de modo a procurar obter a consciência sobre a contextualização das atividades individuais por meio da compreensão das atividades realizadas por outras pessoas e de que forma (elementos de interface gráfica) o sistema informatizado refletirá estes elementos.

No início de cada sessão, é aplicado o questionário do quadro abaixo que tem como objetivo avaliar qualitativamente a evolução das características cooperativas do trabalho, detectando pontos para sua melhoria por meio da teoria da mente coletiva.

Quadro IV.7 - Avaliação qualitativa sobre a intensidade da mente coletiva nas sessões de ACT

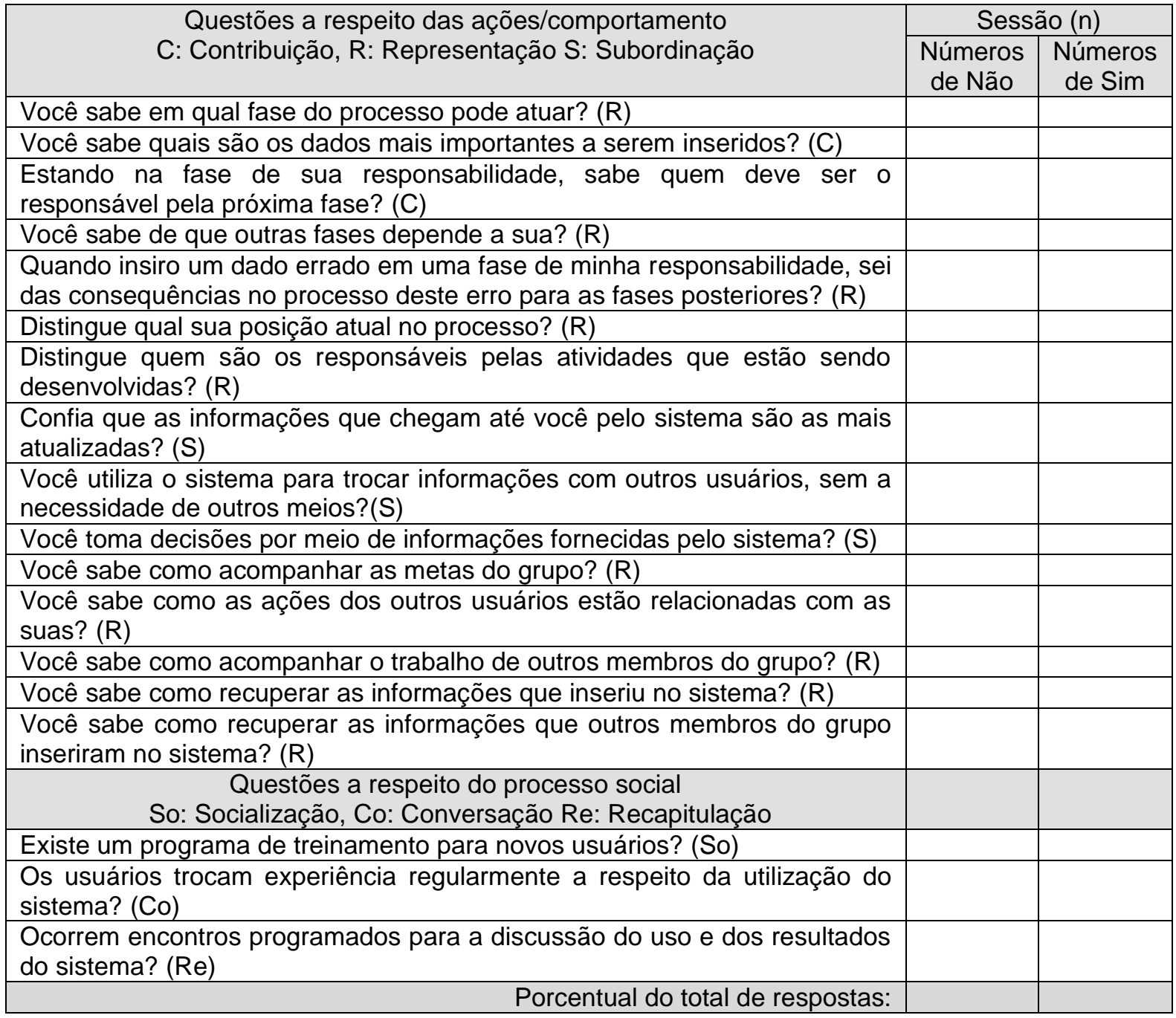

Fonte: Elaborado pelo autor, baseado em Weik and Roberts (1993) 


\section{IV.6.3 Análise dos dados - avaliação do término do protótipo evolutivo}

Os dados oriundos da apresentação do protótipo em uso real são analisados com relação às respostas às perguntas do Quadro IV.7, para obtenção dos elementos de awareness descritos no item II.5.5. Em função dos resultados obtidos, os elementos adequados são selecionados para implementação, e nova sessão de ACT deverá ser realizada, com os requisitos congelados durante os ciclos da pesquisa-ação.

Durante esta fase do processo, com o sistema em uso e antes das sessões, é preciso realizar entrevistas (ver item II.8.2) com os usuários que representam os vários papéis no fluxo de trabalho, visando a obter as informações necessárias para construir/corrigir os artefatos de software em uso.

O planejamento também é desenvolvido para o próximo ciclo (interação) do protótipo funcional, por exemplo, definindo-se, dentro do possível, quais temas serão abordados e quais pessoas serão entrevistadas, além de preparar uma agenda para a sessão com os passos que devem ser seguidos no contexto da iteração do processo. Cada novo tema que será explorado com os usuários selecionados, deverá ser estudado com mais detalhes pelos pesquisadores que realizarão as sessões de ACT.

O término do processo como um todo ocorre quando as novas implementações definidas na fase de apresentação implicarem um ganho marginal para o sistema, de modo que a preocupação dos usuários recaia mais na estética (sem afetar a usabilidade do sistema) do que em suas funcionalidades e, também, que haja concordância dos usuários na sessão de ACT que o sistema já pode ser liberado para uso, ficando eventuais mudanças proteladas para futuras manutenções no sistema (ver Figura IV.1e Figura IV.3), mas sem necessidade de uma nova iteração. Assim como na prototipação não funcional, ao término deste processo um relatório também deve ser escrito pelos pesquisadores e, antes de sua divulgação, deve ser apresentado ao conhecimento dos participantes, para que se possa detectar erros de interpretação e pontos que não ficaram esclarecidos nas reuniões. Esta confirmação, também, pode ser obtida pela concordância dos usuários durante as sessões de ACT, ou posterior confirmação nesta fase (análise dos dados). 


\section{IV.7 PLANEJAMENTO DE EXECUÇÃO DO PROCESSO PROPOSTO EM FUNÇÃO DOS CICLOS DA PESQUISA-AÇÃO}

A Figura IV.10 abaixo mostra a relação entre os ciclos de condução da pesquisaação e as fases dos três processos propostos (que correspondem ao macroprocesso proposto - Figura IV.1). Os três processos propostos correspondem a três ciclos de PA, e cada ciclo deste pode sofrer várias iterações ("voltas" sobre si mesmo).

Assim, os ciclos de condução descritos por Coughlan e Coghlan (2002) sofreram as seguintes adaptações para atingir aos objetivos deste trabalho:

- Os ciclos de avaliação, coleta e feedback de dados correspondem a um único ciclo denominado de levantamento e discussão dos dados, equivalente à fase de apresentação (ciclos 2 e 3) ou simulação ( ciclo 1) do processo proposto;

- Os ciclos de análise dos dados e planejamento da ação correspondem a um único ciclo denominado análise e planejamento, equivalente à fase de análise e avaliação de término;

- O ciclo de implementação da PA equivale à fase de implementação do processo proposto.

Antes do primeiro ciclo da pesquisa-ação, o estudo da viabilidade e a verificação da aplicabilidade do processo serão realizados por meio do estudo do contexto e propósitos (item III.4.2), sendo verificado se o sistema de informação pode ser implementado em um software, e se o processo proposto pode ser aplicado.

Uma nova iteração em qualquer dos três ciclos inicia-se no ciclo de implementação, com a diferença que, no ciclo1, são os artefatos provenientes da fase preliminar da PA que darão início à iteração; no ciclo 2, são os artefatos provenientes do passo de análise e planejamento do ciclo1 e, no ciclo 3 , os artefatos provenientes do passo de análise e planejamento do ciclo 2 (Figura IV.10). 


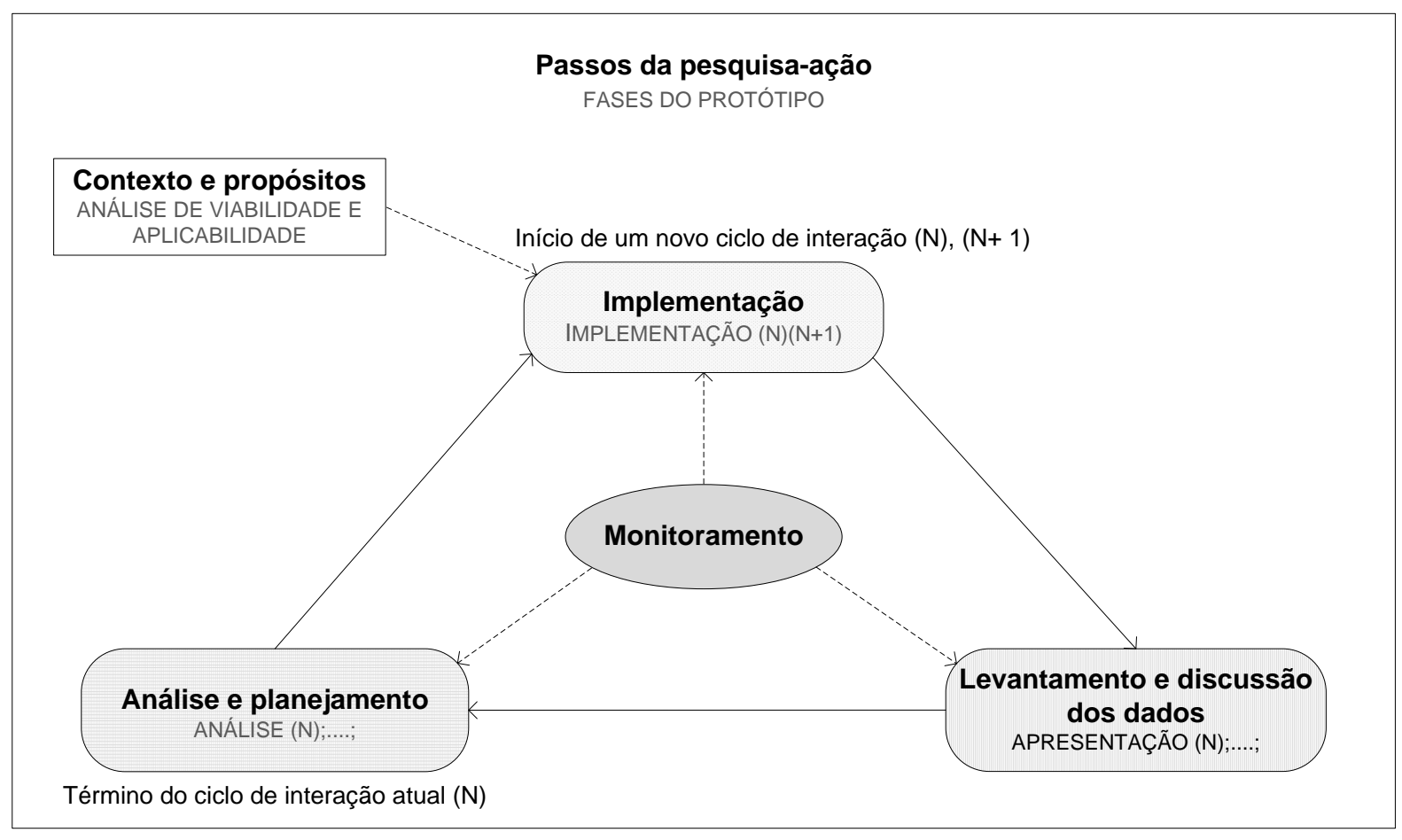

Figura IV.10 - Passos da Pesquisa-ação e correspondentes atividades para os processos de identificação e refinamento das características cooperativas do trabalho Fonte: elaborado pelo autor

Nos dados do Quadro IV.8, pode ser vista a adaptação dos ciclos de desenvolvimento da PA com o macroprocesso proposto e os conceitos utilizados em cada um dos ciclos (quadro metodológico).

Quadro IV.8 - Quadro metodológico

\begin{tabular}{|c|c|c|}
\hline \multicolumn{3}{|c|}{ CICLOS E FASE DA PESQUISA-AÇÃO } \\
\hline \multicolumn{3}{|c|}{ Fase preliminar : Contexto e propósitos } \\
\hline Fase & Componente & Descrição \\
\hline \multirow[t]{2}{*}{ Início } & \multirow[t]{2}{*}{ Fase preliminar } & $\begin{array}{l}\text { Contexto conceitual: } \\
\text { análise de viabilidade e da aplicabilidade do processo (itens } \\
\text { IV.3.1 e IV.3.2, respectivamente) } \\
\text { Fundamentação teórica para entendimento do contexto do } \\
\text { problema, envolvendo as seguintes disciplinas relacionadas: } \\
\text { - Engenharia de Requisitos } \\
\text { - Técnicas utilizadas na descoberta de requisitos }\end{array}$ \\
\hline & & $\begin{array}{l}\text { Contexto empírico: } \\
\text { descrição do SI estudado nesta pesquisa }\end{array}$ \\
\hline \multicolumn{3}{|c|}{ Ciclo 1: Processo para a Identificação dos requisitos individuais do trabalho cooperativo } \\
\hline Passo & Componente & Descrição \\
\hline 1 & Implementação & $\begin{array}{l}\text { Fase do processo: identificação das características iniciais e } \\
\text { implementação/revisão (item IV.4.1) } \\
\text { Fundamentação teórica: } \\
\text { - Storyboarding e prototipação em papel; } \\
\text { - Modelos e processo de software; } \\
\text { - Elementos de Engenharia de Requisitos; } \\
\text { - A ergonomia das interfaces. }\end{array}$ \\
\hline
\end{tabular}




\begin{tabular}{|c|c|c|}
\hline 2 & $\begin{array}{l}\text { Levantamento e } \\
\text { discussão dos dados }\end{array}$ & $\begin{array}{l}\text { Fase do processo: simulação do protótipo em papel (item } \\
\text { IV.4.2). } \\
\text { Fundamentação teórica: } \\
\text { - Storyboarding e prototipação em papel; } \\
\text { - Modelo de desenvolvimento iterativo e evolucionário; } \\
\text { - Cenários. }\end{array}$ \\
\hline 3 & $\begin{array}{l}\text { Análise e } \\
\text { planejamento }\end{array}$ & $\begin{array}{l}\text { Fase do processo: análise dos dados e término da } \\
\text { prototipação em papel (item IV.4.3) } \\
\text { Fundamentação teórica: } \\
\text { - Storyboarding e prototipação em papel; } \\
\text { - Análise Coletiva do Trabalho (planejamento prox. fase). }\end{array}$ \\
\hline 4 & $\begin{array}{l}\text { Monitoramento } \\
\text { (conclusões) }\end{array}$ & $\begin{array}{l}\text { Analisar os resultados e lições aprendidas, relacionando o } \\
\text { empírico ao teórico trazendo ganhos de conhecimento. }\end{array}$ \\
\hline \multicolumn{3}{|c|}{ Ciclo 2: Processo para identificação e simulação dos requisitos do trabalho cooperativo } \\
\hline Passo & Componente & Descrição \\
\hline 1 & Implementação & $\begin{array}{l}\text { Fase do processo: Implementação/revisão protótipo não } \\
\text { funcional (item IV.5.1) } \\
\text { Fundamentação teórica: } \\
\text { - Técnicas de prototipação e ergonomia e concepção } \\
\text { informática; } \\
\text { - Modelos e processo de software; } \\
\text { - Elementos de Engenharia de Requisitos; } \\
\text { - A ergonomia das interfaces. }\end{array}$ \\
\hline 2 & $\begin{array}{l}\text { Levantamento e } \\
\text { discussão dos dados }\end{array}$ & $\begin{array}{l}\text { Fase do processo: apresentação do protótipo não funcional } \\
\text { (item IV.5.2). } \\
\text { Fundamentação teórica: } \\
\text { - Técnicas de prototipação e ergonomia e concepção } \\
\text { informática; } \\
\text { - Modelo de desenvolvimento iterativo e evolucionário; } \\
\text { - Análise Coletiva do Trabalho; } \\
\text { - Cenários; } \\
\text { - Modelo mental e interação; } \\
\text { - A dimensão coletiva do trabalho e o trabalho } \\
\quad \text { cooperativo. }\end{array}$ \\
\hline 3 & $\begin{array}{l}\text { Análise e } \\
\text { planejamento }\end{array}$ & $\begin{array}{l}\text { Fase do processo: análise dos dados e término da } \\
\text { prototipação não funcional (item IV.5.3) } \\
\text { Fundamentação teórica: } \\
\text { - Técnicas de prototipação e ergonomia e concepção } \\
\text { informática; } \\
\text { - Análise Coletiva do Trabalho (planejamento); } \\
\text { - A ergonomia das interfaces; } \\
\text { - Engenharia de Requisitos. }\end{array}$ \\
\hline 4 & $\begin{array}{l}\text { Monitoramento } \\
\text { (conclusões) }\end{array}$ & $\begin{array}{l}\text { Analisar os resultados e lições aprendidas, relacionando o } \\
\text { empírico ao teórico trazendo ganhos de conhecimento. }\end{array}$ \\
\hline \multicolumn{3}{|c|}{ Ciclo 3: Processo para o refinamento dos requisitos do trabalho cooperativo } \\
\hline Passo & Componente & Descricão \\
\hline 1 & Implementação & $\begin{array}{l}\text { Fase do processo: implementação em cascata (item IV.6.1) } \\
\text { Fundamentação teórica: } \\
\text { - Técnicas de prototipação e ergonomia e concepção } \\
\text { informática; } \\
\text { - Modelos e processo de software (modelo em cascata); } \\
\text { - Elementos da Engenharia de Requisitos; } \\
\text { - A ergonomia das interfaces; } \\
\text { - Elementos de awareness. }\end{array}$ \\
\hline 2 & $\begin{array}{l}\text { Levantamento e } \\
\text { discussão dos dados }\end{array}$ & $\begin{array}{l}\text { Fase do processo: apresentação do protótipo evolucionário } \\
\text { (item IV.6.2IV.5.2). } \\
\text { Fundamentação teórica: }\end{array}$ \\
\hline
\end{tabular}




\begin{tabular}{|c|c|c|}
\hline & & $\begin{array}{l}\text { - Técnicas de prototipação e ergonomia e concepção } \\
\text { informática; } \\
\text { - Modelo de desenvolvimento iterativo e evolucionário; } \\
\text { - Análise Coletiva do Trabalho; } \\
\text { - Modelo mental e interação; } \\
\text { - A dimensão coletiva do trabalho e o trabalho } \\
\text { - } \quad \text { Teoperativo; } \\
\text { - CSCW, Groupware, modelo 3C e awareness }\end{array}$ \\
\hline 3 & $\begin{array}{l}\text { Análise e } \\
\text { planejamento }\end{array}$ & $\begin{array}{l}\text { Fase do processo: análise dos dados - avaliação sobre o } \\
\text { término do protótipo evolutivo (item IV.6.3) } \\
\text { Fundamentação teórica: } \\
\text { - Técnicas de prototipação e ergonomia e concepção } \\
\text { informática; } \\
\text { - Análise Coletiva do Trabalho (planejamento); } \\
\text { - A ergonomia das interfaces; } \\
\text { - Engenharia de Requisitos; } \\
\text { - Teoria da mente coletiva; } \\
\text { - CSCW, Groupware, modelo 3C e awareness; } \\
\text { - Técnicas de entrevista. }\end{array}$ \\
\hline 4 & $\begin{array}{l}\text { Monitoramento } \\
\text { (conclusões) }\end{array}$ & $\begin{array}{l}\text { Analisar os resultados e lições aprendidas, relacionando o } \\
\text { empírico ao teórico trazendo ganhos de conhecimento. }\end{array}$ \\
\hline
\end{tabular}

Fonte: Elaborado pelo autor 
V FASE PRELIMINAR E CICLO 1 DA PESQUISA-AÇÃO: PROCESSO PARA ESPECIFICAÇÃO DE REQUISITOS DE SOFTWARE COM FOCO NA IDENTIFICAÇÃO DAS CARACTERÍSTICAS INDIVIDUAIS DO TRABALHO COOPERATIVO E DAS CARACTERÍSTICAS DE DOMÍNIO

A fase preliminar desta PA corresponde a um entendimento sobre o contexto no qual a pesquisa será realizada, o propósito da condução do trabalho e a verificação da viabilidade e aplicabilidade do processo proposto.

O ciclo 1 inicia-se com o levantamento do processo não informatizado e a definição de um conjunto de artefatos para o início da prototipação em papel, além da definição da situação de referência do processo não informatizado e as respectivas ações características futuras prováveis do software que será implementado.

Após a realização das iterações deste ciclo, obtêm-se os principais artefatos relativos aos requisitos individuais do trabalho cooperativo que serão utilizados para iniciar o ciclo 2 desta pesquisa.

\section{V.1 CONTEXTO E PROPÓSITOS}

\section{V.1.1 Contexto empírico}

Neste item, o ambiente onde foi realizada a pesquisa-ação é contextualizado, mostrando a necessidade da condução do trabalho. O estabelecimento das justificativas para a ação requerida, além das justificativas para a pesquisa que são apresentadas no item III.3 (caracterização da condução da PA).

A empresa onde foi realizada a pesquisa-ação corresponde a uma grande empresa nacional que desenvolve tecnologia com aproximadamente 1.500 colaboradores (PesqTec ), com atuação no mercado há mais de 115 anos.

A PesqTec tem como uma de suas missões prover apoio tecnológico aos setores produtivos, o que é realizado tanto pela prestação de serviços laboratoriais, como pelo desenvolvimento de serviços de consultoria técnica, com atuação nas áreas de 
engenharia civil, metalurgia, madeiras, mecânica, eletricidade industrial, engenharia naval e oceânica, transportes, química, geologia, couros e calçados, biotecnologia, tecnologia ambiental, normalização e qualidade industrial, informação tecnológica, informática, educação de nível superior e treinamento.

Anualmente são produzidos mais de 42.349 (em 2008) documentos técnicos, cuja prestação de serviços laboratoriais representa mais de $30 \%$ da receita própria por intermédio de seus 30 laboratórios.

Contudo, não existe um padrão de gerenciamento e atendimento comum aos laboratórios, apesar da existência de uma série de normas internas do sistema da qualidade da PesqTec que orienta os aspectos gerais que devem ser estabelecidos nas principais fases do atendimento de uma determinada solicitação (orçamento, etc.). Cada um destes laboratórios aplica estas normas de modo particular para as solicitações de seus clientes, uma vez que não há centralização dos atendimentos.

Como consequência da falta de padronização, as informações sobre o processo de atendimento são geradas de modo independente por cada um dos laboratórios (em muitos deles, o processo de atendimento é feito por meio de arquivos em papel), as informações são fragmentadas e de difícil agregação, inclusive, para retorno da situação de atendimento ao cliente.

O processo de atendimento corresponde a um workflow (ver Apêndice A), passando por várias etapas, desde a abertura do pedido, até sua finalização, de modo a envolver o trabalho cooperativo dos participantes do laboratório (técnicos, supervisores de laboratório e secretárias), em especial, nos laboratórios que oferecem vários tipos de serviços, complementares uns aos outros (um mesmo pedido do cliente pode conter vários destes serviços de um mesmo laboratório).

Não é incomum também a situação na qual um cliente solicita determinados tipos de serviços que envolvem a participação conjunta de vários laboratórios, cada um contribuindo com o serviço para o qual possui especialização. Neste caso, os laboratórios devem trabalhar cooperativamente para o atendimento, sob pena de um atendimento inadequado ou incompleto para este tipo de solicitação.

Em função da necessidade de padronizar e sistematizar o processo de atendimento da prestação de serviços que permite a integração de todos os laboratórios, a 
diretoria da empresa PesqTec aprovou o desenvolvimento de um software, com o seguinte objetivo (ver item III.4.2):

Desenvolvimento de um software de acompanhamento e gerenciamento laboratorial a ser disponibilizado na intranet da empresa abrangendo todos os laboratórios e que tem como objetivo uniformizar os métodos de acompanhamento e gerenciamento de serviços laboratoriais, dando homogeneidade e maior eficiência ao desenvolvimento e acompanhamento de serviços técnicos correntes, desde o momento da solicitação de um serviço, até o seu faturamento.

O sistema permite gerar orçamentos, registrar amostras, obter número de documentos técnicos e gerar pedidos de faturamento de modo totalmente integrado (instrumentos de controle e acompanhamento do atendimento dos laboratórios). Também deverá ser possível fazer o acompanhamento das atividades diárias dos laboratórios, assim como fornecer informações gerenciais sobre as principais atividades executadas (indicadores de desempenho operacionais) (Programa informatizado de gerenciamento laboratorial, 2005, p.3).

Assim, o processo de mudança para a aplicação da PA fica estabelecido, que é a automatização do processo de atendimento aos clientes da empresa PesqTec (conforme descrito acima, nos objetivos do projeto).

Por outro lado, o ambiente para a aplicação das ações na resolução do problema apresentado corresponde ao trabalho cooperativo dos funcionários dos laboratórios da empresa PesqTec, para o atendimento das solicitações de seus clientes, por meio do software desenvolvido, ambiente este que propiciou também condições para a pesquisa acadêmica apresentada neste trabalho (ver item I.2) e de todo o processo de aprendizagem e monitoramento que acompanhou seu desenrolar, conforme é descrito nos próximos itens e capítulos.

\section{V.1.2 Contexto conceitual: análise de viabilidade}

Considerando-se o objetivo apresentado no item V.1.1, que mostra um resumo da descrição do sistema e de como este pretende dar apoio aos processos de negócio, da descrição da fase de análise de viabilidade descrita no item IV.3.1 e das questões do Quadro IV.1, a concepção e a implementação do software para automação do 
processo de acompanhamento laboratorial mostram-se viáveis em função dos seguintes itens:

- Identificação dos problemas operacionais correntes: conforme apresentado no item V.1.1, atualmente não é possível integrar as solicitações dos serviços dos clientes intra e interlaboratorias, tanto em relação ao fluxo do acompanhamento dos atendimentos, como em relação às informações gerenciais associadas aos mesmos;

- Objetivos do negócio, oportunidades abertas: dado o objetivo descrito no item V.1.1, este projeto dá a oportunidade de pesquisar sobre o processo para especificação de requisitos de software com foco de aplicação no trabalho cooperativo em sistemas de informação com coordenação distribuída nas ações dos usuários;

- Restrições mais importantes da aplicação: a aplicação (software) implementada possui como restrição o fato de não gerar os documentos físicos do processo de atendimento, assim como de não realizar a execução física do serviço (gerenciar o equipamento do laboratório que executa o serviço);

- Fronteiras deste sistema e pontos de interface com outros sistemas de informação (visão geral das entradas, saídas): a análise preliminar do diagrama de contexto e dos principais dados trocados com outros sistemas mostraram que não existem informações críticas que não possam fluir entre os sistemas em razão das questões tecnológicas (ver Figura V.2);

- Metas de custo benefício e a posição da aplicação dentro do contexto da organização: a relação custo/benefício foi avaliada pela diretoria da empresa PesqTec, como positiva para os resultados pretendidos e a posição da aplicação foi discutida no item V.1.1.

Com relação aos dados do Quadro IV.1, as seguintes ponderações são realizadas com relação às questões que ainda não foram consideradas (ver Quadro V.1 abaixo). 
Quadro V.1 - Análise da viabilidade: respostas

\begin{tabular}{|c|}
\hline Respostas sobre a análise de viabilidade \\
\hline $\begin{array}{l}\text { P: O sistema pode ser desenvolvido com a tecnologia existente, dentro das restrições de custos e } \\
\text { prazos? }\end{array}$ \\
\hline $\begin{array}{l}\text { R: Sim, a tecnologia que será utilizada permite acesso em uma navegador na intranet da empresa } \\
\text { PesqTec dentro das restrições de custos e preços especificadas no orçamento do projeto. }\end{array}$ \\
\hline P: Este sistema deve ser integrado a outros já existentes? \\
\hline $\begin{array}{l}\text { R: Sim, aos sistemas de Custos e Preços, ao ERP da empresa, ao sistema de definição de números } \\
\text { de documentos técnicos e ao sistema unificado de colaboradores da empresa, sendo que nenhuma } \\
\text { destas conexões inviabiliza o projeto. }\end{array}$ \\
\hline P: Como a empresa resolve o problema se este sistema não for implantado? \\
\hline $\begin{array}{l}\text { R: Ficará com o sistema de informação atual, desconectado e fragmentado, com os problemas } \\
\text { discutidos no item V.1.1 }\end{array}$ \\
\hline $\begin{array}{l}\text { P: Quais são os problemas com o processo corrente e como o novo sistema informatizado pode } \\
\text { colaborar na solução dos mesmos? }\end{array}$ \\
\hline R: Ver item V.1.1 \\
\hline P: Quais são os ganhos diretos que este sistema pode fornecer para os objetivos de negócio? \\
\hline $\begin{array}{l}\text { R: Menos erros no atendimento aos clientes, verificação em tempo real da posição do serviço } \\
\text { requisitado pelo cliente, controle de orçamentos enviados, controle de material enviado para análise, } \\
\text { integração com outros softwares da empresa, posição em tempo real do faturamento do laboratório e } \\
\text { dos serviços mais executados, maior eficiência e eficácia no atendimento às solicitações dos clientes } \\
\text { através de uma melhor interação entre os trabalhadores dos laboratórios e entre laboratórios, etc. }\end{array}$ \\
\hline P: As informações deverão ser transferidas de e para outros sistemas da organização? \\
\hline R: Sim, mas não representam problemas técnicos em sua execução \\
\hline P: Este sistema necessita de tecnologia que não foi utilizada previamente na empresa? \\
\hline $\begin{array}{l}\text { R: A tecnologia de TI empregada na implementação do software é conhecida dentro da empresa em } \\
\text { questão e a tecnologia para levantamento das características do trabalho cooperativo para este tipo }\end{array}$ \\
\hline
\end{tabular}

\section{Fonte: elaborado pelo autor}

\section{V.1.3 Contexto conceitual: verificação da aplicabilidade do processo ao sistema candidato}

Antes de se aplicar o processo proposto nesta pesquisa, primeiro é importante verificar a aplicabilidade deste processo. Para tanto, é preciso avaliar as seguintes condições (ver item IV.3.2):

- O sistema informatizado não exige grande quantidade de especificação algorítmica: o software a ser desenvolvido possui uma grande quantidade de elementos de dados e relacionamento entre registros, pois se trata de um sistema comercial do tipo workflow administrativo (ver Apêndice A), em que o processamento é realizado, na grande maioria das vezes, com baixo conteúdo algorítmico (prioritariamente com operações de escrita, leitura e atualização de informações no banco de dados); 
- Os usuários devem estar dispostos e capazes de participar ativamente, assim como o gerente do projeto: o desenvolvimento deste software foi solicitado pelas áreas técnicas da empresa PesqTec. As equipes de usuários dos diversos laboratórios sempre se mostraram interessadas em participar das sessões em razão da necessidade deste tipo de solução para os laboratórios;

- O sistema informatizado possui muita interação com os usuários por intermédio de transações, não operando com muito processamento em lote: 0 software que foi desenvolvido não trabalha com processamento em lote (batch), possuindo prioritariamente transações associadas a banco de dados;

- O Sistema de Informação apresenta coordenação distribuída nas ações dos usuários e a comunicação entre eles ocorre preponderantemente de modo indireto por meio dos dados inseridos durante o uso do software, sendo este (software) assíncrono e desacoplado (ver item II.5.5).

Deste modo, o software proposto para dar suporte ao processo de acompanhamento laboratorial atende às condições, para que o processo proposto seja aplicado.

\section{V.2 CICLO 1: PROCESSO PARA ESPECIFICAÇÃO DE REQUISITOS DE SOFTWARE COM FOCO NA IDENTIFICAÇÃO DAS CARACTERÍSTICAS INDIVIDUAIS DO TRABALHO COOPERATIVO}

\section{V.2.1 Introdução}

Este ciclo corresponde ao ciclo tradicional do desenvolvimento de software, em que são levantadas as necessidades dos usuários de modo individual, sem considerar plenamente os requisitos do trabalho cooperativo (na ER tradicional, o modelo dos requisitos é para o indivíduo e não ao trabalho cooperativo).

O principal objetivo é obter os artefatos de software (diagrama de contexto, o fluxograma inicial do processo e as interfaces gráficas, respectivas) necessários para o segundo ciclo da PA, sem uma preocupação maior com seu detalhamento, uma vez que estes sofrerão uma natural evolução ao longo da aplicação do 
processo, com uma consequente evolução dos requisitos individuais do trabalho concomitantemente com as características do trabalho cooperativo.

Estes artefatos são implementados no ciclo 2 (somente as navegações, sem o código), sendo utilizados como ponto de partida (referencial comum) nas sessões de ACT. Deste modo, neste ciclo, não haverá uma preocupação mais pormenorizada no levantamento dos requisitos do trabalho cooperativo.

Não é necessário apresentar todos os artefatos construídos, dada a quantidade de informação e, também, pelo fato que haveria repetição de aplicação do processo proposto. Assim, serão escolhidos alguns dos artefatos como exemplo de aplicação.

O processo definido no item IV.4 será aplicado integramente neste ciclo, mas não serão apresentados os resultados das iterações intermediárias do ciclo, evidenciando-se somente parte dos artefatos de entrada (identificação das características iniciais do sistema - item IV.4.1) e os respectivos artefatos de saída obtidos durante a simulação individual (item IV.4.2), após as devidas iterações.

\section{V.2.2 Implementação}

\section{Identificação das características iniciais do sistema}

A primeira iteração no ciclo da PA ocorre na identificação das características iniciais do sistema, posteriormente, durante a iteração do ciclo, será necessário voltar para esta etapa, mas agora na implementação/revisão do protótipo em papel (ver Figura IV.10).

O levantamento do processo atual de atendimento (não automatizado), antes da implantação do software de atendimento às solicitações de serviços correntes dos laboratórios da empresa PesqTec, foi realizado nos diversos laboratórios por um dos laboratórios da empresa, no qual o pesquisador como funcionário desta empresa também participou.

O material deste levantamento foi usado como subsídio, para que a diretoria da empresa PesqTec decidisse pela aprovação do projeto para o desenvolvimento deste software. É importante ressaltar que os processos atuais de acompanhamento dos diversos laboratórios da empresa PesqTec, de modo geral, têm em comum as 
mesmas fases, pois estes devem sempre atender a uma série de normas impostas pela área de qualidade da empresa.

O fluxograma inicial resultante do levantamento utilizado na primeira iteração para a prototipação em papel é apresentado na Figura V.1 abaixo e foi baseado na sequência-padrão do atendimento dos laboratórios.

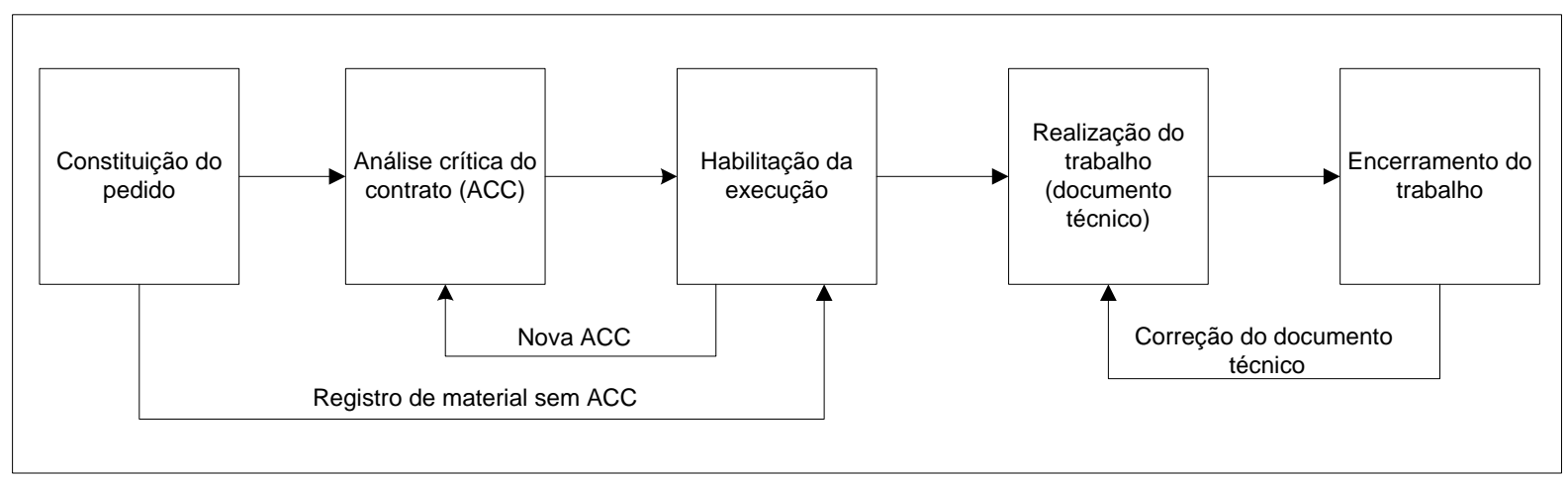

Figura V.1 - Fluxograma inicial e respectivas fases: processo não informatizado Fonte: sistema de acompanhamento (documento interno da PesqTec)

Abaixo encontra-se descrita, de modo resumido, cada uma das fases. É importante ressaltar também que nem todas as atividades descritas que foram levantadas do processo real, serão automatizadas e que o processo atual do SI sofrerá alterações para atender à informatização de parte do mesmo.

Constituição do pedido: ocorre a habilitação da demanda para que possa ser atendida dentro dos critérios de qualidade do laboratório. Este conjunto de atividades pode ser considerado de âmbito administrativo e, normalmente, está sob responsabilidade da secretária do laboratório.

- Principais atividades: registro de solicitação do cliente, consulta/cadastro de clientes e montagem e distribuição do processo;

- Principais entradas: pedido do cliente (dados iniciais do cliente);

- Principais saídas: registro do pedido, identificação do responsável e processo, requisitos iniciais do cliente e cadastro do cliente.

Análise crítica do contrato: verifica-se se a solicitação do cliente pode ser atendida com os recursos disponíveis no laboratório que é composta, geralmente, por uma análise técnica, seguida de uma análise financeira e a confecção da proposta 
orçamentária. Em geral, estas atividades são consideradas de âmbito gerencial e estão sob responsabilidade ou do responsável pela área, cuja competência é atender ao pedido ou de um técnico designado e reconhecido competente para o atendimento.

- Principais atividades: análise técnica, análise financeira, editoração e assinatura da proposta orçamentária.

- Principais entradas: registro do pedido, requisitos iniciais da solicitação do cliente e atendimentos anteriores para o mesmo cliente;

- Principais saídas: projeto da solução técnica, definição do escopo de atendimento, plano de trabalho, proposta comercial e autorização para atendimento.

Habilitação da execução: nesta fase, estão reunidas todas as etapas típicas relacionadas ao acompanhamento da tramitação da proposta orçamentária junto ao cliente e que habilitam a execução do trabalho contratado pelo pessoal técnico. Este conjunto de atividades pode ser considerado de âmbito administrativo e, normalmente, está sob responsabilidade da secretária do laboratório.

- Principais atividades: envio da proposta de atendimento, monitoração da proposta e recebimento do material;

- Principais entradas: proposta comercial editada eletronicamente e autorização para o atendimento;

- Principais saídas: proposta orçamentária, formalização da aceitação da proposta e disponibilização do material para realização do(s) serviços(s) contratado(s).

Realização do trabalho: registram-se as informações decorrentes da realização do trabalho propriamente dita. Este conjunto de atividades é de natureza técnica e, normalmente, está sob responsabilidade do responsável pelo laboratório ou do técnico designado.

- Principais atividades: programação para execução, inspeção técnica, recuperação ou editoração das planilhas de cálculo para o serviço realizado, 
preparação do serviço, aquisição e análise dos dados, editoração e revisão do documento técnico;

- Principais entradas: contrato assinado, material em que o serviço será realizado, plano de trabalho, insumos e dispositivos especiais;

- Principais saídas: documento técnico revisado.

Encerramento do processo: todas as etapas típicas pertinentes ao acompanhamento da tramitação do atendimento estão reunidas no contexto da emissão do documento técnico final e nas providências para seu encerramento. Este conjunto de atividades pode ser considerado administrativo e, normalmente, está sob responsabilidade da secretária do laboratório.

- Principais atividades: impressão do documento, verificações finais, expedição, encerramento do atendimento e pesquisa de satisfação.

- Principais entradas: documento técnico revisado (pronto).

- Principais saídas: documento técnico assinado e entregue ao cliente e quitação do contrato.

Nos dados do Quadro V.2 abaixo, estão descritas, em linhas gerais, as situações de referência do sistema atual (processo não informatizado) e as características futuras do processo (informatizado).

Nesta fase, os principais requisitos de domínio identificados são:

- Interface apropriada para troca de dados com o ERP da empresa;

- Aplicação de normas da qualidade da empresa PesqTec no desenvolvimento do software;

- O software deve ser desenvolvido em plataforma internet, com banco de dados centralizado;

- Conexão do software de acompanhamento com outros softwares legados (ver Figura V.8). 
Quadro V.2 - Situações de referência e ações futuras prováveis

\begin{tabular}{|c|c|}
\hline $\begin{array}{l}\text { Características do processo não } \\
\text { informatizado (situações de referência) }\end{array}$ & $\begin{array}{l}\text { Características do processo informatizado } \\
\text { (ação características futuras prováveis) }\end{array}$ \\
\hline Informações capilarizadas nos laboratórios & $\begin{array}{l}\text { Informações centralizadas em um único } \\
\text { repositório }\end{array}$ \\
\hline $\begin{array}{l}\text { Processo de atendimento fragmentado, com } \\
\text { as informações de cada uma das fases do } \\
\text { processo guardadas em mídias diferentes } \\
\text { (em cadernos de registro, em meio } \\
\text { magnético e em fichários). }\end{array}$ & $\begin{array}{l}\text { Informações armazenadas e recuperadas com } \\
\text { mesmo formato. }\end{array}$ \\
\hline $\begin{array}{l}\text { Obtenção de informações sobre o processo } \\
\text { (status do atendimento, estatísticas, } \\
\text { faturamento, orçamentos aprovados, etc.) de } \\
\text { difícil recuperação, principalmente quando } \\
\text { referentes ao conjunto dos laboratórios } \\
\text { (agregadas). }\end{array}$ & $\begin{array}{l}\text { Informações de fácil recuperação, tanto as } \\
\text { agregadas (referentes ao laboratório ou aos } \\
\text { laboratórios como um todo), como as } \\
\text { informações transacionais (referentes ao } \\
\text { andamento do atendimento). }\end{array}$ \\
\hline $\begin{array}{l}\text { Processos utilizam informações locais dos } \\
\text { laboratórios, sem integração com as } \\
\text { informações centralizadas da empresa } \\
\text { (clientes, usuários, preços, etc.). }\end{array}$ & $\begin{array}{l}\text { Integração com outros sistemas } \\
\text { informatizados da empresa. }\end{array}$ \\
\hline $\begin{array}{l}\text { Laboratórios possuindo processos próprios } \\
\text { de atendimento (desnormalizados), gerando } \\
\text { duplicações de informação e dificuldade de } \\
\text { trabalhos entre laboratórios (inter- } \\
\text { laboratorias). }\end{array}$ & Normalização do atendimento. \\
\hline $\begin{array}{l}\text { As atividade coletivas dos trabalhadores dos } \\
\text { laboratórios nem sempre produzem os } \\
\text { resultados esperados, podendo provocar } \\
\text { duplicações de serviço, atraso no } \\
\text { atendimento de solicitações, erros na } \\
\text { geração de documentos ao longo do } \\
\text { processo, etc. }\end{array}$ & $\begin{array}{l}\text { Através de recursos adequados, o software } \\
\text { desenvolvido dará suporte mais apropriado ao } \\
\text { trabalho cooperativo, melhorando a eficiência } \\
\text { e eficácia dos resultados esperados. }\end{array}$ \\
\hline
\end{tabular}

Fonte: elaborado pelo autor

O diagrama de contexto inicial definido durante esta fase poder ser visto na Figura

V.2 baixo:

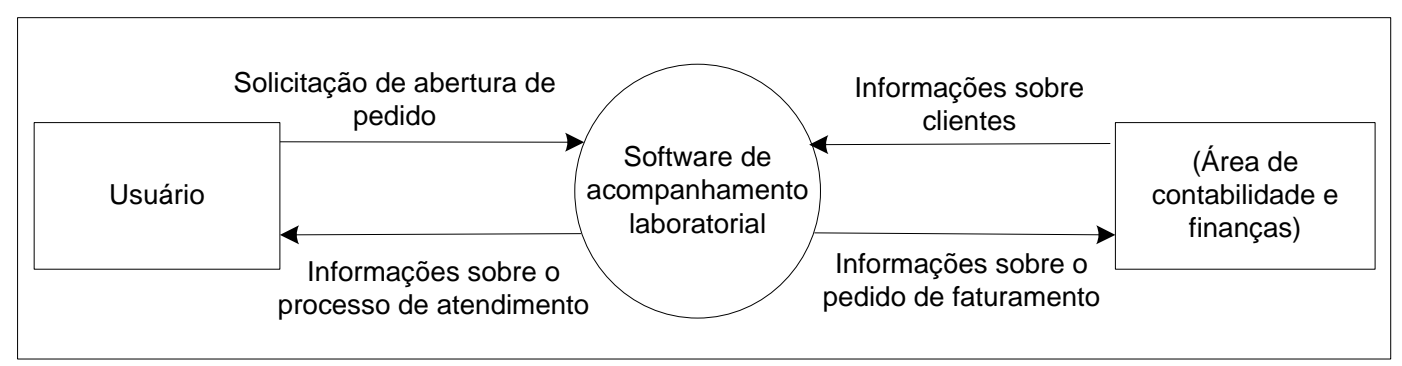

Figura V.2 - Diagrama de contexto inicial do ciclo 1 Fonte: Elaborado pelo autor

Para completar a avaliação das características iniciais do sistema, as questões do Quadro IV.2 que ainda não foram avaliadas, são resumidas nos dados do Quadro V.3 abaixo. 
Quadro V.3 - Identificação das características iniciais: respostas

\begin{tabular}{|c|}
\hline Respostas sobre a identificação das características iniciais \\
\hline P: O que precisa ser suportado pelo software e o que não deve ser suportado? \\
\hline $\begin{array}{l}\text { R: Em termos gerais, este software não realizará o serviço em si (realização física dos ensaios por } \\
\text { meio do controle dos equipamentos), fazendo o gerenciamento lógico de sua execução (se foi } \\
\text { realizado, ou não, por quais motivos, etc.) (ver item V.2.3). }\end{array}$ \\
\hline P: Quem usará esta aplicação (criar uma lista de "stakeholders")? \\
\hline $\begin{array}{l}\text { R: Técnicos, secretárias e responsáveis pelo laboratório, gerentes administrativos e diretores da } \\
\text { empresa PesqTec. }\end{array}$ \\
\hline P: O software faz parte integral do trabalho dos usuários, ou será usado só esporadicamente? \\
\hline $\begin{array}{l}\text { R: Para técnicos, secretárias e responsáveis pelo laboratório, será usado integralmente e para } \\
\text { gerentes administrativos e diretores será usado de modo parcial }\end{array}$ \\
\hline $\begin{array}{l}\text { P: Quais as conseqüências se um usuário cometer um erro, usando o sistema para as } \\
\text { funcionalidades que estão sendo discutidas? }\end{array}$ \\
\hline $\begin{array}{l}\text { R: Os principais erros (em termos de macroprocesso) são: atendimento ao cliente errado ou } \\
\text { informações sobre o cliente escolhidas erroneamente, escolha errada de serviços solicitados, } \\
\text { registro de material indevido, número de documento técnico não apropriado com o tipo de } \\
\text { documento e valor cobrado indevidamente. }\end{array}$ \\
\hline $\begin{array}{l}\text { P: Existem usuários com pouca familiaridade no uso básico de aplicações informatizadas (inclusive } \\
\text { uso em planilhas, navegadores, editores de texto, etc.)? }\end{array}$ \\
\hline $\begin{array}{l}\text { R: No caso da empresa PesqTec, em razão do tipo de serviço oferecido ao cliente e como a } \\
\text { empresa já possui várias outras aplicações que são baseadas em navegadores, os usuários não } \\
\text { possuem deficiência crônicas no uso das tecnologias escolhidas. }\end{array}$ \\
\hline P: Os usuários conhecem o processo que estará sendo automatizado? \\
\hline $\begin{array}{l}\text { R: Sim, para aqueles que são dos laboratórios (técnicos, secretárias e responsáveis pelo } \\
\text { laboratório). }\end{array}$ \\
\hline P: Qual o perfil por execução das tarefas que os usuários podem ser divididos? \\
\hline da Figura V.1 \\
\hline P: O que pode ser caracterizado como uma saída útil que esta solução pode fornecer? \\
\hline $\begin{array}{l}\text { R: Orçamento para o cliente, numeração única de registro de material e de orçamento, associação } \\
\text { automática de documento técnico e respectiva identificação, faturamento integrado ao processo e } \\
\text { identificação única do usuário. }\end{array}$ \\
\hline
\end{tabular}

Fonte: elaborado pelo autor

Finalmente em função do fluxograma apresentado na Figura V.1, as seguintes interfaces associadas aos mesmos foram desenhadas, utilizadas para o início da simulação com os usuários escolhidos: 


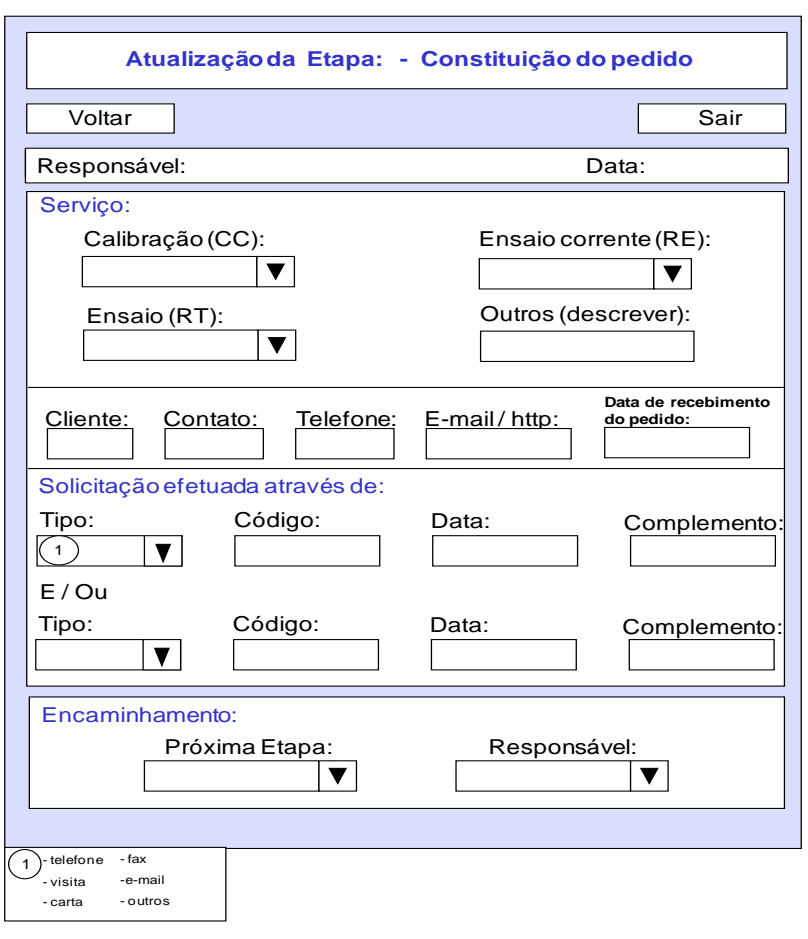

Figura V.3 - Constituição do pedido

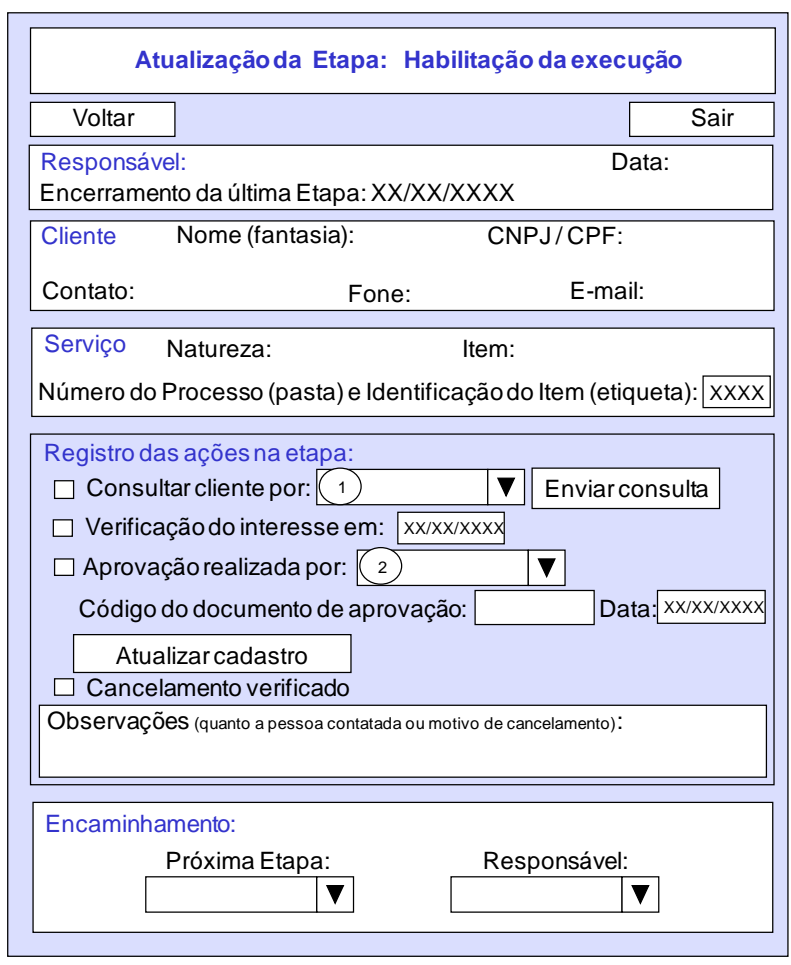

Figura V.5 - Habilitação do pedido

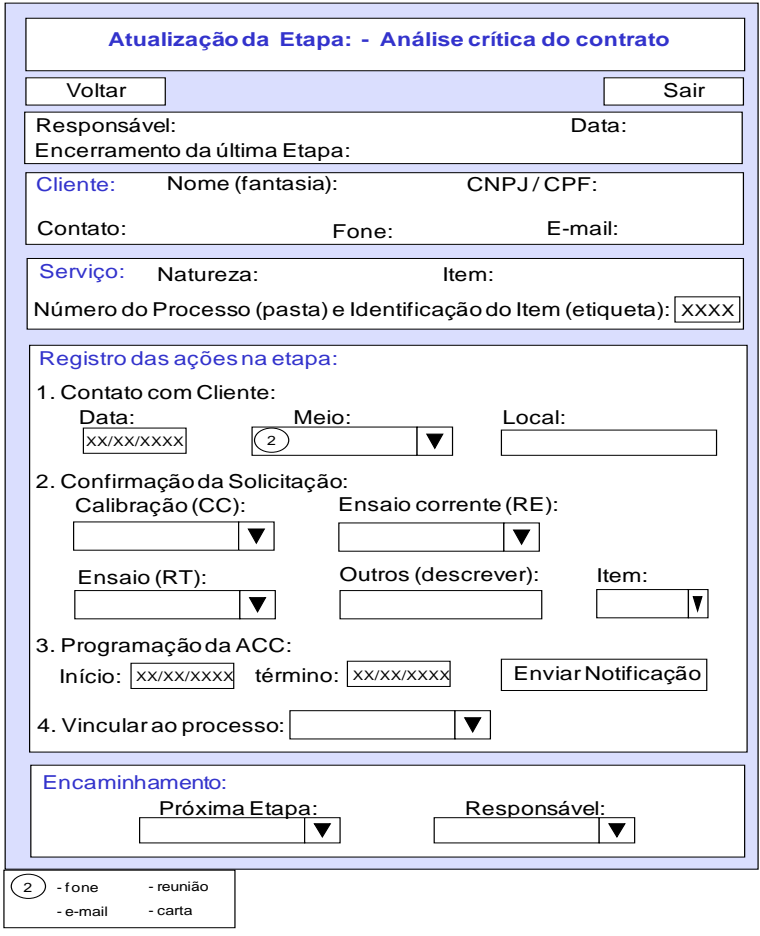

Figura V.4 - Análise crítica do contrato

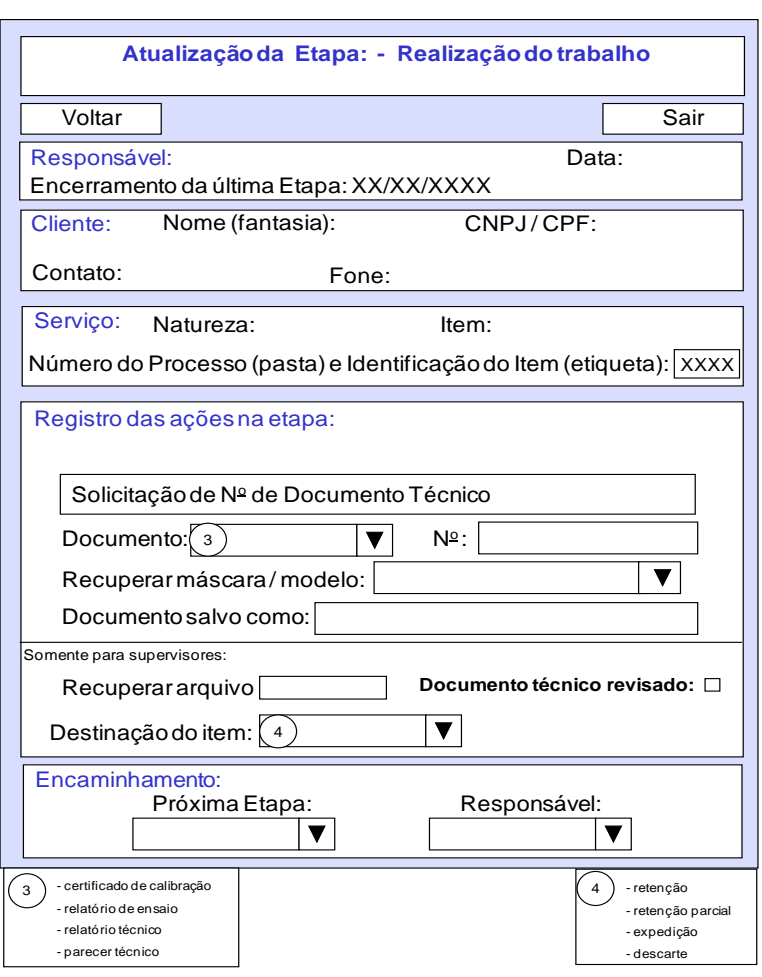

Figura V.6 - Realização do trabalho 


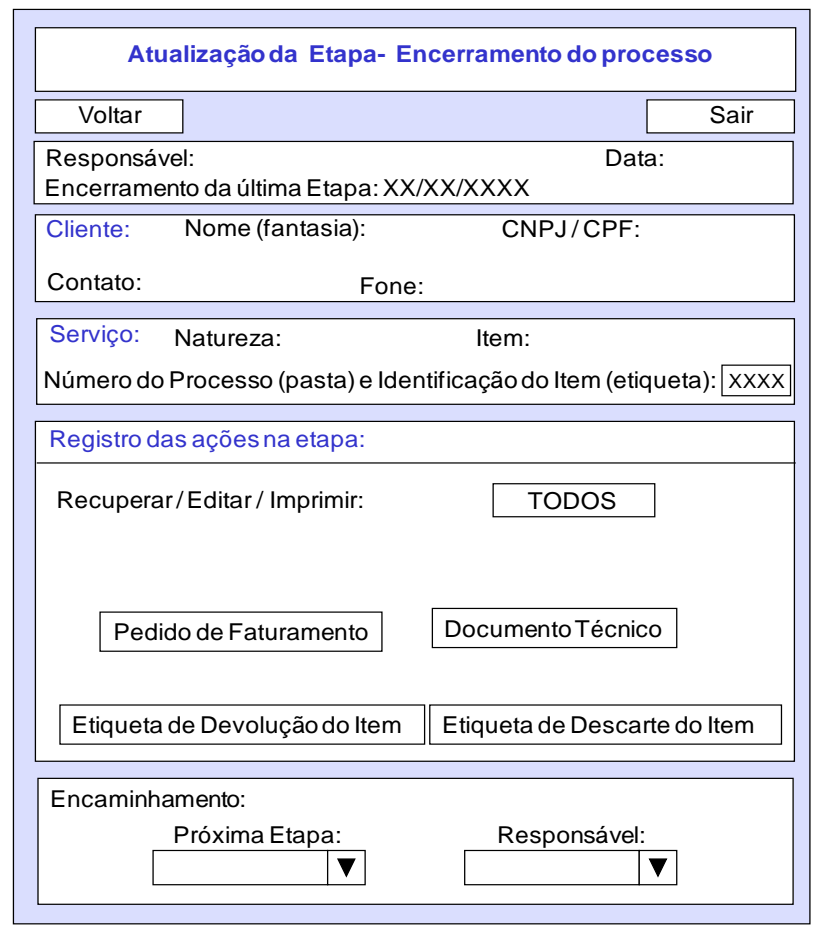

Figura V.7 - Encerramento do processo

\section{Implementação/revisão do protótipo em papel}

Nesta fase do processo a implementação da interface e dos documentos foram realizados e apresentados aos usuários na fase de simulação e resultaram na decisão em continuar a simulação na fase de análise dos dados.

Com relação ao diagrama de contexto (ver item II.7.4 - Modelo de contexto, de processo e de fluxo de trabalho), após as discussões com os usuários sobre as possíveis interfaces com outros sistemas existentes (abordados na fase de simulação) o diagrama final, após as várias iterações no ciclo da PA pode ser visto na Figura V.8 abaixo: 


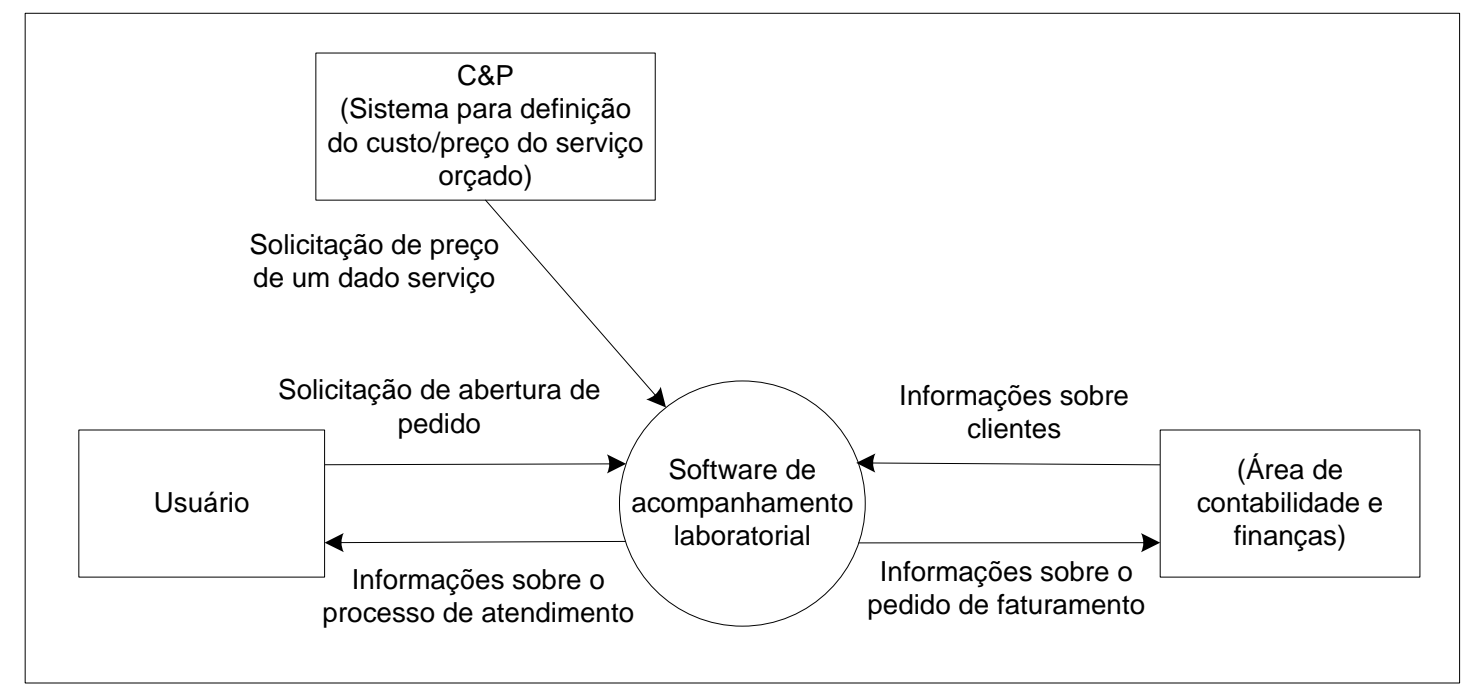

Figura V.8 - Diagrama de contexto final do ciclo 1 do software de atendimento laboratorial Fonte: elaborado pelo autor

Já o fluxograma final está apresentado na Figura V.9 abaixo, também é resultado da simulação com os usuários, levando-se em conta o diagrama de contexto e as interfaces gráficas associadas a cada uma das fases.

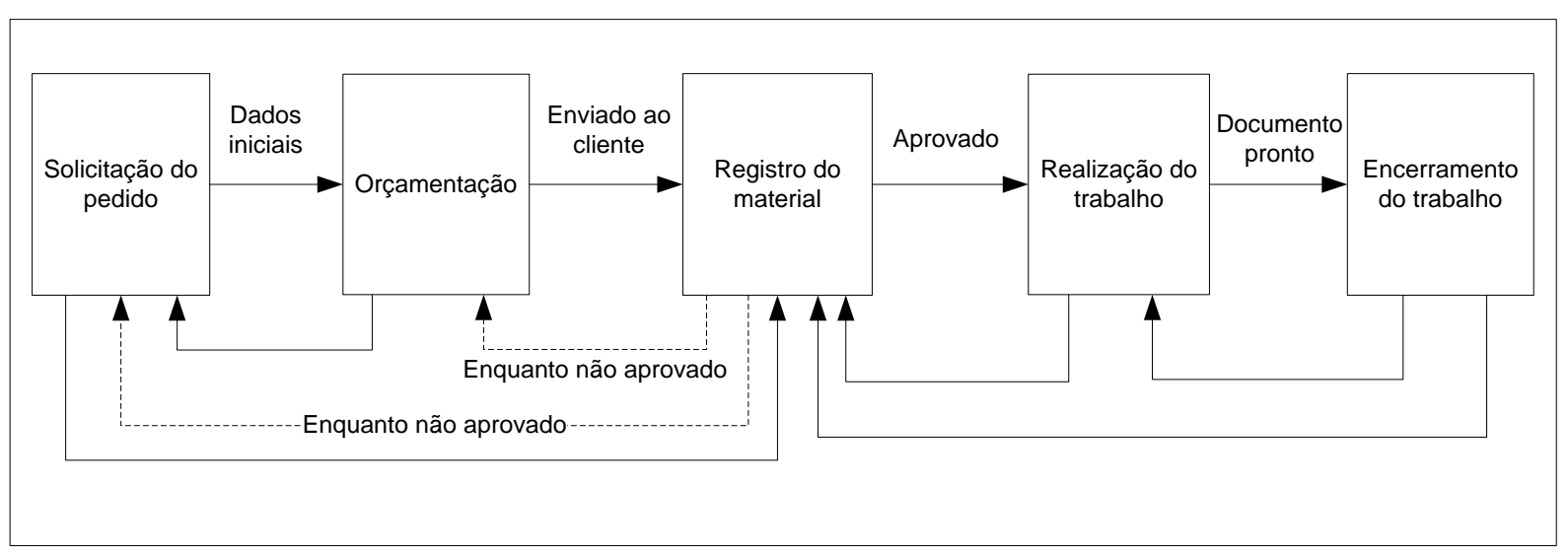

Figura V.9 - Fluxograma final do ciclo 1

Fonte: elaborado pelo autor

As interfaces gráficas referentes aos processos da Figura V.9 foram evoluindo na medida que uma nova iteração com os usuários ocorria (o resultado final das interfaces pode ser visto nas figuras abaixo). Ressalta-se o fato que, embora estas interfaces não tenham sido desenvolvidas na tecnologia alvo na qual o software será desenvolvido, as mesmas foram desenhadas para possuir compatibilidade com a tecnologia adotada, pois no ciclo 2 da pesquisa-ação estas interfaces serão reescritas já na plataforma alvo que será implementada no ciclo 3. 
Outro aspecto importante a ser destacado corresponde ao fato de que os usuários dos laboratórios utilizam o termo "processo" para designar cada uma das fases do fluxograma da Figura V.9 e o termo "atendimento" para se referirem ao processo composto por estas fases. Visando a manter a coerência com os termos utilizados pelos usuários, na implementação dos artefatos serão utilizados os termos "processo" para cada fase do fluxograma da Figura V.9 (que corresponde ao processo) e "atendimento" para o processo.

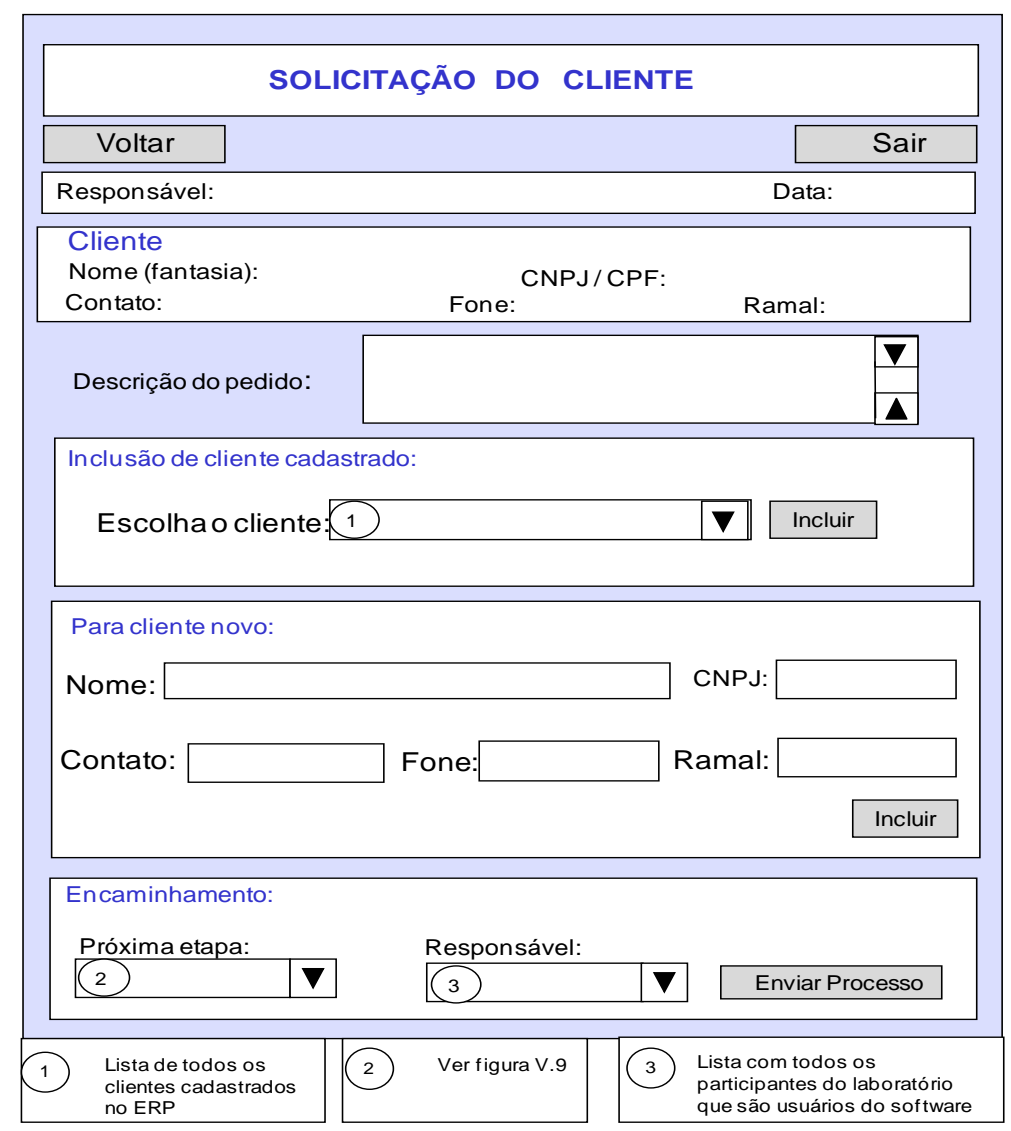

Figura V.10 - Solicitação do pedido 


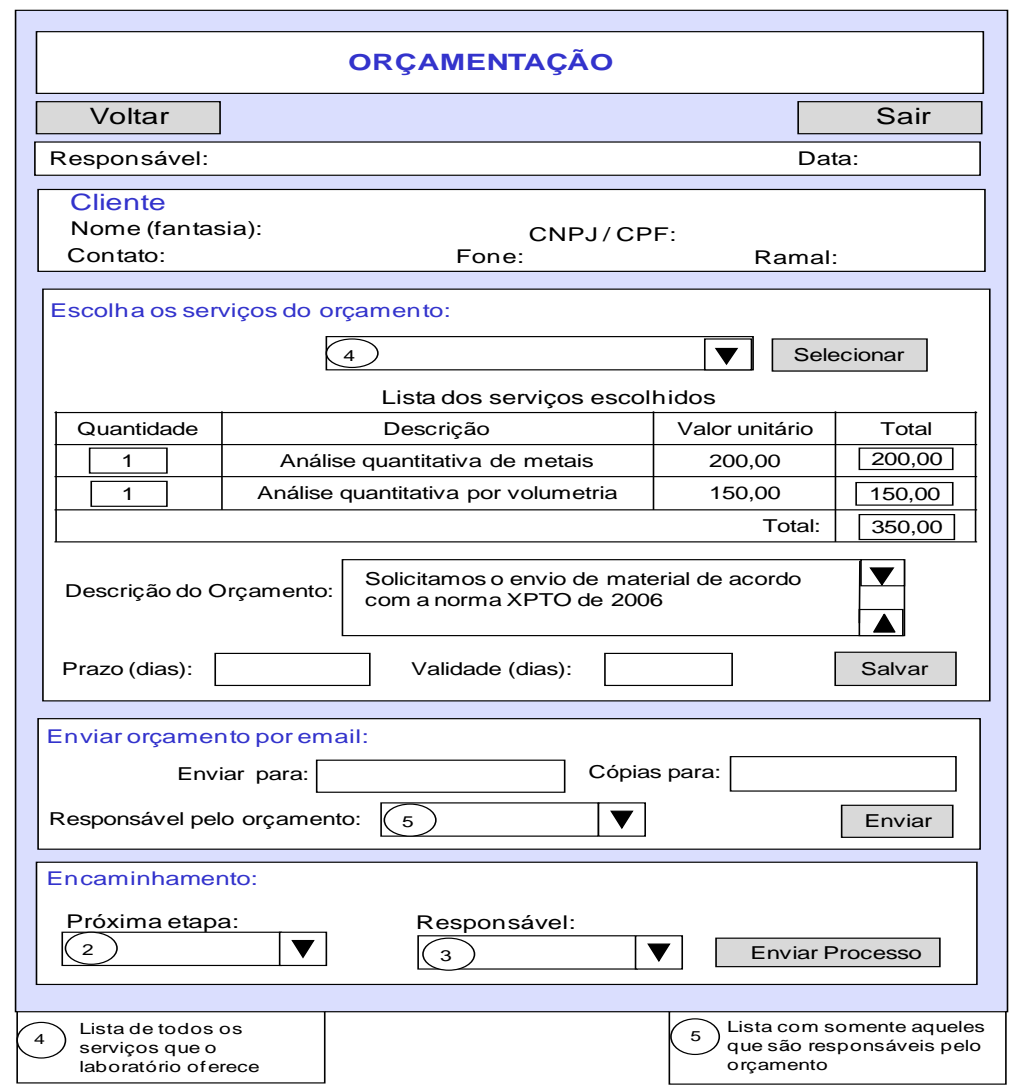

Figura V.11 - Orçamentação

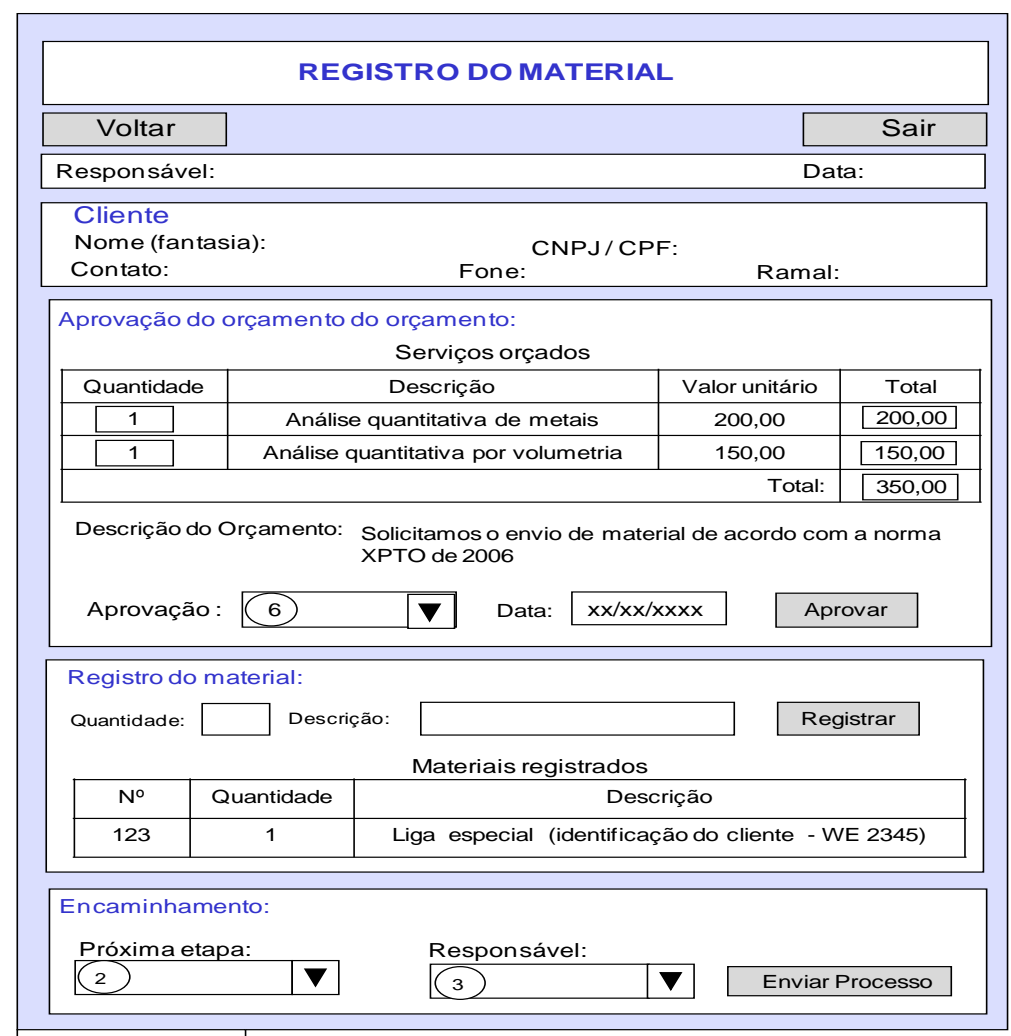

(6) - Em espera

- Aprovado

Figura V.12 - Registro de material 


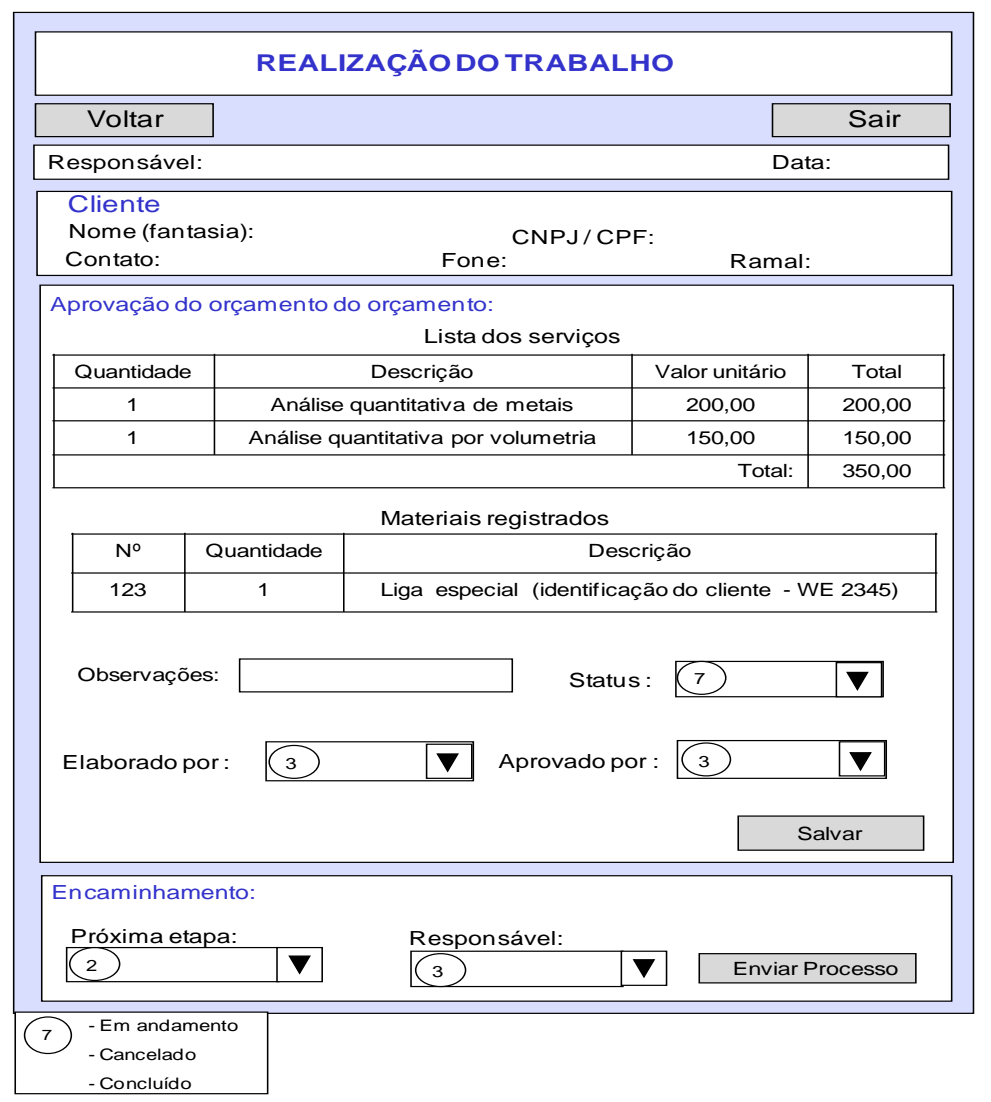

Figura V.13 - Realização do trabalho

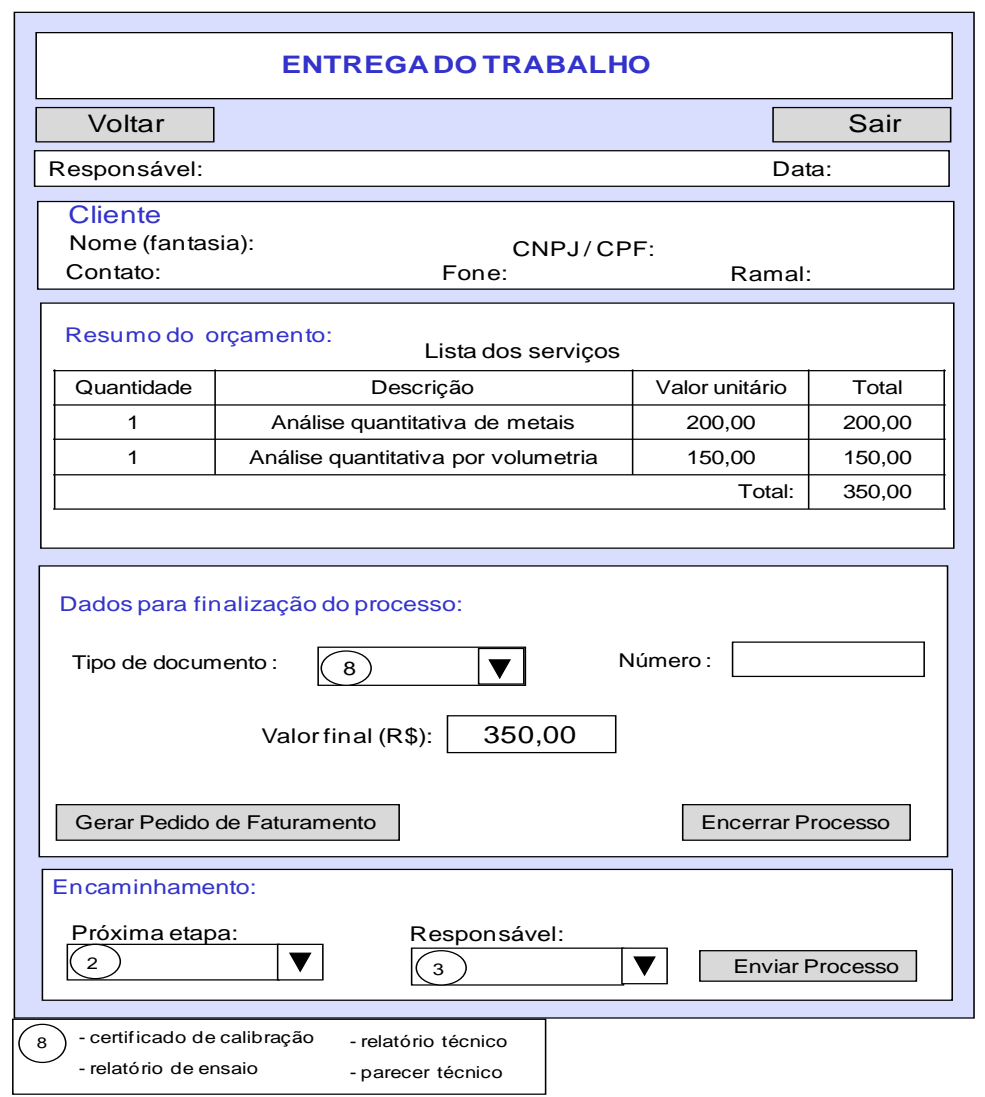

Figura V.14 - Entrega 


\section{V.2.3 Levantamento e discussão dos dados}

Os usuários que participaram deste processo (ciclo 1) foram dois analistas de negócios com grande conhecimento do SI a ser informatizado (ver item III.4), escolhidos de dois laboratórios com tipos de produtos complementares oferecidos aos clientes, de modo a compor várias das opções oferecidas pela empresa PesqTec.

Neste ciclo, quatro iterações foram realizadas com duração total de aproximadamente 2 meses, com início em fevereiro de 2006 e término em março de 2006. Inicialmente, além do fluxograma simplificado da Figura V.1, foi apresentado a estes usuários para simulação do software, um conjunto de interfaces gráficas representativas do fluxograma, a descrição dos processos e o diagrama de contexto (item V.2.2 - identificação das características iniciais do sistema).

A simulação das ações características futuras em função das situações de referência (Quadro V.2), foi realizada, utilizando a técnica apresentada no item IV.4.2, de modo que os artefatos acima descritos foram sucessivamente refinados por meio de várias iterações, utilizando-se também como referência as questões do Quadro IV.3 e suas respectivas respostas nos dados do Quadro V.4 abaixo.

Quadro V.4 - Simulação do protótipo em papel: respostas

\begin{tabular}{|l|}
\multicolumn{1}{|c|}{ Questões básicas sobre a simulação em papel } \\
\hline P: Qual o trabalho realizado pelos diferentes tipos de usuários e em que circunstâncias? \\
\hline R: Ver descrição das fases deste item \\
\hline P: Quais são as tarefas e sub-tarefas realizadas enquanto os usuários executam suas atividades? \\
\hline R: De acordo com a descrição das fases deste item \\
\hline P: Qual é a seqüência do trabalho realizado - workflow do processo em detalhes? \\
\hline R: Ver Figura V.9 \\
\hline P: Dentro dos processos, qual é a hierarquia das atividades? \\
\hline $\begin{array}{l}\text { R: A hierarquia será tratada com detalhes no ciclo } 2 \text { da PA. Neste ciclo somente são listadas as } \\
\text { principais sub-atividades. }\end{array}$ \\
\hline
\end{tabular}

\section{Fonte: elaborado pelo autor}

Ao se analisar em primeiro lugar a evolução do diagrama de contexto inicial (Figura V.2) e o digrama de contexto final (Figura V.8), pode-se notar a existência de uma nova entidade externa denominada de Custos e Preços. Esta entidade é um software responsável pela análise crítica do contrato (ACC), cujas atividades 
(análise técnica, seguida de uma análise financeira) serão realizadas fora do software de acompanhamento laboratorial.

A razão para que a fase de ACC fosse realizada fora do sistema de acompanhamento, foi sobretudo para que os estudos dos custos e preços dos serviços pudessem ser reaproveitados, assim como as análises associadas, deixando para o sistema de acompanhamento realizar as adaptações específicas necessárias a um dado orçamento. Deste modo, a fase de análise crítica do contrato foi substituída pela fase de orçamentação, fase esta que se utilizará das planilhas de serviços criadas no software de Custos e Preços.

A descrição resumida das fases do fluxograma da Figura V.9 é realizada abaixo. As atividades que não serão realizadas pelo software, são indicadas nesta descrição.

Solicitação do pedido (Constituição do pedido): ocorre a habilitação da demanda, para que possa ser atendida dentro dos critérios de qualidade do laboratório. Este conjunto de atividades é realizado, em geral, pela secretária do laboratório, mas pode também ser feito por qualquer participante do laboratório.

- Principais atividades: registro de solicitação do cliente, consulta/cadastro de clientes e montagem e distribuição do processo físico (não realizada pelo software);

- Principais entradas: pedido do cliente (dados iniciais do cliente);

- Principais saídas: registro do pedido, identificação do responsável desta fase do processo, se houver necessidade um estudo no sistema de Custos e Preços e cadastro do cliente.

Orçamentação (Análise crítica do contrato): é realizada a confecção da proposta orçamentária composta das informações referentes aos serviços que são pesquisados no sistema de Custos e Preços. A responsabilidade pelo orçamento ou é um técnico designado e reconhecido competente para o atendimento, ou é do responsável pela área cuja competência é atender ao pedido, mas o envio do orçamento pode ser realizado por qualquer participante do laboratório.

- Principais atividades: editoração, assinatura e envio da proposta orçamentária. 
- Principais entradas: registro do pedido, projeto da solução técnica e serviços anteriores para o mesmo cliente (oriundos do sistema de Custos e Preços);

- Principais saídas: definição do escopo de atendimento, plano de trabalho (não realizado pelo software), envio de proposta comercial.

Registro de material (Habilitação da execução): nesta fase, ocorre o acompanhamento da tramitação da proposta orçamentária junto ao cliente, a aprovação da mesma e o registro do material para início da realização dos serviços. Este conjunto de atividades pode ser realizado por qualquer participante do laboratório, sendo normalmente realizado pela secretária do laboratório ou um técnico.

- Principais atividades: monitoração e aprovação da proposta e recebimento do material para execução do serviço;

- Principais entradas: proposta comercial editada, autorização para o atendimento e chegada do material para registro;

- Principais saídas: proposta orçamentária aprovada (autorização para atendimento) e disponibilização do material para realização do(s) serviços(s) contratado(s).

Realização do trabalho: As informações decorrentes da realização do trabalho propriamente dito são registradas, assim como quem elaborou e aprovou o documento técnico relativo a este atendimento. O conjunto de atividades é de natureza técnica e, normalmente, está sob responsabilidade do responsável pelo laboratório, ou do técnico designado, e na falta deste pode ser realizado por qualquer participante do laboratório.

- Principais atividades: programação para execução (no sistema de Custos e Preços), inspeção técnica do material recebido, recuperação ou editoração das planilhas de cálculo para o serviço realizado (o software não faz a guarda dos documentos físicos do processo de atendimento), preparação do serviço (executado pelo técnico, não realizado pelo software), aquisição e análise dos dados (o software proposto não atua no chão de fábrica, isto é, na aquisição e 
análise dos dados) e editoração e revisão do documento técnico (o software não faz a guarda dos documentos físicos do processo de atendimento);

- Principais entradas: orçamento aprovado, material em que será realizado o serviço, plano de trabalho (no sistema de Custos e Preços) e insumos e dispositivos especiais (material físico do laboratório);

- Principais saídas: documento técnico revisado (o documento físico não é controlado pelo sistema) e informação sobre o término dos trabalhos e da elaboração do documento técnico.

Encerramento do processo: estão reunidas todas as etapas típicas pertinentes ao acompanhamento da tramitação do atendimento no contexto da emissão do documento técnico final e providências para seu encerramento. Este conjunto de atividades pode ser considerado administrativo e, normalmente, está sob responsabilidade da secretária do laboratório, mas pode ser realizado por qualquer participante do laboratório.

- Principais atividades: definição do tipo de documento técnico e respectivo valor final, geração do pedido de faturamento, impressão do documento e verificações finais (o software não faz a guarda dos documentos físicos do processo de atendimento) e encerramento do atendimento;

- Principais entradas: informação sobre a execução dos serviços e sobre o término da elaboração do documento técnico e documento técnico revisado (o software não faz a guarda dos documentos físicos do processo de atendimento).

- Principais saídas: documento técnico assinado e entregue ao cliente (o software não faz a guarda dos documentos físicos do processo de atendimento), realização do faturamento e encerramento do processo de atendimento.

As interfaces gráficas finais definidas no item V.2.2 (Implementação/revisão do protótipo em papel) refletem as descrições das fases descritas acima, de modo que é possível fazer o seguinte recorte relativo ao software que implementará parte deste sistema em função do processo não automatizado: 
- A fase de análise crítica do contrato foi substituída pela fase de orçamentação. Inicialmente, a análise crítica deveria ser desenvolvida no próprio software de acompanhamento, mas, após os refinamentos, optou-se por desenvolver esta funcionalidade em outro sistema independente denominado "Custos e Preços";

- O software de acompanhamento laboratorial não executa o controle dos equipamentos dos laboratórios (fazer aquisição automática de dados e execução do documento técnico equivalente), conforme pode ser visto na fase de realização do trabalho, sendo utilizado sobretudo com a função de gerenciar o acompanhamento lógico de um processo de atendimento;

- Toda a documentação física relacionada a um dado atendimento, ligada sobretudo aos dados coletados durante a execução dos serviços e a realização do documento técnico que contempla a análise destes dados (documentação denominada de processo de atendimento), terá um controle lógico pelo sistema, mas o processo físico não será custodiado (guardado) no banco de dados do software.

Finalmente, a análise entre o fluxograma inicial (ver Figura V.1) e o final (ver Figura V.9) mostra que serão necessárias travas lógicas, para que o processo de workflow possa fluir entre as fases (o que não ocorre com o $\mathrm{SI}$ ), como por exemplo, na fase de registro de material, na qual o processo de atendimento só seguirá adiante pela implementação do workflow do processo pelo software se houver aprovação do pedido pelo cliente e uma vez aprovado o processo não poderá mais retornar para as fases de orçamentação e solicitação de pedido.

\section{V.2.4 Análise e planejamento do ciclo 1}

Durante cada interação no ciclo 1 , antes de uma nova volta no ciclo de iteração é verificado se os artefatos produzidos estão refinados o suficiente para seguirem para o ciclo 2 da PA. Para tanto, de acordo com o item IV.4.3, esta fase estará terminada quando na iteração atual (neste caso na quinta iteração) os dois usuários que participaram da simulação concordarem que a : 
- A interface e demais documentos associados implementam as principais atividades definidas pelos usuários de modo correto;

- A saída para o próximo passo ocorre quando se obtém a aprovação dos usuários entrevistados na simulação;

- Os usuários concordam que o fluxo geral do processo foi mapeado.

Estas condições foram observadas após a simulação da quinta iteração, e os artefatos produzidos na iteração, na fase de implementação, não sofreram alterações.

Os dados do Quadro V.5 abaixo mostram as respostas às questões citadas no Quadro IV.4 e que devem ser avaliadas pelos projetistas do software para definição do término deste ciclo.

Quadro V.5 - Avaliação sobre término da prototipação em papel: respostas

\begin{tabular}{|l|}
\hline \multicolumn{1}{|c|}{ Questões básicas sobre avaliação sobre término da prototipação em papel } \\
\hline P: Cada requisito está consistente com o objetivo global do sistema? \\
\hline R: Neste caso, cada requisito desenvolvido neste ciclo através dos artefatos de software descritos \\
está de acordo com o objetivo do software. \\
\hline P: Este requisito é realmente necessário, ou é uma característica adicional que pode não ser \\
essencial aos objetivos do sistema? \\
\hline R: Esta questão sempre foi avaliada de modo recorrente em cada ciclo de iteração pelos projetistas. \\
\hline P: Cada requisito está bem delimitado e claro? \\
\hline R: Neste caso a avaliação é sob a ótica do projetista, depois da concordância dos dois analistas de \\
negócio. No final do ciclo os dois analistas validaram a descrição das fases do processo no item \\
V.2.3. \\
\hline P: Algum requisito conflita com algum outro? \\
\hline R: Esta situação sempre foi recolocada junto aos dois analistas de negócio em cada iteração do \\
ciclo. \\
\hline P: O requisito pode ser testado depois de implementado? \\
\hline R: Os requisitos foram avaliados pelos projetistas sempre sob a possibilidade da criação de testes \\
durante a simulação com os usuários. \\
\hline P: Os artefatos desenvolvidos aqui representam corretamente estes requisitos, com relação ao seu \\
comportamento, funcionalidade e dados? \\
\hline R: No ciclo 1 somente é possível verificar a questão da funcionalidade, sendo que o comportamento \\
e dados deverão ser avaliados em ciclos posteriores. \\
\hline
\end{tabular}

\section{Fonte: elaborado pelo autor}

Para o ciclo 2, são montadas sessões de ACT com usuários representativos dos diversos laboratórios da empresa. Nesta pesquisa, foram convidados oito pesquisadores, em geral, responsáveis pelos laboratórios ou pela área da qualidade, para participarem das sessões, e os temas abordados foram apresentados ou discutidos na sessão do ciclo anterior e, também, utilizados para familiaridade com os mesmos pelos pesquisadores participantes das sessões de ACT (ver item VI.2). 


\section{V.2.5 Conclusões do ciclo 1 (passo de monitoramento da PA)}

Este ciclo teve como principal objetivo obter os artefatos de software necessários para sua utilização no ciclo 2 da PA, pela aplicação dos conceitos de ER tradicional em sistemas de informação. Os resultados obtidos respondem à questão (ver item III.4.3) :

Como, pelas contribuições individuais dos stakeholders, estabelecer os principais artefatos necessários para a simulação do trabalho cooperativo por meio do software que será implementado?

Os artefatos para este ciclo correspondem ao fluxograma final do processo (ver Figura V.9), o diagrama de contexto final (ver Figura V.8), as interfaces gráficas (Figura V.10, Figura V.11, Figura V.11, Figura V.12, Figura V.13 e Figura V.14) e a descrição dos processos (ver item V.2.3).

Com relação aos requisitos de sistema, a análise dos artefatos construídos mostra dois aspectos:

- Todas as fases representadas pelas interfaces gráficas implementam o workflow por meio de duas listas, contendo as próximas fases possíveis, assim como para qual usuário estas poderão ser enviadas;

- O fluxograma final (ver Figura V.9) e a descrição das atividades realizadas pelos dois usuários mostram que embora exista uma sequência mais comum para as fases do workflow, estas podem ter muitos caminhos alternativos, assim como não existe uma coordenação centralizada para definir o andamento deste fluxo, com a possibilidade de que praticamente todos os usuários dos laboratórios possam ser responsáveis pelas fases (coordenação distribuída e horizontal, ver item VII.2.3). 


\section{CICLO 2 DA PESQUISA-AÇÃO: PROCESSO PARA ESPECIFICAÇÃO DE REQUISITOS DE SOFTWARE COM FOCO NA IDENTIFICAÇÃO E SIMULAÇÃO DAS CARACTERÍSTICAS DO TRABALHO COOPERATIVO}

Este ciclo tem como objetivo a obtenção dos requisitos e modelos do sistema utilizados como ponto de partida para o projeto do software, acentuando-se a definição dos requisitos do usuário e dos requisitos funcionais de alto nível (uma vez que é adotada uma solução evolucionária), com foco sobretudo na evolução dos requisitos do trabalho cooperativo.

\section{VI.1 INTRODUÇÃO}

O processo proposto começa com a entrada dos artefatos que foram desenvolvidos durante o processo anterior (ciclo 1 da PA) e que serão usados como base inicial na atividade de implementação/revisão deste ciclo da PA.

Neste ciclo, serão implementados os diagramas de navegações e interfaces gráficas, assim como os fluxogramas detalhados do processo e o diagrama de contexto necessários para serem utilizados como elemento de representação comum entre os pesquisadores e os demais participantes das sessões.

Assim como foi considerado no ciclo, neste ciclo será escolhida uma parte dos artefatos desenvolvidos durante as iterações, como exemplo de aplicação do processo proposto, dada a quantidade de informação e, também, pelo fato de que haveria repetição de aplicação do processo.

Conforme apresentado no item IV.5, optou-se pela técnica de prototipação não funcional, com o desenvolvimento de protótipos sucessivos do software, oferecendo uma representação comum para se comunicar com os usuários e os projetistas (utilizados como imagem do sistema - item II.3), constituindo também um guia para a especificação de sucessivas versões. Os protótipos foram apresentados aos usuários para discussão coletiva, utilizando-se a técnica de ACT, partindo-se das 
situações de referência do trabalho dos usuários pela própria voz destes e projetando-se as ações características do futuro sistema informatizado.

\section{VI.2 DINÂMICA DA ITERAÇÃO DO CICLO 2}

\section{VI.2.1 Dados do grupo e do ambiente das sessões}

Ao todo foram executadas seis iterações neste ciclo da PA, com intervalo entre 3 a 4 semanas entre os passos de levantamento e a discussão dos dados (ou sessões), com duração entre $1 \mathrm{~h} 30$ a $2 \mathrm{~h} 30$ cada sessão e 2 a 3 dias para o passo de implementação, e em torno de 1 semana para o passo de análise e planejamento. Estas iterações iniciaram-se em outubro de 2006 e terminaram em março de 2007. O número de participantes de cada sessão foi de seis a oito pessoas, sendo que além dos dois participantes do ciclo 1 (técnicos de dois laboratórios com conhecimentos da dinâmica das regras do negócio dos demais laboratórios), foram convidados outros quatro representantes de laboratórios (permitindo assim o relato de cada segmento sobre o objeto da avaliação), assim como um representante da diretoria e outro da qualidade da empresa PesqTec.

Todos possuíam curso superior completo e estavam acostumados a utilizar aplicações WWW disponíveis na intranet da empresa (portanto, com conhecimentos homogêneos com relação à tecnologia e às regras de negócio).

Apesar do projeto ser institucional, todos os participantes convidados concordaram prontamente em participar das reuniões. As sessões foram todas realizadas dentro da empresa, mas em ambiente isolado da situação de trabalho dos participantes (as datas das reuniões foram marcadas, sempre que possível, com antecedência necessária visando justamente a esta possibilidade).

No ambiente onde as sessões foram realizadas, foram apresentadas aos participantes partes do protótipo a serem discutidas na sessão corrente por meio de um equipamento multimídia conectado a um microcomputador utilizado por um dos pesquisadores para orientar a realização das sessões e as observações feitas pelos participantes, além de quadro para desenho. 
As sessões sempre foram conduzidas por dois pesquisadores, e um deles foi responsável por anotar ou gravar (com o consentimento dos participantes) partes da sessão, auxiliar o outro pesquisador na condução do grupo, tomar nota das principais impressões verbais e estar atento à aparelhagem multimídia.

Ao outro pesquisador, coube a condução da sessão, permitindo a discussão dos vários pontos de vista dos participantes, mas sempre atento aos objetivos da sessão e da demanda como um todo, permitindo assim, maior diretividade da sessão corrente. Este pesquisador, também, procurou promover a participação de todos, evitando a dispersão dos objetivos da discussão e a monopolização de alguns participantes sobre outros, além de ouvir as diversas observações sobre o assunto que estava sendo apresentado.

\section{VI.2.2 Dinâmica geral das iterações}

A Figura VI.1 abaixo mostra a sequência de iteração para este ciclo de PA .

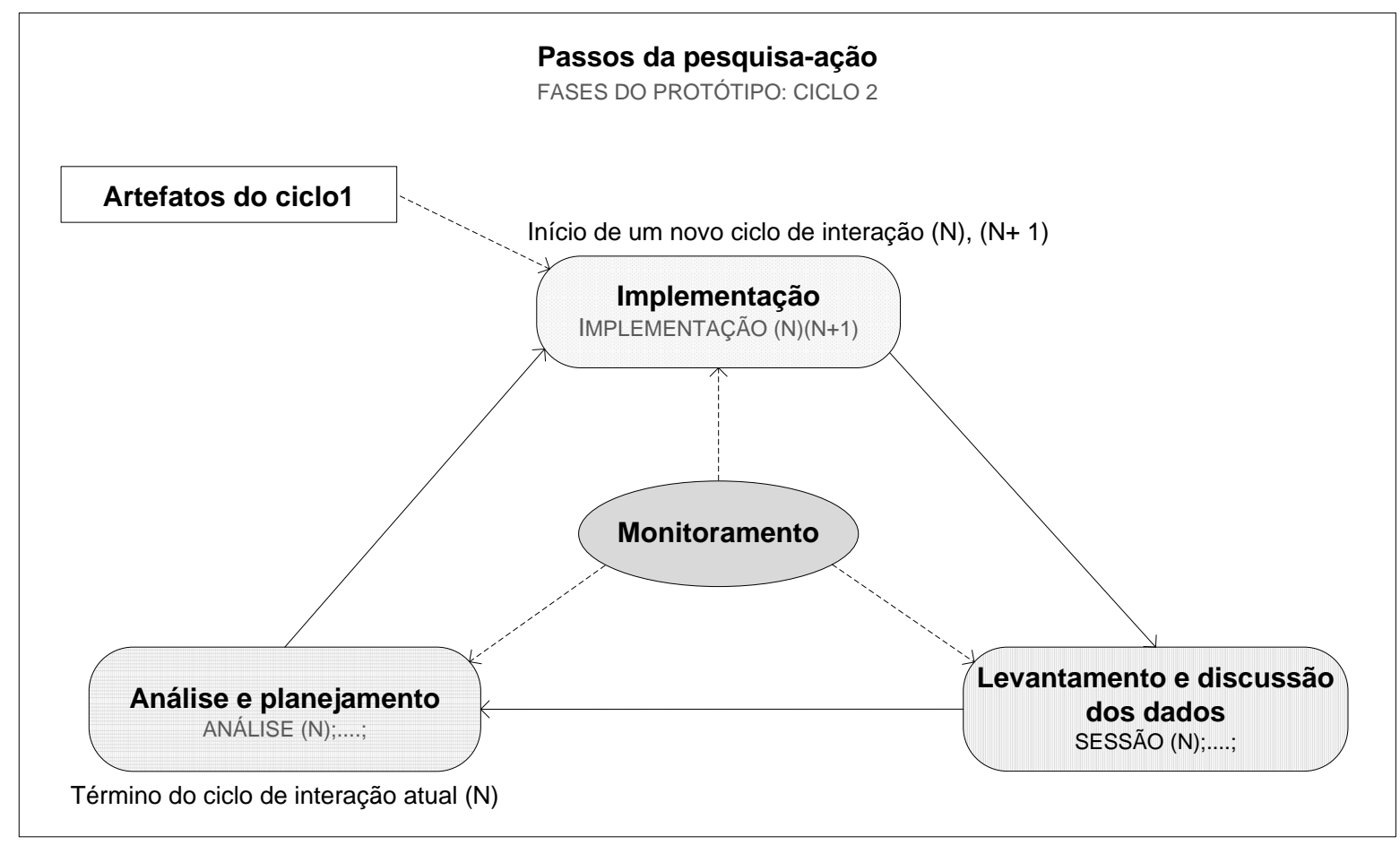

Figura VI.1 - Passos da Pesquisa-ação e correspondentes atividades Fonte: elaborado pelo autor

Procurou-se dividir cada sessão de apresentação em duas partes. Na primeira, foram apresentados temas para detalhamento da validação e fechamento (temas 
estes que foram discutidos na segunda parte da sessão da iteração anterior). $\mathrm{Na}$ segunda parte da sessão corrente, novos assuntos foram discutidos (e foram, em geral, listados na segunda parte da sessão da iteração anterior) sendo sugerido também aos participantes que elegessem assuntos para discussão na segunda metade da sessão da iteração seguinte e, assim, possibilitar que os artefatos correspondentes fossem preparados ou, pelos menos, esboçados para discussão do grupo (Figura VI.2).

Tanto na primeira, como na segunda parte da sessão, os artefatos para esta discussão foram implementados no passo de implementação da iteração corrente (Figura VI.2), com a diferença que os artefatos da primeira parte foram detalhados para validação, e os artefatos da segunda parte foram esboçados, já que os mesmos seriam ainda detalhados. Neste passo, também, foram detalhados alguns artefatos para o projeto e codificação do software no ciclo 3 e que não serão abordados neste trabalho. Gonçalves et al. (2005) detalham alguns artefatos de implementação do software.

$\mathrm{Na}$ iteração corrente, no passo de análise e planejamento, foram realizadas entrevistas individuais de detalhamento com um ou mais participantes da sessão sobre o que foi discutido na segunda parte da sessão (ou na primeira, caso o detalhamento fosse insuficiente). Estes artefatos, posteriormente, foram construídos no passo de implementação no início da próxima iteração (Figura VI.2). Desse modo, a próxima sessão contaria com artefato(s) mais adequado(s) para validar o que foi discutido na segunda parte da sessão anterior, assim como permitiria a apresentação de novos assuntos em sua segunda parte.

No passo de análise e planejamento, também, verificou-se a necessidade de se realizar uma nova iteração ou se o ciclo poderia terminar (quando o grupo não era mais capaz de produzir novidades em suas discussões foi sinal de que se conseguiu mapear o tema para os quais a pesquisa foi dirigida). 


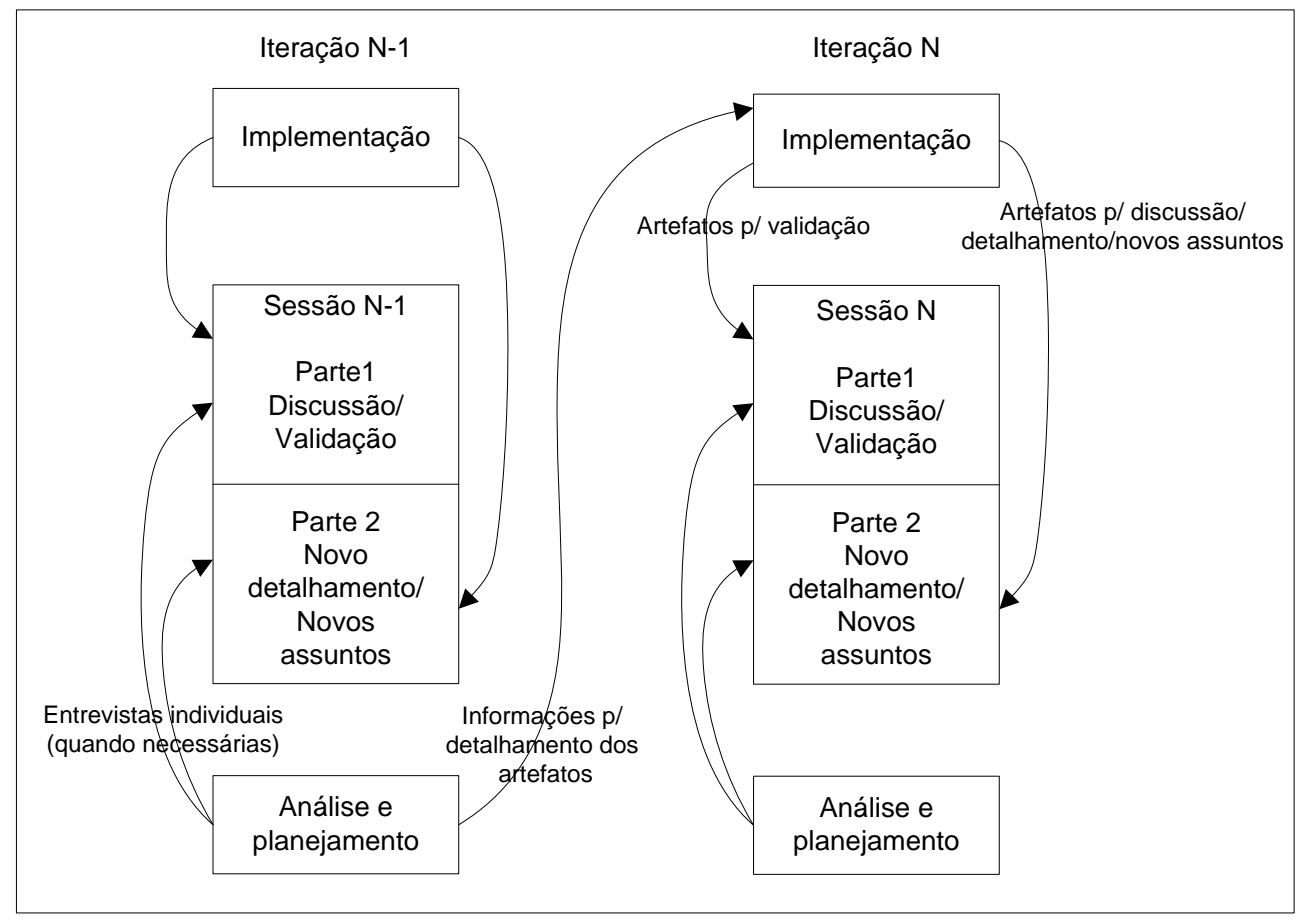

Figura VI.2 - Dinâmica das iterações do ciclo 2 Fonte: elaborado pelo autor

A primeira iteração serviu para apresentação dos participantes do grupo, dos objetivos, da forma de discussão e os principais artefatos que foram desenvolvidos no ciclo 1 e implementados na tecnologia utilizada (plataforma WWW), assim como de uma discussão dos próximos passos.

A segunda iteração tratou da validação da navegação de algumas fases, em particular, a orçamentação, considerando 0 aspecto ligado ao ambiente multilaboratorial, não abordado no ciclo 1 , alem de discutir e detalhar o fluxograma do processo de negócio, e discutir as demais fases (mais cooperativas). A terceira validou o fluxograma e a distribuição de tarefas e responsabilidades, bem como detalhou as fases restantes do processo de atendimento.

A quarta iteração validou as fases discutidas na terceira iteração, e também discutiu a necessidade da criação de objetos para coordenação do trabalho cooperativo. A quinta iteração validou os artefatos de coordenação e passou a discutir relatórios específicos para o andamento do trabalho dos participantes dos grupos. Finalmente, a última concluiu com a validação do ciclo 2, como um todo. 


\section{VI.3 RESULTADOS (DETALHAMENTO DAS ITERAÇÕES)}

\section{VI.3.1 Iteração 1}

Na primeira iteração deste ciclo, no passo de implementação, no início, os artefatos produzidos no ciclo1 foram convertidos em linguagem DHTML, tais como: as interfaces gráficas e respectivas navegações, o fluxograma do processo (respectivos mapas de navegações), bem como o diagrama de entidade-relacionamento do banco de dados (para fins de projeto).

Em particular, na confecção das interfaces gráficas e navegações, foram desenvolvidos formulários DHTML, com menus, entradas do tipo texto com múltiplas linhas ou entradas do tipo texto com um único campo e botões do tipo radio ou checkbox. Como elementos de interação, foram utilizados os botões de envio (submit), ou ícones específicos para navegação, assim como validações DHTML em parte dos campos de entrada de dados.

Para a segunda parte da sessão, também foi complementado o diagrama de navegação da fase de orçamentação, em razão de apresentar uma interface com o software de Custos e Preços que não foi detalhada no ciclo 1 (ver item V.2.3).

$\mathrm{Na}$ primeira sessão, os participantes apresentaram-se, e os pesquisadores fizeram esclarecimentos a respeito dos objetivos da pesquisa e apresentaram um conjunto de regras para melhor encaminhamento das sessões:

- Deixaram claro que todas as opiniões interessavam e, portanto, não existiam opiniões certas ou erradas, ressaltaram a importância das manifestações individuais contra ou a favor;

- A duração prevista para a sessão;

- A dinâmica da sessão, conforme descrito em VI.2.2;

- Dentro do possível, só uma pessoa falaria por vez;

- Evitar discussões paralelas, de modo que todos pudessem participar.

Antes que a primeira sessão fosse realizada, a documentação gerada no ciclo 1 foi enviada aos participantes para que pudessem avaliar o material de referência sobre os requisitos do processo até então levantados. 
Na primeira parte da sessão, inicialmente os artefatos do ciclo 1 foram apresentados aos participantes, em particular, as interfaces gráficas já convertidas para o formato DHTML (como exemplo, na Figura VI.3 encontra-se a fase de orçamentação do ciclo 1 e na Figura VI.4 após a conversão) para seu conhecimento mais detalhado e esclarecimentos de dúvidas a seu respeito.

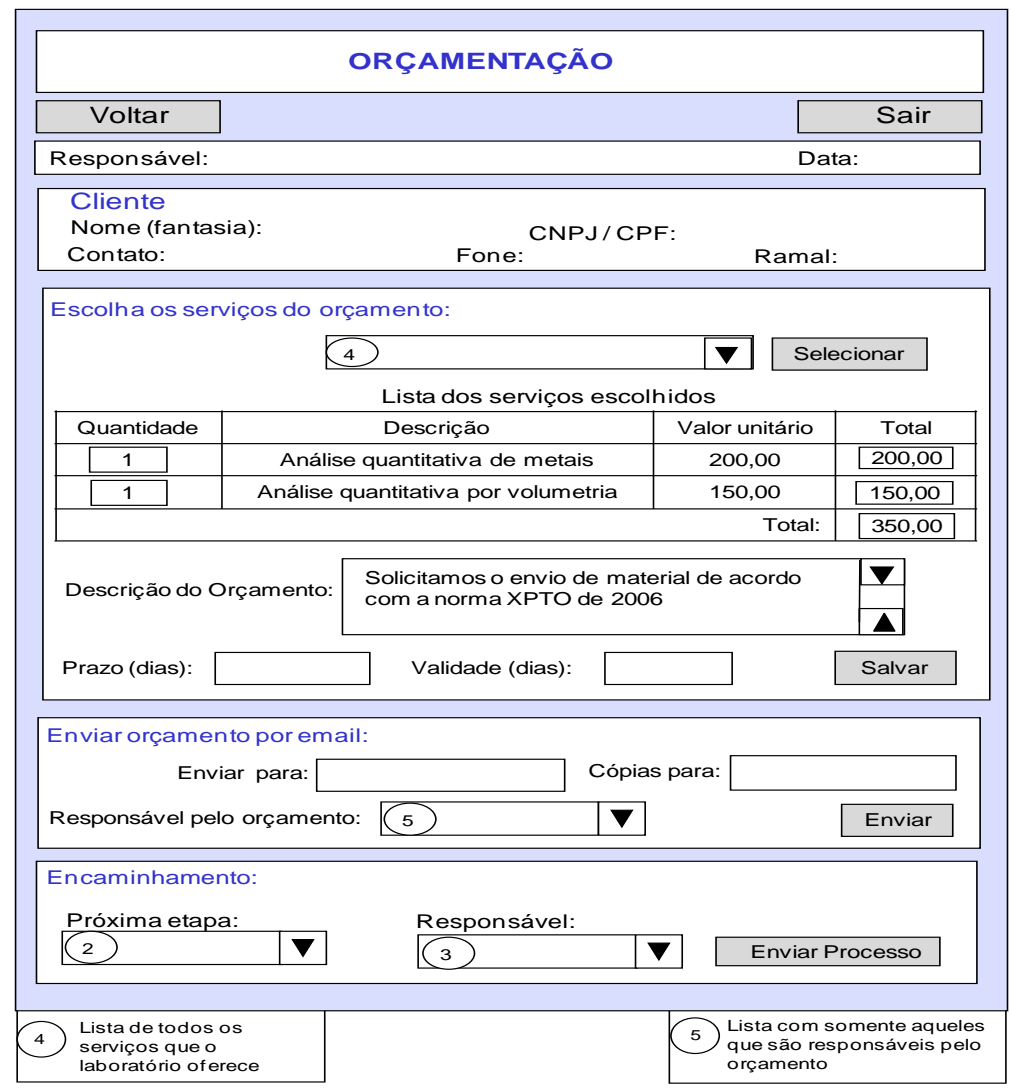

Figura VI.3 - Orçamentação (reprodução do ciclo 1)

A presença dos dois técnicos que, também, participaram do primeiro ciclo foi importante para ajudar esclarecer as dúvidas iniciais a respeito das fronteiras entre 0 SI e o sistema a ser informatizado, bem como com relação ao fluxograma inicial do processo e suas respectivas interfaces. 


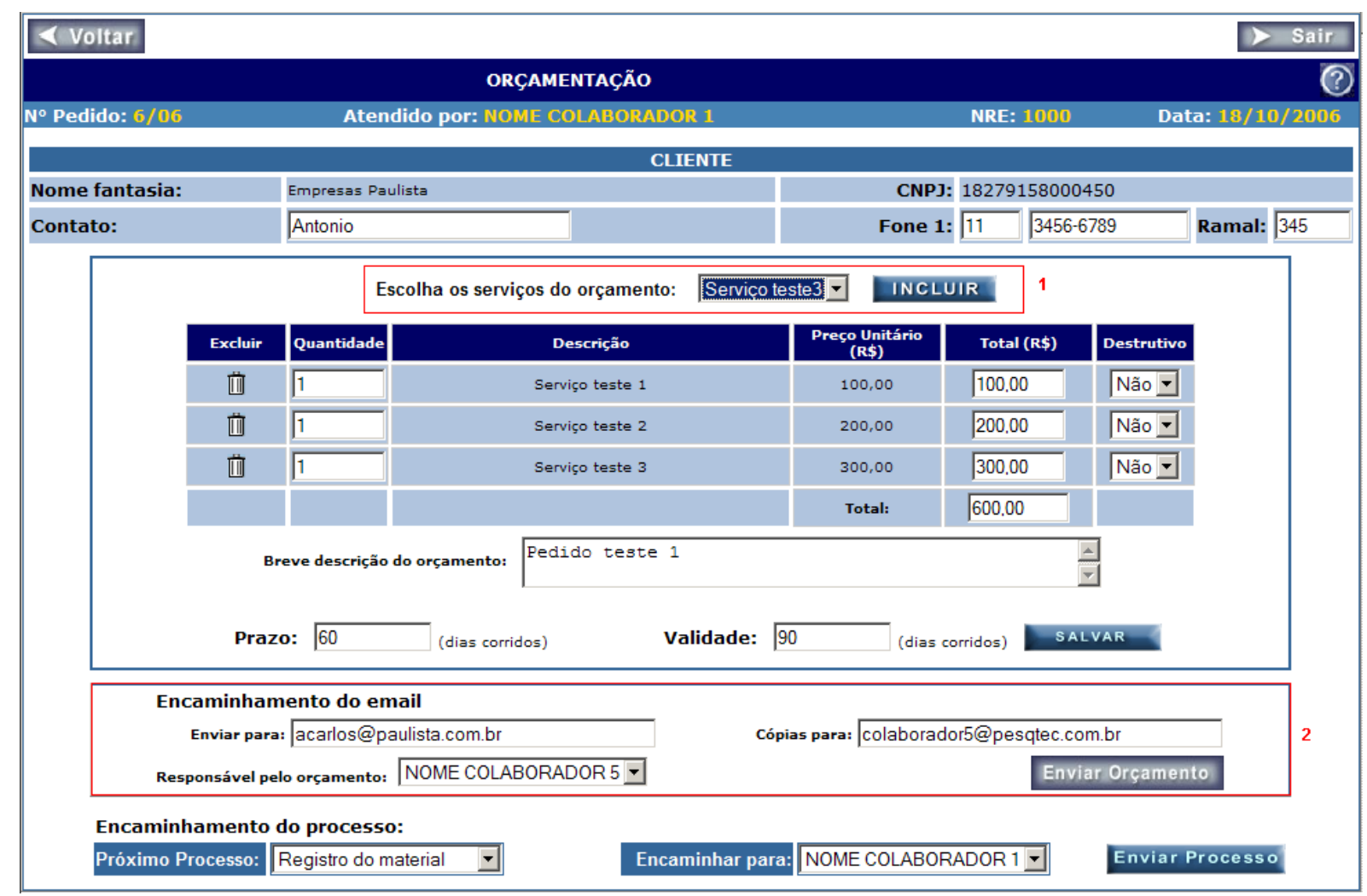

Figura VI.4 - Fase de orçamentação: interface em DHTML

Esta fase foi mais bem detalhada pelos participantes, sobretudo, durante a segunda parte da sessão, visto que o envio do orçamento de forma automática por email era uma antiga reivindicação dos laboratórios.

Por exemplo, a lista da opção "Escolha os serviços do orçamento:" da Figura VI.4-1 não mostrava todas as informações necessárias para escolha do serviço, de modo que se decidiu pela construção de uma opção de navegação para interfacear diretamente com o software de custos e preços (ver Figura VI.5). Outra situação correspondeu à opção: "Encaminhamento do email" (Figura VI.4-2), na qual ficou claro que ela deveria ser aberta em novas subopções para compor adequadamente as informações do email enviado ao cliente (por exemplo, uma descrição mais detalhada de cada serviço, observações sobre a quantidade do material a ser enviado, etc.).

A Figura VI.5 abaixo corresponde ao diagrama simplificado de navegação, considerando-se as novas navegações discutidas na Figura VI.4. 


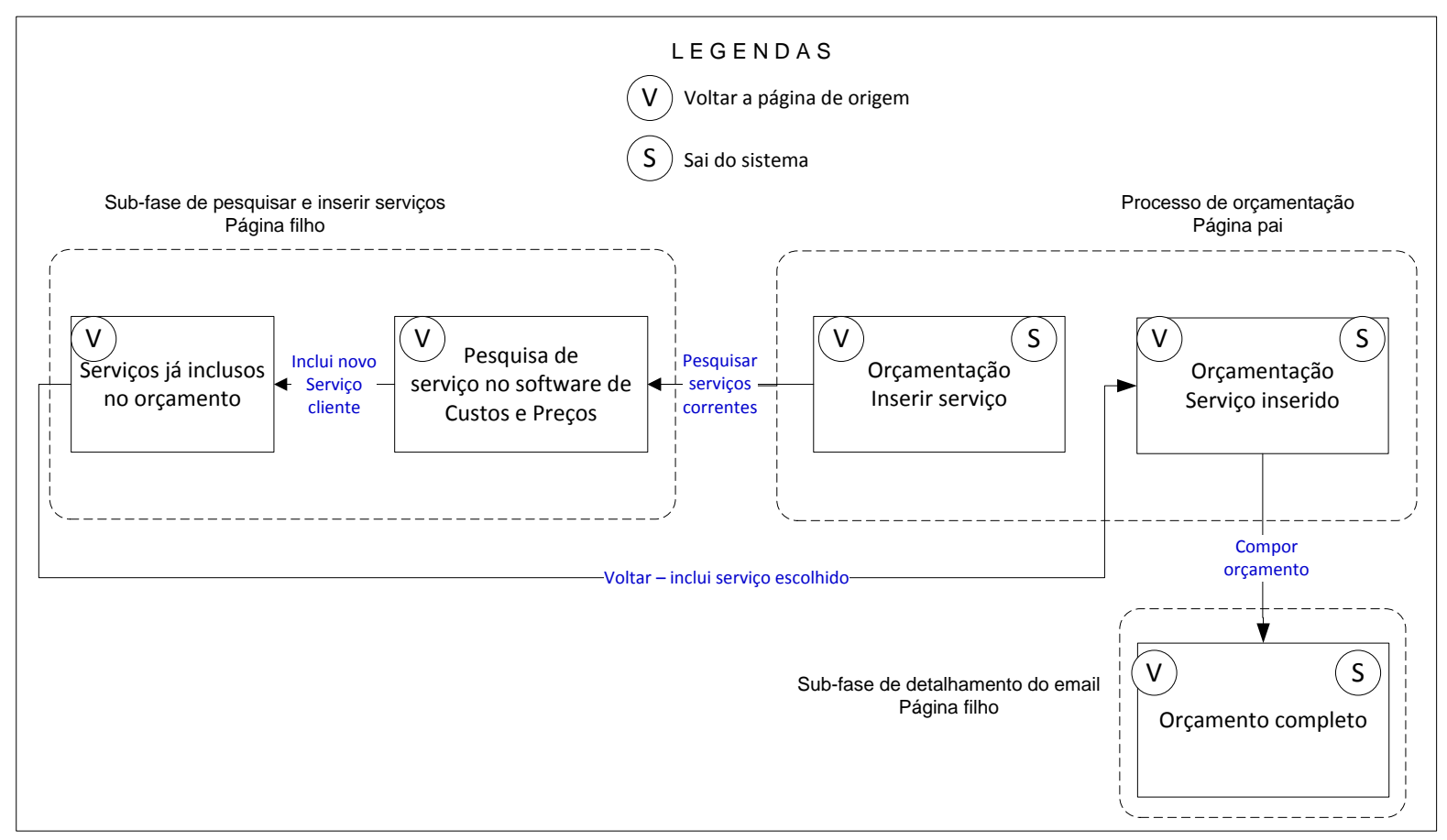

Figura VI.5 - Diagrama simplificado de navegação da fase de orçamentação: Inserir serviço do laboratório

Durante a discussão da navegação desta fase, um importante aspecto emergente foi levantado pelos participantes: o fato de um laboratório poder compor um orçamento com orçamentos realizados por outros laboratórios (multilaboratorial). Neste caso, todos os demais laboratórios encaminhariam orçamentos a este laboratório que, então, os enviaria aos cliente, tornando-se o único responsável frente a este cliente. A questão foi muito debatida na sessão, já que vários responsáveis por laboratórios comentaram que, atualmente, no envio de um orçamento desse tipo, cada laboratório envia o seu de modo independente ou o laboratório responsável envia todos os demais orçamentos com o dele, ficando difícil para o cliente analisar o conjunto de orçamentos recebidos, sobretudo, pela sua falta de padronização.

Ficou claro, também, pelas observações dos participantes, que o fluxo inicial levantado (reproduzido na Figura VI.6 abaixo), não era representativo de todas as situações encontradas nos fluxos de atendimento dos laboratórios e que o mesmo deveria ser revisado (ver Figura VI.10), pois a relação entre o material registrado e a realização do trabalho não era necessariamente um para um (a execução de um ou mais serviços sobre um material poderia ser realizada por um ou mais usuários, dependendo da especialização dos mesmos em executar determinados serviços). 


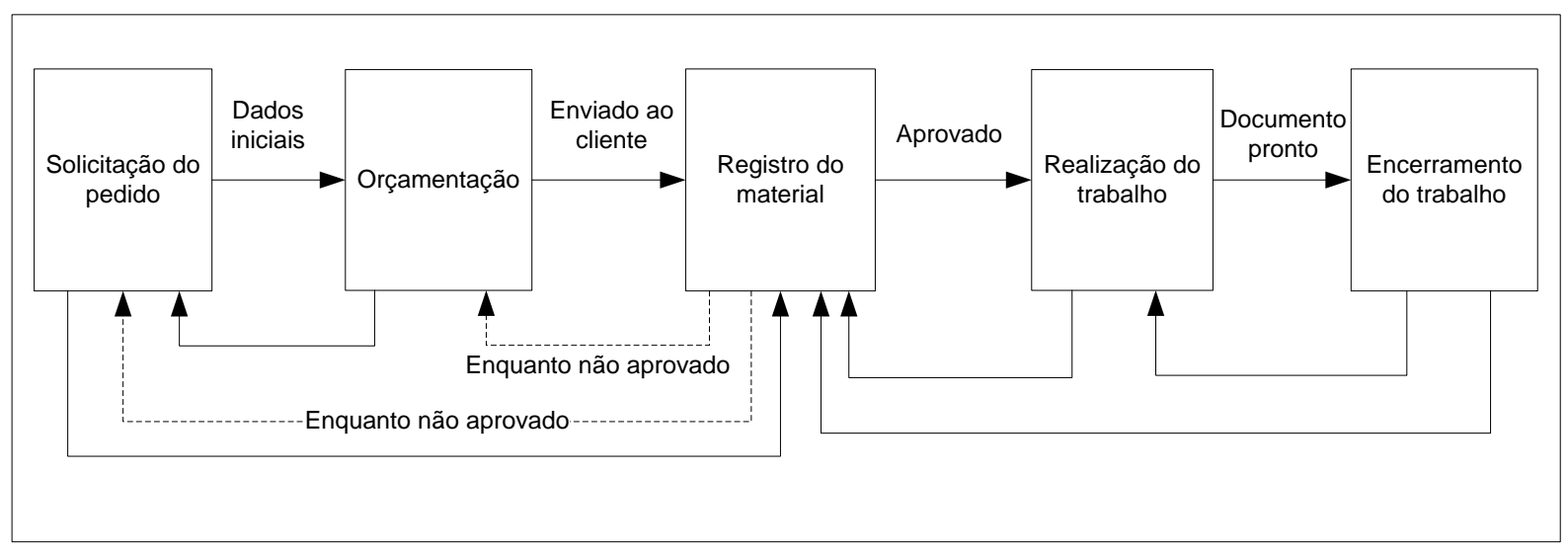

Figura Vl.6 - Reprodução do fluxograma final do ciclo 1

Após o término da sessão, o detalhamento da navegação da orçamentação e de suas respectivas interfaces foram detalhados nos passos de análise e planejamento da PA com dois usuários designados na segunda parte da sessão. Considerou-se além das questões relativas à Figura VI.4, também, a questão do orçamento multilaboratorial, assim como os dados importados do software de Custos e Preços. Como próximos objetivos, o fluxo do processo também foi mais bem detalhado para servir como elemento inicial na segunda parte da próxima sessão.

\section{VI.3.2 Iteração 2}

Em função do que foi discutido pelos participantes na segunda parte da sessão anterior (iteração 1) e dos detalhamentos realizados com os dois usuários designados no passo da análise e planejamento da iteração anterior, foram construídas, no passo de implementação desta iteração, as principais interfaces gráficas da fase de orçamentação e o respectivo diagrama de navegação, associados a uma característica emergente discutida na sessão anterior: o orçamento multilaboratorial.

Visando, também, a preparação para a segunda sessão, foi elaborada uma revisão no fluxo de processo como um todo, já que devido à participação de representantes de laboratórios diferentes, algumas variações importantes foram discutidas, a partir do fluxo principal levantado no ciclo 1.

Na primeira parte da sessão desta iteração, foi apresentado aos representantes dos laboratórios para discussão e validação o diagrama de navegação e as interfaces 
associadas à fase de orçamentação. Na Figura Vl.7 abaixo, pode ser vista a interface gráfica da fase de orçamentação, já considerando a questão do orçamento multilaboratorial e as mudanças apresentadas na Figura VI.4 e na Figura VI.5.

Assim, a escolha dos serviços do laboratório (Figura VI.4-1) foi substituída pela opção 1 da Figura VI.7 (pesquisar serviços correntes do laboratório), dando mais flexibilidade ao usuário na escolha de um serviço realizado pelo próprio laboratório (Figura VI.8), onde esta figura mostra que o usuário pode fazer uma escolha por nome de serviços (opção 1), excluir serviços (opção 2) já incluídos (opção 3), ou ver detalhes do orçamento (opção 4 - o serviço não pôde ser inserido, pois não tinha preço final).

Com relação ao orçamento multilaboratorial, a opção 2 da Figura VI.7 (pesquisar orçamento interno) permitiu ao usuário escolher um orçamento interno enviado por outro laboratório (no caso do exemplo o laboratório Teste 2 - diagrama de navegação da Figura VI.9 ), cujo retorno corresponde à opção 3 da Figura VI.7.

Por fim, a opção 4 da Figura VI.7 corresponde ao detalhamento de um orçamento mostrado na Figura VI.4-2. 


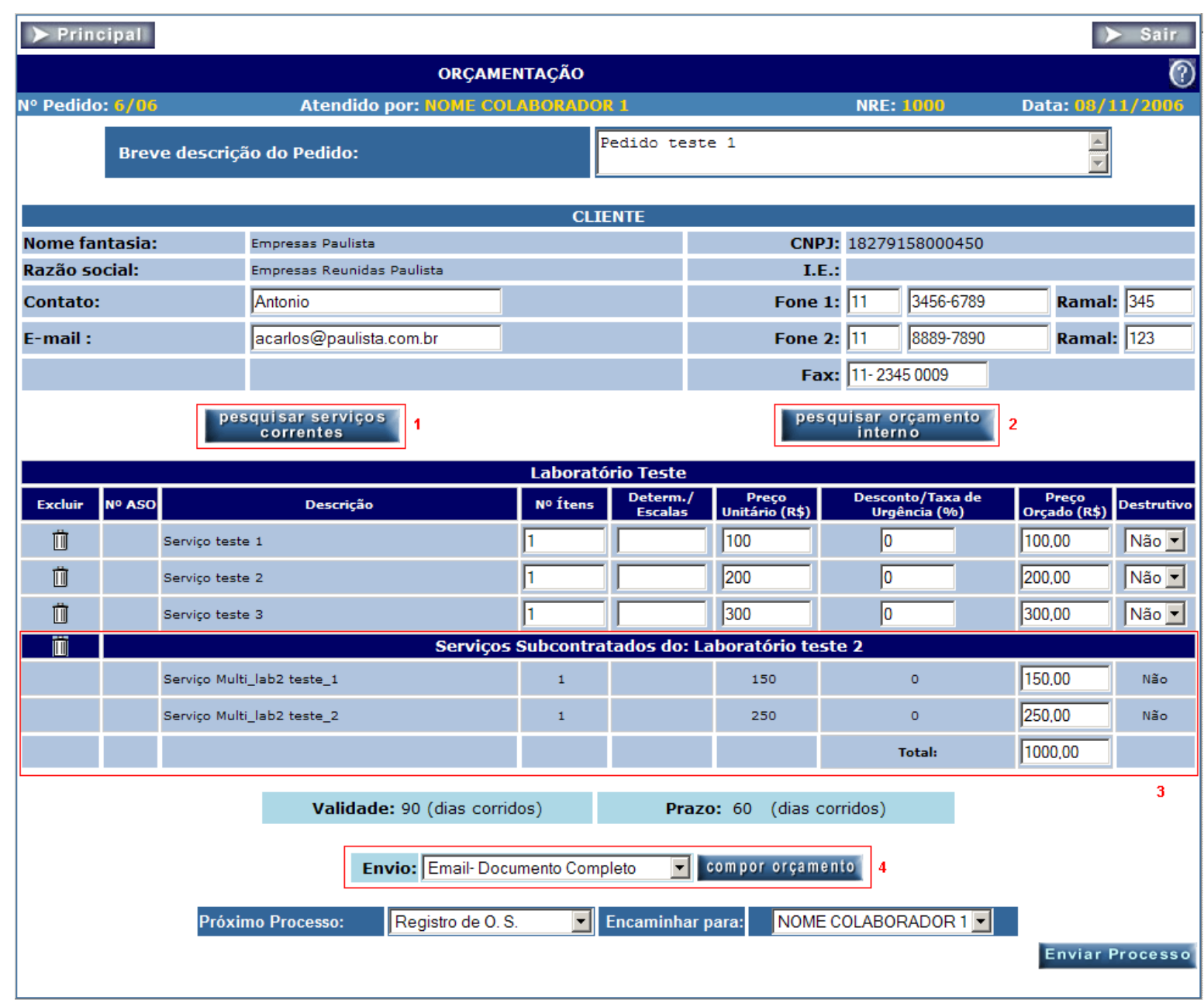

Figura VI.7 - Orçamentação multilaboratorial

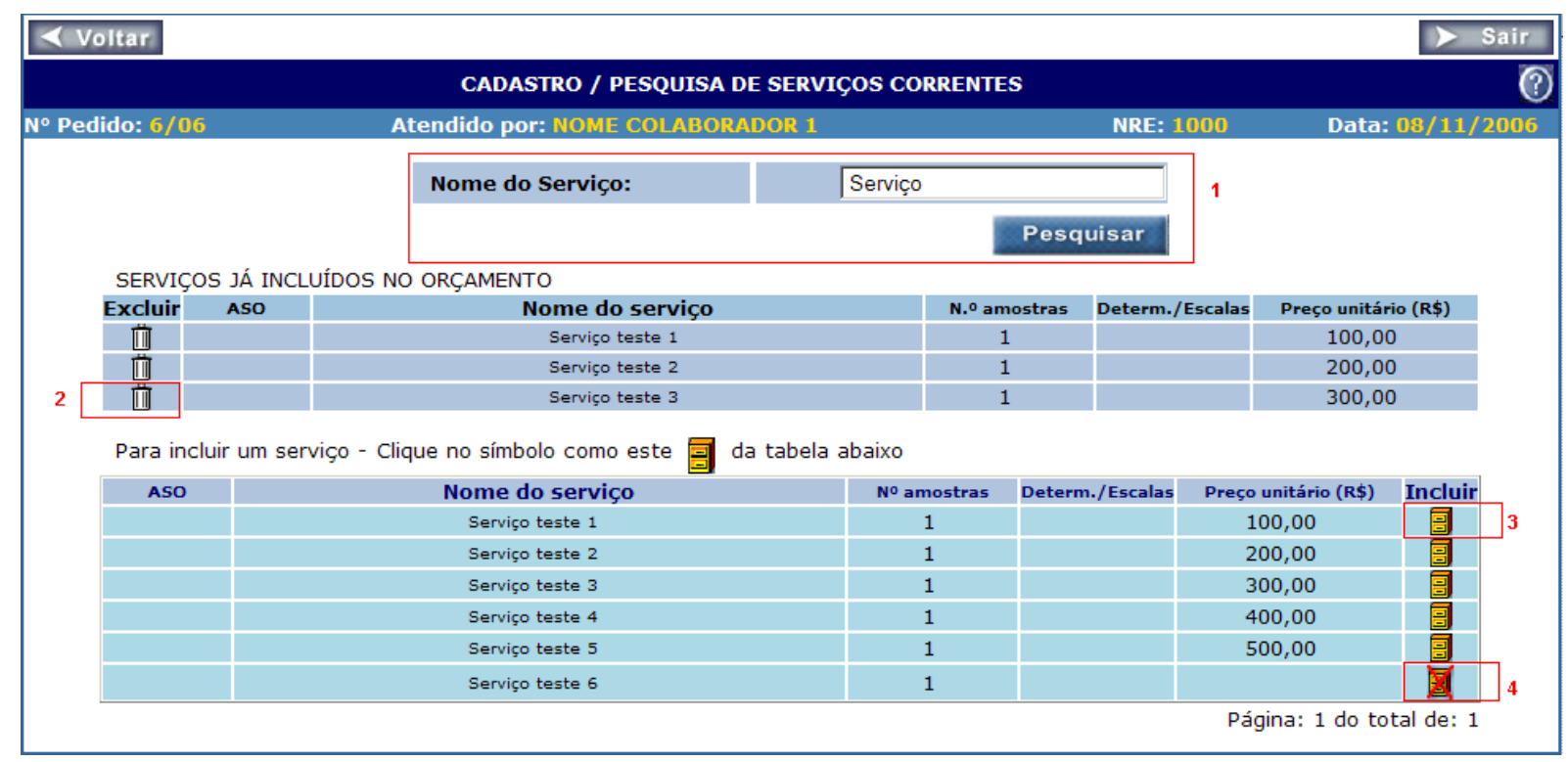

Figura VI.8 - Dados utilizados do sistema Custos e Preços 


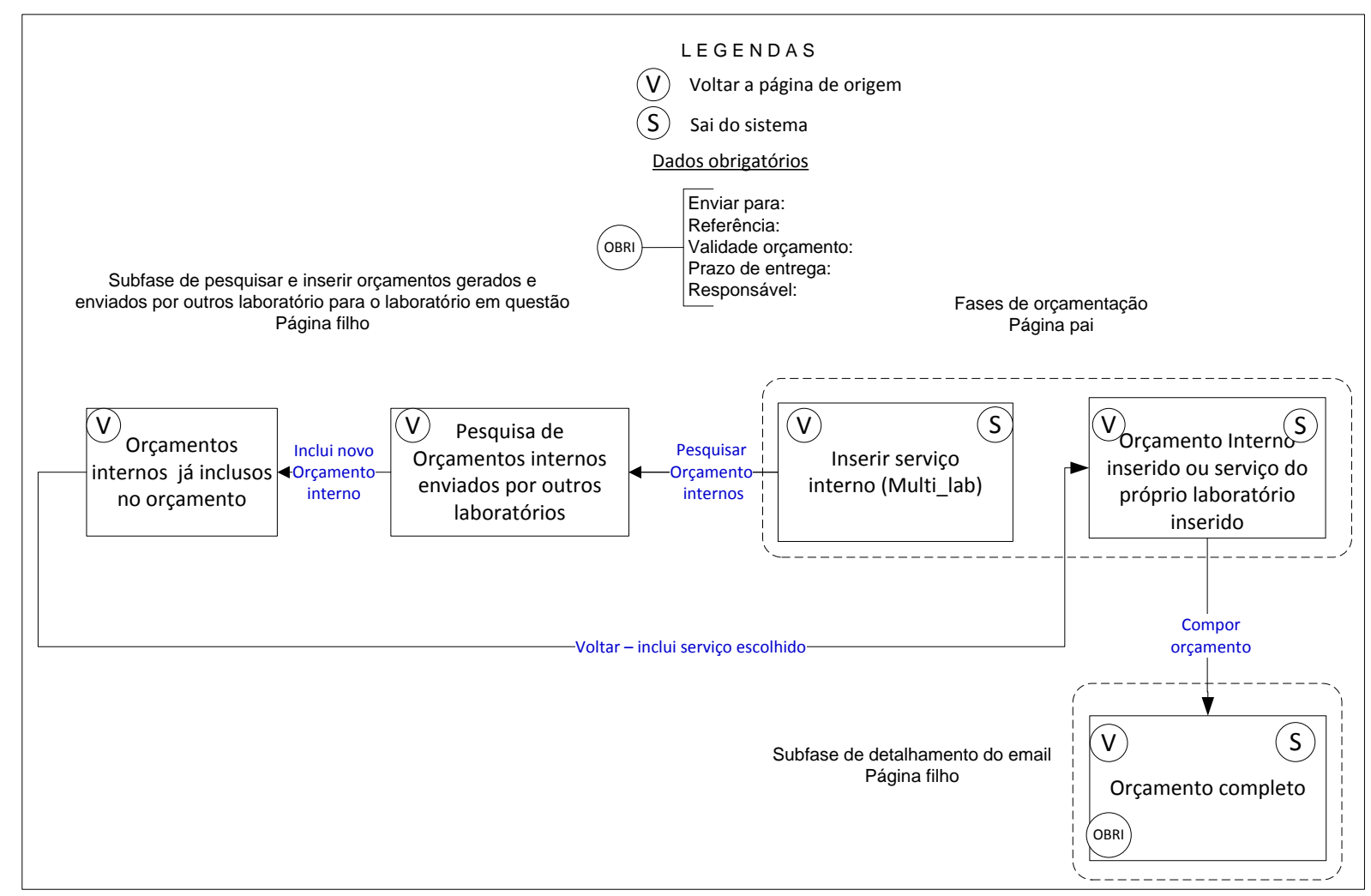

Figura VI.9 - Diagrama simplificado de navegação da fase de orçamentação: inserir orçamento gerado por outro laboratório

A fase inicial da abertura de uma nova solicitação de pedido (fase de solicitação do pedido), também, foi lembrada pelos participantes, já que um pedido deve ser aberto pelo usuário, antes de ser orçado. Assim, a cada pedido seria associado um número único de atendimento para toda empresa PesqTec com o formato 9999/99, sendo XX os dois últimos dígitos do ano (por exemplo, pedido 1234/09). Esta fase não será detalhada neste trabalho.

Na segunda parte da sessão, o novo fluxograma (Figura VI.10) foi apresentado e desenvolvido no passo de implementação desta iteração e corresponde a uma evolução do fluxograma desenvolvido no final do ciclo 1 e apresentado na Figura VI.6.

O fluxograma mostra que, na fase de registro de material, é possível que os usuários não tenham especialização adequada para executar todos os serviços orçados, de modo que, no limite, cada serviço seja realizado por um executor diferente (denominada OS). Como neste ponto ocorre uma "divisão" do fluxo, a fase do registro material deverá oferecer uma funcionalidade de distribuição das ordens de serviço (OS). Uma OS corresponde a uma determinada associação entre um ou 
mais serviços, um material e seu respectivo executante. Os usuários também sugeriram a mudança do nome da fase de "Realização do trabalho" para "Inspeção/execução do serviço".

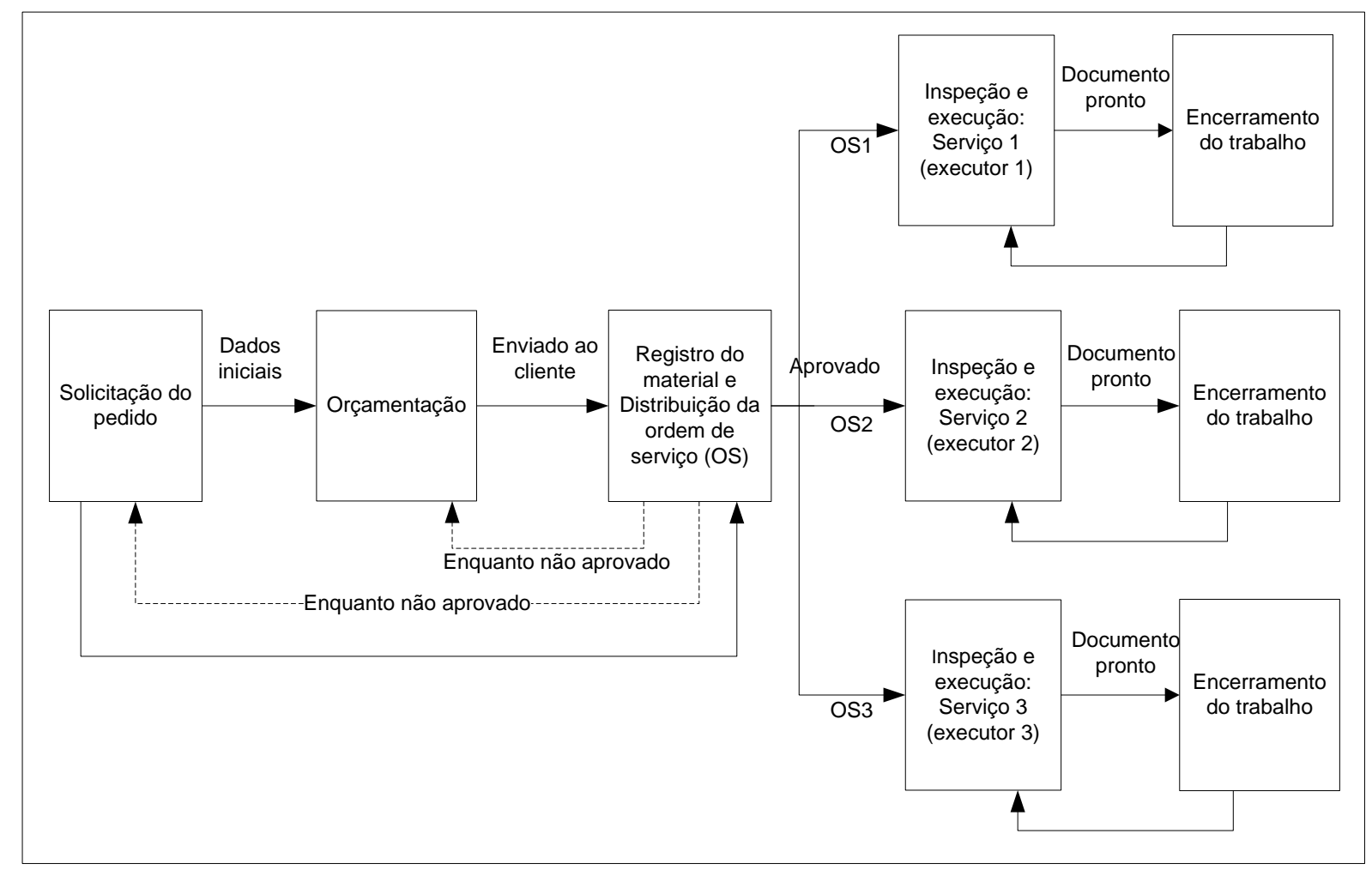

Figura VI.10 - Fluxograma do processo após a iteração 1

Após este detalhamento, alguns usuários perceberam que as ordens de serviço poderiam ser reagrupadas para formar um ou mais documentos técnicos no processo, assim como seria necessário mudar parte das interfaces gráficas já discutidas para atender a estas novas regras do fluxo. Foram, então, desenhadas no quadro as alterações que deveriam conter o fluxograma do processo, para que 0 mesmo pudesse realizar a distribuição dos documentos técnicos.

Nesta sessão, também, foram definidos dois usuários (aqueles que levantaram estas questões) para detalhar melhor esta situação no passo de análise e planejamento, de modo a permitir sua implementação na iteração seguinte, para apresentação na terceira sessão. 


\section{VI.3.3 Iteração 3}

Inicialmente, no passo de implementação, foram desenvolvidos os artefatos necessários à terceira sessão: o novo fluxograma do processo, assim como uma primeira versão das interfaces gráficas associadas a estas novas fases. Os artefatos foram detalhados com as sugestões feitas pelos usuários na segunda parte da sessão anterior e, posteriormente, complementados no passo de análise e planejamento durante a realização da segunda iteração.

$\mathrm{Na}$ Figura VI.11 abaixo, pode ser visto o fluxograma do processo discutido na iteração anterior, onde foi criada a nova fase no processo de atendimento (Composição do documento técnico) e novas opções de navegação do workflow em função do que foi discutido na segunda parte da sessão anterior.

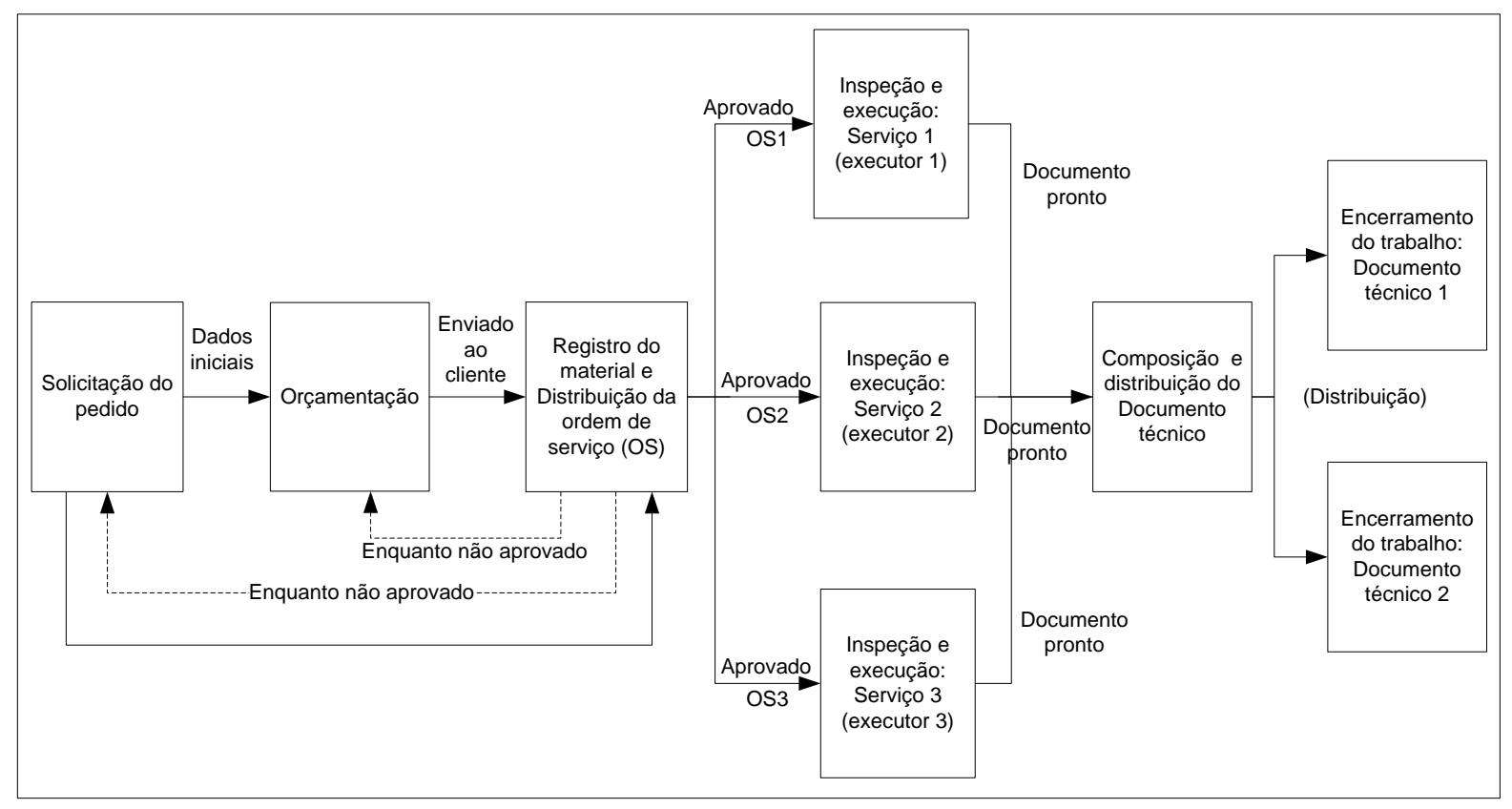

Figura VI.11 - Fluxograma do processo discutido na iteração 2 (segunda sessão)

No detalhamento do fluxo das tarefas, alguns usuários perceberam que seria necessário separar a funcionalidade da aprovação do orçamento que se encontrava na fase do registro do material (ver Figura V.12) e criar uma nova fase entre a orçamentação e a fase de registro do material para possibilitar aos usuários fazer um acompanhamento mais próximo das aprovações dos orçamentos, inclusive, possibilitando o gerenciamento dos contatos com os clientes. Deste modo, os participantes da sessão decidiram criar a fase de follow-up. 
Outro aspecto referente ao workflow do processo levantado pelos usuários foi a necessidade de uma nova conexão (interface) do sistema informatizado com um outro sistema da empresa PesqTec para a obtenção de uma numeração que os documentos técnicos deveriam possuir. Alguns usuários lembraram que no modo não informatizado era comum ocorrer erros de associação entre o número do documento, que é solicitado manualmente em outro sistema e o documento técnico entregue ao cliente.

A criação de uma nova fase denominada elaboração do documento técnico foi proposta. Fase esta que estaria entre as de composição do documento técnico e encerramento do trabalho. Por sua vez, também, foi proposta pelos usuários a mudança do nome da fase de encerramento para entrega do documento, por ser esta mais apropriada com as atividades relacionadas à mesma.

$\mathrm{Na}$ Figura VI.12, pode ser visto o diagrama de contexto considerando a nova interface e na Figura V.13 o fluxograma completo do processo de atendimento, considerando as duas novas fases discutidas nesta sessão.

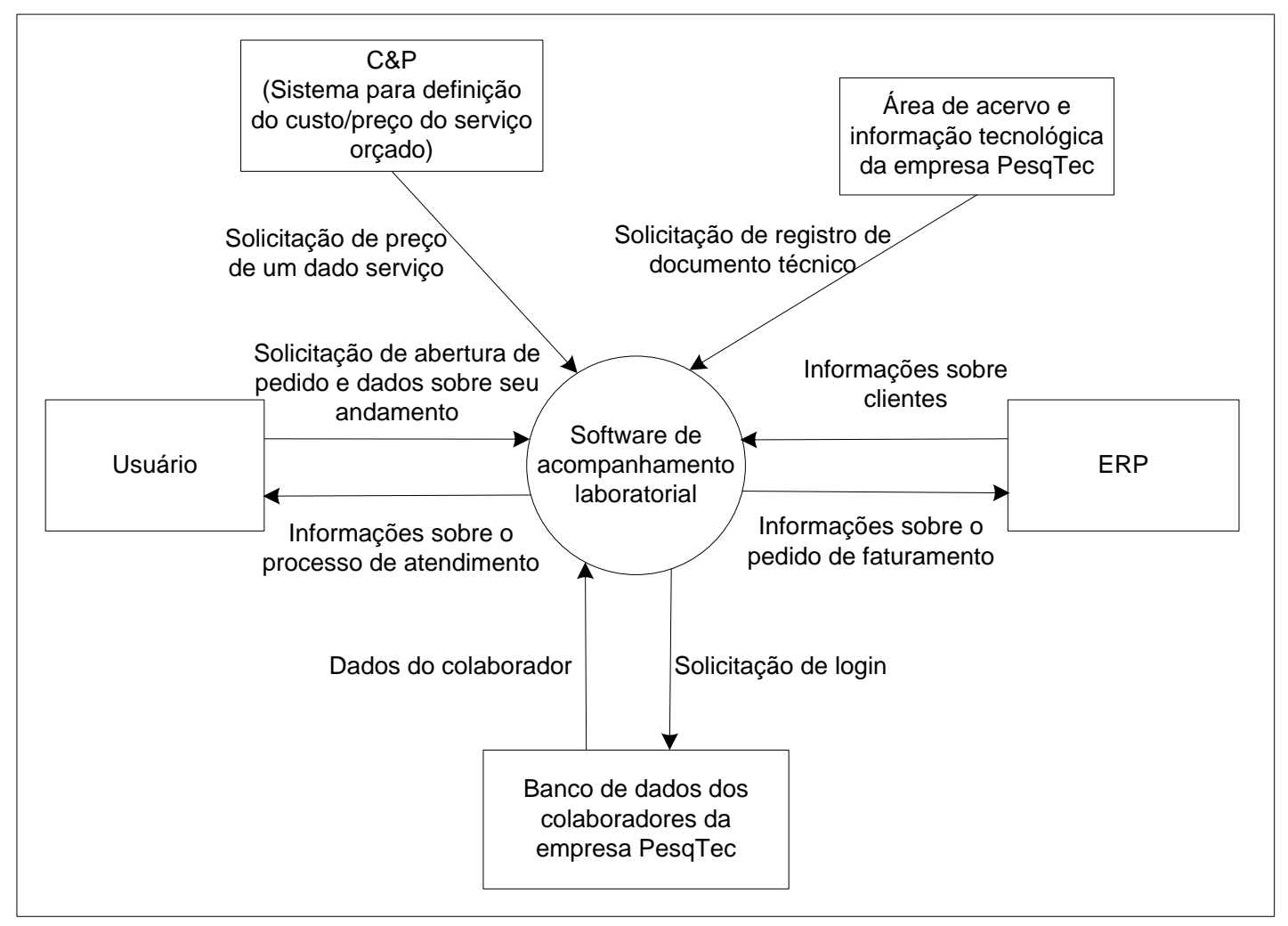

Figura VI.12 - Diagrama de contexto, considerando a interface com o sistema de numeração do documento técnico 


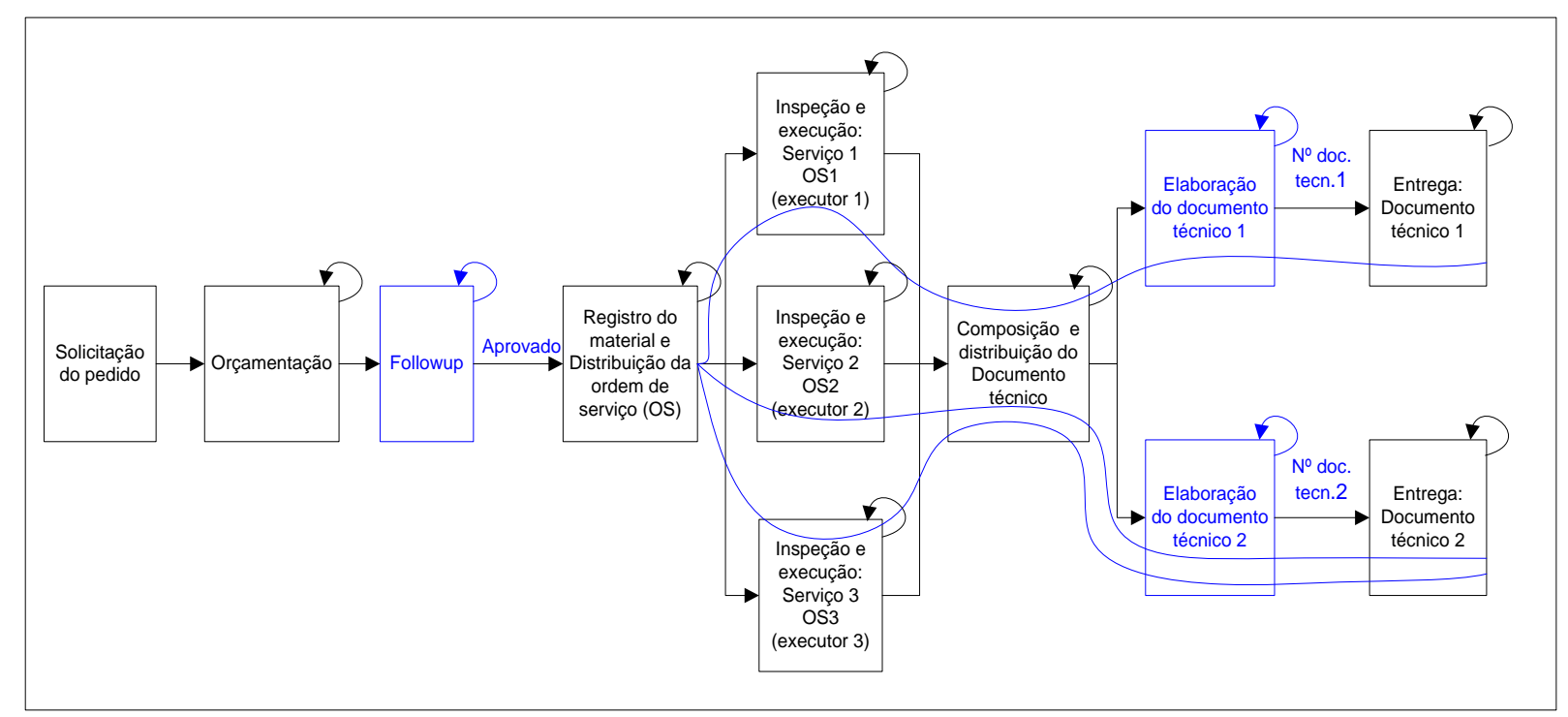

Figura VI.13 - Fluxograma final do processo, considerando o detalhamento desta sessão

Após o detalhamento do fluxo, solicitou-se aos usuários como deveria ser a distribuição das atividades e responsabilidades associadas a este fluxo de trabalho, procurando associar às várias especializações de profissionais encontradas nos laboratórios (técnico executante do serviço, secretárias, chefes de laboratório e pesquisadores) uma ou mais fases do processo discutido.

Percebeu-se que não seria possível atribuir as atividades associadas a cada fase aos tipos de profissionais encontrados nos laboratórios, sobretudo em razão da heterogeneidade destes laboratórios, onde, dependendo de seu tamanho, um mesmo profissional poderia assumir várias das fases apresentadas e, também, pelo fato de nenhuma das fases exigir um perfil técnico para sua realização, já que o objetivo da automação era realizar o acompanhamento do atendimento e não realizar automaticamente o serviço em si (ver ciclo 1).

Deste modo, cada laboratório poderia estabelecer quem iria trabalhar em determinada fase, mas sem criar grupos específicos dentro do software para esta finalidade, possuindo uma configuração próxima ao de grupos semiautônomos, sobretudo pelo fato do grupo ser responsável por atingir um determinado volume de produção em um certo intervalo de tempo, dentro dos padrões de qualidade especificados, possuindo certa autonomia para troca de funções no processo (SALERNO, 1999). 
Em comum acordo, ficou estabelecido que cada novo pedido (solicitação de orçamento) teria um único responsável, este sim escolhido de uma lista mais restrita de usuários e também, o pedido de faturamento só poderia ser realizado pelas secretárias, em razão do conhecimento e permissão específicos em outros sistemas (ERP) que estas possuíam. Outro grupo de usuários que também surgiu nas discussões foi o grupo administrador.

Assim, não haveria uma lista específica de responsáveis para cada fase, de modo que todo usuário do sistema poderia acessar qualquer fase do mesmo, tornando o fluxo do processo dependente do conhecimento que cada usuário tinha de seu serviço e do conhecimento do andamento do serviço dos demais.

$\mathrm{Na}$ segunda parte da sessão, foram detalhadas as fases com funcionalidade mais cooperativas do sistema. Primeiramente, foi apresentado o esboço da interface do processo de registro de material que também passou a ter a função de distribuição das ordens de serviço (ver Figura VI.14); e os usuários poderiam associar um material registrado a um determinado executor para a realização de um ou mais serviços orçados para o cliente.

Posteriormente, detalhou-se também a fase de composição (Figura VI.16), permitindo a associação das ordens de serviço distribuídas (fase de inspeção e execução) a um ou mais documentos técnicos.

No final da sessão, surgiu uma questão emergente, após a observação de alguns usuários sobre como seria possível coordenar a sequência de execução das fases do workflow em um contexto, em que as mesmas poderiam ser acessadas, em tese, por qualquer usuário do grupo. Percebeu-se, então, que seria preciso criar algum meio de coordenação das atividades do grupo em um ambiente autocoordenado, isto é, as ações do grupo deveriam levar à sua própria coordenação.

No passo de análise e planejamento, foram detalhadas as novas fases surgidas na validação do workflow (follow-up, registro de OS, composição de documento técnico e elaboração), assim como a confecção de um artefato para tratar a questão da autocoordenação do grupo (por meio de entrevista individual com alguns usuários que participaram da sessão corrente).

Nesta iteração, outros artefatos foram detalhados diretamente pela equipe de desenvolvimento do software para serem apresentados aos usuários, considerados 
como ferramentas do sistema informatizado: de administração (definição de quem acessa o sistema, do grupo de responsáveis pelo orçamento e do grupo de administradores), de geração de pedido de faturamento e de solicitação interna de serviço (equivalente a um pedido de faturamento, mas para um cliente interno).

\section{VI.3.4 Iteração 4}

No passo de implementação, os artefatos detalhados no passo de análise e planejamento da iteração anterior foram preparados como elementos de suporte para a sessão desta iteração. Deste modo, a fase de registro de OS e a fase de composição foram reestruturadas e as novas fases de follow-up e de elaboração construídas. Um esboço de um artefato de coordenação também foi desenvolvido para apresentação e discussão na segunda fase da sessão corrente.

Os artefatos definidos como ferramentas para execução do fluxo, também, foram implementados para apresentação e validação dos usuários, mas seu detalhamento não será realizado na sessão corrente pelas razões apresentadas no item VI.1, cabendo a observação que estes artefatos não fazem parte do fluxo apresentado na iteração 3 , sendo seu acesso realizado por meio do artefato de coordenação mostrado na Figura VI.17.

Seguindo a dinâmica das iterações apresentada no item VI.2.2, na primeira parte da sessão foram validados os artefatos detalhados na segunda parte da sessão anterior. Só as fases de registro de OS e de composição serão discutidas nesta iteração, uma vez que apresentam maior importância para o trabalho cooperativo dos laboratórios.

A Figura VI.14 corresponde à fase de registro de material e distribuição de OS. Inicialmente, registra-se o material e associa-se ao mesmo os serviços e os executores, como pode ser visto na Figura VI.14-1. Neste caso, é possível associar até três serviços diferentes (serviço teste 1, serviço teste 2 e serviço teste 3 ), cada um deles, por sua vez, pode ser associado a qualquer usuário do laboratório (grupo de trabalho).

Uma vez feita as associações, estas devem ser efetivadas pelo botão "inserir", com o resultado da ação mostrado na Figura VI.14-2, em que pode ser visto que existe 
um material registrado no sistema (550) e associados ao mesmo três serviços e usuários (Serviço teste 1/ Nome do colaborador 1-OS1; Serviço teste 2/Nome do colaborador 2 - OS2 e Serviço teste 3 /Nome do colaborador 3- OS3 ) .

Quando o botão "Distribuir OS" for acionado, serão geradas três ordens de serviço distintas para os três usuários (ou seja, três fases distintas de Inspeção/Execução), assim como será gerada uma fase de composição de documento técnico para o usuário Nome colaborador 4 (acima do botão inserir na caixa: "Após execução, a composição do Doc.Técnico será feita por:").

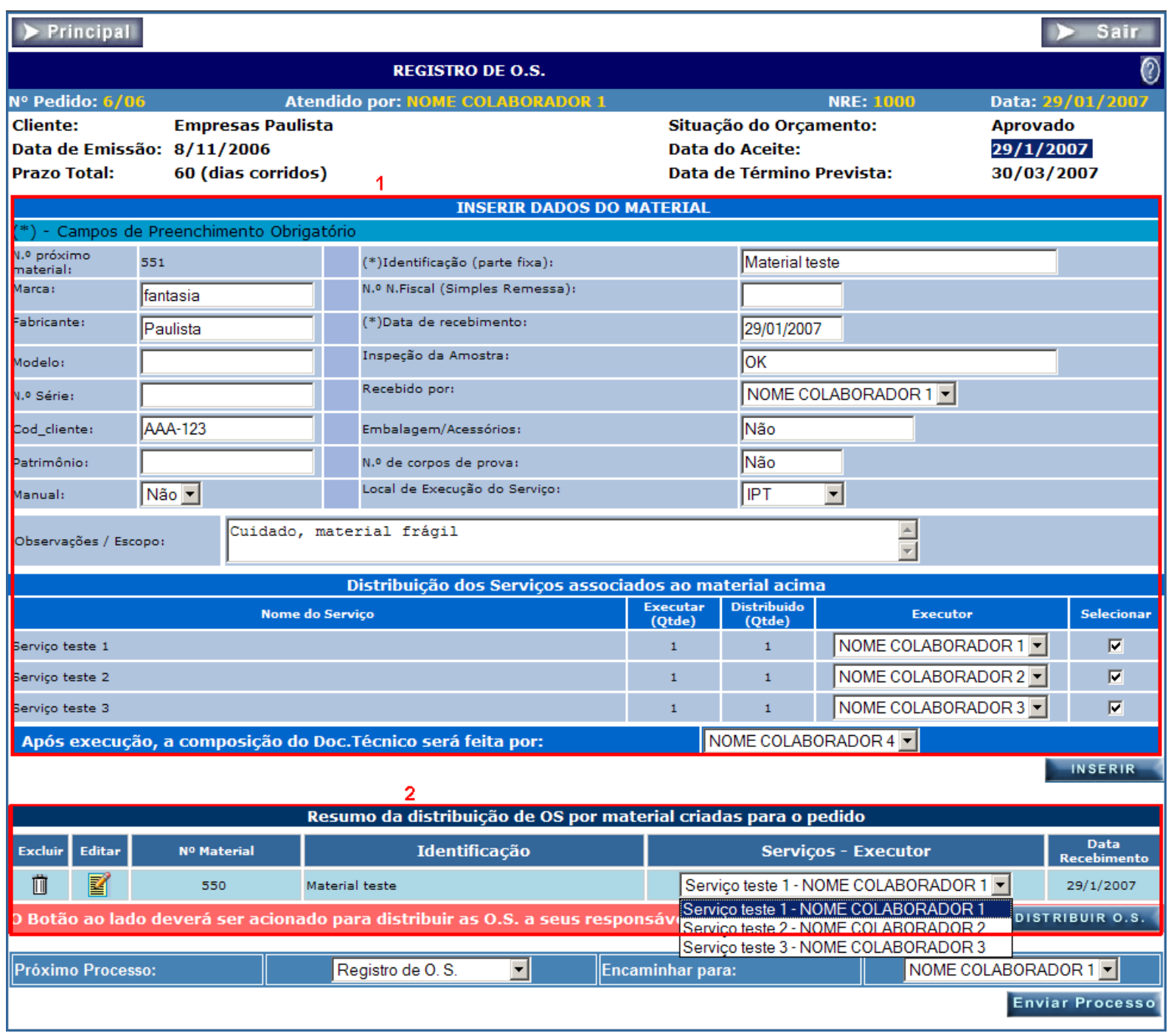

Figura VI.14 - Registro de material e distribuição de OS

Na Figura VI.15, pode ser visto um artefato típico da fase de inspeção e execução (uma das ordens de serviço geradas na fase anterior) recebido pelo usuário "NOME COLABORADOR 3". 
Nesta fase, o executante do serviço em um dado material deve informar a situação da inspeção (conforme/não conforme), assim como o estado da execução (coluna Status da execução). Em particular, na Figura VI.15-1 pode-se notar que a situação da inspeção é "conforme e a o "Status"da execução é "Concluído".

Quando o botão "salvar" for acionado, esta informação fará parte do painel da fase de Composição do documento técnico mostrado na Figura VI.16-1, onde se pode notar que a coluna "Status" para o NOME COLABORADOR 3 possui o valor "concluído".

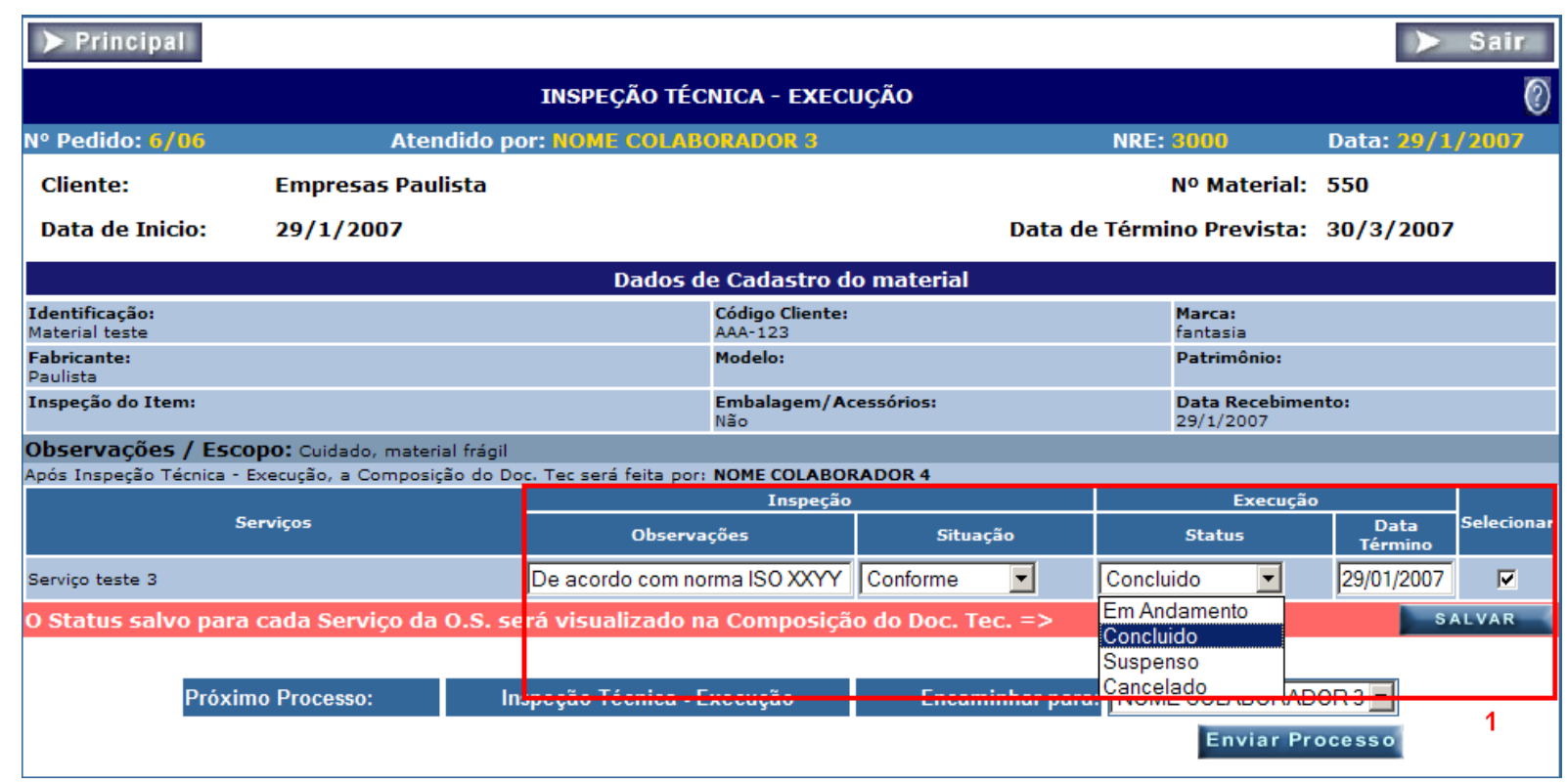

Figura VI.15 - Inspeção e execução da OS

A Figura VI.16-1 mostra um painel com todas as fases de Inspeção/execução que foram distribuídas na fase de Registro e distribuição de OS, assim como é possível verificar se estas já foram ou não concluídas. A informação permite ao usuário (no caso "NOME COLABORADOR 4") verificar em uma única figura um resumo sobre o andamento das execuções dos serviços.

Utilizando-se os conceitos de ergonomia das interfaces (ver item II.3.2 e Apêndice B), em particular, o critério de consistência, procurou-se garantir que as características da interface de Registro e distribuição de OS (códigos, procedimentos, denominações, posições, etc.) fossem conservadas nesta fase, de modo que a mesma foi dividida em duas, em que foi dada a possibilidade para 0 usuário escolher quais ordens de serviço poderiam compor o documento técnico (Figura Vl.16-1) e depois permitir que este verificasse a composição escolhida e 
fizesse sua distribuição (no caso criando as respectivas fases de Elaboração do documento técnico- Figura VI.16-2).

No exemplo em particular mostrado na Figura VI.16-1, já foram escolhidas duas ordens de serviço para fazer parte de um documento técnico (estão marcadas como "inseridas" na coluna Inserir), sendo este documento apresentado na Figura VI.16-2 para distribuição: (material 550 - Serviço teste 2 e material 550 - Serviço teste 3), nome do documento: "Documento técnico 2" e que será enviado para o "NOME COLABORADOR 6" na fase de "Elaboração do Documento".

O outro documento técnico ainda não foi composto na Figura VI.16-1, mostrando que será composto somente do material 550 associado ao serviço teste 1, nome do futuro documento: "Documento técnico 1" e será enviado para o "NOME COLABORADOR 1".

$\mathrm{Na}$ Figura V.13 podem ser vistos por meio das linhas indicadas nesta figura, os caminhos percorridos pelo fluxo de atendimento para as fases de registro de OS, inspeção/execução, composição e elaboração do documento técnico utilizados neste exemplo.

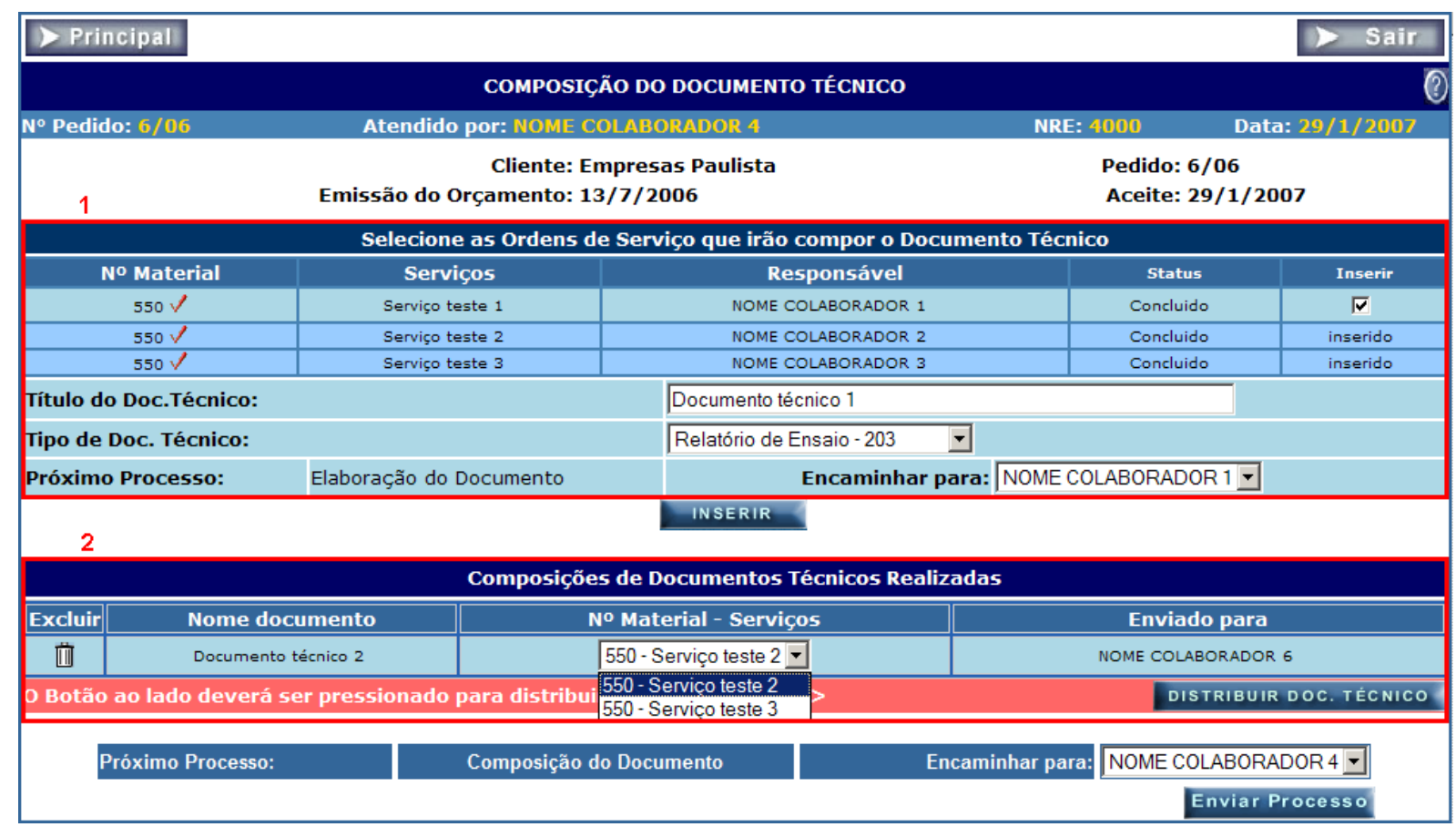

Figura VI.16 - Composição do documento técnico

Na segunda parte da sessão, o objeto de coordenação necessário foi apresentado, para que um dado usuário conseguisse se coordenar dentro de suas atividades, 
levando-se em conta o fato que o mesmo poderia possuir vários pedidos abertos sob sua responsabilidade. Assim, foi criado um artefato de coordenação no qual os usuários poderiam visualizar todas as suas fases pendentes, além de permitir o acesso às mesmas para executar suas respectivas atividades (Figura VI.17).

Outro aspecto emergente que surgiu durante a discussão da coordenação das atividades, foi o fato de que o usuário do grupo de trabalho também tinha necessidade de saber o que os demais participantes do grupo estavam fazendo, além da situação de seu trabalho, para deste modo encaixar suas atividades com as atividades dos demais participantes do grupo.

Para tanto, outro artefato foi proposto pelos participantes da sessão, de modo a atender a esta necessidade (Figura VI.19), cujo objetivo foi mostrar todas as fases pendentes de um determinado pedido, independente de quem era seu responsável. Assim, o usuário poderia saber como estava o andamento do pedido como um todo.

A necessidade de criação de relatórios também foi mostrada aos participantes, tanto os gerencias para verificação de estatísticas do atendimento (número de orçamentos gerados, aprovados, valores faturados, número de documentos técnicos gerados, tipo de documentos gerados, etc.), como internos (como o caso do artefato para verificação dos pedidos em andamento).

Por último, no passo de análise e planejamento foram identificados os detalhes dos dois artefatos de coordenação para sua construção na quinta iteração por meio de entrevistas individuais, assim como foram detalhados também alguns dos relatórios internos e gerenciais.

\section{VI.3.5 Iteração 5}

Na penúltima iteração, no passo de implementação, foram construídos os artefatos de coordenação, e os relatórios internos e gerenciais detalhados no passo de análise da iteração anterior.

Na primeira parte da sessão, estes artefatos foram validados. Assim, na Figura VI.17 pode ser vista a proposta final da interface gráfica referente ao artefato de coordenação individual das atividades dos usuários, em que estão listadas todas as pendências de fases de processos abertas relacionadas somente ao usuário "NOME 
COLABORADOR 1". Conforme citado na segunda parte da sessão anterior, o objetivo deste artefato é permitir que o usuário verifique, dentro de suas pendências, qual(is) fase(s) do processo estão sob sua responsabilidade para que possa, deste modo, coordenar suas ações (coordenação individual).

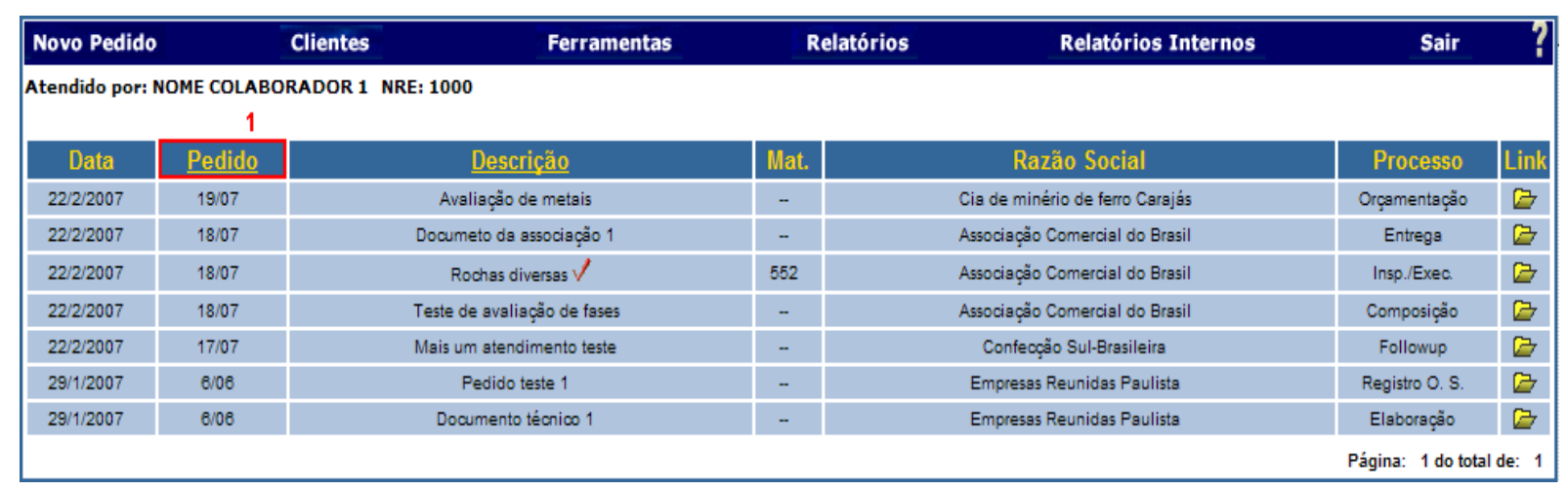

Figura VI.17 - Coordenação individual e página principal do software

$\mathrm{Na}$ validação sobre quais informações deveriam constar deste artefato, assim como formas de filtro, os usuários consideraram importante que as fases dos pedidos deveriam ser mostradas por ordem direta e inversa em relação a seu número (Figura VI.17-1).

Uma vez que para a coordenação individual de um usuário sempre seria necessário definir qual fase do processo este deveria escolher para dar andamento ao fluxo do processo; outra questão emergente foi estabelecida: que este artefato seria a página principal do sistema, de modo que, após a conclusão de qualquer atividade relacionada a qualquer fase do processo, sempre haveria um retorno para este artefato. Assim, outros aspectos deveriam ser contemplados por este artefato de coordenação e que deveriam ser acessados pelos usuários independente da fase em que o mesmo se encontrasse.

$\mathrm{Na}$ Figura VI.18, podem ser vistas as opções apresentadas aos participantes da sessão, como por exemplo, um ponto de entrada para a solicitação de um novo pedido (Figura VI.18-1), opção para pesquisar clientes (Figura VI.18-2), as ferramentas do software (Figura VI.18-3), relatórios e relatórios internos (Figura VI.18-4 e Figura VI.18-5, respectivamente). 


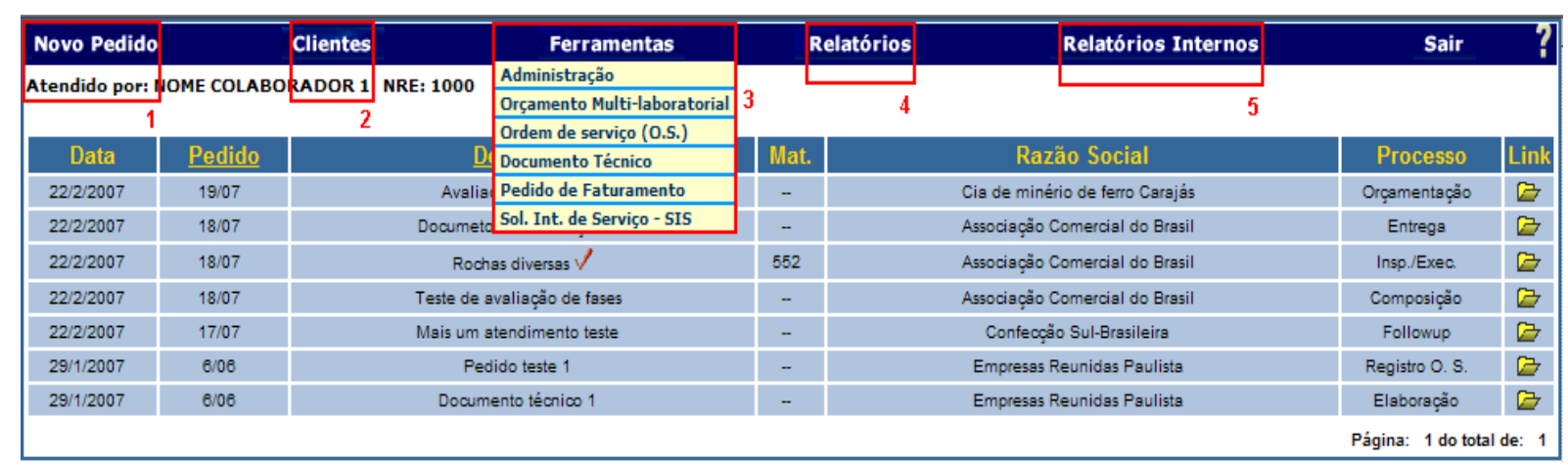

Figura VI.18 - Coordenação individual e página principal do software

$\mathrm{Na}$ segunda parte da sessão anterior, outro aspecto levantado foi a necessidade percebida pelos usuários de que somente as informações sobre suas próprias ações não seriam suficientes para esta coordenação, de modo que para se coordenar, também, era necessário usar mecanismos que lhes permitissem receber uma indicação das atividades dos demais usuários do laboratório.

Na Figura VI.19, este novo artefato de coordenação pode ser visto como: (relatório de) pedidos em andamento (que pode ser acessado na opção de "Relatórios internos" da Figura VI.18-5). Como exemplo, foi usado o pedido 6/06 (Figura VI.191) empregado nas iterações anteriores. Percebe-se que este processo possui algumas fases pendentes que não estão com o usuário "NOME COLABORADOR1", por exemplo, a fase de Composição do documento está com o "NOME COLABORADOR 4" (iteração 4) e umas fase de "Elaboração do documento" está com o usuário "NOME COLABORADOR 6".

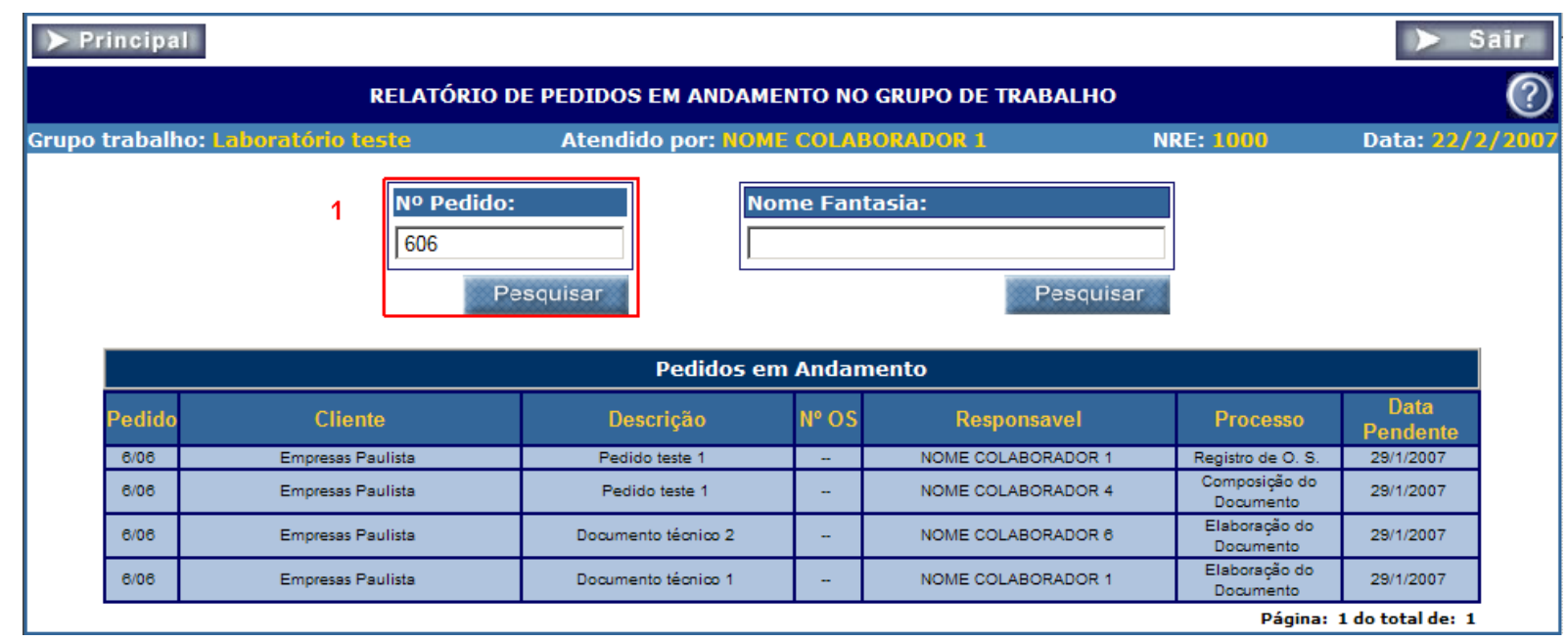

Figura VI.19 - Coordenação com as atividades do grupo 
Assim, estes dois artefatos possibilitariam que o usuário fosse capaz de entender a situação de sua atividade, permitindo se encaixar no trabalho (processo de atendimento), como um todo.

$\mathrm{Na}$ segunda parte da sessão, os relatórios gerencias detalhados na iteração anterior foram apresentados. Para o trabalho cooperativo, seu objetivo era mostrar os resultados agregados de todos os atendimentos do grupo.

$\mathrm{Na}$ Figura VI.20, pode ser visto um exemplo de relatório discutido na iteração anterior, mostrando em um quadro geral os principais indicadores que os participantes da sessão consideraram importantes para avaliação das metas do trabalho do grupo.

Além dos indicadores de desempenho financeiro, outros foram sugeridos no sentido de acompanhar a qualidade das atividades cooperativas, como por exemplo: número de orçamentos concluídos na data ou em atraso, número de orçamentos em execução atualmente, número de orçamentos atrasados em execução atualmente, número de orçamentos em aberto e número total de orçamentos e followup sem aprovação (ver Figura VI.20).

Na parte final da sessão, a possibilidade de haver somente mais uma sessão para fechamento do ciclo 2 foi apresentada aos participantes, visto que os principais requisitos funcionais já tinham sido especificados (o grupo não estava produzindo mais novidades em suas discussões), onde já no passo de análise e planejamento da iteração anterior esta questão tinha sido diagnosticada. 


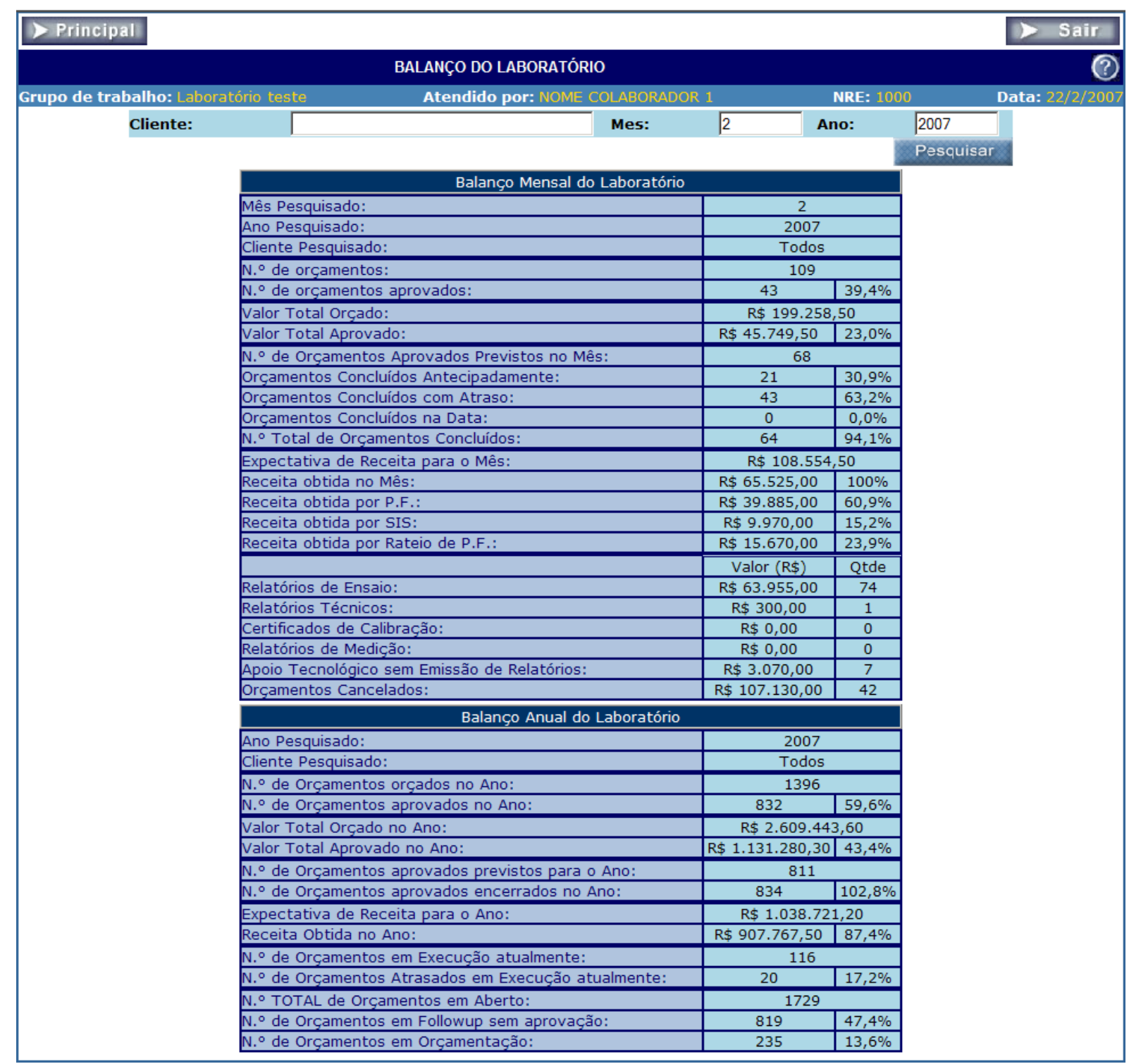

Figura VI.20 - Balanço das atividades do grupo de trabalho

No passo de análise e planejamento desta iteração, foram revisados os artefatos produzidos durante as cinco iterações e enviados aos participantes para análise e validação final na próxima e última iteração.

\section{VI.3.6 Iteração 6}

Esta iteração foi realizada para o fechamento dos requisitos levantados nas cinco iterações anteriores. 
No passo de implementação, foram realizadas algumas correções nos documentos entregues aos usuários no passo da análise da iteração anterior para facilitar a validação dos artefatos na sessão desta iteração.

Assim, na sexta sessão foram validados os principais artefatos necessários ao projeto e implementação do sistema (sob a visão dos usuários): fluxograma geral do processo (Figura V.13) e respectivas interfaces gráficas (nas iterações deste trabalho foram apresentadas parte das interfaces, para os usuários foram mostradas todas as interfaces relativas às fases analisadas) e navegações, diagrama de contexto (Figura VI.12) e descrição de cada uma das fases do processo a ser informatizado.

A descrição resumida das fases do fluxograma da Figura V.13 é realizada abaixo.

\section{Solicitação do pedido (abertura do pedido)}

Ocorre a habilitação da demanda para que possa ser atendida dentro dos critérios de qualidade do laboratório. Esta atividade pode ser realizada por qualquer membro do laboratório.

- Principais atividades: registro de solicitação do cliente, cadastro de clientes (quando o cliente ainda não é cadastrado no ERP), definição se o pedido é multilaboratorial (ou orçamento interno para outro laboratório) e montagem da solicitação;

- Principais entradas: pedido do cliente (dados iniciais do cliente) e dados iniciais do pedido, conforme fase de solicitação do pedido;

- Principais saídas: registro do pedido e número para acompanhamento, identificação do responsável desta fase do processo e cadastro do cliente.

\section{Orçamentação:}

A confecção da proposta orçamentária é realizada, sendo composta das informações referentes aos serviços pesquisados no sistema de Custos e Preços, ou então, por meio da composição de orçamentos internos enviados por outros laboratórios. 
A responsabilidade pelo orçamento ou é um técnico designado e reconhecido como competente para o atendimento, ou é do responsável pela área cuja competência é atender ao pedido, mas o envio do orçamento pode ser realizado por qualquer participante do laboratório, podendo inclusive ser reenviado quantas vezes forem necessárias.

- Principais atividades: escolha dos serviços pertencentes ao orçamento no software de Custos e Preços, ou então, definição de um ou mais orçamentos internos (multilaboratoriais) que comporão o orçamento. Ajuste do orçamento em função da solicitação do cliente e respectiva composição (número de materiais, taxa de urgência e desconto, descrição detalhada dos serviços, etc.), assinatura e envio da proposta orçamentária;

- Principais entradas: registro do pedido (solicitação), projeto da solução técnica e serviços (oriundos do sistema de Custos e Preços) e orçamentos multilaboratorias (oriundos de outros laboratórios);

- Principais saídas: definição do escopo de atendimento, envio de proposta comercial (orçamento) ou por meio de email, ou em formato impresso para envio via fax.

\section{Followup:}

A verificação do interesse do cliente pelo orçamento é feita e pode, posteriormente ser realizada uma renegociação do mesmo. A responsabilidade pela fase de Followup pode ser de uma secretária designada para fazer o acompanhamento da proposta, de um técnico designado e reconhecido competente para a negociação, ou do responsável pela área, cuja competência é atender e validar a renegociação.

- Principais atividades: escolha do período de followup (prazo que define de quanto em quanto tempo o orçamento estará disponível ao usuário para o acompanhamento do interesse do cliente). Monitoração e aprovação ou recusa do orçamento, com os motivos. Renegociação dos serviços contidos no orçamento (culminando até com a retirada de alguns destes serviços) e descrição do resumo de negociação ou acompanhamento (followup) para histórico do acompanhamento; 
- Principais entradas: orçamento enviado ao cliente, aprovação do cliente, ou respectivos motivos para o caso de recusa, data de aprovação, informações de renegociação (número de amostras, taxas de desconto/urgência) e informações sobre o acompanhamento do envio do orçamento;

- Principais saídas: orçamento devidamente aprovado e respectivo histórico de renegociações/acompanhamentos.

\section{Registro de material e distribuição da OS:}

Nesta fase, ocorre o registro do material para início da realização dos serviços, a numeração do material é sequencial, com seu valor de início definido pelo laboratório.

Após ser registrado, o material é associado a um ou mais serviços e seus respectivos executores (é criada uma Ordem de Serviço - OS), assim como deve ser definido o responsável pela fase de composição de documento técnico. Se o pedido já foi aprovado pelo cliente, então a(s) OS(s) serão distribuídas os respectivos executores, criando-se assim a(s) fase(s) de Inspeção/execução, bem como a fase de Composição de documento técnico.

Este conjunto de atividades pode ser realizado por qualquer participante do laboratório, sendo normalmente executado pela secretária do laboratório (registro) ou um técnico (registro e distribuição).

- Principais atividades: registro do material recebido do cliente, associação do material aos serviços e executores, escolha do responsável pela fase de composição e distribuição das ordens de serviços a seus respectivos executores (fases de Composição do documento técnico e Inspeção/execução respectivamente);

- Principais entradas: orçamento editado e aprovado, vindo da fase de Followup e dados do material para registro;

- Principais saídas: criação da(s) fase(s) de Inspeção/Execução e da fase de Composição do documento técnico e disponibilização do material para realização do(s) serviços(s) contratado(s). 


\section{Inspeção/Execução do trabalho:}

As informações decorrentes da inspeção do material são registradas e sob o qual será realizado o serviço (conforme, não conforme), assim como a efetiva situação da execução dos serviços associados a esse material (em andamento, suspenso, concluído, cancelado).

O status da execução será visualizado na fase de Composição do documento técnico e só após o mesmo estar registrado como "concluído", poderá ser composto (criado) um documento técnico.

As informações técnicas a respeito da execução (por exemplo, as grandezas físicas medidas durante o serviço) não serão registradas no software de acompanhamento, dada sua característica ligada à questão de administração do andamento do fluxo do trabalho (conforme discutido no ciclo1, item V.2.3).

A realização do serviço é de natureza técnica e, normalmente, está sob responsabilidade do responsável pelo laboratório, ou do técnico designado, sendo importante a correta informação da data de execução do serviço para avaliação dos pontos críticos de atendimento. Mas, na falta destes, esta fase pode ser realizada por qualquer participante do laboratório.

- Principais atividades: inspeção técnica do material recebido, recuperação ou editoração das planilhas de cálculo para o serviço realizado (atividade não controlada pelo software de acompanhamento laboratorial), realização dos serviços sobre o material e informe sobre a data e status (situação) da execução dos serviços;

- Principais entradas: material em que será realizado o serviço, os insumos, os dispositivos especiais (material físico do laboratório) e a fase de Inspeção/Execução enviada ao responsável pelo serviço;

- Principais saídas: liberação das informações técnicas relativas aos serviços executados (não controlados pelo software) e liberação da fase de Inspeção/execução para a composição do documento técnico. 


\section{Composição e distribuição do documento técnico:}

Nesta fase, ocorre a associação das ordens de serviços realizadas na fase de Inspeção/Execução e os documentos técnicos das quais farão parte. Assim que o responsável pela fase de Inspeção/execução altera o status para "concluído", a sua inclusão (composição) é liberada em um novo documento técnico da empresa PesqTec.

Esta fase foi implementada em termos de interface gráfica, mantendo o mesmo formata da fase de Registro de OS (para manter o mesmo modelo mental do usuário).

Assim, após ter sido feita a escolha dos serviços associados aos materiais que farão parte do documento técnico, o usuário, também, deverá escolher para quem será enviada (distribuída) a fase de Elaboração do documento técnico. Após serem feitas as composições do documento, sua distribuição nos mesmos moldes da fase de Registro de OS é realizada e os documentos serão distribuídos aos respectivos executores, criando-se assim a(s) fase(s) de Elaboração do documento técnico.

Em geral, este conjunto de atividades é executado pela secretária ou pelo responsável pelo laboratório (mas, pode também ser feito por qualquer participante do laboratório).

- Principais atividades: associação entre serviços executados nos materiais e o documento técnico e escolha do responsável pela próxima fase (Elaboração do documento). Distribuição dos documentos técnicos a seus respectivos executores na fase de Elaboração do documento;

- Principais entradas: serviços concluídos na fase de Inspeção/execução. Composição do conteúdo do documento técnico e definição do responsável pela sua elaboração (Fase de Elaboração do documento técnico);

- Principais saídas: criação da(s) fase(s) de Elaboração do documento técnico.

\section{Elaboração do documento:}

Nesta fase, o documento técnico é confeccionado, assim como é obtida uma numeração sequencial única para o documento de outro sistema informatizado da empresa PesqTec (ver Figura VI.12). 
Nesta fase, também, são registradas informações a respeito da elaboração, como por exemplo, o local para armazenamento do documento técnico, a data de término e os eventuais revisores.

É possível fazer um acompanhamento do processo de revisão do documento técnico, permitindo registrar, além dos eventuais revisores, todas as alterações sofridas pelo mesmo por meio de um histórico de alterações.

A elaboração do documento físico deve ser realizada ou pelo técnico designado, ou pelo responsável do laboratório. Assim, esta fase preferencialmente é utilizada pelos executores do documento técnico para registrar as alterações sofridas pelo mesmo durante sua revisão, mas pode também ser acessada pela secretária, para inserir estas ou outras informações relativas à fase (local de armazenamento do documento, solicitação, número de relatório, etc.).

- Principais atividades: definição do tipo de documento técnico e de seu respectivo número (acessível por meio de outro sistema informatizado), registro das alterações decorrentes das revisões no documento e escolha do responsável para envio à fase de Entrega do documento.

- Principais entradas: criação da fase de Elaboração do documento por intermédio de sua distribuição na fase de Composição, solicitação de número de documento e registro de suas respectivas revisões e dados sobre seu armazenamento (todo laboratório deve ter uma cópia do documento gerado para fins de auditoria)

- Principais saídas: documento técnico revisado e criação da fase de Entrega do documento técnico.

\section{Entrega:}

Estão reunidas todas as etapas típicas relacionadas ao acompanhamento da tramitação do atendimento no contexto da emissão do documento técnico final e providências para seu encerramento.

Nesta fase, a entrega do documento técnico é realizada para seu envio ao cliente (normalmente, via correio, mas também pode ser retirado na empresa PesqTec). 
No entanto, antes de ser entregue ao cliente, devem ser fornecidos os dados do documento relativos a seu faturamento e sobre seu modo de entrega, além das informações referentes ao arquivamento da documentação final do processo (o processo físico, com as medidas realizadas, observações, conclusões, documentos técnicos intermediários, etc.)

Nesta fase, o faturamento não será realizado, visto que pode ser necessário incluir vários documentos técnicos em um único faturamento. Deste modo, conforme definido na quinta iteração, esta funcionalidade será acessada no artefato de coordenação individual do usuário (para usuários com permissão apropriada), na aba de ferramentas (Figura VI.18-3).

O conjunto de atividades pode ser considerado administrativo e normalmente está sob responsabilidade da secretária do laboratório, mas pode ser realizado por qualquer participante do laboratório.

- Principais atividades: definição do valor final do documento técnico e outras informações relativas a seu faturamento (preparação para faturamento), definição de informações sobre o arquivamento final do processo de atendimento e encerramento do fluxo relativo ao documento técnico (Figura V.13).

- Principais entradas: fase de Elaboração concluída, inclusive, com o número do documento técnico. Informações necessárias ao faturamento do documento (preço final, tipo de envio, data de envio, etc.) e também sobre o arquivamento do documento físico relativo ao documento técnico que está sendo encerrado.

- Principais saídas: encerramento do processo de atendimento relativo ao documento técnico (pré-requisito para que seja faturado) e envio físico do documento ao setor de expedição.

Após os requisitos descritos acima serem validados pelos usuários em suas respectivas iterações ( 1 a 5 ), além de sua confirmação nesta iteração (6), estes artefatos, com os de implementação (ver item VI.2.2) serão utilizados para implementação do primeiro protótipo funcional do software que é apresentado no ciclo 3 desta pesquisa. 


\section{VI.4 CONCLUSÕES DO CICLO 2 (PASSO DE MONITORAMENTO DA PA)}

Visando a orientar as conclusões deste capítulo, procura-se responder às questões relativas a este ciclo da PA (ver item III.4.4):

\section{Quais são os instrumentos a serem elaborados para captar os requisitos de} software da dimensão cooperativa do trabalho de um SI durante a simulação do sistema informatizado que lhe dará suporte?

Os instrumentos utilizados para captar a dimensão cooperativa do trabalho correspondem às técnicas, métodos, conceitos e modelos e são listados a seguir:

- Dimensões do trabalho coletivo (ver item II.1.2);

- Análise coletiva do trabalho (ver item II.2);

- Modelo mental e interação (ver item II.3);

- Prototipação funcional (ver item II.8.3);

- Modelos do sistema (ver item II.7.2);

- Processo de desenvolvimento de software (ver item II.7.2);

- A ergonomia e concepção informática na simulação e prototipação de sistemas (ver item II.8.3);

- Modelo de desenvolvimento iterativo evolucionário (ver item II.6.3);

- Processo de Engenharia de Requisitos (ver item II.7.2);

- Entrevistas (ver item II.8.2);

O uso da Análise Coletiva do Trabalho para orientar as iterações do grupo em torno da atividade coletiva atual e simulação da atividade futura realizada, dos elementos comuns de comunicação, do conceito de modelo mental, dos conceitos da ergonomia de concepção de análise das situações de referência (aquelas encontradas no começo do projeto) e das ações características futuras prováveis permitiram uma evolução dos artefatos desenvolvidos na prototipação realizada no ciclo 2 de modo a coletar, além dos requisitos do trabalho individual dos usuários, os requisitos do trabalho cooperativo pelas questões emergentes abaixo resumidas. 
Ao se usar como exemplo esta pesquisa-ação, surgiram várias questões emergentes que permitiram detalhar os requisitos do trabalho cooperativo para esta situação:

- Iteração 1: os usuários perceberam a necessidade de gerar orçamentos multilaboratoriais;

- Iteração 2: necessidade de alteração do fluxograma do processo para atender ao trabalho cooperativo;

- Iteração 3: necessidade de alteração das atividades das fases, criação de novas fases e descrição das atividades e responsabilidades (coordenação distribuída nas ações dos usuários em um sistema horizontal, isto é, sem coordenação centralizada);

- Iteração 4: necessidade de criação de artefatos de coordenação;

- Iteração 5: necessidade de criação de artefatos específicos para acompanhar as atividades do grupo.

\section{Como estes instrumentos podem ser concatenados para captar os} requisitos de software do trabalho cooperativo durante a simulação do sistema informatizado?

Os instrumentos acima descritos foram concatenados pelo uso do processo apresentado no item IV.5 (Processo para a identificação e simulação de requisitos de software do trabalho cooperativo) e implementados por meio do ciclo da PA deste capítulo.

A aplicação da dinâmica das iterações descritas no item VI.2.2, também, contribui para melhor aproveitamento das sessões realizadas com os usuários, pela construção a priori dos artefatos compartilhados, de seu detalhamento na iteração anterior (passo de análise e planejamento) e de sua construção no passo de implementação da iteração corrente.

Neste ciclo, a aplicação do processo mostrou que nas sessões realizadas, uma nova ideia gerada por alguns dos participantes era imediatamente testada, com base na reação dos outros participantes, em apoio ou não. 
Assim, quando alguém expressava um desejo ou necessidade, outra reagia, concordando ou discordando, e uma terceira ainda podia modificar a mesma ideia para torná-la mais acessível. Enfim, todo o grupo acabava emitindo uma opinião a respeito. Com isso, ganhou-se tempo no projeto, atendendo às expectativas dos usuários reais.

Os requisitos emergentes surgiram em razão do fato de que o processo empregado trouxe à tona aspectos que não seriam facilmente acessíveis sem a interação do grupo e que o processo de compartilhar e comparar ofereceu rara oportunidade de compreensão por parte do pesquisador de como os participantes entendiam suas similaridades e diferenças.

\section{A solução proposta neste ciclo pode ser aplicada para refinar os requisitos} de software do trabalho cooperativo durante o uso do sistema informatizado (ciclo 3)?

Para responder a esta questão, é preciso realizar o terceiro ciclo desta pesquisaação. 


\section{CICLO 3 DA PESQUISA-AÇÃO: PROCESSO PARA ESPECIFICAÇÃO DE REQUISITOS DE SOFTWARE COM FOCO NO REFINAMENTO DAS CARACTERÍSTICAS DO TRABALHO COOPERATIVO (EM USO REAL)}

O objetivo deste ciclo é o refinamento dos requisitos obtidos no ciclo 2 por meio do sistema em uso, sobretudo os que privilegiam o trabalho cooperativo dos usuários finais do sistema.

O modelo 3C é apresentado, bem como sua relação com a pesquisa desenvolvida, oferecendo elementos de awareness que facilitem a contextualização das atividades individuais pela compreensão das atividades realizadas pelos demais participantes do grupo.

A partir da segunda iteração do ciclo, estes elementos são considerados e são definidos quais artefatos de software devem ser desenvolvidos para complementar os requisitos do trabalho cooperativo, sendo posteriormente avaliados pelos usuários na terceira iteração deste ciclo.

\section{VII.1 INTRODUÇÃO}

Assim como nos dois ciclos anteriores, o processo proposto começa com a entrada dos artefatos que foram desenvolvidos durante o ciclo anterior e que serão utilizados como base inicial na atividade de implementação/revisão deste ciclo da PA.

A diferença deste ciclo com os anteriores é que o sistema informatizado será efetivamente construído, e os usuários finais substituirão parte do sistema de informação em uso pela automatização fornecida por este software.

Do mesmo modo, como foi considerado nos ciclos 1 e 2, neste ciclo serão escolhidos uma parte dos artefatos desenvolvidos durante as iterações, como exemplo de aplicação do processo proposto, dada a quantidade de informação e, também, pelo fato de que haveria repetição da aplicação do processo. 
Apesar do sistema informatizado estar em uso quando estes dados foram levantados, os exemplos ilustrados neste capítulo (iterações 2 e 3 ) são continuação dos exemplos do ciclo 2 (para facilitar a compreensão), nos quais foram mantidos os nomes dos usuários hipotéticos. Os serviços e os clientes utilizados como exemplo não guardam relação com a empresa PesqTec.

Uma vez que o objetivo deste ciclo foi refinar as características do trabalho cooperativo com o sistema em produção, partiu-se para a avaliação coletiva destas características implementadas na segunda iteração do ciclo, utilizando-se como elemento de representação comum o software em uso real para se comunicar com os usuários finais e os projetistas (utilizados como imagem do sistema - item II.3).

Os protótipos funcionais foram apresentados aos usuários para discussão coletiva, utilizando-se a técnica de ACT, partindo-se das situações de referência do trabalho dos usuários pela própria voz destes e projetando-se as ações características cooperativas ainda não implementadas no sistema informatizado, considerando também os elementos de awareness e os conceitos da teoria da mente coletiva (ver itens VII.3.2 e VII.3.3).

\section{VII.2 DINÂMICA DE ITERAÇÃO DO CICLO 3}

\section{VII.2.1 Dados do grupo e do ambiente das sessões}

Ao todo foram realizadas três iterações neste ciclo da PA, cuja primeira iteração durou em torno de 3 meses e meio, a segunda 4 meses e a terceira em torno de 3 meses e meio. Estas sessões iniciaram-se em março de 2007 e terminaram no início de janeiro de 2008.

Dois laboratórios foram escolhidos para a implantação do software. O número de participantes no treinamento foi oito para um dos laboratórios e dez para o outro e para as duas sessões foram doze pessoas (seis participantes por laboratório), e dois dos participantes também fizeram parte do grupo de usuários do ciclo 2. Todos os participantes possuíam curso superior completo ou curso técnico e estavam acostumados a utilizar aplicações WWW disponíveis na intranet da empresa 
PesqTec (por serem participantes de laboratório, possuíam conhecimentos homogêneos com relação às regras de negócio).

Os integrantes das sessões 2 e 3 concordaram participar das reuniões. O treinamento, assim como as sessões foram todas realizadas dentro da empresa, mas, em ambiente isolado da situação de trabalho dos participantes (as datas de reunião foram marcadas, sempre que possível com a antecedência necessária visando justamente a esta possibilidade).

No ambiente onde o treinamento foi realizado (iteração 1), fez-se uso de um equipamento multimídia conectado a um microcomputador usado pelos pesquisadores para orientar a realização do treinamento e as observações feitas pelos participantes, além do quadro para desenho, assim como cada participante teve disponível para si um microcomputador, onde podia acessar um ambiente-teste com os vários exemplos previstos para o treinamento.

As sessões das iterações 2 e 3 foram conduzidas por dois pesquisadores; e um deles foi responsável por anotar ou gravar (com o consentimento dos participantes) partes da sessão, auxiliar o outro pesquisador na condução do grupo, tomar nota das principais impressões verbais e estar atento à aparelhagem multimídia.

Cada participante das sessões, também, teve disponível para si um microcomputador, onde podia reproduzir seu ambiente de trabalho por meio de uma cópia atualizada da aplicação em uso em seu ambiente de trabalho (inclusive com os últimos dados de produção).

Assim como no ciclo 2, o outro pesquisador foi responsável pela condução da sessão, permitindo a discussão dos vários pontos de vista dos participantes, mas sempre atento aos objetivos da sessão e da demanda como um todo, permitindo assim maior diretividade da sessão corrente. Este pesquisador, também, buscou promover a participação de todos, evitando a dispersão dos objetivos da discussão e a monopolização de alguns participantes sobre outros, além de ouvir as diversas observações sobre o assunto que estava sendo apresentado. 


\section{VII.2.2 Modelo 3C e awareness para o ciclo 3}

O conhecimento dos mecanismos de comunicação, coordenação e colaboração, principalmente como eles devem ser usados para manter diferentes elementos de awareness permite criar técnicas e ferramentas que forneçam aos usuários as informações apropriadas sobre as metas, tarefas e sobre os outros integrantes do ambiente.

A Figura VII.1 abaixo corresponde ao diagrama 3C utilizado nas iterações 2 e 3 deste ciclo (ver item II.5.4), em que, para possibilitar a coordenação e a cooperação como um todo, são necessárias informações sobre o que está acontecendo e o que as outras pessoas estão fazendo. Por meio destas informações, os participantes podem construir um entendimento compartilhado em torno dos objetos de cooperação e dos objetivos das tarefas, ou de todo o trabalho.

Na Figura VII.1, nota-se que o ponto inicial que alimenta este diagrama, é o objetivo do grupo, isto é, a realização do trabalho de forma cooperativa.

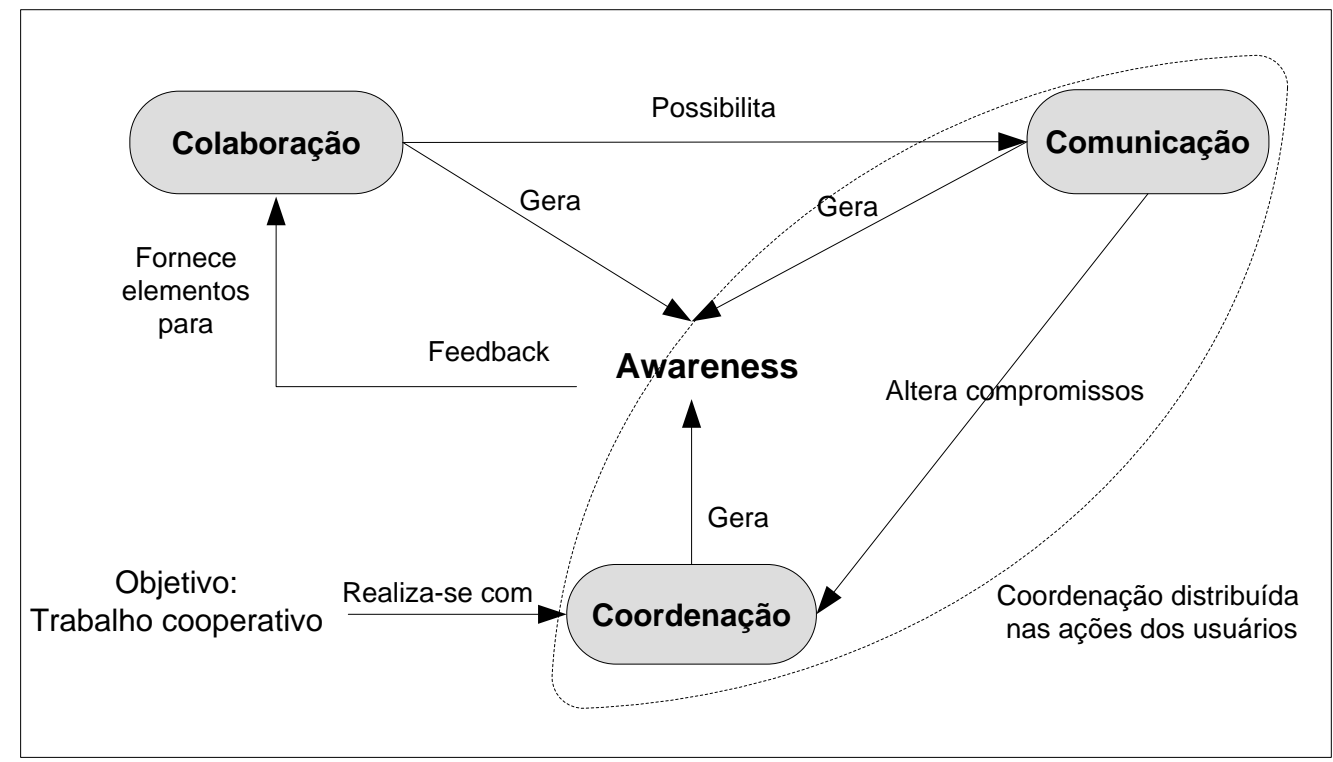

Figura VII.1 - Diagrama dos 3Cs e awareness adaptado ao ciclo 3 Fonte: elaborado pelo autor

Esta figura apresenta diversos estímulos de entrada e um de saída. Isso significa que vários eventos dos participantes de um grupo sejam eles voluntários ou não, devem ter um elemento de awareness que gere feedback (retorno) para a colaboração dos membros do grupo de trabalho. 
No exemplo da Figura VII.1, pode ser ressaltado que a geração de informações destinadas à colaboração e comunicação não deve ser obrigatória, visto que o feedback pode não ser desejado em todos os momentos do trabalho. Já o evento de coordenação irá proporcionar sempre algum grau de awareness, visto que o fluxo de realização do trabalho poderia ser interrompido e estagnar, sem transmissão da informação.

Conforme descrito na iteração 5 do ciclo 2 (item VI.3.5), o usuário tem como ponto de partida da aplicação um artefato de coordenação que mostra todas as suas pendências (ver Figura VII.2 - reprodução da Figura VI.17). Por meio deste artefato e da representação que o usuário possui do sistema (item II.4.1), que lhe permitem a compreensão do estado total do mesmo (awareness), o usuário organiza suas atividades e define qual objeto compartilhado de colaboração (neste caso corresponde a uma das oito fases do processo) irá utilizar por meio da coluna "Link", concatenando sua ação frente aos demais usuários.

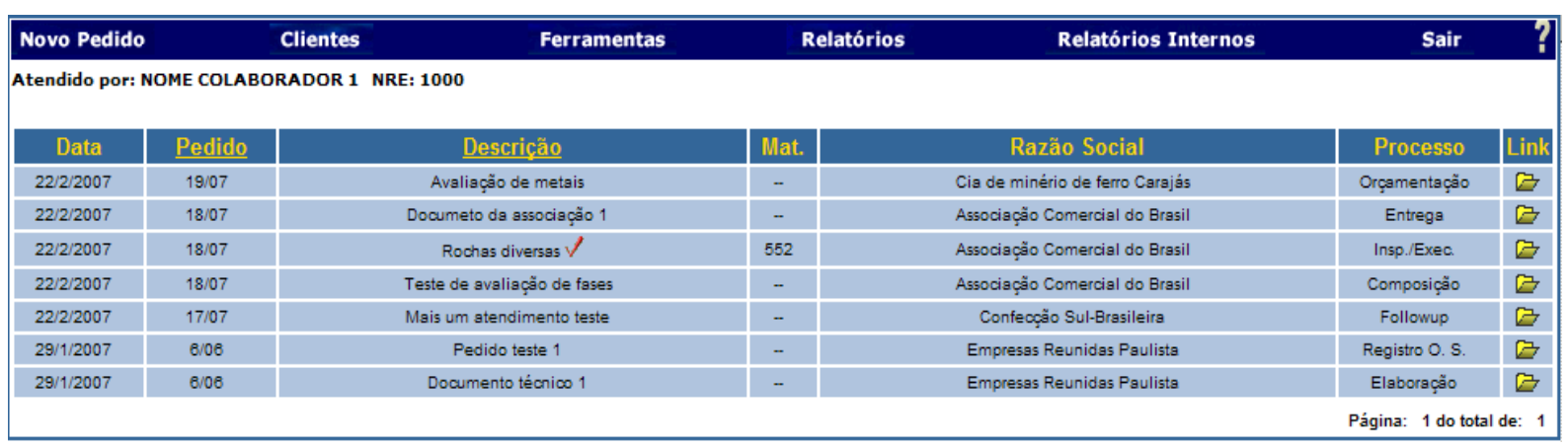

Figura VII.2 - Coordenação individual e página principal do software - reprodução

Quando colabora por intermédio de um destes objetos compartilhados (ver item II.5.5), novas informações são armazenadas no sistema, possibilitando a comunicação entre os usuários pela alteração dos compromissos nos artefatos de coordenação.

Assim, não existe uma distinção clara entre coordenação e comunicação, e ambas estão colapsadas (Figura VII.1), de modo que a comunicação ocorre sempre de modo indireto e assíncrono (ver item II.5.5), como conseqüência da colaboração, isto é, pelos dados que são inseridos no sistema. 
Como não há um objeto explícito de comunicação, a coordenação é feita pelo entendimento da relação das ações dos usuários (Figura VII.2) e suas inter-relações com as ações dos demais usuários (Figura VII.3 - reprodução da Figura VI.19).

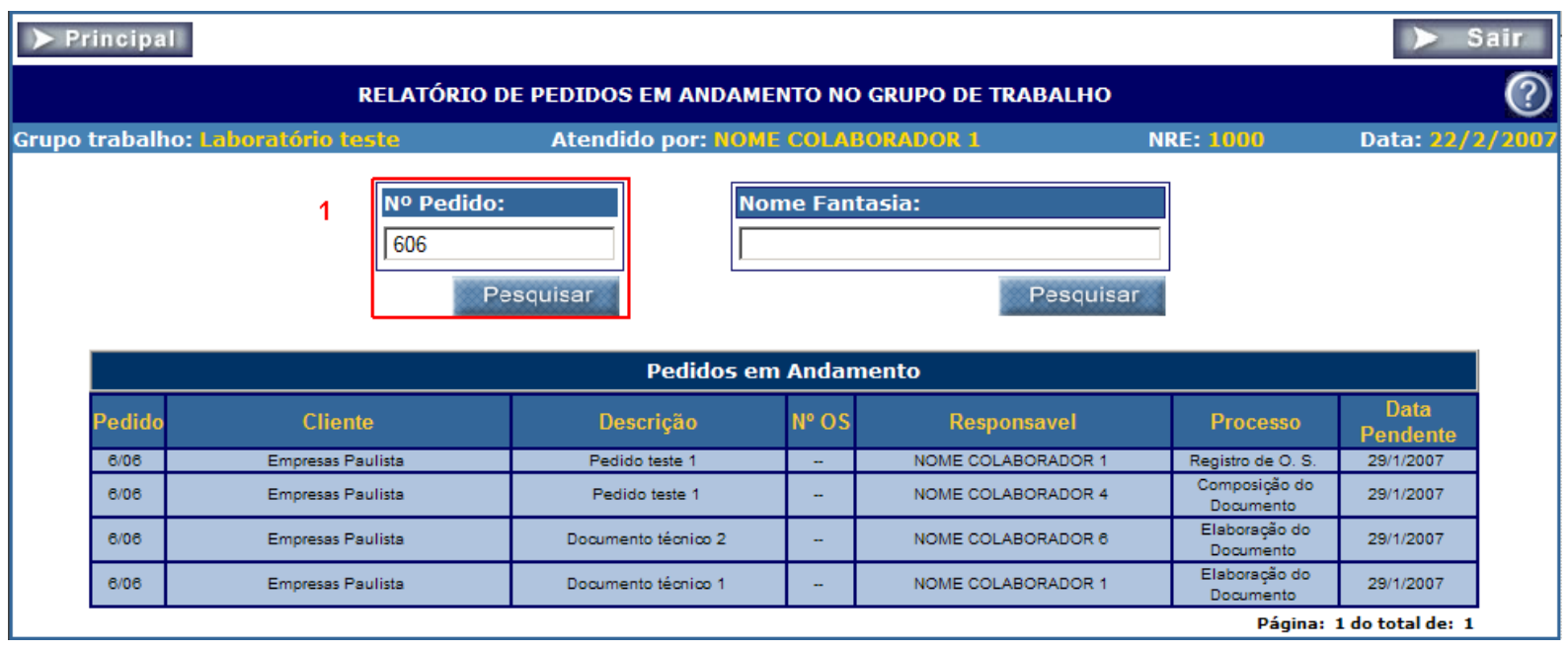

Figura VII.3 - Coordenação com as atividades do grupo - reprodução

\section{VII.2.3 Características gerais do sistema informatizado desta PA}

Em função do que foi apresentado no item VII.2.2, o sistema desenvolvido nesta PA possui como características:

- Coordenação distribuída nas ações dos usuários (sem um centro definido de coordenação - item VII.2.2),

- Comunicação entre os usuários realizada de modo indireto por meio dos dados inseridos nos artefatos de colaboração (não existem ferramentas específicas (hardware/software) para comunicação direta entre os usuários item VII.2.2),

- Ambiente assíncrono (os usuários não precisam estar trabalhando simultaneamente, para que o objetivo seja atingido - item II.5.5),

- Interfaces gráficas desacopladas (não são acopladas às interfaces dos demais participantes do grupo- item II.5.5), 
- Embora as fases do processo estejam normalmente associadas a papéis específicos no grupo, as mesmas podem ser realizadas por qualquer participante (item VII.3.1).

\section{VII.2.4 Dinâmica geral das iterações}

A Figura VII.4 abaixo mostra a sequência de iteração para este ciclo de PA .

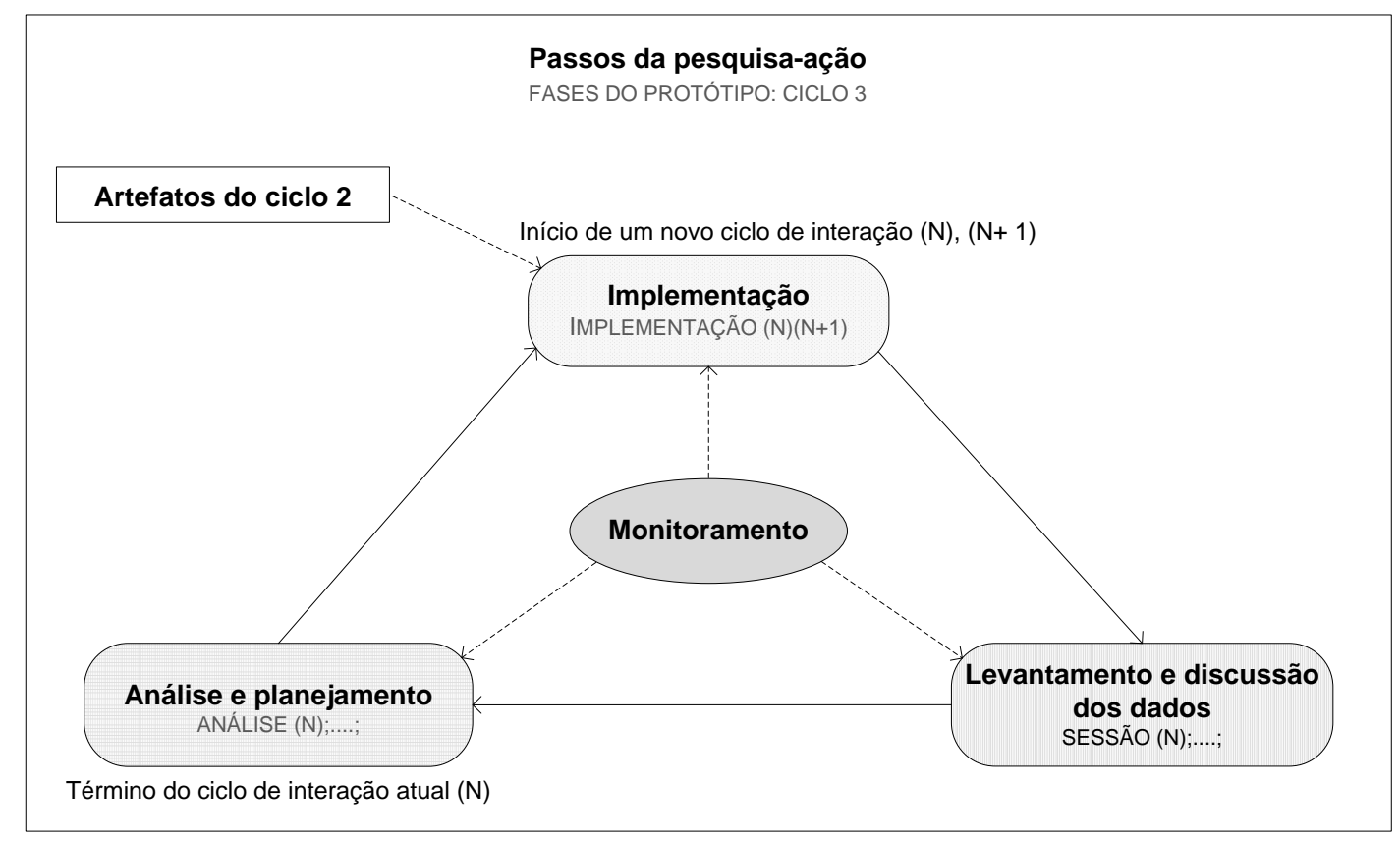

Figura VII.4 - Passos da Pesquisa-ação e correspondentes atividades (ciclo 3) Fonte: elaborado pelo autor

Em sua primeira versão funcional, sistema foi construído no passo da implementação 1 (ver item VII.2.1 e Figura VII.5), após seu término, realiza-se o treinamento dos usuários. Com o sistema em uso, constatou-se divergências entre o comportamento simulado no ciclo 2 e seu uso efetivo, de modo que durante o passo de análise e planejamento da iteração 1 foram escolhidos usuários representativos do perfil das atividades de cada laboratório para a realização de entrevistas (ver item II.8.2) para avaliação destas questões.

Como consequência, no passo de implementação da iteração 2, foram desenvolvidos artefatos visando a corrigir os problemas encontrados em campo. Com estes artefatos desenvolvidos, mas não colocados em produção, foi realizada a 
primeira sessão com parte dos usuários dos laboratórios, dividindo-se a sessão de apresentação em duas partes.

$\mathrm{Na}$ primeira, foram discutidos alguns dos problemas levantados nas entrevistas, empregando-se como guia um conjunto de questões para avaliação das características do trabalho cooperativo (ver questionário do Quadro IV.7 ).

$\mathrm{Na}$ segunda parte da sessão, foram usados como proposta para resolver os problemas encontrados em campo os artefatos desenvolvidos durante o passo de implementação da iteração corrente (resultantes da avaliação das entrevistas durante o passo de análise da iteração 1), servindo como elementos de representação comum e dando suporte, também, à discussão de novas questões emergentes surgidas pelo uso do sistema.

No passo de análise e planejamento, a avaliação do questionário aplicado na primeira parte da sessão foi realizada, decidindo-se pelo treinamento de dois usuários (tutores) com a função de manter o processo social em seus laboratórios. Neste passo, também, verificou-se a necessidade de se realizar uma nova iteração ou se o ciclo poderia terminar.

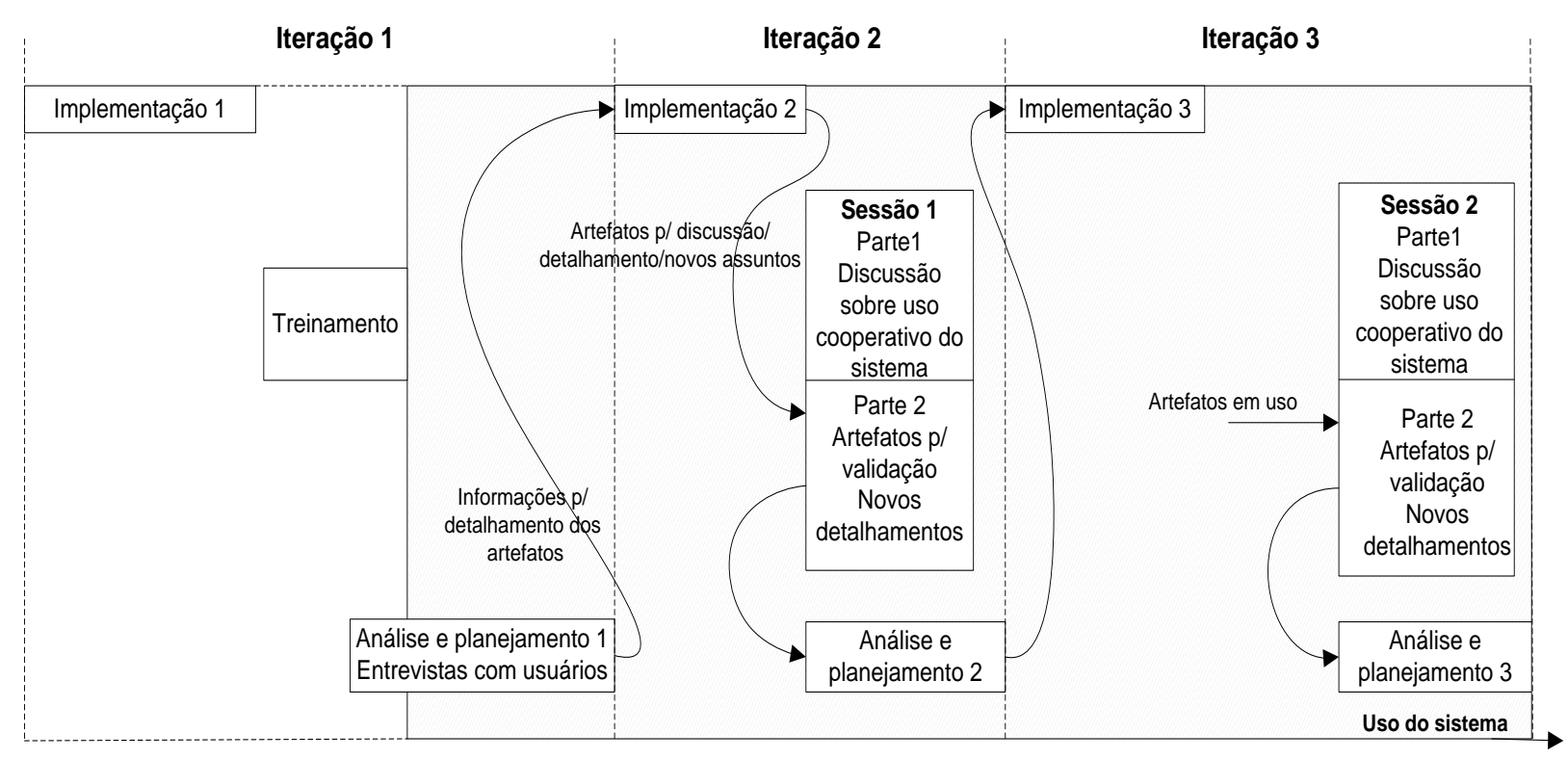

Figura VII.5 - Dinâmica das iterações do ciclo 3

$\mathrm{Na}$ terceira, iteração foram implementados (implementação 3 da Figura VII.5) os artefatos emergentes discutidos na segunda parte da sessão da iteração anterior e colocados em produção (para uso no sistema) e os artefatos desenvolvidos no 
passo de implementação da segunda iteração, além do treinamento dos tutores para dar apoio aos usuários dos grupos de trabalho.

Após o uso destes artefatos, foi realizada uma nova sessão com parte dos usuários dos laboratórios e, assim como na sessão anterior foi dividida duas partes. $\mathrm{Na}$ primeira, foi aplicado um conjunto de questões para avaliação das características do trabalho cooperativo (ver questionário do Quadro IV.7).

$\mathrm{Na}$ segunda parte da sessão, foram discutidos os resultados dos artefatos desenvolvidos (utilizados como elementos de representação comum), assim como a questão do tutor do grupo (ver item VII.3.2).

Na segunda parte da sessão, foi realizada também uma discussão geral sobre o uso do sistema, com alguns novos artefatos sugeridos, mas que não precisariam ter sua implementação realizada no curto prazo (ou seja, não haveria necessidade de se realizar uma nova iteração), assim como a validação das alterações realizadas nas iterações 2 e 3.

\section{VII.3 RESULTADOS (DETALHAMENTO DAS ITERAÇÕES)}

\section{VII.3.1 Iteração 1}

Esta iteração iniciou-se com a implementação do software para uso em ambiente de trabalho, a partir dos requisitos e modelos de sistema discutidos no ciclo 2 (neste ciclo, somente foram apresentados os artefatos relativos ao estudo desta pesquisa, já que para a implementação do software são necessários outros artefatos não discutidos no ciclo 2 e que não fazem parte desta pesquisa).

Assim, o desenvolvimento do software passa da fase de análise de requisitos à fase de projeto, codificação e testes de produto (de unidade e integração), permitindo o acompanhamento da evolução dos requisitos do trabalho cooperativo ao longo da construção do sistema (ciclo 3), sem entrar em detalhes sobre a construção desses artefatos.

Gonçalves et al. (2005) descrevem tais artefatos de projeto e implementação e sua relação com os projetistas, nos quais um analista de banco de dados gera os procedimentos armazenados (camada de dados), de acordo com as funcionalidades 
levantadas com o projetista Web (camada de negócios). É gerado, então, um protótipo funcional da aplicação. Para isto, o projetista Web recebe o código HTML das páginas, feito pelo Web designer e, usando programação em ASP (Active Server Pages), faz a integração funcional com o banco de dados, a partir dos procedimentos armazenados, criados pelo analista de banco de dados.

No passo de levantamento e discussão dos dados, o treinamento dos usuários foi realizado em duas turmas: uma para cada laboratório. Antes do treinamento, foi necessário um estudo nos laboratórios com o objetivo de verificar quem eram os prováveis responsáveis pelas fases do processo de atendimento (para preparar os exemplos do treinamento) e a adequação do SI ao sistema informatizado a ser implantado, com o planejamento da mudança do processo não automatizado para o processo automatizado.

Durante a realização do treinamento para cada um dos laboratórios, foram usados exemplos desenvolvidos para esta finalidade por meio de prévia avaliação realizada nos laboratórios. $O$ objetivo dos exemplos de aplicação foi aproximar o modelo mental de projeto (ciclo 2 desta PA) ao modelo mental do usuário (ver item II.3.1). A estrutura do ambiente de treinamento é descrita no item VII.2.1.

Após o treinamento, o sistema foi colocado em produção e, durante os primeiros 2 meses de operação, verificou-se que 0 uso em ambiente real não estava correspondendo plenamente ao esperado como foi simulado no ciclo 2. Estas constatações foram observadas nos resultados do uso do sistema e pelo apoio aos usuários (help desk):

- Os pedidos de faturamento foram emitidos de forma incorreta acima da taxa observada, antes da implantação do sistema, em função sobretudo da escolha indevida dos clientes do pedido, assim como da escolha incorreta do conteúdo dos documentos técnicos;

- Utilização de meios alternativos, como planilhas, para registrar informações fornecidas pelo sistema;

- Dificuldade no gerenciamento dos orçamentos, causando, em alguns casos, atrasos na entrega dos serviços ao cliente;

- Dificuldade para concatenar as tarefas do próprio usuário com as dos demais participantes do grupo, em especial, na fase de Inspeção/execução; 
- Dificuldade de organizar suas pendências dentro de um dado processo.

Em paralelo com a fase de implementação da primeira iteração, o autor participou de uma pesquisa realizada em Web Sites de projetos da indústria de arquitetura, engenharia e construção de edifícios com o objetivo de estudar os aspectos do trabalho cooperativo no uso destes sites por meio dos conceitos da teoria da mente coletiva (ver item II.4) (GONÇALVES et al., 2008).

Este estudo mostrou em relação às ações que:

- No aspecto da contribuição, a falta de retorno (feedback) do site não permitia aos usuários verificar o resultado de sua contribuição com relação aos demais participantes;

- A representação era dificultada por falta de ferramentas visuais no site;

- A subordinação era baixa sobretudo em razão da imposição do uso do software pelas empresas de construção.

Em relação aos processos sociais,

- Eram necessárias reuniões periódicas para manter a representação do sistema;

- Experiência anterior no processo não automatizado permitia aumentar a representação para uso do software.

Assim, esta pesquisa evidenciou que, para melhorar o uso cooperativo do sistema, era necessário implementar ferramentas que permitissem melhorar as diferentes formas de visualização das informações (usabilidade) no site, assim como para manter os processos sociais era preciso o treinamento dos usuários e promover encontros periódicos para conservar a representação.

Visando a entender melhor as razões pelas quais 0 uso em ambiente real não estava correspondendo ao esperado e considerando-se os resultados da pesquisa acima descrita, foram realizadas entrevistas com usuários encontrados nos laboratórios: secretárias, técnicos executantes dos serviços, chefes de laboratório e pesquisadores (estes dois últimos normalmente eram responsáveis pelo orçamento). Antes da realização das entrevistas, os objetivos e a forma de realização das mesmas foram apresentados aos usuários, sendo normalmente realizadas em local de trabalho, consistindo na descrição dos usuários de suas atividades após a 
realização das mesmas, porém não foram acompanhadas dos dados de observação.

Procurou-se orientar os usuários, utilizando sua atividade efetiva como fio condutor e quando necessário, ajudando-os pela referência a uma ocorrência particular da atividade por meio de exemplos de visualização de algumas das interfaces gráficas utilizadas. Esta orientação foi facilitada na medida que o entrevistador possuía pleno conhecimento da sequência do fluxo do processo automatizado.

Primeiro, foram entrevistadas duas secretárias (uma de cada laboratório) e o que se observou pela descrição de suas atividades, com relação aos erros observados no pedido de faturamento, foi que não existia um mecanismo para informar possíveis alterações cadastrais do cliente durante o processo de atendimento a um pedido, nem a possibilidade de sua troca, caso fosse escolhido erroneamente no início do processo.

Outro aspecto descrito por uma das secretárias foi que em razão destes problemas, a mesma possuía uma planilha para registro dos valores faturados, pois alguns faturamentos eram realizados "por fora" do sistema, isto é, diretamente pela ferramenta de pedido do faturamento do ERP (neste caso, o sistema não contabilizava tal faturamento), além do fato que, em atendimentos de curta duração (3 a 4 dias úteis), o processo informatizado não estava fluindo na mesma velocidade da execução física do serviço, com um estrangulamento na fase de Composição do documento.

Pela descrição destas usuárias e por meio de um exemplo apresentado pelo entrevistador, percebeu-se também que pelo fato delas terem para si a responsabilidade de atuar em mais de uma fase, sua lista de pendência (página principal) estava sobrecarregada com muitos processos pendentes, já que todos eram visualizados, dificultando a organização das pendências de um dado pedido (processo).

Nestas entrevistas com as secretárias, realizou-se uma última avaliação que, em alguns casos, os pedidos deveriam ser encerrados antes do faturamento do pedido (por exemplo, pela desistência do cliente após a aprovação do orçamento, pela impossibilidade técnica da realização do serviço, etc.) 
Após as entrevistas com as secretárias, foram entrevistados dois técnicos executantes de serviços (um de cada laboratório) e, pela descrição de suas atividades no uso do software, percebeu-se que estes ficavam desorientados na fase de Inspeção/execução, sobretudo quando as ordens de serviços distribuídas na fase de Distribuição de OS (ver item VI.3.4) deveriam ser realizadas por mais de um técnico (ou seja, os serviços a serem realizados em um material deveriam ser executados por mais de um técnico), isto porque ao serem confrontados com a interface de inspeção/execução, estes técnicos não conseguiam perceber para quem deveriam enviar a fase (e o material respectivo), após a realização do serviço que lhes era atribuído.

Neste caso, para que pudesse saber como sua ação estava relacionada às de outros colegas do grupo, seria necessário que o técnico fosse até a página principal, na opção de "Relatórios internos" da Figura VI.18-5 e acessasse a opção de "Pedidos em andamento do grupo de trabalho" e verificasse para quem deveria enviar o material para realização do serviço.

$\mathrm{E}$, por último, um chefe de laboratório e um pesquisador (cada um pertencente a laboratórios distintos) foram entrevistados, em geral, estes usuários eram responsáveis pela composição do orçamento (criação de um novo orçamento) e do envio ao cliente (fase de Orçamentação), negociação (fase de Followup) e da composição e distribuição do documento técnico (fase de Composição do documento técnico).

Verificando-se as atividades executadas pelos mesmos por meio de sua descrição sobre como operavam suas fases no processo e como gerenciavam seu trabalho, percebeu-se que estes usuários tinham dificuldades para avaliar as entregas e a execução dos serviços durante o processo de atendimento, pois precisavam consultar vários locais diferentes da aplicação para obter as informações necessárias a este gerenciamento.

Durante a entrevista de um destes usuários (responsável pelo laboratório), quando estava descrevendo como operava a fase de Composição do documento técnico, pôde-se confirmar a questão colocada na entrevista aos técnicos e das secretárias, pois muitas vezes, demorava-se muito tempo para poder compor e distribuir um documento técnico (ver Figura VI.16), uma vez que o técnico não tinha informado na 
fase de Inspeção/execução sobre o status do pedido (em andamento, concluído, suspenso e cancelado - ver Figura VI.15).

Durante a descrição da fase de Followup pelo usuário pesquisador, percebeu-se pelas suas observações que sentia dificuldade para recuperar uma determinada negociação com o cliente; e, em certas situações, em que ocorria intensa negociação, esta era registrada em documento externo ao sistema para futura consulta (sobretudo no caso de auditoria do sistema interno da qualidade).

Nos dados do Quadro VII.1 abaixo, pode ser visto um resumo destas entrevistas.

Quadro VII.1 - Resumo das entrevistas realizadas no passo de análise e planejamento 1

\begin{tabular}{|c|c|c|}
\hline Entrevista & Usuários & Resumo \\
\hline \multirow{4}{*}{ Grupo 1} & \multirow{4}{*}{ Secretárias } & Problemas no cadastro de cliente. \\
\hline & & Fluidez do processo para prazos curtos de atendimento. \\
\hline & & Lista de pendências sobrecarregada de fases de processos. \\
\hline & & Encerramento intempestivo. \\
\hline Grupo 2 & Técnicos & $\begin{array}{l}\text { Dificuldade para perceber para quem enviar a fase de } \\
\text { Inspeção/execução, no caso de mais de um serviço ser } \\
\text { realizado no material. }\end{array}$ \\
\hline \multirow{2}{*}{ Grupo 3} & \multirow{2}{*}{$\begin{array}{l}\text { Chefe de } \\
\text { laboratório e } \\
\text { pesquisador }\end{array}$} & $\begin{array}{l}\text { Dificuldade em avaliar as entregas e execução dos serviços } \\
\text { durante o processo de atendimento. }\end{array}$ \\
\hline & & $\begin{array}{l}\text { Dificuldade para recuperar uma determinada negociação } \\
\text { com o cliente. }\end{array}$ \\
\hline
\end{tabular}

Fonte: elaborado pelo autor

\section{VII.3.2 Iteração 2}

\section{Implementação 2}

No passo de implementação desta iteração, os artefatos que serviram como elemento de representação comum durante a segunda parte da sessão foram desenvolvidos. Para esta implementação, foram consideradas as entrevistas realizadas no passo de análise e planejamento da iteração 1.

Ao se analisar os resultados das entrevistas, percebeu-se que os usuários entrevistados nem sempre tinham conhecimento das atividades do grupo (a contextualização das atividades individuais por meio da compreensão das atividades realizadas por outras pessoas), ficando em algumas situações sem saber o que aconteceu, o que estava acontecendo e/ou o que poderia vir a acontecer, ou seja, havia necessidade de considerar mais detalhadamente o awareness do sistema (ver item II.5.5) . 
Deste modo, a utilização dos elementos de awareness foi importante para orientar a construção dos artefatos no passo de implementação desta iteração. Outro fator que reforçou a necessidade de se considerar estes elementos, foi a pesquisa da qual participou o autor desta tese (item VII.3.1) que mostrou a necessidade do uso de ferramentas visuais para melhoria da representação do trabalho cooperativo em Web Sites de projetos da indústria de arquitetura, engenharia e construção de edifícios.

Do mesmo modo que os conceitos da teoria da mente coletiva foram usados na pesquisa realizada nos Web Sites de projetos de construção civil para avaliação do trabalho cooperativo, no presente estudo também foi utilizada esta teoria para avaliar a evolução do trabalho cooperativo nas iterações 2 e 3 deste ciclo, uma vez que o sistema empregado nesta PA tem como característica importante o fato de que sua coordenação é distribuída nas ações dos usuários, ou seja, sem um centro definido de coordenação (item VII.2.3), pois esta característica é importante para a aplicação da teoria.

Assim, utilizando-se os dados do Quadro VII.2 sobre os elementos de awareness e tendo como guia de orientação a teoria da mente coletiva, foram desenvolvidos os artefatos do Quadro VII.3, em que podem ser vistos quais elementos de awareness foram considerados na construção desses artefatos e as respectivas ações da teoria da mente coletiva. Estes artefatos serão mais bem detalhados na segunda parte da sessão desta iteração.

\section{Quadro VII.2 - Elementos de awareness para sistemas assíncronos e desacoplados}

\begin{tabular}{|c|c|c|}
\hline Categoria & Elemento & Significado \\
\hline \multirow[t]{7}{*}{ O quê } & Atividades: & $\begin{array}{l}\text { Visão ampla das tarefas individuais e do grupo e de sua } \\
\text { produção: }\end{array}$ \\
\hline & Ações & O que fazer e o que os outros estão fazendo \\
\hline & Artefatos & Em quais objetos estão trabalhando no momento \\
\hline & Produção & Quais são os resultados preliminares do trabalho \\
\hline & $\begin{array}{c}\text { Histórico de } \\
\text { ações }\end{array}$ & O que um indivíduo esteve realizando \\
\hline & Papéis: & Diferenciação das informações em função do papel \\
\hline & Alcance & Até onde podem ou devem \\
\hline Quando & $\begin{array}{c}\text { Eventos } \\
\text { passados, } \\
\text { passado } \\
\text { continuo e }\end{array}$ & $\begin{array}{l}\text { Contexto sobre o que foi feito (eventos no passado) e do que } \\
\text { ainda está sendo feito (passado contínuo), }\end{array}$ \\
\hline
\end{tabular}




\begin{tabular}{|c|c|c|}
\hline \multirow[t]{3}{*}{ Categoria } & \multirow{3}{*}{$\begin{array}{l}\text { Elemento } \\
\text { presentes: } \\
\text { Histórico de } \\
\text { eventos }\end{array}$} & \multirow[t]{2}{*}{ Significado } \\
\hline & & \\
\hline & & Quando um evento aconteceu \\
\hline & Eventos futuros & $\begin{array}{l}\text { Representam uma opção interessante para manter os } \\
\text { membros atentos aos possíveis rumos do trabalho. }\end{array}$ \\
\hline & Persistência & $\begin{array}{l}\text { Alta: Definição de um critério de caducidade, que inutiliza } \\
\text { estas informações. }\end{array}$ \\
\hline & $\begin{array}{l}\text { Apresentação } \\
\text { das informações } \\
\text { de awareness }\end{array}$ & Posterior (a critério do usuário) \\
\hline \multirow[t]{4}{*}{ Onde } & $\begin{array}{c}\text { Espaço } \\
\text { compartilhado }\end{array}$ & $\begin{array}{l}\text { Objetos compartilhados pelo grupo. Por meio de sua } \\
\text { manipulação, mostra o que houve e está acontecendo dentro } \\
\text { do trabalho em grupo. }\end{array}$ \\
\hline & $\begin{array}{l}\text { Histórico de } \\
\text { artefatos }\end{array}$ & Como um determinado artefato chegou àquele estado \\
\hline & $\begin{array}{l}\text { Histórico de } \\
\text { localização }\end{array}$ & Onde um indivíduo esteve \\
\hline & $\begin{array}{l}\text { Metáforas de } \\
\text { sistema }\end{array}$ & $\begin{array}{l}\text { Relacionam o groupware com versões monousuárias do } \\
\text { sistema, havendo a necessidade de enriquecê-la } \\
\text { adequadamente com as informações de awareness. }\end{array}$ \\
\hline \multirow[t]{2}{*}{ Como } & Interface & $\begin{array}{l}\text { Interfaces desacopladas, mas não impedindo a interface de } \\
\text { incluir elementos para awareness }\end{array}$ \\
\hline & $\begin{array}{l}\text { Balanceamento } \\
\text { de interface }\end{array}$ & $\begin{array}{l}\text { Filtragem ou um agrupamento das informações, mostrando } \\
\text { apenas aquilo que for mais útil }\end{array}$ \\
\hline \multirow[t]{3}{*}{ Quem } & Autoria & Quem realizou um determinado evento \\
\hline & $\begin{array}{l}\text { Histórico de } \\
\text { presença }\end{array}$ & Quem esteve em um local do ambiente e quando \\
\hline & $\begin{array}{l}\text { Ferramentas de } \\
\text { comunicação }\end{array}$ & $\begin{array}{l}\text { Essencialmente ferramentas assíncronas (email, quadro de } \\
\text { avisos e notas, etc.) }\end{array}$ \\
\hline
\end{tabular}

Fonte: reproduzido do Quadro II.1

Quadro VII.3 - Artefatos desenvolvidos como resultados obtidos das entrevistas da iteração 1

\begin{tabular}{|c|c|c|}
\hline Artefato/Entrevista & Elementos de awareness & Ações \\
\hline $\begin{array}{c}\text { Troca de cliente/Alteração } \\
\text { cadastral /Grupo 1 }\end{array}$ & $\begin{array}{c}\text { Onde (espaço } \\
\text { compartilhado)/Quem } \\
\text { (Ferramentas de } \\
\text { comunicação) }\end{array}$ & Contribuição, subordinação \\
\hline Filtros na página principal/Grupo 1 & $\begin{array}{c}\text { Como (balanceamento das } \\
\text { interfaces) }\end{array}$ & Representação \\
\hline $\begin{array}{c}\text { Encerramento intempestivo do } \\
\text { pedido/ Grupo1 }\end{array}$ & Quando (persistência) \\
\hline $\begin{array}{c}\text { Relação das OSs distribuídas na } \\
\text { fase de Inspeção/execução / } \\
\text { Grupo 2 }\end{array}$ & O quê (artefatos) & Representação \\
\hline Visão geral dos pedidos/Grupo 3 & O quê (produção) & Contribuição, subordinação \\
\hline $\begin{array}{c}\text { Histórico de negociações com } \\
\text { cliente/ Grupo 3 }\end{array}$ & Onde (histórico de artefatos) & \\
\hline
\end{tabular}

Fonte: elaborado pelo autor 


\section{Levantamento e discussão dos dados (sessão 1)}

No início da sessão 1 , conforme descrito na iteração 1 do ciclo 2, os participantes apresentaram-se e os pesquisadores deram esclarecimentos a respeito dos objetivos da pesquisa e mostraram um conjunto de regras para melhor encaminhamento das sessões:

- Deixaram claro que todas as opiniões interessavam e, portanto, não existiam opiniões certas ou erradas e ressaltaram a importância das manifestações individuais contra ou a favor;

- A duração prevista para a sessão;

- A dinâmica da sessão, conforme descrito no item VII.2.4;

- Dentro do possível, só uma pessoa falaria de cada vez;

- Evitar discussões paralelas para que todos pudessem participar;

Inicialmente, na primeira parte da sessão, a cada usuário foi entregue um formulário com questões (ver Quadro VII.4) sobre o uso do sistema baseado na teoria da mente coletiva (GAVA et al., 2008).

O formulário apresenta também questões sobre os processos sociais (ver item II.4.2) que estão em curso em todo sistema social a que pertence um grupo de trabalho com particular importância no sistema de informação em que foi realizada esta PA (coordenação distribuída no padrão de comportamento dos usuários), já que estes processos são úteis para manter a representação do sistema.

Os pesquisadores esclareceram as dúvidas dos usuários e procuraram evitar vieses nas explicações, confirmando a cada questão o preenchimento das respostas por parte dos usuários.

Após o preenchimento dos formulários pelos usuários, passou-se para a discussão e validação dos artefatos desenvolvidos no passo de implementação 2. Para tanto, primeiro foi apresentado qual problema o mesmo deveria resolver e a situação real verificada em campo pelas entrevistas. 


\section{Quadro VII.4 - Avaliação qualitativa do trabalho cooperativo nas sessões de ACT}

\begin{tabular}{|c|c|c|}
\hline \multirow{2}{*}{$\begin{array}{c}\text { Questões a respeito das ações/comportamento } \\
\text { C: Contribuição, R: Representação S: Subordinação }\end{array}$} & \multicolumn{2}{|c|}{ Sessão1 } \\
\hline & $\begin{array}{l}\text { Números } \\
\text { de Não }\end{array}$ & $\begin{array}{l}\text { Números } \\
\text { de Sim }\end{array}$ \\
\hline \multicolumn{3}{|l|}{ Você sabe em qual fase do processo pode atuar? (R) } \\
\hline \multicolumn{3}{|l|}{ Você sabe quais são os dados mais importantes a serem inseridos? (C) } \\
\hline \multicolumn{3}{|l|}{$\begin{array}{l}\text { Estando na fase de sua responsabilidade, sabe quem deve ser o responsável } \\
\text { pela próxima fase? (C) }\end{array}$} \\
\hline \multicolumn{3}{|l|}{ Você sabe de que outras fases depende a sua? (R) } \\
\hline \multicolumn{3}{|l|}{$\begin{array}{l}\text { Quando insiro um dado errado em uma fase de minha responsabilidade, sei } \\
\text { das consequências no processo deste erro para as fases posteriores? }(R)\end{array}$} \\
\hline \multicolumn{3}{|l|}{ Distingue qual sua posição atual no processo? $(\mathrm{R})$} \\
\hline \multicolumn{3}{|l|}{$\begin{array}{l}\text { Distingue quem são os responsáveis pelas atividades que estão sendo } \\
\text { desenvolvidas? }(R)\end{array}$} \\
\hline \multicolumn{3}{|l|}{$\begin{array}{l}\text { Confia que as informações que chegam até você pelo sistema são as mais } \\
\text { atualizadas? (S) }\end{array}$} \\
\hline \multicolumn{3}{|l|}{$\begin{array}{l}\text { Você utiliza o sistema para trocar informações com outros usuários, sem a } \\
\text { necessidade de outros meios?(S) }\end{array}$} \\
\hline \multicolumn{3}{|l|}{ Você toma decisões por meio das informações fornecidas pelo sistema? (S) } \\
\hline \multicolumn{3}{|l|}{ Você sabe como acompanhar as metas do grupo? (R) } \\
\hline \multicolumn{3}{|l|}{$\begin{array}{l}\text { Você sabe como as ações dos outros usuários estão relacionadas com as } \\
\text { suas? }(\mathrm{R})\end{array}$} \\
\hline \multicolumn{3}{|l|}{ Você sabe como acompanhar o trabalho de outros membros do grupo? (R) } \\
\hline \multicolumn{3}{|l|}{ Você sabe como recuperar as informações que inseriu no sistema? (R) } \\
\hline \multicolumn{3}{|l|}{$\begin{array}{l}\text { Você sabe como recuperar as informações que outros membros do grupo } \\
\text { inseriram no sistema? }(R)\end{array}$} \\
\hline \multicolumn{3}{|l|}{$\begin{array}{c}\text { Questões a respeito do processo social } \\
\text { So: Socialização, Co: Conversação Re: Recapitulação }\end{array}$} \\
\hline \multicolumn{3}{|l|}{ Existe um programa de treinamento para novos usuários? (So) } \\
\hline \multicolumn{3}{|l|}{$\begin{array}{l}\text { Os usuários trocam experiência regularmente a respeito da utilização do } \\
\text { sistema? (Co) }\end{array}$} \\
\hline $\begin{array}{l}\text { correm encontros programados para a discussão do uso e dos res } \\
\text { stema? (Re) }\end{array}$ & & \\
\hline
\end{tabular}

Fonte: Elaborado pelo autor, baseado em WEIK and ROBERTS (1993)

Desse modo, os primeiros artefatos discutidos foram os referentes às entrevistas com as secretárias (Grupo 1 do Quadro VII.1), iniciando-se com os artefatos relativos à Troca de cliente/Alteração cadastral. $O$ acesso a esta opção é realizado pela página principal, como pode ser visto na Figura VII.6-2, já que poderá ser escolhido em qualquer fase do processo (ou atendimento no jargão dos usuários).

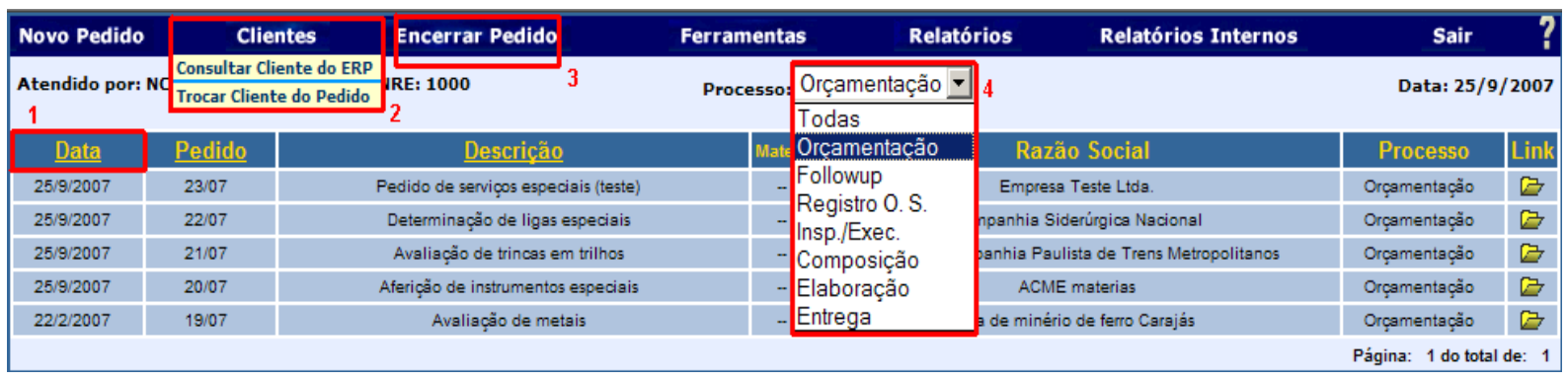


Inicialmente o usuário faz uma pesquisa para procurar um pedido (Figura VII.7), no qual the é oferecida a opção de escolher entre editar um cliente ou editar/trocar (nem sempre será possível trocar um cliente, dependendo do pedido já possuir ou não um documento técnico).

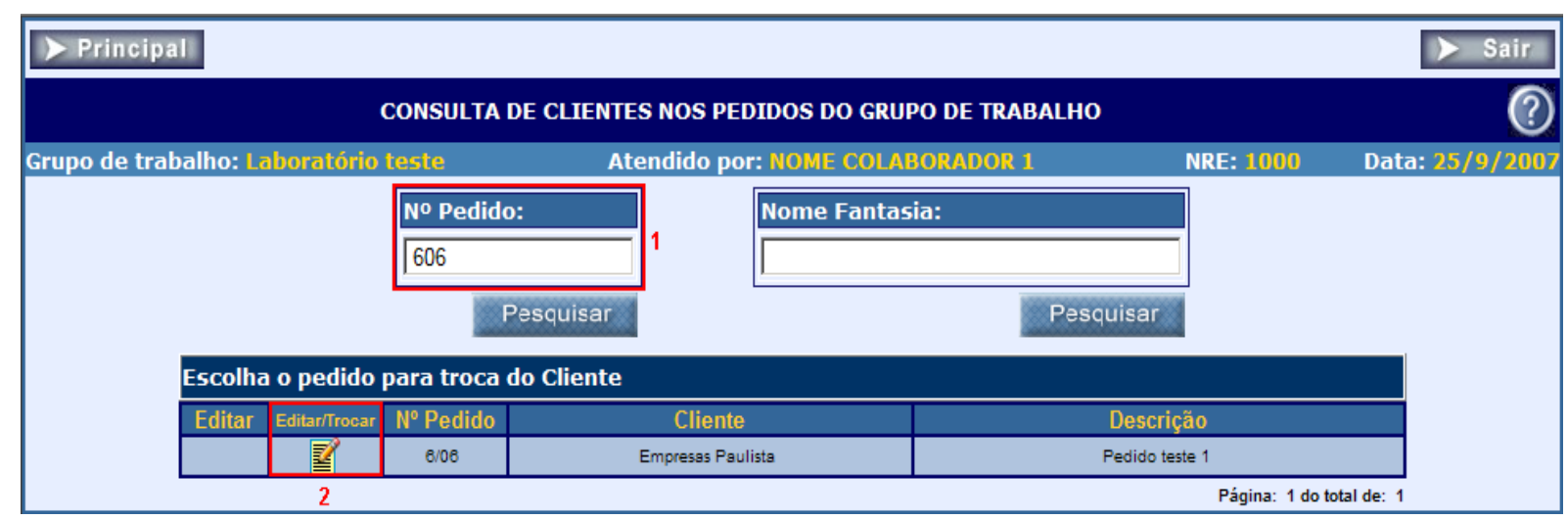

Figura VII.7 - Troca de cliente/Alteração cadastral

Após esta escolha (Figura VII.7-2), o usuário pode editar um quadro de observação (Figura VII.8-1) que será transferida para um campo correspondente no formulário do pedido de faturamento. Deste modo, quando um usuário informar os dados relativos a este campo em qualquer parte do processo, esta informação será repassada ao usuário responsável pelo pedido de faturamento, como se fosse um quadro de aviso relativo àquele pedido.

Outro aspecto abordado foi o fato da lista de pendências apresentar várias fases de processos distintos. Para esta situação na página principal, foi criado um filtro (ver Figura VII.6-4) para o usuário escolher qual fase do processo (convém relembrar que no jargão dos laboratórios os termos fase e processo utilizados nesta pesquisa correspondem, respectivamente a processo e a atendimento) poderia ser visualizada, diminuindo as fases pendentes e facilitando sua coordenação dentro de suas pendências (no exemplo em questão estão sendo listados apenas os processos na fase de orçamentação). 


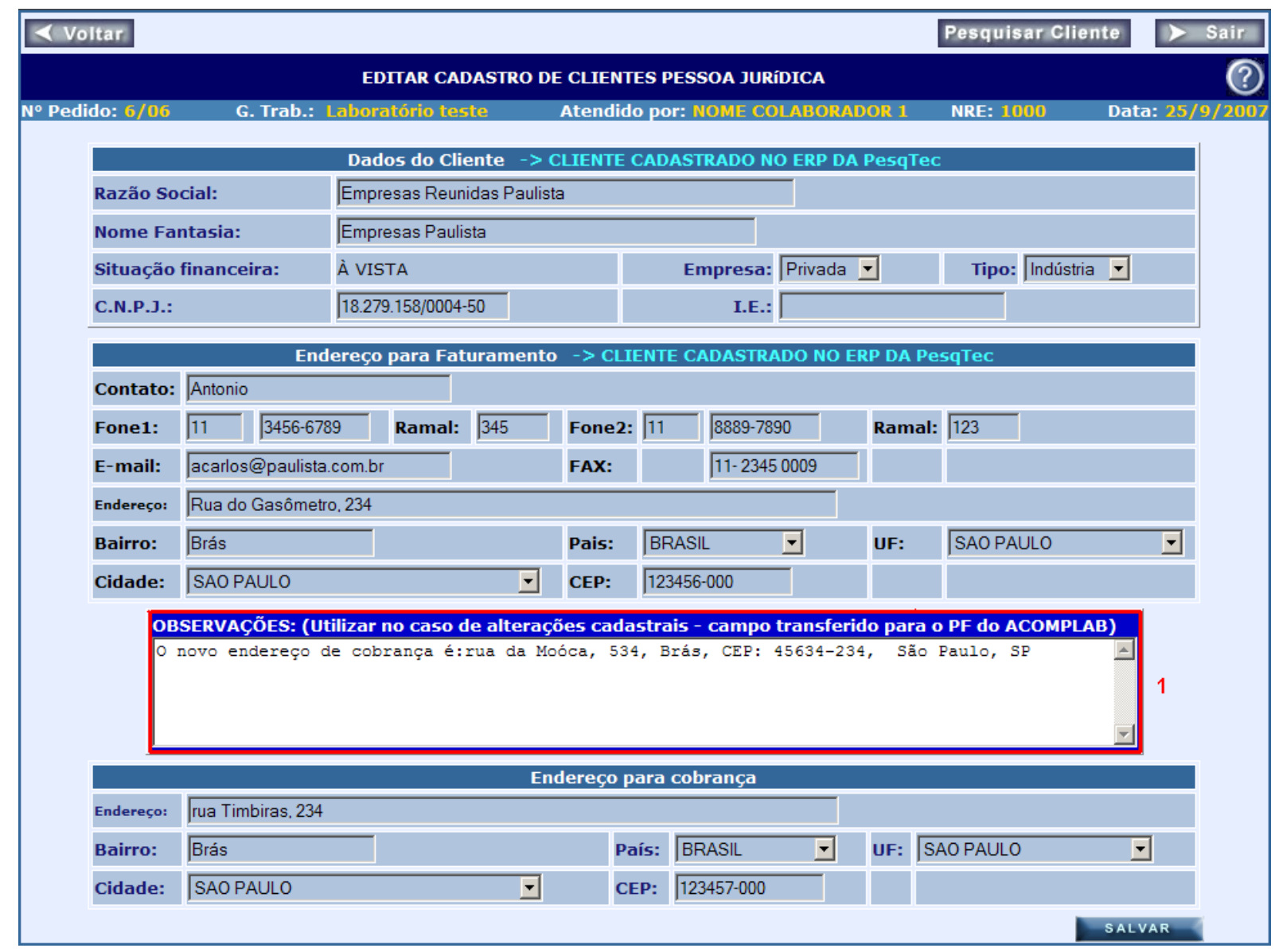

Figura VII.8 - Alteração cadastral

Na discussão desta opção, os usuários citaram a importância de se realizar uma ordenação por data (direta e reversa) de atualização da fase (ver Figura VII.6-1) visto que, muitas vezes, era mais importante acessar uma fase que teve atualização recente, a despeito de seu número de pedido ser menor (mais antiga), dificultando sua localização na lista.

$\mathrm{Na}$ sequência foi apresentada a opção para o problema do término do processo em qualquer fase (desistência do cliente após aprovação, problema com o material, problemas no laboratório, etc.). Para tanto, foi criado um artefato (acessado pela página principal, ver Figura VII.6-3) para tratar a questão. Assim, ficou estabelecido que só os responsáveis pelo orçamento poderiam encerrar um pedido, antes de seu término normal (após o faturamento). Este artefato não será apresentado neste trabalho pelos motivos descritos no item VII.1.

O próximo artefato apresentado para discussão na sessão foi relativo à situação descrita pelos técnicos nas entrevistas (Grupo 2 do Quadro VII.1). Na Figura VII.9-1, 
pode ser vista a fase de Inspeção/execução, com a adição de uma opção para ajudar a resolver o problema mencionado, no qual o usuário pode ver em sua fase todas as distribuições realizadas e não apenas a ordem de serviço que lhe diz respeito.

Desse modo, seria possível para o usuário perceber outros serviços associados ao material e que não estavam sob sua responsabilidade, permitindo o relacionamento de suas ações com as dos demais participantes do grupo (no exemplo em questão, o Serviço teste 4 deverá ser executado pelo NOME COLABORADOR 2, além do Serviço teste 2 que o próprio NOME COLABORADOR 1 deverá executar) .

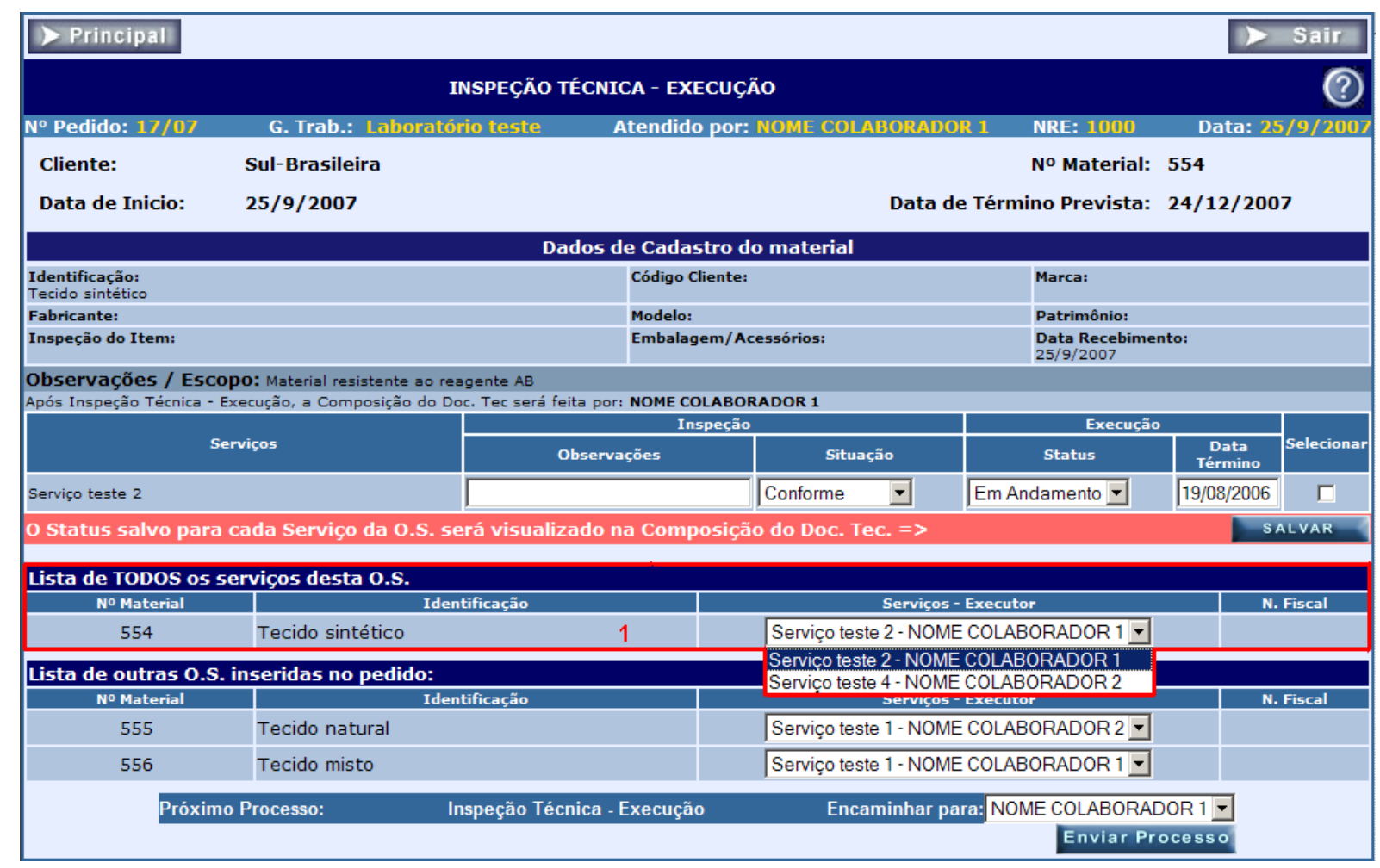

Figura VII.9 - Inspeção e execução da OS (serviços associados ao material da fase)

$\mathrm{Na}$ discussão deste artefato, os usuários concluíram que também seria importante mostrar na fase, além das ordens de serviço relativas ao material associado àquela fase, todas as ordens de serviços referentes aos materiais registrados (Figura VII.10$1)$. 


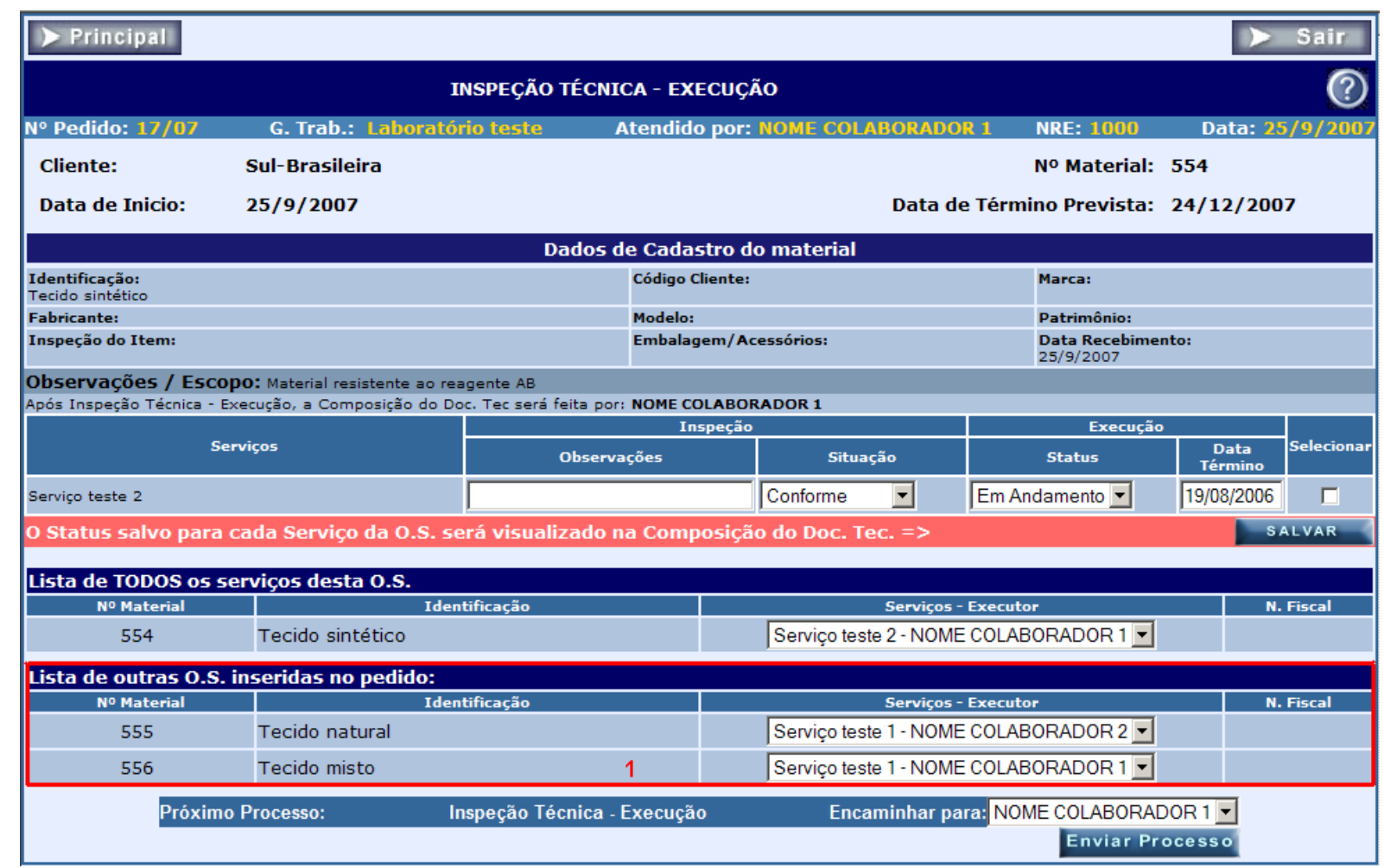

Figura VII.10 - Inspeção e execução da OS (serviços associados aos demais materiais)

As entrevistas do grupo 3 mostraram a necessidade de apresentar as informações do processo de atendimento de forma mais integrada, permitindo aos usuários fazer uma previsão de suas atividades, assim como a necessidade de manter o estado de negociação na fase de Followup.

Para o primeiro caso (informações integradas), foi apresentado o artefato da Figura VII.11, acessado por meio da página principal, na aba relatórios internos, subitem "Visão-geral" (Figura VII.6).

Por intermédio de um conjunto de filtros (Figura VII.11-1) relativos às diversas fases do atendimento é possível verificar, por exemplo, a situação das ordens de serviços realizadas (Figura VII.11-4), a folga entre a data atual de pesquisa e a data de entrega (Figura VII.11-5) e a data de entrega prevista (Figura VII.11-6). 


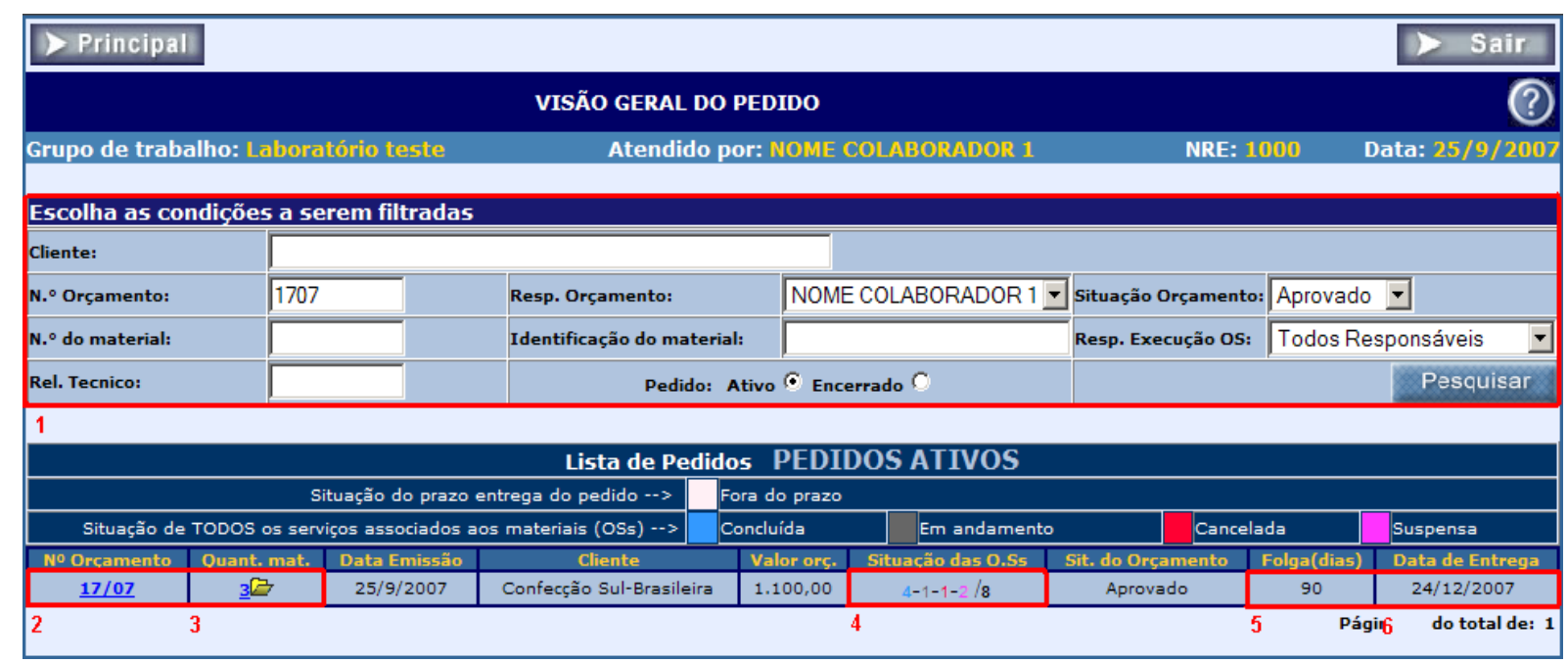

Figura VII.11 - Visão geral

Durante a discussão coletiva deste artefato, os usuários também consideraram importante visualizar uma cópia do orçamento enviado ao cliente (link da Figura VII.11-2), assim como um detalhamento das ordens de serviço (link da Figura VII.113), mostrando em outra janela de navegação todos os serviços associados aos respectivos materiais, responsáveis pela execução e situação da execução (ver Figura VI.16-1). Estas duas últimas opções não serão apresentadas neste trabalho.

$\mathrm{O}$ artefato permite monitorar os pontos nos quais a fase de Composição do documento pode impedir a fluidez do processo, centralizando em um único local as informações distribuídas nas fases do processo de atendimento relativas à distribuição e execução das ordens de serviço.

Na Figura VII.12-1, o registro de um histórico pode ser visto na negociação realizada com um cliente na fase de Followup que corresponde ao último artefato apresentado aos usuários relativo ao grupo 3 de entrevistas. Durante esta discussão, os usuários perceberam que a fase de Elaboração do documento técnico, também, deveria ter esta característica de awareness (esta fase não será mostrada neste trabalho, já que seu histórico é equivalente ao da fase de Followup). 


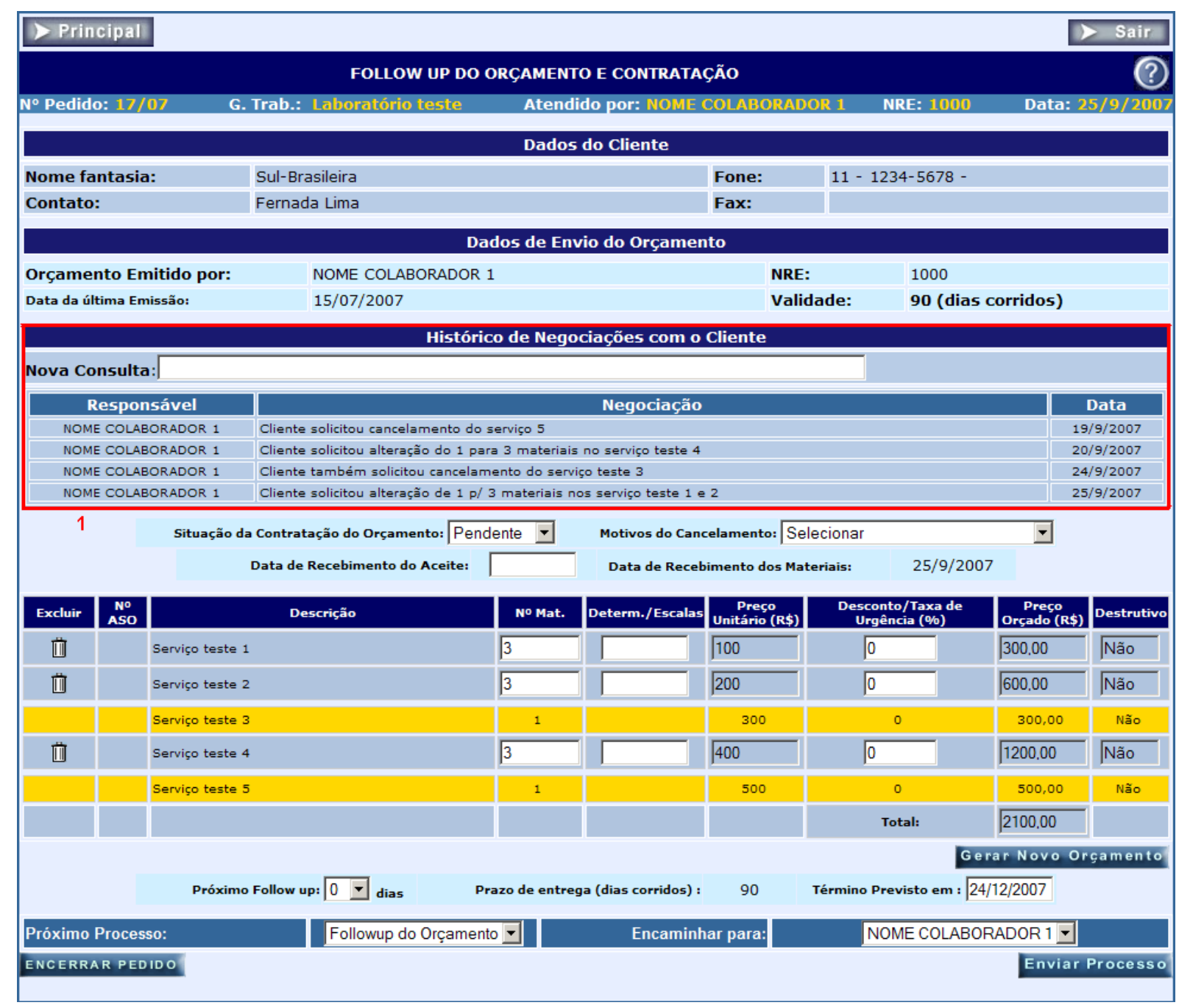

Figura VII.12 - Histórico de follow-up

Após a discussão sobre os artefatos desenvolvidos nas entrevistas da iteração 1 , foram citadas algumas questões sobre a dinâmica do envio das fases dentro do grupo de trabalho pelos usuários. Um aspecto emergente desta discussão foi a necessidade de visualizar a fase que estava com outro usuário para dar seguimento às atividades do próprio usuário, ou mesmo, a situação onde era necessário assumir a fase de outro usuário para dar andamento ao próprio trabalho e o trabalho do grupo (por exemplo, na situação da ausência do responsável pela fase).

Para atender a esta necessidade, foi discutida uma solução na qual um usuário poderia visualizar uma fase que não estivesse sob sua responsabilidade, podendo enviá-la ainda a outro usuário ou assumi-la para si (acesso transversal ao processo, isto é, sem que o mesmo estivesse na pendência do usuário). 
Nas Figura VII.14 e Figura VII.15, podem ser vistas a solução adotada após sua implementação na iteração 3. É importante ressaltar que estes artefatos foram implementados de fato no passo implementação 3 da iteração 3 e que para elemento de representação comum foram adaptados trechos de outros artefatos para simular parte da solução, ou mesmo, ferramenta para desenho, uma vez que durante esta discussão estes artefatos ainda não existiam, como os demais apresentados até o momento.

O acesso ao mesmo é realizado pela página principal, na aba de "Acesso transversal" (Figura VII.13-1).

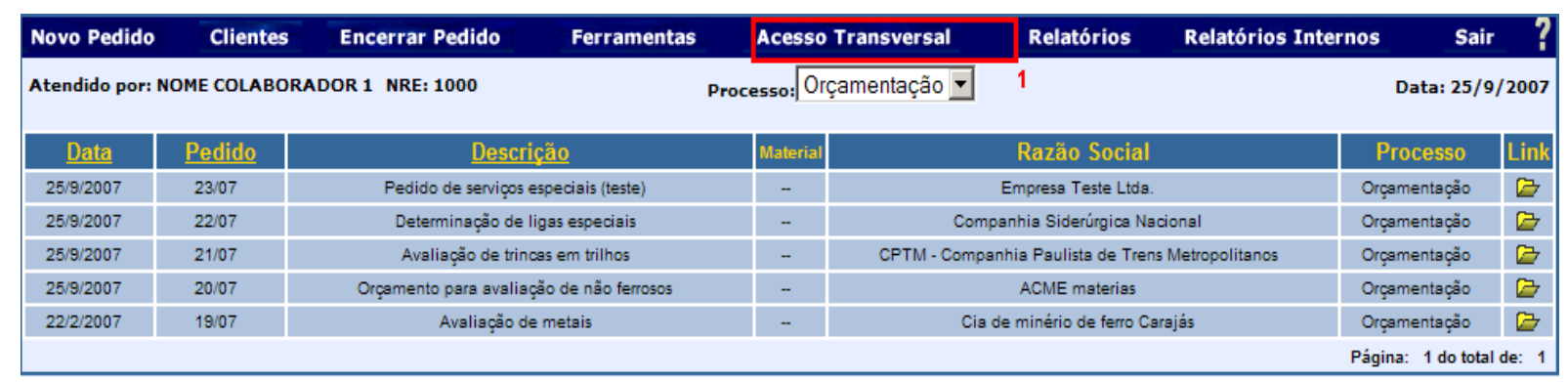

Figura VIl.13 - Página principal: acesso transversal

Na Figura VII.14-1, as opções de filtro são mostradas e, nesse caso, foi inserido um filtro por usuário e na Figura VII.14-2 encontra-se a lista de pendências para o item pesquisado (no caso, é o número de pedido). Esta lista de pendência é equivalente ao artefato de coordenação das atividades do grupo "Pedidos em andamento" (ver Figura VI.19) e o objetivo é permitir ao usuário perceber quais são todas as fases pendentes daquele pedido, sem ter a necessidade de voltar à página principal e procurar esta opção na aba "Relatórios internos". 


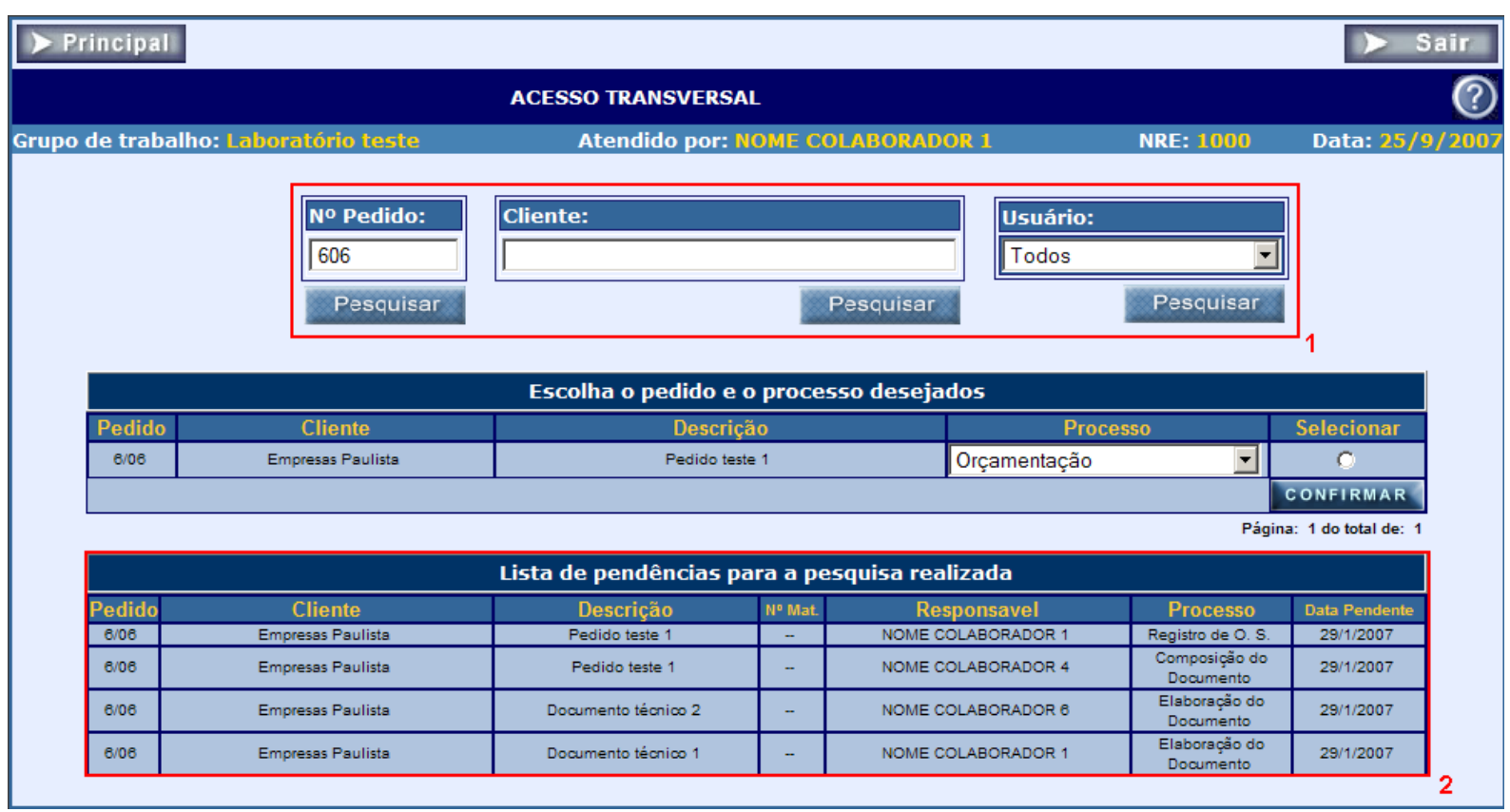

Figura VII.14 - Acesso transversal: pendências

Uma vez verificada as fases pendentes nesta lista, o usuário escolhe a fase que deseja visualizar (Figura VII.15-1), acionando o botão "Confirmar" (Figura VII.15-2, no caso em questão foi selecionada a fase "Composição do documento" que está com o NOME COLABORADOR 4). Assim, o usuário poderá visualizar/editar o conteúdo desta fase (ver Figura VII.16) e se quiser poderá, inclusive, enviá-la a outro usuário (no caso será enviada para o NOME COLABORADOR 5, ver Figura VII.161).

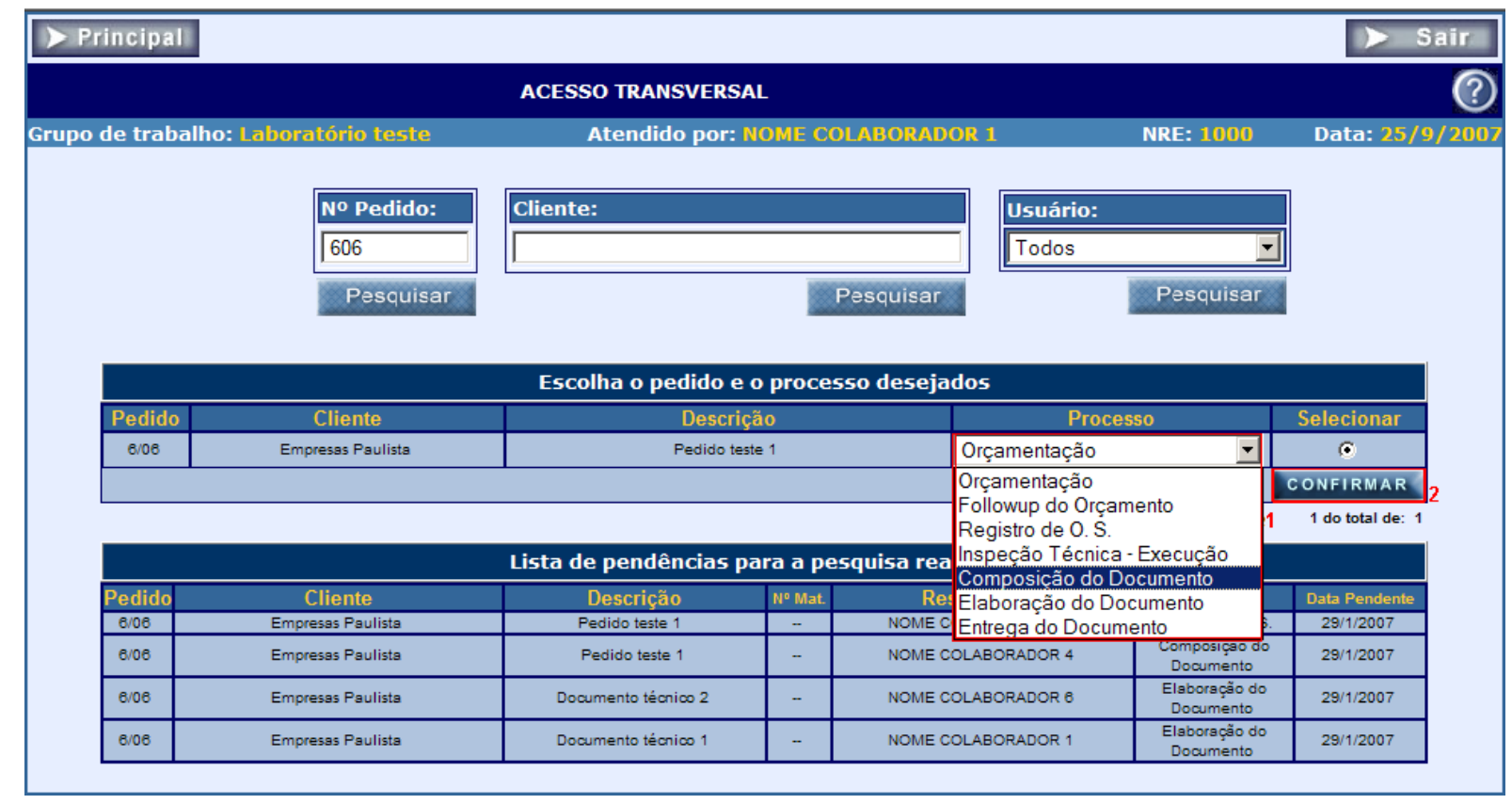

Figura VII.15 - Acesso transversal: escolha da fase 


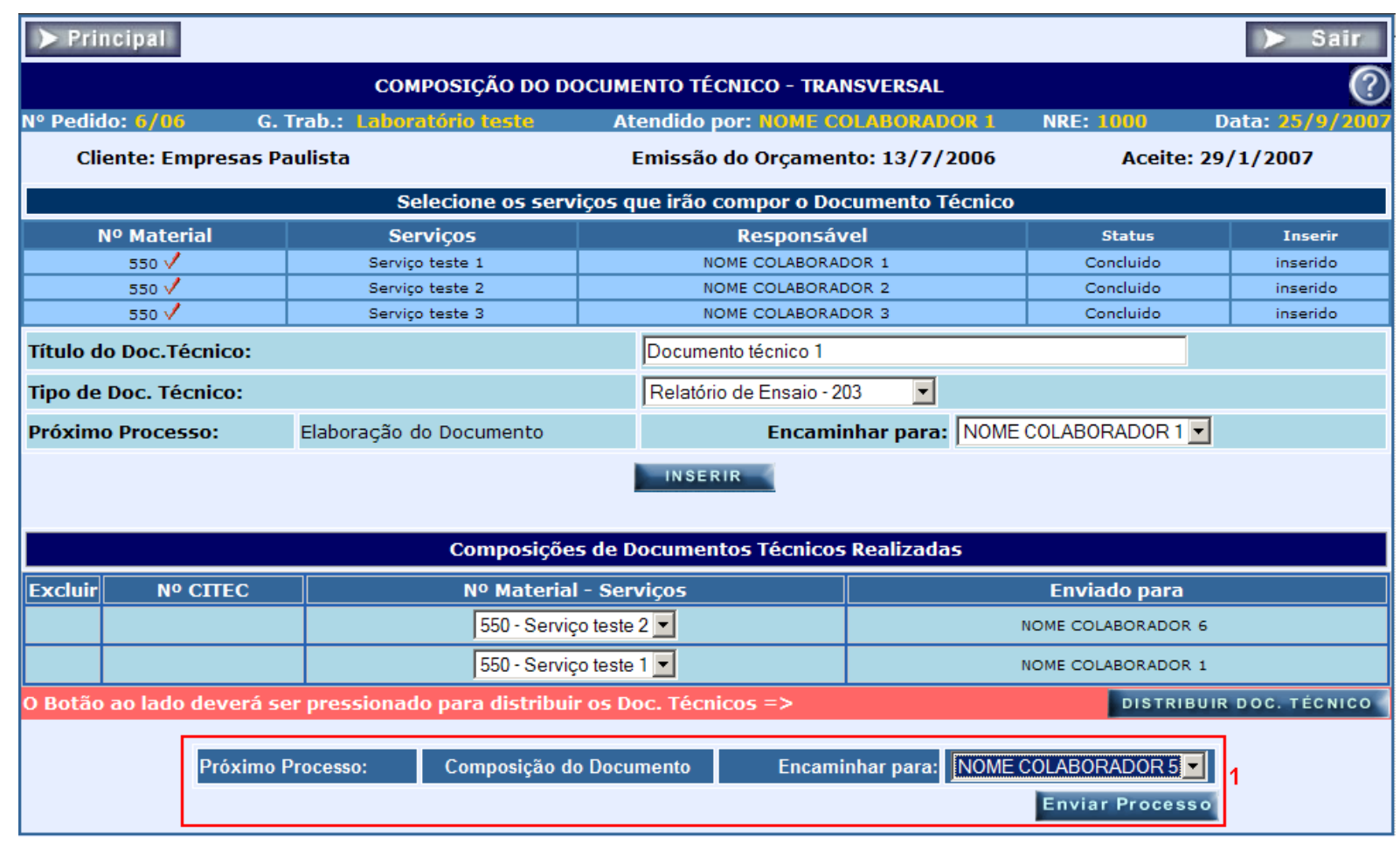

Figura VII.16 - Composição do documento técnico visualizado por meio do artefato Acesso transversal

Na discussão sobre o acesso transversal, os participantes da sessão levantaram a situação na qual se um usuário pudesse entrar e atualizar uma fase que não estivesse em sua lista de pendências (sob sua responsabilidade), o sistema deveria registrar um histórico sobre o acesso a esta fase.

Assim, surgiu outro aspecto emergente da sessão que foi a necessidade de um artefato para registrar quem era o responsável pela fase, quem a acessou e para quem a enviou. A discussão das características que este artefato deveria possuir trouxe à tona o fato de que o mesmo poderia contribuir como ferramenta auxiliar para verificar a fluidez do processo, verificar se houve encerramento intempestivo e aumentar a confiança (subordinação) no sistema, pois os usuários poderiam saber quem acessou/alterou determinada fase.

A Figura VII.17 mostra como ficou este artefato após sua implementação na iteração 3, na Figura VII.17-1 estão as opções de filtro que foram sugeridas durante a sessão e na Figura VII.17-2 um exemplo de resultado para pesquisa por número de pedido, mostrando a situação descrita na Figura VII.16-1, cuja fase estava com o usuário 
NOME COLABORADOR 4 foi acessada pelo NOME COLABORADOR 1 e enviada ao usuário NOME COLABORADOR 5.

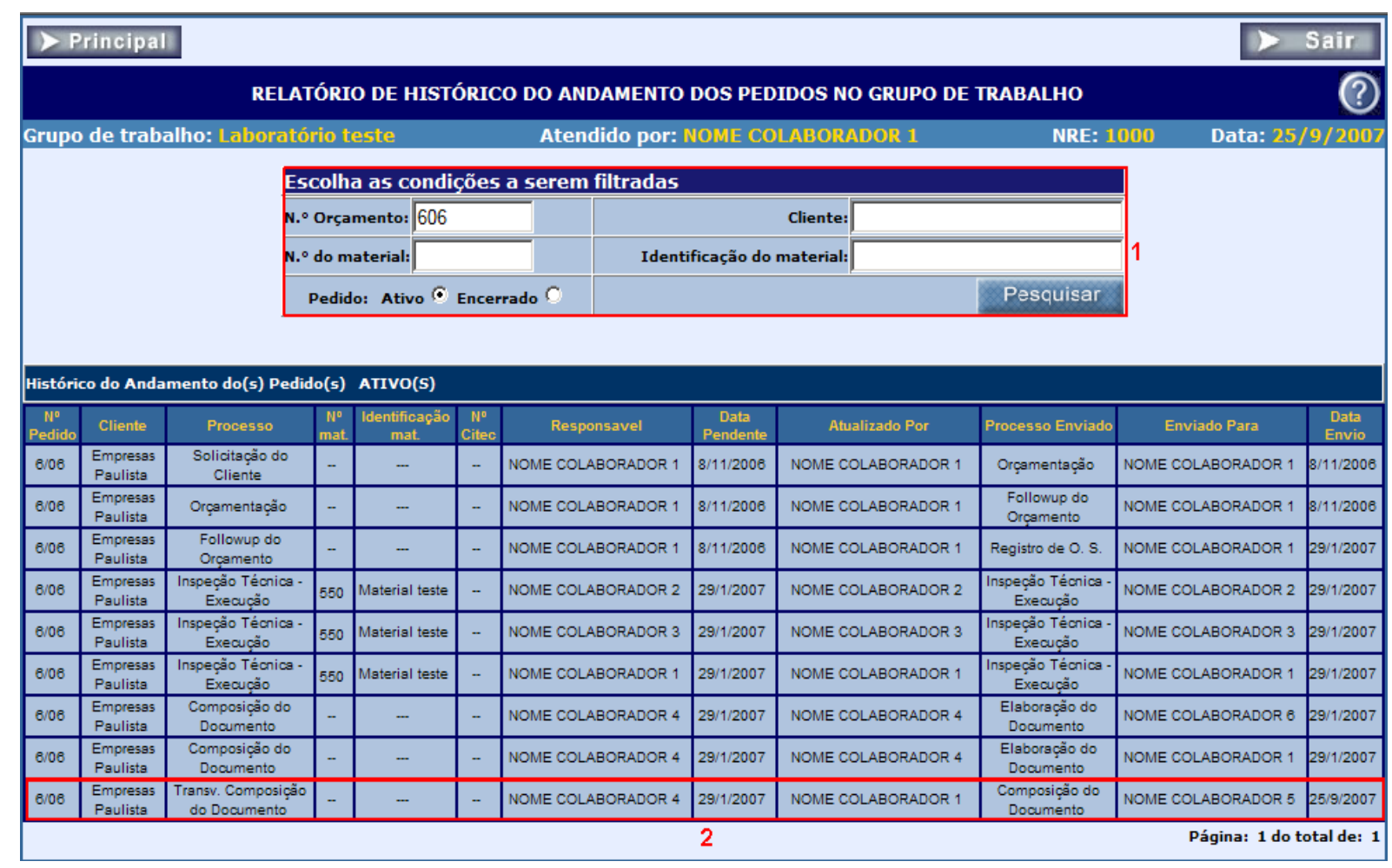

Figura VII.17 - Histórico de andamento do pedido

Nos dados do Quadro VII.5, pode ser observada a relação entre os elementos de awareness associados aos artefatos emergentes surgidos nesta sessão e as respectivas ações da teoria da mente coletiva.

Quadro VII.5 - Artefatos emergentes da sessão 2, elementos de awareness e ações

\begin{tabular}{|c|c|c|}
\hline Artefato/Entrevista & Elementos de awareness & Ações \\
\hline Acesso transversal & $\begin{array}{l}\text { O que (ações, artefatos e } \\
\text { produção) }\end{array}$ & $\begin{array}{c}\text { Representação, contribuição e } \\
\text { subordinação }\end{array}$ \\
\hline $\begin{array}{l}\text { Histórico de andamento de } \\
\text { pedidos }\end{array}$ & $\begin{array}{c}\text { O que (histórico de ações), } \\
\text { Quando (histórico de } \\
\text { eventos) e Onde (histórico } \\
\text { de localização) }\end{array}$ & Representação, subordinação \\
\hline
\end{tabular}

Fonte: elaborado pelo autor 


\section{Análise e planejamento 2}

No passo de análise e planejamento desta iteração, o resultado do questionário sobre o trabalho cooperativo aplicado aos usuários foi avaliado na primeira parte da sessão (ver Tabela VII.1).

Tabela VII.1 - Avaliação qualitativa do trabalho cooperativo da sessão 1

\begin{tabular}{|c|c|c|}
\hline \multirow{2}{*}{$\begin{array}{l}\text { Questões a respeito das ações/comportamento } \\
\text { C: Contribuição, R: Representação S: Subordinação }\end{array}$} & \multicolumn{2}{|c|}{ Sessão1 } \\
\hline & $\begin{array}{l}\text { Números } \\
\text { de Não }\end{array}$ & $\begin{array}{l}\text { Números } \\
\text { de Sim }\end{array}$ \\
\hline Você sabe em qual fase do processo pode atuar? (R) & 3 & 9 \\
\hline Você sabe quais são os dados mais importantes a serem inseridos? (C) & 2 & 10 \\
\hline $\begin{array}{l}\text { Estando na fase de sua responsabilidade, sabe quem deve ser } 0 \\
\text { responsável pela próxima fase? (C) }\end{array}$ & 4 & 8 \\
\hline Você sabe de que outras fases dependem a sua? $(R)$ & 5 & 7 \\
\hline $\begin{array}{l}\text { Quando insiro um dado errado em uma fase de minha responsabilidade, sei } \\
\text { das consequências no processo deste erro para as fases posteriores? (R) }\end{array}$ & 9 & 3 \\
\hline Distingue qual sua posição atual no processo? $(\mathrm{R})$ & 4 & 8 \\
\hline $\begin{array}{l}\text { Distingue quem são os responsáveis pelas atividades que estão sendo } \\
\text { desenvolvidas? }(R)\end{array}$ & 7 & 5 \\
\hline $\begin{array}{l}\text { Confia que as informações que chegam até você pelo sistema são as mais } \\
\text { atualizadas? (S) }\end{array}$ & 5 & 7 \\
\hline $\begin{array}{l}\text { Você utiliza o sistema para trocar informações com outros usuários, sem a } \\
\text { necessidade de outros meios?(S) }\end{array}$ & 7 & 5 \\
\hline Você toma decisões por meio de informações fornecidas pelo sistema? (S) & 7 & 5 \\
\hline Você sabe como acompanhar as metas do grupo? (R) & 8 & 4 \\
\hline $\begin{array}{l}\text { Você sabe como as ações dos outros usuários estão relacionadas com as } \\
\text { suas? (R) }\end{array}$ & 9 & 3 \\
\hline Você sabe como acompanhar o trabalho de outros membros do grupo? (R) & 8 & 4 \\
\hline Você sabe como recuperar as informações que inseriu no sistema? (R) & 8 & 4 \\
\hline $\begin{array}{l}\text { Você sabe como recuperar as informações que outros membros do grupo } \\
\text { inseriram no sistema? (R) }\end{array}$ & 10 & 2 \\
\hline $\begin{array}{c}\text { Questões a respeito do processo social } \\
\text { So: Socialização, Co: Conversação Re: Recapitulação }\end{array}$ & & \\
\hline Existe um programa de treinamento para novos usuários? (So) & 10 & 2 \\
\hline $\begin{array}{l}\text { Os usuários trocam experiência regularmente a respeito da utilização do } \\
\text { sistema? (Co) }\end{array}$ & 5 & 7 \\
\hline $\begin{array}{l}\text { Ocorrem encontros programados para a discussão do uso e dos resultados } \\
\text { do sistema? (Re) }\end{array}$ & 10 & 2 \\
\hline Porcentual do total de respostas (média geral): & $56 \%$ & $44 \%$ \\
\hline
\end{tabular}

Fonte: Elaborado pelo autor, baseado em WEIK and ROBERTS (1993)

Em função dos resultados qualitativos obtidos, nos quais só $44 \%$ das respostas foram positivas a respeito do estabelecimento das ações e dos processos sociais, decidiu-se pelo treinamento de dois usuários (tutores) com a função de manter o processo social em seus laboratórios.

Os usuários tinham como responsabilidade incentivar a discussão sobre o uso do sistema, providenciar a integração dos novos usuários, dar suporte local às dúvidas 
sobre o emprego do sistema e das novas funcionalidades e realizar reuniões locais para discussão e incentivo do relato de experiências no uso do sistema.

Os resultados gerais, também, mostraram que em torno da metade dos usuários não possuía uma representação adequada do processo automatizado, reforçando o resultado das entrevistas realizadas durante o passo de análise e planejamento da iteração 1, incentivando a construção dos artefatos emergentes discutidos durante esta sessão na fase de implementação da próxima iteração.

\section{VII.3.3 Iteração 3}

Nesta iteração, no passo de implementação, foram construídos os seguintes artefatos emergentes discutidos durante a iteração 2: Acesso transversal às fases e Histórico de fases do pedido, além de correções nos artefatos desenvolvidos durante o passo de implementação 2 e apresentados durante a sessão da iteração 2.

Durante este passo, os tutores foram treinados no uso dos artefatos que entrariam em produção para dar apoio aos usuários dos grupos de trabalho, sendo instruídos no sentido de manter os processos sociais, conforme a teoria da mente coletiva: socialização, conversação e recapitulação (ver item II.4.2).

Os artefatos dos passos de implementação 2 e 3 foram colocados em produção logo após sua implementação (contrariamente, ao que aconteceu nas iterações 1 e 2), pois, além de já terem sido validados pelos usuários na sessão 1, também, teriam o apoio dos tutores, logo após serem colocados em produção.

Quando a sessão 2 foi realizada, os artefatos implementados já estavam em uso, assim como o apoio dos tutores aos grupos. Na primeira parte desta sessão, os pesquisadores fizeram os mesmos esclarecimentos da sessão 1 (ver item VII.3.2).

Do mesmo modo que ocorreu na sessão 1, inicialmente, foi entregue a cada usuário um formulário com questões (ver Quadro VII.4) para avaliação da evolução do trabalho cooperativo pelo uso do sistema (GAVA et al., 2008).

Nesta sessão, também, os pesquisadores esclareceram eventuais dúvidas dos usuários, procurando evitar vieses nas explicações e confirmando a cada questão o preenchimento da resposta por parte dos usuários. 
Para facilitar a discussão coletiva, algumas situações foram apresentadas relativas ao processo automatizado e encontradas no dia a dia dos laboratórios (após a análise feita pelos desenvolvedores dos dados associados às fases dos processos no banco de dados e também consulta aos tutores).

Uma das situações discutidas foi até que ponto os orçamentos enviados e não aprovados deveriam ficar no sistema, já que no processo não informatizado esta situação, em geral, não precisava ser tratada. Após as discussões ficou estabelecido que o sistema deveria encerrar de modo automático os pedidos cujos orçamentos já estavam vencidos após um determinado número de dias (a ser definido pelo responsável da fase de Followup). A data final seria contada a partir da data de envio do orçamento e do prazo de validade do pedido, somado ao número de dias definido na fase de Followup.

Para atender a esta questão, os usuários concordaram com o pesquisador que estava conduzindo a sessão que seria necessário desenvolver um mecanismo de software (um programa que seria executado pelo sistema operacional todo noite para desativar os orçamentos não aprovados na situação descrita), mas este não precisaria ser apresentado aos usuários em uma nova sessão.

Algumas dúvidas sobre o melhor uso das ferramentas do software foram discutidas, mas de um modo geral os problemas discutidos restringiram a dúvidas de alguns usuários sobre os aspectos específicos do sistema, mas que não implicavam em alterações do processo de atendimento.

No passo de análise e planejamento 3 , a necessidade de realização de novas sessões foi avaliada, assim como o resultado do questionário sobre o trabalho cooperativo aplicado aos usuários na primeira parte da sessão. 
Tabela VII.2 - Avaliação qualitativa do trabalho cooperativo da sessão 2

\begin{tabular}{|l|c|c|}
\hline \multicolumn{1}{|c|}{ Questões a respeito das ações/comportamento } & \multicolumn{2}{|c|}{ Sessão2 } \\
\cline { 2 - 3 } Contribuição, R: Representação S: Subordinação & $\begin{array}{c}\text { Números } \\
\text { de Não }\end{array}$ & $\begin{array}{c}\text { Números } \\
\text { de Sim }\end{array}$ \\
\hline Você sabe em qual fase do processo pode atuar? (R) & 0 & 12 \\
\hline Você sabe quais são os dados mais importantes a serem inseridos? (C) & 0 & 12 \\
\hline $\begin{array}{l}\text { Estando na fase de sua responsabilidade, sabe quem deve ser o } \\
\text { responsável pela próxima fase? (C) }\end{array}$ & 0 & 12 \\
\hline Você sabe de que outras fases dependem a sua? (R) & 0 & 12 \\
\hline $\begin{array}{l}\text { Quando insiro um dado errado em uma fase de minha responsabilidade, sei } \\
\text { das consequências no processo deste erro para as fases posteriores? (R) }\end{array}$ & 1 & 11 \\
\hline Distingue qual sua posição atual no processo? (R) & 0 & 12 \\
\hline $\begin{array}{l}\text { Distingue quem são os responsáveis pelas atividades que estão sendo } \\
\text { desenvolvidas? (R) }\end{array}$ & 0 & 12 \\
\hline $\begin{array}{l}\text { Confia que as informações que chegam até você pelo sistema são as mais } \\
\text { atualizadas? (S) }\end{array}$ & 5 & 7 \\
\hline $\begin{array}{l}\text { Você utiliza o sistema para trocar informações com outros usuários, sem a } \\
\text { necessidade de outros meios?(S) }\end{array}$ & 4 & 8 \\
\hline Você toma decisões por meio das informações fornecidas pelo sistema? (S) & 5 & 7 \\
\hline Você sabe como acompanhar as metas do grupo? (R) & 2 & 10 \\
\hline $\begin{array}{l}\text { Você sabe como as ações dos outros usuários estão relacionadas com as } \\
\text { suas? (R) }\end{array}$ & 1 & 11 \\
\hline Você sabe como acompanhar o trabalho de outros membros do grupo? (R) & 2 & 10 \\
\hline Você sabe como recuperar as informações que inseriu no sistema? (R) & 2 & 10 \\
\hline $\begin{array}{l}\text { Você sabe como recuperar as informações que outros membros do grupo } \\
\text { inseriram no sistema? (R) }\end{array}$ & 2 & 10 \\
\hline \multicolumn{1}{|c|}{ Questões a respeito do processo social } \\
So: Socialização, Co: Conversação Re: Recapitulação & & \\
\hline Existe um programa de treinamento para novos usuários? (So) & 0 & 12 \\
\hline $\begin{array}{l}\text { Os usuários trocam experiência regularmente a respeito da utilização do } \\
\text { sistema? (Co) }\end{array}$ & 2 & 10 \\
\hline $\begin{array}{l}\text { Ocorrem encontros programados para a discussão do uso e dos resultados } \\
\text { do sistema? (Re) }\end{array}$ & 1 & 11 \\
\hline
\end{tabular}

Fonte: Elaborado pelo autor, baseado em WEIK and ROBERTS (1993)

Nos dados da Tabela VII.2, encontram-se os resultados deste questionário (GAVA et al., 2008).

Verifica-se que houve um aumento da percepção dos usuários sobre 0 estabelecimento das ações e dos processos sociais, de modo que em função dos resultados qualitativos obtidos nas duas sessões, houve uma evolução de $44 \%$ (ver Tabela VII.1) para $87 \%$ do número de respostas positivas.

A evolução do número de respostas positivas, fruto da introdução dos novos artefatos de awareness, com o maior grau de consciência dos usuários de como os inter-relacionamentos de suas atividades eram realizados, foi confirmado por meio de um decréscimo nos erros individuais dos usuários e suas respectivas consequências nos resultados do trabalho em grupo. 
Por exemplo, pelas medidas estabelecidas na iteração 2 (novos artefatos de awareness e treinamento dos tutores), os erros individuais como escolha indevida de cliente de um pedido, falta de aviso sobre mudanças cadastrais do mesmo na hora de faturamento, falta de fluidez do processo, demora na informação sobre a execução de um serviço, execução de faturamento sem o uso do sistema, etc. diminuíram, tendo como consequência uma melhoria nos resultados finais do trabalho cooperativo, onde, por exemplo, os erros na emissão dos pedidos de faturamento caíram em 50\% com relação à mesma situação antes da informatização do processo.

Para a diminuição de erro na emissão de PF, também contribuiu o fato dos usuários fazerem uma melhor amarração entre o número dos documentos e o pedido de faturamento em si, em razão do uso do software.

No caso da diminuição dos erros do pedido de faturamento, é importante ressaltar que esta redução tem um limite, pois em muitos casos os próprios clientes informam de modo incorreto os dados referentes à sua empresa.

Outra melhoria foi na velocidade e qualidade na emissão/aprovação e negociação dos orçamentos, de modo que antes da implantação do sistema havia um "gargalo" lógico na emissão destes (cerca de quatro por dia), passando para a emissão em torno de 20 por dia com o sistema informatizado, mudando do gargalo lógico para o físico (impossibilidade de atendimento da demanda por falta de equipamento e funcionários especializados).

Finalmente, analisando-se os resultados obtidos na Tabela VII.2, bem como o fato que, durante a sessão 2, o grupo não foi mais capaz de produzir novidades relativas ao trabalho cooperativo em suas discussões, optou-se pelo término das sessões, indicando que o processo de desenvolvimento do software e, também, de análise de requisitos entraram em uma fase de manutenção (ver Figura IV.8 e Figura IV.3).

\section{VII.4 CONCLUSÕES DO CICLO 3 (PASSO DE MONITORAMENTO DA PA)}

Assim como ocorreu no ciclo 2, as questões de pesquisa foram utilizadas para orientar a discussão dos resultados obtidos (ver item III.4.5). 
1. Quais são os instrumentos a serem elaborados para refinar os requisitos de software da dimensão cooperativa do trabalho de um SI durante o uso do sistema informatizado que lhe dará suporte?

Os instrumentos empregados para captar a dimensão cooperativa do trabalho correspondem às técnicas, métodos, conceitos e modelos e são listados a seguir:

- Dimensões do trabalho coletivo (ver item II.1.2);

- Análise coletiva do trabalho (ver item II.2);

- Modelo mental e interação (ver item II.3);

- Prototipação funcional (ver item II.8.3);

- Modelos do sistema (ver item II.7.2);

- Processo de desenvolvimento de software (ver item II.7.2);

- A ergonomia e a concepção informática na simulação e prototipação de sistemas (ver item II.8.3);

- Modelo de desenvolvimento iterativo evolucionário (ver item II.6.3);

- Processo de Engenharia de Requisitos (ver item II.7.2);

- Entrevistas ( ver item II.8.2).

Com relação ao ciclo 2, novos instrumentos foram introduzidos visando ao refinamento da especificação de requisitos do trabalho cooperativo durante o uso do sistema:

- Teoria da mente coletiva (ver item II.4);

- Modelo 3C (ver item II.5.2);

- Elementos de awareness (ver item II.5.5).

2. Como estes instrumentos podem ser concatenados para refinar os requisitos de software do trabalho cooperativo durante o uso do sistema informatizado?

Os elementos acima descritos foram concatenados empregando-se o processo proposto no item IV.6 e aplicado por meio do ciclo da PA descrito neste capítulo.

Assim, pela aplicação do processo estabelecido para este ciclo, foi possível verificar que um sistema informatizado (com as características descritas no item VII.2.3), 
projetado visando a atender aos requisitos do trabalho cooperativo de um SI, deve considerar a mudança das iterações face a face dos usuários em um $\mathrm{SI}$, a fim de que haja um contato intermediado pelo sistema informatizado que apresenta um ambiente menos rico para realizar as iterações necessárias para que os objetivos do trabalho cooperativo sejam alcançados.

Para tratar esta questão, elementos de awareness e do modelo 3C (ver item VII.2.2) foram usados no passo de implementação da iteração 2, com o desenvolvimento de uma série de artefatos (ver Quadro VII.3). Além destes, outros dois artefatos emergentes de awareness surgiram na segunda parte desta sessão:

- Acesso transversal: necessidade colocada pelo grupo para visualizar a fase que estava com outro usuário para dar seguimento às atividades do próprio usuário, ou mesmo, a situação que precisava assumir a fase de outro usuário, para dar andamento ao próprio trabalho e ao do grupo;

- Histórico de fases dos processos: necessidade de um artefato para registrar o responsável pela fase, quem a acessou e para quem foi enviada. A discussão das características que este artefato deveria possuir, trouxe à tona que o mesmo poderia contribuir como ferramenta auxiliar para verificar a fluidez do processo, verificar se houve encerramento intempestivo e aumentar a confiança (subordinação) no sistema.

Outro aspecto importante foi que graças ao fato deste sistema informatizado ter sua coordenação distribuída nas ações dos usuários (coordenação horizontal) e sendo dependente do maior ou menor grau de consciência de como estes interrelacionamentos são feitos, os usuários devem continuamente extrair um senso de mudança de suas próprias inter-relações e recolocarem-nas em ação no sistema de informação, tornando-se importante manter os processos sociais de socialização, conversação e recapitulação (ver item II.4.2).

Para atender a esta questão, dois tutores foram treinados no início do passo de implementação da iteração 3. 


\section{Como avaliar a evolução da identificação dos requisitos de software do}

\section{trabalho cooperativo obtidos neste ciclo pela aplicação da solução proposta?}

Para avaliar qualitativamente a evolução do trabalho cooperativo pelo uso sistema, nas sessões 1 e 2 foi aplicado um questionário com esta finalidade, utilizando os conceitos da teoria da mente coletiva (ver Tabela VII.3 abaixo) (GAVA et al., 2008).

Tabela VII.3 - Avaliação qualitativa do trabalho cooperativo das sessões 1 e 2

\begin{tabular}{|c|c|c|c|c|}
\hline \multirow{2}{*}{$\begin{array}{l}\text { Questões a respeito das ações/comportamento } \\
\text { C: Contribuição, R: Representação S: Subordinação }\end{array}$} & \multicolumn{2}{|c|}{ Sessão1 } & \multicolumn{2}{|c|}{ Sessão 2} \\
\hline & $\begin{array}{l}\text { Números } \\
\text { de Não }\end{array}$ & $\begin{array}{l}\text { Números } \\
\text { de Sim }\end{array}$ & $\begin{array}{l}\text { Números } \\
\text { de Não }\end{array}$ & $\begin{array}{l}\text { Números } \\
\text { de Sim }\end{array}$ \\
\hline Você sabe em qual fase do processo pode atuar? (R) & 3 & 9 & 0 & 12 \\
\hline $\begin{array}{l}\text { Você sabe quais são os dados mais importantes a } \\
\text { serem inseridos? }(C)\end{array}$ & 2 & 10 & 0 & 12 \\
\hline $\begin{array}{l}\text { Estando na fase de sua responsabilidade, sabe quem } \\
\text { deve ser o responsável pela próxima fase? (C) }\end{array}$ & 4 & 8 & 0 & 12 \\
\hline Você sabe de que outras fases depende a sua? (R) & 5 & 7 & 0 & 12 \\
\hline $\begin{array}{l}\text { Quando insiro um dado errado em uma fase de minha } \\
\text { responsabilidade, sei das consequências no processo } \\
\text { deste erro para as fases posteriores? }(\mathrm{R})\end{array}$ & 9 & 3 & 1 & 11 \\
\hline Distingue qual sua posição atual no processo? $(\mathrm{R})$ & 4 & 8 & 0 & 12 \\
\hline $\begin{array}{l}\text { Distingue quem são os responsáveis pelas atividades } \\
\text { que estão sendo desenvolvidas? }(R)\end{array}$ & 7 & 5 & 0 & 12 \\
\hline $\begin{array}{l}\text { Confia que as informações que chegam até você pelo } \\
\text { sistema são as mais atualizadas? (S) }\end{array}$ & 5 & 7 & 5 & 7 \\
\hline $\begin{array}{l}\text { Você utiliza o sistema para trocar informações com } \\
\text { outros usuários, sem necessidade de outros } \\
\text { meios?(S) }\end{array}$ & 7 & 5 & 4 & 8 \\
\hline $\begin{array}{l}\text { Você toma decisões por meio de informações } \\
\text { fornecidas pelo sistema? (S) }\end{array}$ & 7 & 5 & 5 & 7 \\
\hline Você sabe como acompanhar as metas do grupo? (R) & 8 & 4 & 2 & 10 \\
\hline $\begin{array}{l}\text { Você sabe como as ações dos outros usuários estão } \\
\text { relacionadas com as suas? (R) }\end{array}$ & 9 & 3 & 1 & 11 \\
\hline $\begin{array}{l}\text { Você sabe como acompanhar o trabalho de outros } \\
\text { membros do grupo? }(\mathrm{R})\end{array}$ & 8 & 4 & 2 & 10 \\
\hline $\begin{array}{l}\text { Você sabe como recuperar as informações que inseriu } \\
\text { no sistema? (R) }\end{array}$ & 8 & 4 & 2 & 10 \\
\hline $\begin{array}{l}\text { Você sabe como recuperar as informações que outros } \\
\text { membros do grupo inseriram no sistema? (R) }\end{array}$ & 10 & 2 & 2 & 10 \\
\hline $\begin{array}{l}\text { Questões a respeito do processo social } \\
\text { So: Socialização, Co: Conversação Re: } \\
\text { Recapitulação }\end{array}$ & & & & \\
\hline $\begin{array}{l}\text { Existe um programa de treinamento para novos } \\
\text { usuários? (So) }\end{array}$ & 10 & 2 & 0 & 12 \\
\hline $\begin{array}{l}\text { Os usuários trocam experiência regularmente sobre a } \\
\text { utilização do sistema? (Co) }\end{array}$ & 5 & 7 & 2 & 10 \\
\hline $\begin{array}{l}\text { Ocorrem encontros programados para a discussão do } \\
\text { uso e dos resultados do sistema? (Re) }\end{array}$ & 10 & 2 & 1 & 11 \\
\hline Porcentual do total de respostas: & $56 \%$ & $44 \%$ & $13 \%$ & $87 \%$ \\
\hline
\end{tabular}

Fonte: Elaborado pelo autor, baseado em Weik and Roberts (1993)

Houve um aumento da percepção dos usuários sobre o estabelecimento das ações e dos processos sociais, de modo que em função dos resultados qualitativos obtidos 
nas duas sessões, ocorreu uma evolução de 44\% (ver Tabela VII.1) para 87\% do número de respostas positivas.

Esta evolução do número de respostas positivas, fruto da introdução dos novos artefatos de awareness, com o maior grau de consciência dos usuários de como os inter-relacionamentos de suas atividades eram realizados, foram confirmados por meio de um decréscimo nos erros individuais dos usuários e suas respectivas consequências nos resultados do trabalho em grupo (ver item VII.3.3).

\section{O processo proposto no ciclo 2 pode ser aplicado para refinar os requisitos do trabalho cooperativo de um SI neste ciclo?}

A questão foi citada no ciclo 2, conforme discutido na questão 3 desta seção, 0 processo pode ser aplicado, mas deve levar em conta os conceitos de mente coletiva, elementos de awareness e modelo $3 \mathrm{C}$ da engenharia de groupware. Além disso, com o sistema em uso, algumas adaptações devem ser feitas ao processo que foi aplicado no ciclo anterior:

- Na primeira iteração, deve ser realizado o treinamento dos usuários (no lugar da sessão) e na fase de análise e planejamento desta iteração (com o sistema em uso) deve ser realizada uma avaliação por meio de entrevistas com os usuários representativos dos vários perfis da aplicação sobre o uso do sistema, utilizando-se os conceitos de awareness, modelo $3 \mathrm{C}$ e de mente coletiva;

- Durante os passos de implementação e apresentação (sessão) do ciclo 3, os artefatos foram construídos, levando-se em conta os elementos de awareness e a teoria da mente coletiva (com relação às ações) que foram apresentados durante a respectiva sessão desta iteração para avaliação e validação dos usuários;

- O passo de implementação da iteração 3 (e outras iterações que se fizerem necessárias) foi realizado logo após o passo de análise e planejamento da iteração 2 com o objetivo de construir os artefatos emergentes que surgiram durante a sessão 2 e foram colocados em produção, logo após sua construção. Nesse passo, também, foram treinados os tutores responsáveis por manter os processos sociais nos laboratórios 


\section{ANÁLISE FINAL}

Neste capítulo, as conclusões finais deste trabalho são apresentadas, considerando as questões de pesquisa, as premissas e as proposições formuladas, assim como os resultados obtidos. A aplicabilidade, as contribuições e algumas questões para futuros trabalhos são descritas com base no conteúdo desta pesquisa.

\section{VIII.1 CONCLUSÕES}

O objetivo principal deste trabalho apresentado no capítulo I foi:

- Contribuir, por meio de um processo para levantamento de requisitos de software, para o entendimento de como as características do trabalho cooperativo de um SI devem ser consideradas no desenvolvimento de um software que dê suporte a este SI.

Assim como seus objetivos específicos:

- Estudar e propor, com base na literatura, conceitos, técnicas e métodos que devem ser aplicados à Engenharia de Requisitos, levando em conta o trabalho cooperativo em sistemas de informação;

- Planejar, estruturar e executar uma pesquisa-ação voltada para desenvolver, aplicar, avaliar e aperfeiçoar o processo proposto.

Visando a atender ao objetivo principal da pesquisa, assim como a seus objetivos específicos, este trabalho apresentou como propósito definir um processo de requisitos de software orientado ao trabalho cooperativo de um SI. Ao longo da aplicação deste processo, por intermédio da pesquisa-ação, foi possível mostrar os caminhos percorridos para analisar e melhorar o processo, focando o acompanhamento da evolução dos requisitos cooperativos pelas diversas fases de construção do sistema informatizado.

Para discutir as conclusões finais desta tese, convém retornar a questão principal, inicialmente colocada no capítulo I:

- Como considerar, na especificação de requisitos de software, a dimensão cooperativa do trabalho em sistemas de informação? 
Durante a execução dos ciclos 1, 2 e 3, as evidências empíricas relatadas levaram às conclusões parciais desta tese e que podem ser compiladas para responder à questão principal de pesquisa:

- Os artefatos desenvolvidos durante o processo para identificação dos requisitos individuais (ou tradicionais da ER clássica) do trabalho cooperativo foram importantes para iniciar ao processo proposto,

- A escolha e o uso dos artefatos, como o fluxograma do processo e sua hierarquia de subatividades e respectivas interfaces gráficas, com o diagrama de contexto, utilizados como elementos comuns de comunicação contribuíram para a evolução dos requisitos do trabalho cooperativo nos ciclos 2 e 3 ;

- O uso da Análise Coletiva do Trabalho para orientar as iterações do grupo em torno da atividade coletiva atual e a simulação da atividade futura realizada, dos elementos comuns de comunicação, do conceito de modelo mental, dos conceitos da ergonomia de concepção de análise das situações de referência e das ações características futuras prováveis permitiram uma evolução dos artefatos desenvolvidos na prototipação realizada no ciclo 2 para coletar, além dos requisitos do trabalho individual dos usuários, os requisitos do trabalho cooperativo;

- Os requisitos emergentes surgiram em razão do fato de que o processo empregado trouxe à tona aspectos que não seriam facilmente acessíveis sem a interação do grupo e que o processo de compartilhar e comparar ofereceu rara oportunidade de compreensão por parte do pesquisador de como os participantes entendiam suas similaridades e diferenças;

- A aplicação da dinâmica das iterações proposta neste trabalho, também, contribuiu para melhor aproveitamento das sessões realizadas com os usuários, de modo que a aplicação do processo mostrou que, nas sessões realizadas, uma nova ideia gerada por algum dos participantes era imediatamente testada, de forma que todo o grupo emitia opinião a respeito. Com isso, ganhou-se tempo no projeto, atendendo às expectativas dos usuários reais;

- Por intermédio da aplicação do processo estabelecido para o ciclo 3, foi possível verificar que um sistema informatizado (com as características 
descritas no item VII.2.3), projetado visando a atender aos requisitos do trabalho cooperativo de um SI, deve considerar a mudança das iterações face a face dos usuários, para um contato intermediado por esse sistema informatizado;

- Para tratar esta questão, foram utilizados elementos de awareness, do modelo $3 \mathrm{C}$ e da teoria da mente coletiva (ver item VII.2.2), durante o passo de implementação da iteração 2 do ciclo 3;

- Outro aspecto importante foi que em razão do fato do sistema informatizado ter sua coordenação distribuída nas ações dos usuários (coordenação horizontal), sendo dependente do maior ou menor grau da consciência de como estes inter-relacionamentos eram realizados, assim, os usuários deveriam continuamente extrair um senso de mudança de suas próprias interrelações e as recolocarem em ação no sistema de informação, tornado-se importante manter os processos sociais de socialização, conversação e recapitulação (ver item II.4.2). Para atender esta questão foi introduzida a figura do tutor;

- Foi proposta uma forma qualitativa para se avaliar a evolução do trabalho cooperativo realizado por intermédio do sistema informatizado durante o uso do mesmo (ciclo 3), utilizando os conceitos da teoria da mente coletiva;

- O aumento no grau de consciência dos usuários de como os interrelacionamentos de suas atividades foram realizadas por meio da introdução dos tutores e dos artefatos de awareness no ciclo 3, foi confirmado por um decréscimo nos erros individuais dos usuários e de suas respectivas consequências nos resultados do trabalho em grupo.

Estas conclusões parciais levaram às seguintes conclusões gerais:

- A análise de requisitos tradicional produziu os artefatos de entrada do processo proposto;

- No ciclo 2, em razão da simulação do trabalho cooperativo por meio do sistema informatizado, foram refinados os requisitos do trabalho individual e levantados os requisitos mais transacionais do trabalho cooperativo, isto é, 
mais ligados às ações e seus inter-relacionamentos dentro do SI. Os requisitos de awareness foram pouco explorados;

- Contrariamente ao ciclo 2, no ciclo 3 foram refinados com mais intensidade os requisitos do trabalho cooperativo ligado ao awareness do sistema, isto é, os requisitos necessários para compensar a falta de interação face a face dos usuários pela introdução de uma perturbação neste ambiente: o sistema informatizado;

- Os resultados obtidos mostraram que o maior grau de consciência dos usuários de como os inter-relacionamentos de suas atividades eram realizados, contribuiu para um decréscimo em seus erros individuais, diminuindo o retrabalho de recodificação do software e, acima de tudo, o uso inadequado do sistema, evitando a propagação das consequências desses erros nos resultados do trabalho em grupo.

$\mathrm{Na}$ figura abaixo (Figura VIII.1), as conclusões acima descritas são apresentadas graficamente para mostrar como os requisitos variaram durante a execução dos ciclos desta PA.

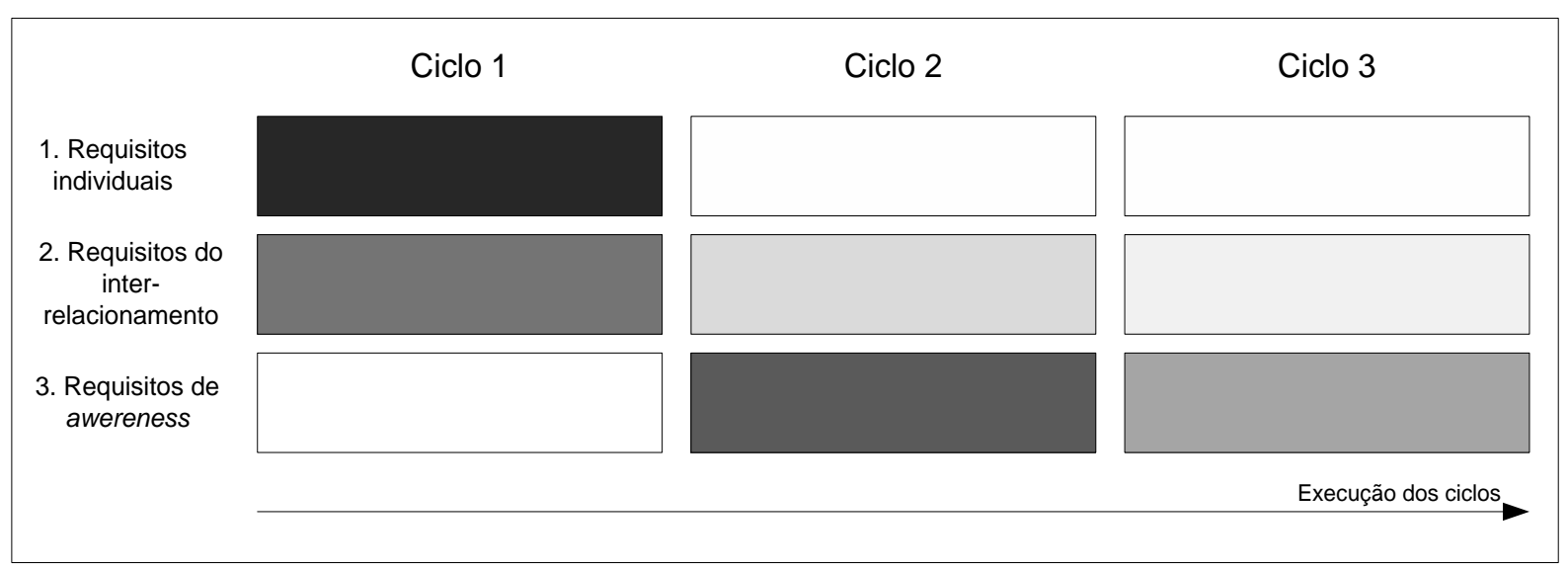

Figura VIII.1 - Variação da intensidade dos tipos de requisitos nos ciclos da PA

\section{VIII.2 PROPOSTA DE ALTERAÇÃO DO PROCESSO}

O ciclo 3 mostra diferenças com relação ao ciclo 2 , sobretudo porque durante a simulação não é levado em conta o ambiente mais restritivo para as iterações entre os usuários, proporcionado pelo sistema informatizado. 
Assim, em função dos resultados obtidos no ciclo 3, o processo para especificação de requisitos de software (identificação e simulação das características do trabalho cooperativo) pode sofrer algumas adaptações no sentido de reduzir o número de iterações do ciclo 3 , melhorar a qualidade das interações com os usuários e diminuir o tempo de projeto:

- Na fase de implementação (ver item IV.5.1) do processo para a identificação e simulação dos requisitos de software do trabalho cooperativo (ciclo 2, ver item IV.5), os artefatos a serem construídos devem considerar também os elementos de awareness, modelo $3 \mathrm{C}$ e da teoria da mente coletiva (com relação às ações), ou seja, considerar também a fase de implementação do processo de refinamento das características do trabalho cooperativo (ver item IV.6.1). Esta alteração deve ser aplicada às iterações do ciclo, quando os usuários passarem a discutir nas sessões os requisitos ligados ao interrelacionamento das ações (Figura VIII.1);

- Os tutores responsáveis por manter os processos sociais podem ser treinados no início do ciclo 3 , durante o treinamento dos usuários e não só na iteração 3 deste ciclo.

Após a aplicação das mudanças sugeridas, espera-se que o ciclo 3 seja necessário apenas para acertos normais em razão do uso que não foi previsto no ciclo 2, mas, sem a necessidade maior de se tratar os artefatos de awareness e dos interrelacionamentos das ações dos usuários (ver Figura VIII.2). Outra melhoria esperada é a diminuição do retrabalho de codificação de software com o sistema em uso, uma vez que menos correções no ciclo 3 serão necessárias.

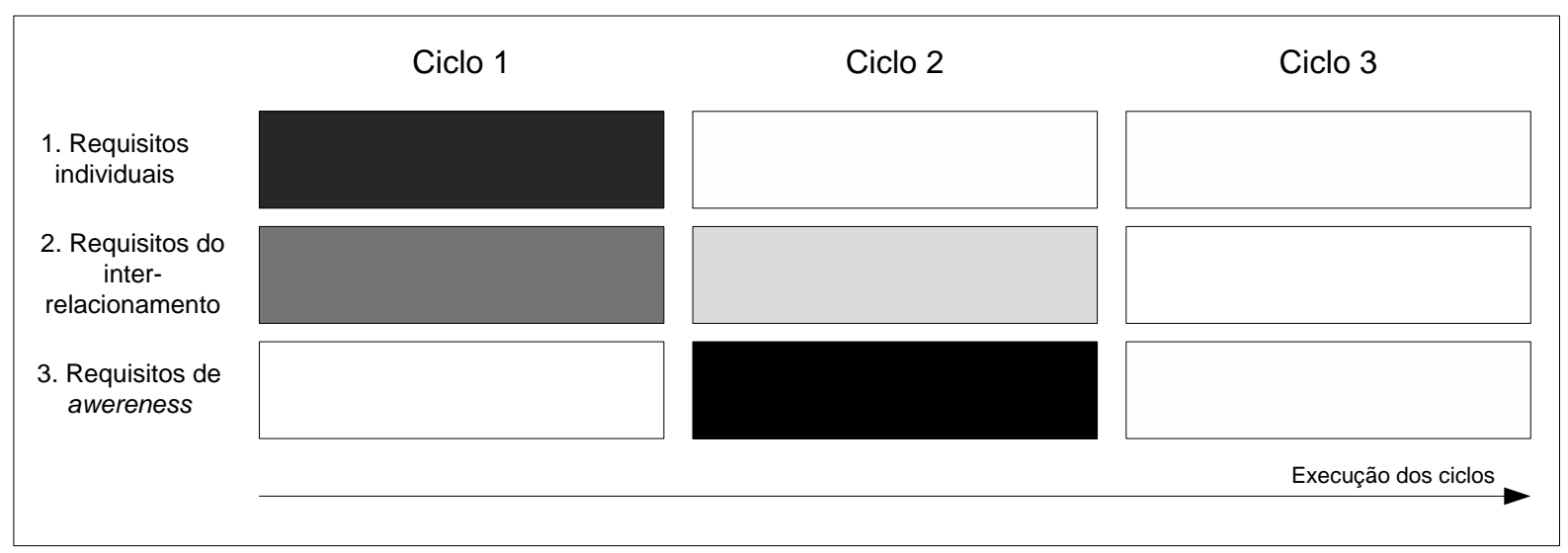

Figura VIII.2 - Variação esperada da intensidade dos tipos de requisitos nos ciclos da PA, após a aplicação das mudanças sugeridas 


\section{VIII.3 CONTRIBUIÇÕES}

A aplicação do processo proposto, por meio da pesquisa-ação apresentada durante a parte prática desta pesquisa, possibilitou a realização das seguintes contribuições:

- Desenvolvimento de um processo para levantamento de requisitos de software com foco no trabalho cooperativo dos sistemas de informação horizontais (coordenação distribuída nas ações dos usuários);

- Proposta de um modelo de software híbrido entre o modelo incremental e a prototipação descartável clássica, com o aproveitamento dos artefatos produzidos na prototipação não funcional, de modo que a fase de implementação do processo só ocorra com os requisitos definidos, contrariamente ao modelo incremental, facilitando a medição do progresso do desenvolvimento e, consequentemente, do gerenciamento do projeto;

- Utilização, em Engenharia de Requisitos, de conhecimentos desenvolvidos em outras áreas, sobretudo pelo uso do método de Análise Coletiva do Trabalho e da concepção informática na simulação e prototipação de sistemas, ambas da ergonomia, do conceito de modelo mental e da teoria da mente coletiva;

- Utilização do modelo $3 \mathrm{C}$ e dos elementos de awareness da engenharia de groupware para tratar de sistemas informatizados tradicionais, nos quais estes conceitos, normalmente, não são considerados (ver itens VII.2.2 e VII.2.3);

- Proposta para avaliar a evolução dos requisitos cooperativos implementados em um software durante a prototipação funcional;

- Proposta para melhorar os processos sociais por meio do treinamento e utilização dos tutores;

- Aplicação do processo proposto, utilizando o método de pesquisa-ação, o que contribuiu para o aperfeiçoamento deste processo.

Estas contribuições permitem considerar, de modo explícito, as características do trabalho cooperativo no desenvolvimento de sistemas informatizados que não são considerados groupware. 


\section{VIII.4 PROPOSTAS PARA FUTUROS TRABALHOS}

Ao longo do desenvolvimento deste estudo, outras oportunidades de pesquisas complementares foram identificadas, mas não fizeram parte de seu escopo:

- Realização da pesquisa científica voltada à experimentação do processo descrito neste trabalho em outras organizações com necessidade de sistemas de informação que satisfaçam as condições de aplicabilidade descritas nos itens IV.3.2 e VII.2.3, o que permitirá um reforço das conclusões deste trabalho, além de avaliar a replicabilidade do mesmo;

- Aplicação das mudanças propostas no item VIII.2 ao processo e realização de pesquisa nos mesmos moldes do item anterior, no sentido de verificar as melhorias esperadas neste processo;

- Realização de pesquisa voltada para verificação da eficiência do processo proposto, já que neste estudo a maior preocupação foi com sua eficácia;

- Realização de novos trabalhos de campo análogos, utilizando outras técnicas de descoberta de requisitos, como por exemplo, a etnografia, além das técnicas empregadas nesta pesquisa;

- Aperfeiçoamento do método proposto neste trabalho (ver itens IV.6.2, VII.3.2 e VII.3.3) para avaliação da evolução do levantamento dos requisitos do trabalho cooperativo ao longo do processo de desenvolvimento de um sistema informatizado.

\section{VIII.5 CONSIDERAÇÕES FINAIS}

Esta pesquisa possui limitações referentes à aplicação e à generalização de seus resultados. No caso da prototipação evolutiva (ver item II.8.3), este processo deve ser aplicado a sistemas informatizados com as seguintes características:

- O sistema deve ser um problema estruturado com uma grande quantidade de elementos de dados e relacionamento entre registros mas, uma pequena quantia de processos algorítmicos (BOAR, 1984); 
- Os usuários devem estar dispostos e capazes a participar ativamente, assim como o gerente do projeto (BOAR, 1984);

- O preparo da equipe envolvida com o uso da metodologia não pode significar risco, assim como a questão da falta espírito da equipe do grupo que estiver participando das sessões (BOAR, 1984);

- O sistema possui muita interação com os usuários por meio de transações com relatórios associados aos bancos de dados, não operando com muito processamento em lote (batch) (BOAR, 1984);

- O Sistema de Informação apresenta coordenação distribuída nas ações dos usuários (coordenação horizontal) e a comunicação entre eles ocorre preponderantemente de modo indireto pelos dados inseridos nos objetos de colaboração durante o uso do software. O software que implementa o SI é assíncrono e desacoplado (ver itens II.5.5 e VII.2.3).

Outro aspecto a ser considerado corresponde ao fato que a PA que deu suporte a este trabalho foi realizada em uma situação onde foi priorizada a eficácia do processo proposto, sendo executada em condições onde o fator tempo, embora influente, não foi fundamental para a sua realização. Assim, foi possível realizar um número ótimo de iterações em cada processo do macro-processo proposto (ver item IV.2).

Em condições mais restritivas de tempo, menos iterações deverão ser realizadas em cada um dos processos propostos, em particular nos processos de simulação e refinamento do trabalho cooperativo (ver itens IV.5 e IV.6 respectivamente). Visando a futura generalização do processo proposto, esta situação poderá ser compensada com uma dinâmica de iterações (ver itens VI.2 e VII.2) mais adequada para uma determinada situação de projeto, além da introdução das mudanças propostas no item VIII.2.

Com relação à Análise Coletiva do Trabalho, a participação dos usuários nas sessões foi facilitada por ser uma aplicação interna à empresa. Visando também a futura generalização, no caso de uma aplicação onde os usuários estejam geograficamente dispersos, uma alternativa poderia ser a participação de usuários com perfis análogos para as sessões, ou mesmo a realização de sessões virtuais. 
A partir das observações acima descritas visando a generalização do processo, além da realização dos futuros trabalhos propostos (item VIII.4), espera-se que os resultados obtidos refinem e melhorem o processo apresentado nesta pesquisa, confirmando também a eficiência do mesmo, permitindo sua generalização e agregação à Engenharia de Requisitos tradicional e tornando explícita a influência do trabalho cooperativo na especificação de software que não seja considerado puramente groupware. 


\section{REFERÊNCIAS}

ASSIS, R. L. Facilitando a percepção em ambientes virtuais de aprendizado através da tecnologia groupware. 2000. 148p. Dissertação (Mestrado) -

Departamento de Informática, Pontifícia Universidade Católica, Rio de Janeiro, 2000.

BAL, J. Process Analysis tools for process improvement. The TQM Magazine, v. 10, n. 5 , p. $342-354,1998$.

BARTHE, B. Elaboration, mise en oeuvre et apport classificatoire d'un cadre d'analyse des aspects collectifs du travail. In: XXXVIIIème Congrès de la SELF. Paris, p. 181-188, 2003.

BASTIEN, C.; SCAPIN, D. A concepção de programas de computador interativos centrada no usuário: etapas e métodos. In: FALZON, P. (Ed.). Ergonomia. São Paulo: Edgard Blücher, 2007.

BOAR, B. H. Application prototyping. 1. ed. New York: John Wiley \& Sons, 1984. $210 \mathrm{p}$.

BECK, K. Extreme Programming Explained: Embrace Change. Addison Wesley, 2004. $181 \mathrm{p}$.

BRINCK, T.; McDANIEL, S. E. Awareness in Collaborative Systems. Conference on Human Factors in Computing Systems, SIGCHI Bulletin, v. 29, n. 4, 1997.

BOEHM, B.W. A Spiral Model of Software Development and Enhancement. IEEE Computer, v. 21, n. 5, p. 61-72, 1988.

$\mathrm{BOOCH}$, G. Object-Oriented Analysis and Design with Applications. 2. ed. California: Benjamin/Cummings Pub. Co., 1994. 578 p.

BRYMAN, A. Research methods and organization studies. London: Unwin Hyman Ltd, 1989. 300p.

BURKHARDT, J. M.; SPERANDIO, J. C. Ergonomia e concepção informática. In: FALZON, P. (Ed.). Ergonomia. São Paulo: Edgard Blücher, 2007. 
CARROL, J. M.; OLSON, J. R. Mental models in human-computer interaction, In: HELANDER, M.; LANDAUER, K. T.; PRABHU, V. P. (Ed.). Handbook of HumanComputer Interaction. 2. ed. Amsterdam: Elsevier Science Pub Co, 1988.

CHEN, P. A abordagem entidade-relacionamento para projeto lógico. São Paulo: Makron Books do Brasil, 1990. 80 p.

CHEESMAN, J.; DANIELS, J. UML Components: A Simple Process for Specifying Component-Based Software. EUA: Addison-Wesley, 2001. 208 p.

COUGHLAN, P.; COGHLAN, D. Action research for operational management. Internacional journal of operation \& Production management, v. 22, n. 2, p. 220240, 2002.

CROWSTON, K.; KAMMERER, E.E. Coordination and Collective Mind in Software Requirements Development. IBM Systems Journal, v. 37, n. 2, 1998.

CRUZ, T. Workflow II: A tecnologia que revolucionou processo. Rio de Janeiro: Epaper, 2004. $212 \mathrm{p}$.

DANIELLOU, F. A ergonomia em busca de seus princípios: debates epistemológicos. 1. ed. São Paulo: Edgard Blücher, 2004. 244 p.

DANIELLOU, F. A ergonomia na condução de projetos de concepção de sistemas de trabalho. In: FALZON, P. (Ed.). Ergonomia. São Paulo: Edgard Blücher, 2007.

DANIELLOU, F.; SIX, F. Les ergonomes, les prescripteurs et les prescritions. In: MARTIN, C.; BARADAT, D. (Ed.). Des pratiques en réflexion - Dix ans de débats sur l'intervention ergonomique. Toulouse: Octarès Editions, 2003.

DAVENPORT, T. H. Process innovation: reengineering work through information technology. Boston: Harvard Business School Press, 1993.

DEJOURS, C. 0 fator humano. 5. ed. Rio de Janeiro: Editora Fundação Getulio Vargas, 2005. $102 \mathrm{p}$.

DEMARCO, T. Análise estruturada e especificação de sistemas. Rio de Janeiro: Editora Campus, 1989. 352 p. 
DE TERSSAC, G.; MAGGI, B. O trabalho e a abordagem ergonômica. In:

DANIELLOU, F. (Ed.), A Ergonomia em busca de seus princípios: debates epistemológicos. São Paulo: Edgard Blücher, 2004.

DOURISH, P.; BELLOTI, V. Awareness and Coordination in Shared Workspaces. In: Proceedings of the ACM conference on Computer-supported cooperative work, Canadá, 1992.

ERCEAU, J.; CHAUDRON, L.; FERBER, J.; BOURON, T. Systèmes personne(s): patrimoines cognitifs et mondes multi-agents, coopération et prises de décision collectives. In: Systèmes coopératifs: de la modélisation á la conception. Toulouse: Octarès Editions, 1994.

ELLIS, C. A.; GIBBS, S. J.; REIN, G. L. Groupware - Some Issues and Experiences. Communications of the ACM, v. 34, no 1, p. 38-58, 1991.

ELLIS, C. A. An Evaluation Framework for Collaborative Systems. Colorado University: Technical Report CU-CS-901-00, February, 2000.

ESTORILIO, C. C. A. O trabalho dos engenheiros em situações de projeto de produto: uma análise de processo baseada na ergonomia. 2003. 301 p. Tese (Doutorado) - Departamento de Produção da Escola Politécnica, Universidade de São Paulo, São Paulo, 2003.

FALZON, P. Natureza, objetivos e conhecimentos da ergonomia. In: FALZON, P. (Ed.). Ergonomia. São Paulo: Edgard Blücher, 2007.

FERREIRA, L. L. Análise coletiva do trabalho. Revista brasileira de saúde ocupacional. São Paulo, v.21, n.78, p.7-19, abril/maio/junho. 1993.

FERREIRA, L. L. Análise coletiva do trabalho: com a palavra, os trabalhadores.In: DUARTE, F.; FEITOSA (Org.). Linguagem \& Trabalho. Rio de Janeiro: COPPE/UFRJ/Lucerna, 1998. p.82-92.

FERREIRA, L. L. Diferenças e semelhanças entre a análise ergonômica do trabalho e a análise coletiva do trabalho. In: IX Congresso Brasileiro de Ergonomia ABERGO, 1999, Salvador, BA. Anais da Associação Brasileira de Ergonomia, ABERGO: Salvador, 1999. 
FUKS, H.; ASSIS, R. L. Facilitating Perception on Virtual Learningware based Environments. The Journal of Systems and Information Technology, v.5, n.1, 2001.

FUKS, H.; RAPOSO, A. B.; GEROSA, M. A.; PIMENTEL, M.; FILIPPO, D.;LUCENA, C. J. P. Inter- e Intra-relações entre Comunicação, Coordenação e Cooperação. Anais do IV Simpósio Brasileiro de Sistemas Colaborativos - SBC: Rio de Janeiro - RJ, 2007.

FUKS, H.; RAPOSO, A. B.; GEROSA, M.A. \& LUCENA, C. J. P. Applying the 3C Model to Groupware Development. International Journal of Cooperative Information Systems (IJCIS), v.14, n.2-3, Jun-Sep 2005.

GAVA, L. V.; ALMEIDA, P. A.; SPINOLA, M. Proposta de processo de especificação de software a partir de técnicas baseadas em suas funcionalidades sob a óptica de seus usuários finais. In: XXIV ENEGEP - Encontro Nacional de Engenharia de Produção, 2004, Florianópolis. Anais do XXIV ENEGEP, 2004.

GAVA, L. V.; GONÇALVES, R. F.; SPINOLA, M. The use of Ergonomics techniques and JAD for the collective work definition in information Systems. In: $4^{\circ}$ CONTECSICongresso Internacional de Gestão de Tecnologia e Sistemas de Informação, 2007, São Paulo. Anais do 4ํㅡㄴ CONTECSI, São Paulo : FEA/USP, 2007. v. CD-ROM.

GAVA, L. V.; GONÇALVES, R. F.; SPINOLA, M. Cooperative Work Definition in Information Systems Development. In: SZNELWAR, L. I.; MASCIA, F. L.; MONTEDO, U. B. (Ed.). In: Human Factors in Organizational Design and Management - IX. São Paulo: Edgard Blücher, 2008.

GEROSA, M. A. Desenvolvimento de Groupware Componentizado com Base no Modelo 3C de Colaboração. 2006. 275 p. Tese (Doutorado) - Departamento de Informática, Pontifícia Universidade Católica, Rio de Janeiro, 2006.

GEROSA, M. A.; FUKS, H.; LUCENA, C. J. P. Elementos de percepção como forma de facilitar a colaboração em cursos via Internet. XII Simpósio Brasileiro de Informática na Educação - SBIE 2001, Vitória, Espírito Santo. 2001.

GEROSA, M. A.; FUKS, H.; LUCENA, C. J. P. Suporte à Percepção em Ambientes de Aprendizagem Colaborativa. Revista Brasileira de Informática na Educação, v. 11, n. 2, Nov. 2003. 
GONÇALVES, R. F.; GAVA, V. L.; PESSÔA, M. S. P.; SPINOLA, M. M. Uma proposta de processo de produção de aplicações Web. Revista Produção, v. 15, n. 3, Set./Dez. 2005.

GONÇALVES, R. F.; GAVA, L. V.; FERREIRA, R. C.; PESSÔA, M. S. P. Ergonomic challenges in system information implantation for building design support: a Brazilian experience. In: SZNELWAR, L. I.; MASCIA, F. L.; MONTEDO, U. B. (Ed.). In: Human Factors in Organizational Design and Management - IX. São Paulo: Edgard Blücher, 2008.

GOGUEN, J.; C. LINDE. Software Requirements Analysis and Specification in Europe: An Overview. First International Symposium on Requirements Engineering, IEEE Computer Society Press, p. 152-164, 1993.

GORDEN, V.S.; BIEMAN, J. M. Rapid prototyping: lessons learned. Software, IEEE. v. 12, n. 1, p. 85-95. 1995.

GROSS, T.; TRAUNMULLER, R. Methodological Considerations on the Design of Computer Supported Cooperative Work. Cybernetics and Systems: An International Journal, v. 27, n. 3, p. 279-303, 1996.

GUÉRIN, F.; LAVILLE A.; DANIELLOU, F.; DURAFFOURG J.; KERGUELEN A. Compreender o trabalho para transformá-lo: a prática da ergonomia. São Paulo: Edgard Blücher, 2001.

GUMMESSON, E. Qualitative Methods in Management Research. 2. ed. Thousand Oaks: Sage Publications, 2000.

HANNA, M. Farewell to Waterfalls. Software Magazine, p. 38-46, Maio. 1995.

HARRINGTON, J. Aperfeiçoando Processos Empresariais. São Paulo: Makron Books, 1993.

HIX, D,; HARTSON, H. R. Developing user interfaces: ensuring usability through product and process. New York: John Wiley \& Sons, 1993.

IDEF. Integrated Definition Methods. Disponível em: < http://www.idef.com/>. Acesso em: 02 ago 2008.

JACKSON, M. Software Requirements and Specifications: A Lexicon of Practice, Principles and Prejudices. USA: Addison-Wesley, 1995. 228 p. 
JACOBSON, I.; CHRISTERSON, M; JONSSON, P.; GUNNAR, O. Object-Oriented Software Engineering: A Use Case Driven Approach. USA: Addison-Wesley, 1992.

KOCH, M.; GROSS, T. Computer-Supported Cooperative Work - Concepts and Trends. Proc. 11th Conf. of the Association Information and Management (AIM), Luxembourg, 2006.

KOTONYA, G.; SOMMERVILLE, I. Requirements Engineering (Processes and Techniques). 1. ed. England: John Wiley \& Sons Ltd, 1998.

KRUCHTEN, P.; KROLL, P. The Rational Unified Process and Introduction. USA: Addison-Wesley, 2003.

LEFFINGWELL, D.; WIDRIG, D. Managing Software Requirements. A Use Case Approach. 2. Ed. Boston: Addison-Wesley, 2003.

LEITE, J. C. S. P. Como Registrar Requisitos de Software, livro da Qualidade 2002. Disponível em < http://www-di.inf.puc-rio.br/ julio/Livro-qualidade-2002.pdf >. Acesso em: 02 fev 2007.

MAGGI, B. Do agir organizacional - um ponto de vista sobre o trabalho, o bemestar, a aprendizagem. São Paulo: Edgard Blücher, 2005.

MARTIN, D.; SOMMERVILLE, I. Patterns of Cooperative Interaction: Linking Ethnomethodology and Design. ACM Transactions on Computer-Human Interaction, p. 59-89. 2004.

MARCONI, M. A.; LAKATOS, E. V. Metodologia científica. 3. ed. São Paulo: Atlas, 2000.

MILLS, H.D., O'NEILL, D. et al. The management of software engineering. IBM Systems Journal, v. 24, n. 2, p. 414-477. 1980.

MIGUEL, P.A.C. Estruturação do desenvolvimento de produtos e implantação de um método de suporte: intervenção através da pesquisa-ação. 2005. 138 p. Tese (Livre Docência) - Departamento de Produção da Escola Politécnica, Universidade de São Paulo, São Paulo, 2005.

MORGAN, D. L. Focus groups as qualitative research. London: Sage University Paper, 1997. v. 16. 
MORIN, E. Ciência com consciência. 6. ed. Rio de Janeiro: Bertrand Brasil, 2002.

NAKANO, D. N.; Fleury, A. C. C. Métodos de Pesquisa na Engenharia de Produção. IN: XVI ENEGEP - Encontro Nacional de Engenharia de Produção, 1996, Piracicaba. Anais do XVI ENEGEP, 1996.

NORMAN, D. A. Cognitive engineering. In: NORMAN, D. A.; DRAPER, S. W (Ed.). User centered systems design new perspectives on Human-Computer Interaction. New Jersey: Laurence Erlbaum, 1986.

NORMAN, D. A. O design do dia-a-dia. Rio de Janeiro: Editora Rocco, 2002.

NUSEIBEH, B.; FINKELSTEIN A.; KRAMER, J. ViewPoints: meaningful relationships are difficult. International Conference on Software Engineering, Portland, Oregon, 2003.

PAULK, M. C.; WEBER, C. V.; CURTIS, B. The Capability Maturity Model:

Guidelines for Improving the Software Process. USA: SEl, Addison-Wesley Longman Inc., 1994. $456 \mathrm{p}$.

Programa informatizado de gerenciamento laboratorial: PesqTec. [S.I.:s.n.]. 2005.

PIAGET, J. A construção do real na criança. São Paulo: Ática, 1996.

PINHEIRO, M. K.; LIMA, J. V.; BORGWE, M. R. S. Awareness em Sistemas de Groupware. In: IV Jornadas Iberoamericano de Ingeniería de Requisitos y Ambientes de Software, 2001, Santo Domingo, Costa Rica. Proceedings of IV Jornadas Iberoamericano de Ingeniería de Requisitos y Ambientes de Software (IDEAS 2001), 2001.

PFLEEGER, S. L.; ATLEE, J.M. Software Engineering - Theory and Practice. USA: Prentice Hall, 2006.

PRESSMAN, R.S. Software Engineering: A Practitioner's Approach. 6. ed. New York: McGraw-Hill, 2005. 880 p.

RETTIG, M. Prototyping for tiny fingers. Communications of the ACM, Vol. 37, No. 4, p. 21-27. 1994. 
ROYCE, W.W. Managing the development of large software systems: concepts and techniques. Proceedings of the 9th international conference on Software Engineering, Monterey, California, p. 328 - 338, 1987.

RUMBAUGH, J.; BLAHA, M.; PREMERLANI, W.; EDDY, F.; LORENSEN, W. Object-Oriented Modelling and Design. USA: Prentice-Hall, 1991.

RYAN, K. Requirements Engineering - getting value for money. In: XII Simpósio Brasileiro de Engenharia de Software (SBES), 1998, Maringá. Anais do XII SBES, 1999.

SCAPIN, D.L. Guide ergonomique de conception des interfaces HommeMachine. Inria-00070083, v. 1, 1986. Disponível em < http://hal.inria.fr/view_by_stamp.php?label=INRIARRRT\&langue $=$ fr\&action_todo=view\&id=inria-00070083\&version=1 $>$. Acesso em 10 dez. 2008.

SILVA, L. A. Qualidade em sistemas automatizados de informação: a ergonomia na criação da dimensão usabilidade. 1997. 239 p. Dissertação (Mestrado) -

Departamento de Produção da Escola Politécnica, Universidade de São Paulo, São Paulo, 1997.

SABETZADEH, M.; FINKELSTEIN, A.; GOEDICKE, M. Viewpoints. In: LAPLANTE, P. (Ed.). In: Encyclopedia of Software Engineering. New York: Taylor and Francis, 2010.

SALERNO, M. S. Projeto de organizações integradas e flexíveis: processos, grupos e gestão democrática via espaços de comunicação-negociação. São Paulo: Atlas, 1999.

SNYDER, C. Paper Prototyping. San Francisco: Elsevier Science, 2003. 378 p.

SOMMERVILLE, I. Software Engineering. 8. ed. Edinburgh: Pearson Education Limited, 2007.

SOMMERVILLE, I.; SAWYER, P.; VILLER, S. Viewpoint for Requirements Elicitation: a practical approach. ICRE'98 Third International Conference on Requirements Engineering, ed. 1. USA : IEEE CSP, Los Alamitos, CA. Proceedings, p 74-81, 1998. 
SOUZA, G. M.; CASTRO, J. F. B. Improving the Separation of Non-Functional Concerns in Requirements Artifacts. 12th IEEE International Requirements Engineering Conference, Japan, 2004.

TAVARES, J. C. Análise do trabalho em grupos semi-autônomos por uma terceira via: investigação da cooperação com vistas na autonomia. 2002. 190 p. Tese (Doutorado) - Departamento de Produção da Escola Politécnica, Universidade de São Paulo, São Paulo, 2002.

THIOLLENT, M. Metodologia da pesquisa-ação. 13. ed. São Paulo: Cortez, 2004.

TRINDADE, A. L. P. Uma contribuição para o entendimento do papel da ensinagem na preservação do conhecimento em ambientes de Fábrica de Software. 2006. 295 p. Tese (Doutorado) - Departamento de Produção da Escola Politécnica, Universidade de São Paulo, São Paulo, 2006.

TUROFF, M.; HILTZZ, S. R. Computer Support for Group versus Individual Decisions. IEEE Transactions on Communications, v. 30, n. 1, p. 82-91, 1982.

UML. Unified Modelling Language. Disponível em: <http://www.uml.org/.>. Acesso em: 14 ago. 2008.

VILLER, M.; SOMMERVILLE, I. Ethnographically informed analysis for software engineers. International Journal of Human-Computer Studies, v. 53, p. 169-196. 2000.

YIN, R. K. Estudo de Caso - Planejamento e Métodos. Porto Alegre: Bookman, 2003.

YOURDON, E. Analise estruturada moderna. Rio de Janeiro: Ed Campus, 1992.

WARD, P. T.; MELLOR, S. J. Structured development for real-time systems. New York; London: Yourdon, 1985.

WEICK, K. E.; ROBERTS K.H. Collective Mind in Organizations: Heedful Interrelating on Flight Decks. Administrative Science Quarterly, v. 38, 1993.

WfMC. Workflow Management Coalition. Disponível em: <http://www.wfmc.org/>. Acesso em: 15 de ago 2008. 
WITTORSKI, R. Analyse du travail et production de compétences collectives.

Paris : L'Harmattan, 1997. 


\section{APÊNDICE A: PROCESSOS, MODELAGEM E WORKFLOW}

Este apêndice trata de modo resumido sobre o que é um workflow, processo de negócio e modelagem de processos, mostrando o relacionamento entre estes conceitos dentro de uma organização.

\section{Processos de negócio}

Segundo a WfMC (Workflow Management Coalition), um processo é um conjunto coordenado de atividades (sequenciais ou paralelas) que são interligadas com o objetivo de alcançar um meta comum, sendo a atividade conceituada como uma descrição de um fragmento de trabalho que contribui para o cumprimento de um processo (WfMC, 2008).

A Figura 1 do apêndice A mostra, de forma esquemática, um processo e sua divisão em fases e todos os elementos que o compõem com a finalidade de melhorar o entendimento e o controle sobre o projeto de análise e modelagem de processos de negócio (CRUZ, 2004).

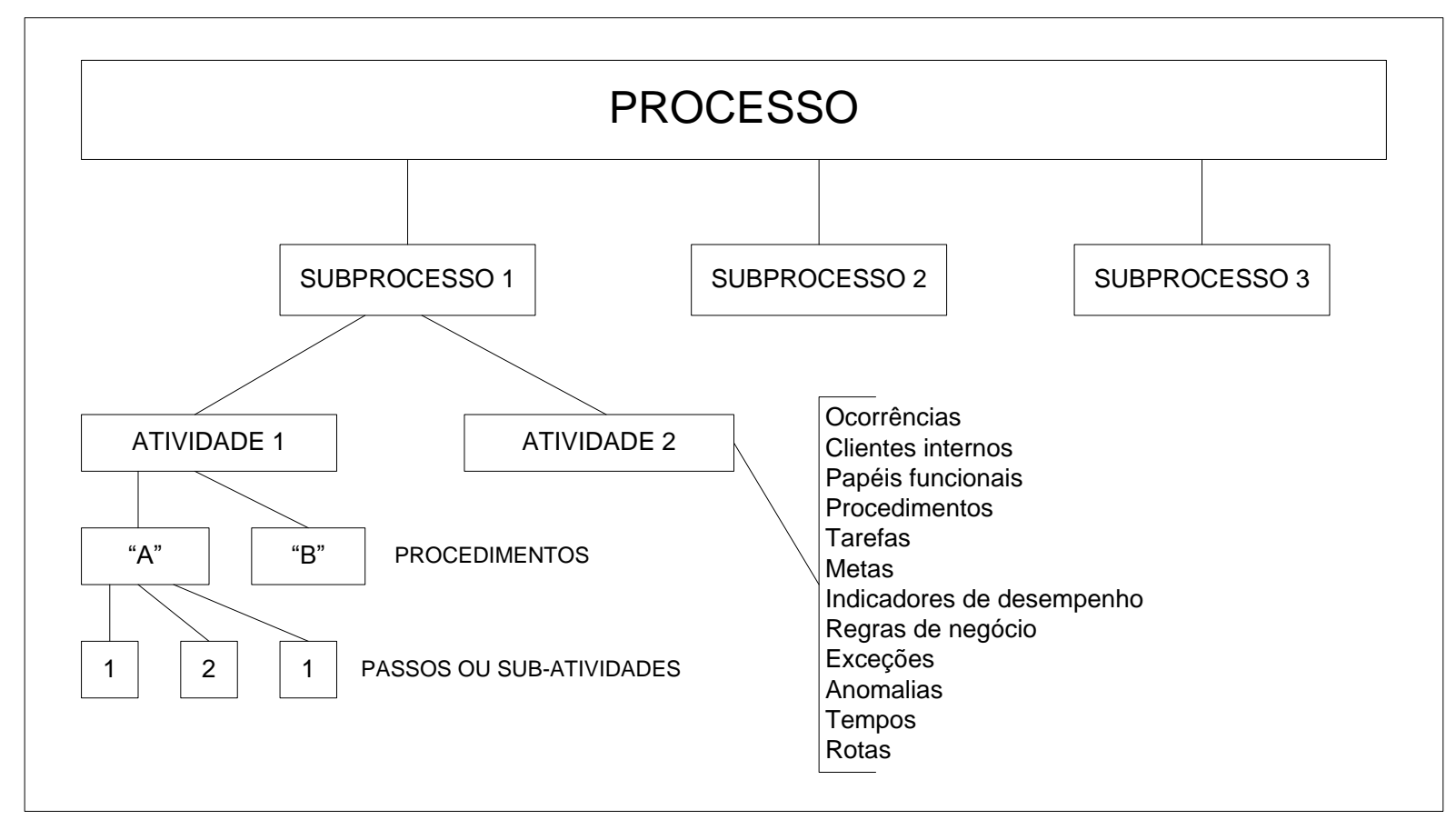

Figura 1 do apêndice A - Processo, divisões e elementos Fonte: baseado em CRUZ (2004) 


\section{Subprocesso}

É um conjunto de atividades correlacionadas que executa uma parte específica do processo, do qual recebe insumos e para o qual envia o produto do trabalho realizado por todas as atividades que o compõem.

\section{Atividade}

É o conjunto de procedimentos que deve ser executado com o objetivo de produzir um determinado resultado.

As atividades podem ser classificadas em:

- Primárias: são as que têm participação direta na criação do bem ou serviço, que é objeto do processo;

- Secundárias: são aquelas que não estão diretamente envolvidas com a produção do bem ou serviço que a organização é responsável. Este tipo de atividade existe para permitir que as atividades principais sejam executadas;

- Transversais: é o conjunto de várias especialidades, executadas em uma única operação com a finalidade de resolver problemas. As atividades transversais compõem processos de negócios transversais.

\section{Procedimento}

Trata-se do conjunto de informações para indicar ao responsável por uma atividade como, quando e com quem um evento deve ser executado. Toda atividade contém, pelo menos, um evento. Evento é um acontecimento e por meio de sua realização torna-se possível que cada atividade produza sua parte do produto, dentro do processo.

Para a tecnologia workflow (ver item 3 deste apêndice), o que de fato é importante é o controle dos eventos, de modo que durante a definição de um processo a ser implementado por um workflow, o mesmo é realizado passo a passo, definindo-se cada evento. 
Assim, alguns aspectos são importantes na definição de um procedimento: o que dá início à atividade, de que forma ela deve ser executada e com quais ferramentas devem ser executadas.

Para executar um evento, há o procedimento que, por sua vez, é dividido em passos.

\section{Passo}

É a menor parte realizável de um procedimento para reduzir um evento em atividade. O passo é a decomposição de um procedimento, e o conjunto de passos ou subatividades compõe os procedimentos inerentes a cada um dos eventos existentes em cada atividade.

Esta decomposição, além de permitir a execução do evento, também ajuda a racionalizar a atividade.

\section{Modelagem de Processos de Negócios}

Trata-se de uma atividade corporativa que produz modelos de recursos, de fluxos de informação e das operações dos negócios que ocorrem na empresa.

Um dos principais objetivos buscados na construção da especificação de uma organização é melhor entendê-la, procurando identificar problemas e buscar soluções que melhorem o desempenho organizacional, tal como aumentar a velocidade das atividades, reduzir custos e melhorar a qualidade dos serviços.

Os métodos de modelagem a serem utilizados para representar os processos organizacionais precisam relacionar a estrutura das informações e dos processos com os negócios e objetivos organizacionais.

Harrington (1993) define fluxograma, diagramação lógica ou fluxo como um método para descrever graficamente um processo existente ou um novo processo proposto, usando símbolos simples, linhas e palavras, de forma a apresentar graficamente as atividades e a seqüência no processo. Segundo o autor, bons fluxogramas destacam as áreas onde procedimentos confusos afetam a qualidade e a produtividade, além de facilitar as comunicações entre as áreas problemáticas, em função da capacidade de esclarecer processos complexos. 
Durante o mapeamento do processo, observa-se aumento da compreensão do problema, e as respostas às perguntas tornam-se mais aparentes, o que possibilita a correta modelagem desses processos.

Um processo pode ser modelado sob várias perspectivas:

- Visão funcional: representa as atividades a serem executadas;

- Visão comportamental: relaciona como e quando as atividades são conduzidos;

- Visão organizacional: representa quem está conduzindo as atividades;

- Visão informacional: preocupa-se com os detalhes relativos às informações tratadas na realização das atividades, considerando-se tanto as informações criadas e trocadas como suas relações de dependência.

Um dos métodos de representação bem conhecidos e empregados é ao IDEF (Integrated Definition for Function Modelling), considerando-se a simplicidade e contribuição para fornecer os vários tipos de prospectivas. Este método foi desenvolvido na década de 80 pela Força Aérea Americana, concebido inicialmente para suportar três tipos de representações, posteriormente foi implementado com mais um tipo (IDEF, 2008):

- IDEFo: modela o aspecto funcional do processo;

- IDEF 1 : modela a cadeia de informações circulantes;

- $\mathrm{IDEF}_{2}$ : modela dinâmica do processo;

- IDEF 3 : criado para implementar o IDEF, sendo utilizado para modelar o fluxo de desenvolvimento das atividades e pode ser considerado logicamente equivalente a um fluxograma.

O IDEF 0 baseia-se em um diagrama conhecido como "ativigrama", composto por caixas que representam as atividades (Figura 2 do apêndice A). Estas caixas são ligadas por linhas e dispostas de forma que a ordem de condução das atividades seja explicitada, da esquerda para a direita. As linhas da esquerda indicam as entradas para a execução da atividade ou fase, e as setas que saem pela direita das caixas, as saídas. As setas que entram por cima das caixas, mostram as restrições para execução das atividades e as setas que entram por baixo, representam os mecanismos/recursos. 


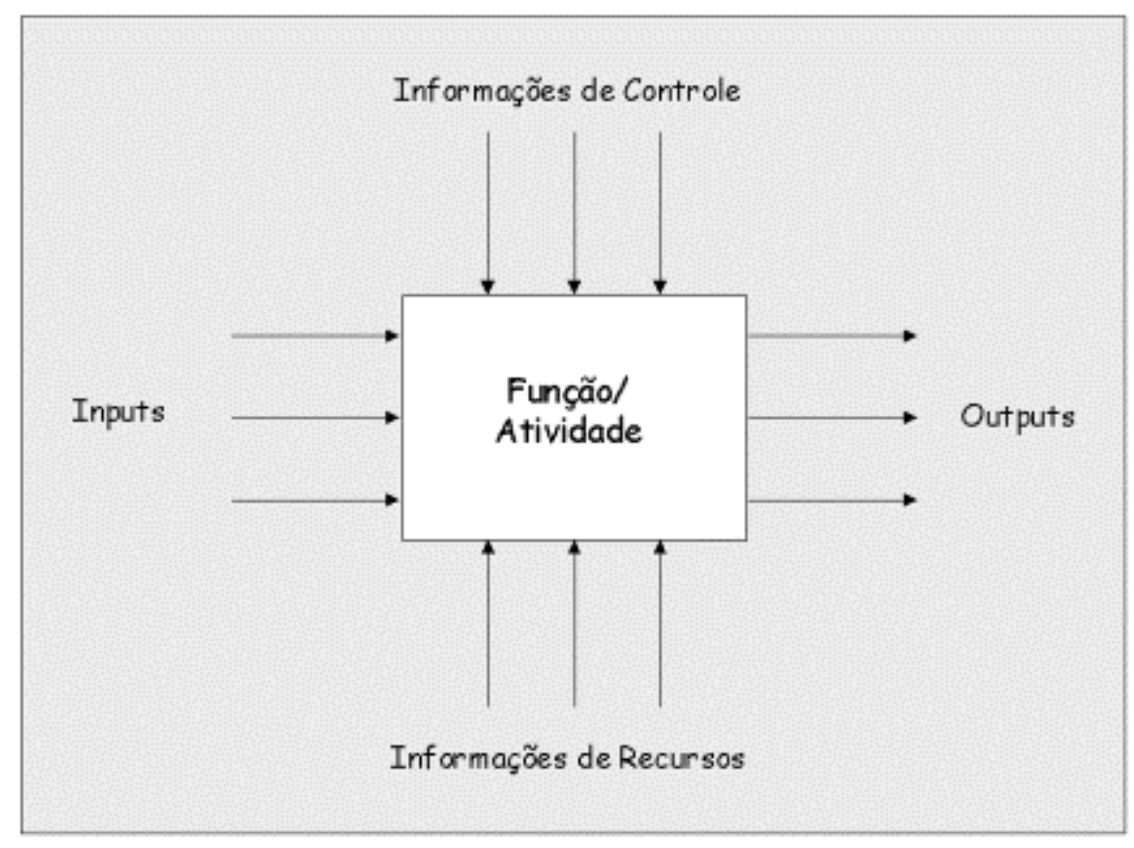

Figura 2 do apêndice A - Ativigrama do IDEF $_{0}$ Fonte: IDEF (2008)

Esta representação é adequada para a representação estática de processos. Por meio do $\mathrm{IDEF}_{0}$ o fluxo de informações existentes entre funções é mapeado, possibilitando uma visão gradativamente detalhada do processo. Este detalhamento é feito para cada função ou atividade, por intermédio da estrutura hierárquica das funções.

O IDEF $\mathrm{IDE}_{0}$ desconsidera os inúmeros caminhos e as variáveis existentes nos processos, não dando clareza a respeito do comportamento dinâmico do sistema, nem apresentando a dinâmica dos fluxos, somente mostrando as dependências entre as atividades. Segundo Bal (1998), o fluxograma e o IDEF 3 suportam, além do aspecto funcional, a visão informacional, mostrando as relações de dependência entre as atividades.

Estes métodos, também, podem ser adaptados para representar o aspecto comportamental e organizacional do processo, de modo que as quatro visões do processo podem ser atendidas (atividades executadas, como e quando são conduzidas, quem as conduz e quais são as informações tratadas durante a realização das atividades, incluindo suas relações de dependência). 


\section{Workflow}

Workflow é definido pela WfMC como a automação total ou parcial de um processo de negócio, durante a qual documentos, informações e atividades são passadas entre os participantes do processo, conforme as regras definidas (WfMC, 2008).

No modelo workflow, é focado o processo, pois este é o meio pelo qual a informação será processada e dentro do qual, logicamente, irá viajar. Em workflow, as regras associados aos subprocessos orientam a execução de cada atividade, permitindo um nível de detalhamento que é difícil encontrar em outros modelos, tornando o processo ativo, isto é, cada usuário será solicitado a executar sua atividade, ao invés de permitir que cada um faça o que deve ser feito apenas na hora que lhe for mais conveniente.

Os tipos de workflow podem ser caracterizados de três formas distintas, de modo que a combinação entre este tipos de workflow e modelos de processos fazem com que a implantação desta tecnologia seja flexível e praticamente abranja a maior parte das necessidades de automação dos fluxos de trabalho. (CRUZ, 2004):

\section{Ad Hoc}

Este tipo de workflow descreve processos simples em que é difícil encontrar um esquema para a coordenação e cooperação de atividades, nem há um padrão fixo para o fluxo de informações entre as pessoas envolvidas.

Este tipo de workflow é criado dinamicamente por um grupo de trabalho, cujos participantes necessitem executar procedimentos individualizados para cada documento processado dentro do processo de negócio. Geralmente, utiliza-se do email como plataforma.

Alguns exemplos: processos de escritório, documentação de produtos e propostas de vendas.

\section{Transação/Produção}

Um workflow de produção é predefinido e priorizado, suportando assim um grande volume - não existem negociações sobre quem fará o trabalho ou como ele será tratado. Ele pode ser completamente predefinido ou seguir um procedimento geral, 
com alguns passos adicionais incluídos quando forem necessários (embora alguns autores não concordem com a idéia).

Os dados tratados por este tipo de workflow têm duas origens, sendo uma delas fora do fluxo. Estes dados dão início ao fluxo, como por exemplo, a solicitação de um pedido de um cliente. A origem interna está ligada ao banco de dados que suporta as aplicações ligadas ao sistema, por exemplo, uma consulta sobre a situação do andamento do atendimento a um determinado cliente.

Alguns exemplos: processamento de requisição de seguros, processamento de faturas bancárias e de cartão de crédito e acompanhamento de realizações de serviços aos clientes.

\section{Administrativo}

Este terceiro tipo é um meio-termo entre um workflow "Ad hoc" e um de transação. Envolve atividades fracamente estruturadas, repetitivas, previsíveis e com regras não muito complexas de coordenação de atividades.

Exemplos: processamento de ordens de compras, procedimentos de aprovação de despesas e autorização de férias e viagens. 


\section{APÊNDICE B: ERGONOMIA DAS INTERFACES (USABILIDADE)}

Scapin (1986) descreveu um conjunto de critérios para analisar/projetar a relação homem-sistema, consistentes com os estilos de interação. Este modelo pode ser considerado como um guia aos projetistas para orientar a construção de formas mais naturais e intuitivas de interação homem-computador, por meio da melhor adequação às necessidades dos usuários, melhorias da eficácia de utilização e de aprendizado.

É importante lembrar que a aplicação destes critérios é subjetiva e necessita de validação frente aos usuários. Abaixo estão listados, de modo resumido, estes critérios:

\section{Orientação}

São os meios disponíveis para recomendar, orientar, instruir e guiar o usuário por intermédio da interação, permitindo a qualquer tempo saber onde se está em uma sequência de ações, quais ações possíveis, suas consequências, inclusive, com a obtenção de informações adicionais, sendo subdividos em:

- Prompting (ação que sugere ou indica ao usuário uma ação): meios empregados para levar o usuário a ações específicas e ajudá-lo a conhecer alternativas existentes e informações sobre o estado do sistema, ajudas e como obtê-las;

- Agrupamento/distinção: refere-se à organização visual dos elementos de informação do diálogo, considerando as informações de localização, formato, cor e outras características que podem indicar a relação entre diversos elementos;

- Feedback imediato: fornecer um resultado observável, rápido e claro a toda ação do usuário ou do sistema. Esta característica estabelece a confiança e a satisfação do usuário, reduzindo a possibilidade de distração (evita que o usuário tome alguma ação que venha a prejudicar o processo em execução);

- Legibilidade: facilitar a leitura das informações, levando-se em conta as características perceptivas dos usuários. Refere-se às características lexicais 
de reapresentação das informações (dimensão das letras, espaçamento entre assuntos, espaçamento entre linhas, espaçamento entre parágrafos, etc.).

\section{Carga de trabalho}

Este critério é relativo a todos os elementos de interface que afetam a carga perceptiva ou cognitiva do usuário e a melhoria da efetividade do diálogo, subdividido em:

- Brevidade: garantir que as unidades elementares registradas ou memorizadas (derivadas da quantidade de ações, leituras exigidas, digitação de dados e do número de passos para se atingir um determinado objetivo) sejam as mais reduzidas possíveis, dividindo-as em:

- Concisão: assegurar que as entradas e saídas sejam as mais curtas possíveis.

- Ações mínimas: minimizar o número de ações necessárias para atingir um objetivo ou executar uma tarefa, limitando os passos e procedimentos ao mínimo possível.

- Densidade de informação: minimizar o número de elementos em uso, visando a todo conjunto de informações apresentadas aos usuários e não a cada elemento separadamente, de modo que itens não relacionados às tarefas devem ser removidos.

\section{Controle explícito}

O critério refere-se ao processamento pelo sistema das ações explícitas dos usuários e pelo controle que o mesmo possui sobre o processamento de suas ações pelo sistema, subdividindo-se em:

- Ações explícitas do usuário: o sistema deve executar apenas as ações requeridas pelo usuário e quando forem requeridas;

- Controle do usuário: a pluralidade de ações do usuário deverá ser antecipada, permitindo cancelar, interromper, suspender e continuar e desfazer o processamento de uma ação qualquer. Todas as possíveis ações dos usuários devem ser previstas e opções adequadas devem ser oferecidas. 


\section{Adaptabilidade}

Permite assegurar que o projeto do sistema seja capaz de reagir às necessidades do contexto, de acordo com as necessidades e preferências do usuário, de modo que quanto maiores forem as chances do usuário encontrar uma ação que se adapte às suas preferências melhor será o aprendizado. Este critério subdivide-se em:

- Flexibilidade: refere-se aos meios disponíveis ao usuário para personalizar partes da interface, a fim de permitir variações da tarefa e de estratégias ou hábitos de trabalho;

- Experiência do usuário: oferecer os meios para considerar a experiência do usuário; para iniciantes é desejável maior nível de orientação e iniciativa do sistema, e aos mais experientes, é desejável a existência de atalhos.

\section{Gestão de erros}

Permitir que o usuário evite ou reduza erros, além de permitir que sejam corrigidos no momento em que aparecem:

- Proteção contra erros: fornecer condições aos usuários para detectar e prevenir erros na introdução de dados ou ações que poderão causar consequências destrutivas à tarefa;

- Qualidade das mensagens de erros: garantir a pertinência e a exatidão da informação oferecida ao usuário sobre a natureza dos erros (sintaxe, formato, etc.) e ações necessárias à correção;

- Correção de erros: disponibilizar ao usuário os meios para correção de seus erros.

\section{Consistência}

Procurar garantir que as características da interface (códigos, procedimentos, denominações, posições, etc.), sejam conservadas em contextos idênticos; aplica-se também ao formato da sintaxe utilizada.

Títulos, ícones, links e outros objetos da interface são melhores reconhecidos, lembrados, localizados e utilizados se o formato, localização, sintaxe e comportamento forem estáveis de tela para tela. Deste modo, o comportamento do 
sistema será mais previsível, o aprendizado e a generalização serão facilitados e o número de erros reduzido.

Interfaces consistentes formam um melhor modelo mental do sistema, implicando maior influência no desempenho a seus usuários.

A falta de consistência pode ser um dos motivos de rejeição do sistema, pois pode aumentar consideravelmente o tempo de pesquisa e a quantidade de ações.

\section{Significação dos códigos}

Permite assegurar a identificação entre objetos ou informações fornecidas pelo sistema, qualificando o relacionamento entre um termo/sinal e sua referência. Nomes e códigos são significativos aos usuários, quando ocorre uma forte semântica entre eles e os itens ou ações aos quais se referem.

\section{Compatibilidade}

Permite assegurar a correspondência entre as características do usuário (memória, percepção, hábitos, conhecimentos, idade, competência, etc.), as características da tarefa e a organização dos dados de entrada e diálogo.

A terminologia deve ser pautada na linguagem dos usuários e não no jargão da informática, utilizando as palavras com o sentido padrão existente na comunidade dos usuários.

Os usuários que aprendem a usar interfaces consistentes, formam um melhor modelo mental do sistema. 